\title{
ESTUDO E ANÁLISE DE POLIGONAIS SEGUNDO A NBR 13.133 E O SISTEMA DE POSICIONAMENTO GLOBAL
}

Tule César Barcelos Maia

Dissertação apresentada à Escola de
Engenharia de São Carlos da
Universidade de São Paulo, como parte
dos requisitos para a obtenção de título de
Mestre em Transportes

ORIENTADOR: Prof. Dr. Paulo César Lima Segantine

São Carlos - SP 1999 


\section{DEDICATÓRIA}

Dedico esta dissertação a minha família e a minha namorada Patricia. 


\section{AGRADECIMENTOS}

Agradeço a todos colegas pela compreensão e apoio e aos colaboradores Ricardo

Ernesto Schaal, Hebert Erwes e ao orientador Paulo César Lima Segantine pelas orientações, críticas e sugestões 


\section{SUMÁRIO}

LISTA DE FIGURAS ......................................................................................... V

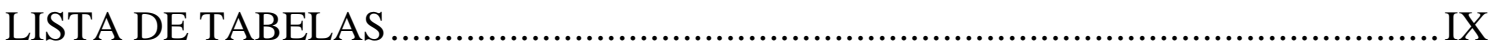

LISTA DE ABREVIATURAS E SIGLAS............................................................

LISTA DE SÍMBOLOS ................................................................................

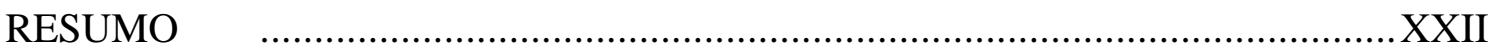

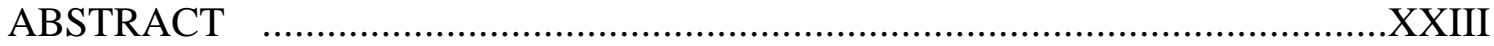

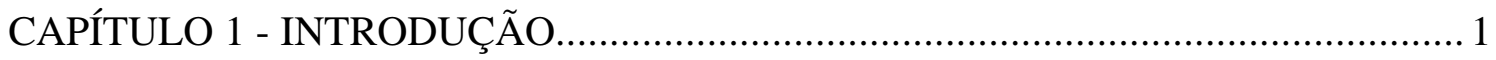

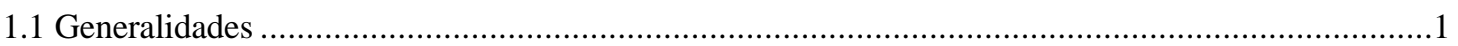

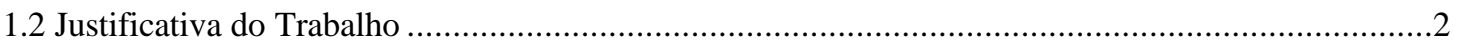

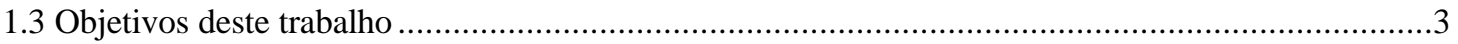

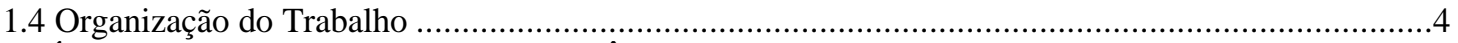

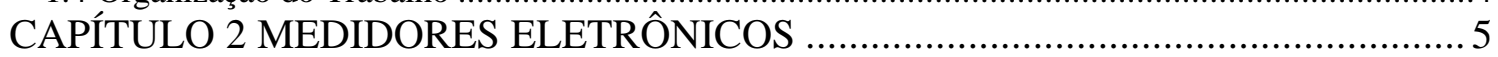

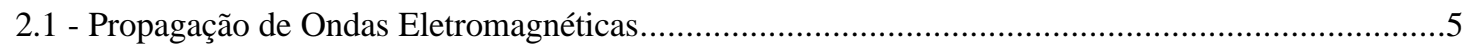

2.1.1 - Ondas de Baixa Freqüência............................................................. 6

2.1.2 - Ondas de Altas Freqüências ....................................................................... 7

2.2 - Princípios de Medições com Ondas Eletro-Magnéticas (OEM) ……...................................................

2.2.1 - Método do Pulso (Timed-Pulse) .................................................................. 8

2.2.2 - Método da Diferença de Fase ...................................................................... 9

2.3- Constituição dos Medidores Eletrônicos de Distâncias (MED) ......................................................12

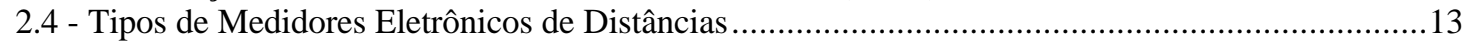

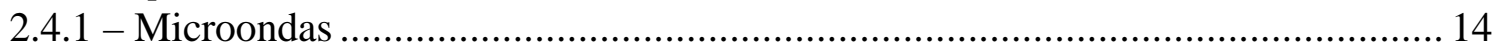

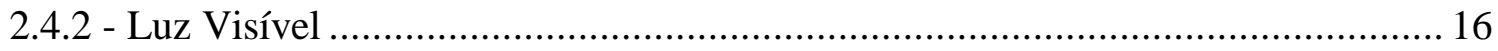

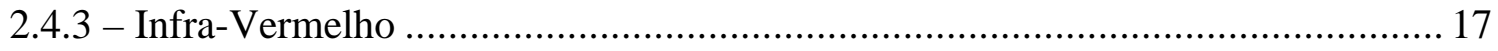

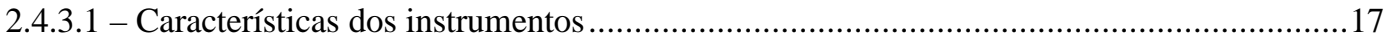

2.4.5 - Erros Sistemáticos em Medições com MED ................................................. 19

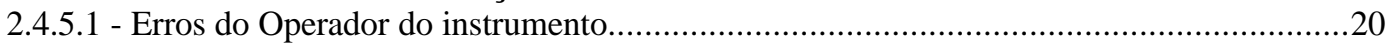

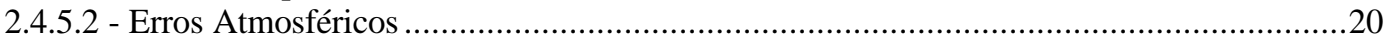

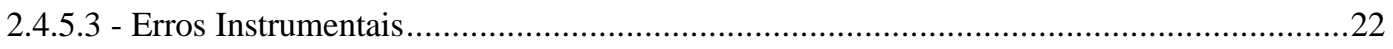

2.4.5.3.1 - Erro de Escala $\left(k_{1}\right)$ ou Constante de Multiplicação ....................................................22

2.4.5.3.2 - Erro de Zero ou de Índice $\left(k_{2}\right)$...................................................................23

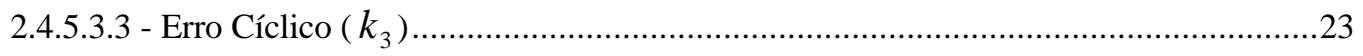


CAPÍTULO 3 - Teodolitos eletrônicos................................................................ 24

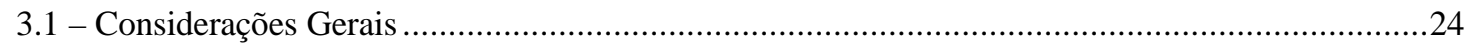

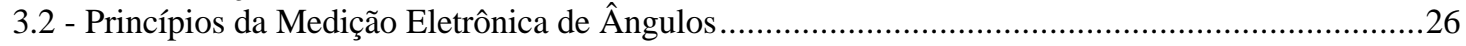

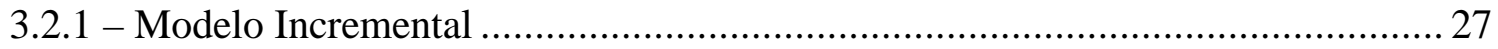

3.2.2 - Modelo Absoluto ................................................................................. 28

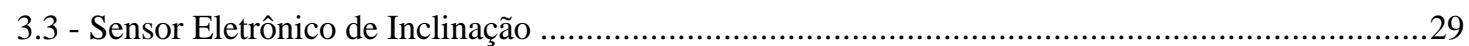

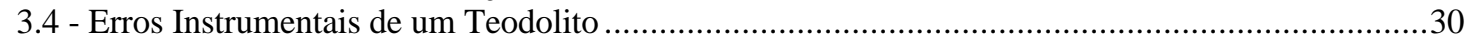

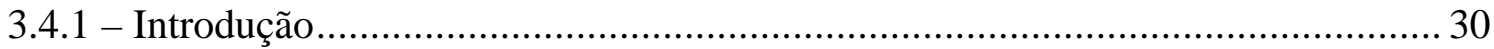

3.4.2 - Erros de Eixo de um Teodolito................................................................... 31

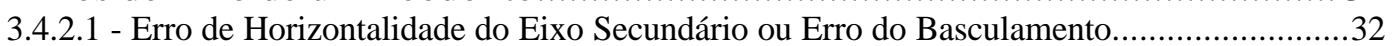

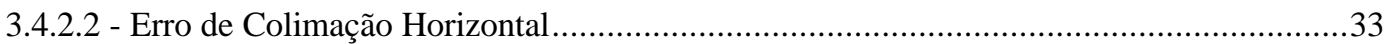

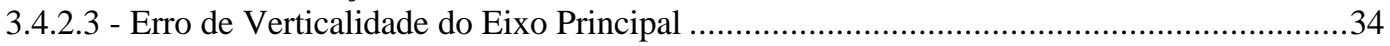

3.4.3 - Erros de Excentricidade dos Círculos ……………........................................... 36

3.4.4 - Erros de Graduação dos Círculos ...................................................................... 38

3.4.5 - Erros do Índice do Círculo Vertical - Colimação Vertical ................................. 38

3.5 - Correções das Medidas dos Ângulos Lidos com um Teodolito Eletrônico .........................................39

3.6 - As Estações Totais Modernas e a Leitura de Ângulos e Distâncias ................................................39

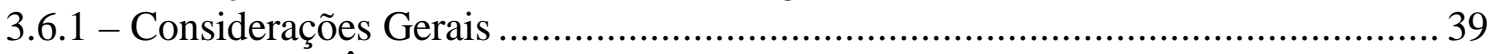

3.6.2 - Medição de Ângulos.................................................................................. 40

3.6.3 - Medição de Distâncias................................................................................... 42

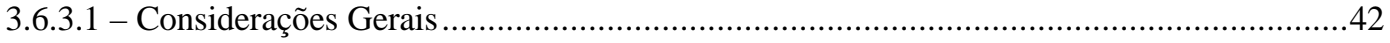

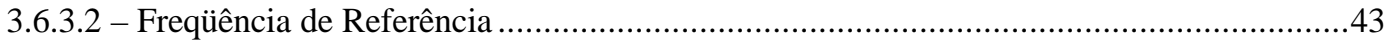

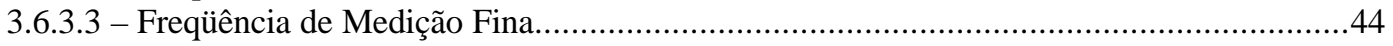

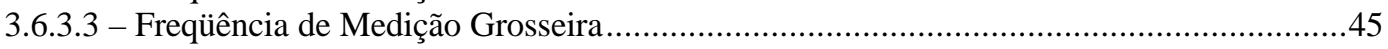

3.6.3.4 - Processo de Medição de Distâncias .................................................................................45

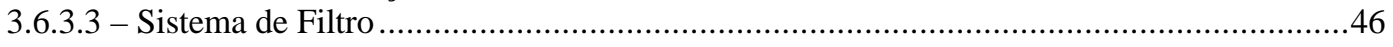

3.7 - Impacto das Estações Totais e dos Teodolitos Eletrônicos nos Processos de Medição....................48

CAPÍTULO 4 - SISTEMA DE POSICIONAMENTO GLOBAL (GPS) ……...............50

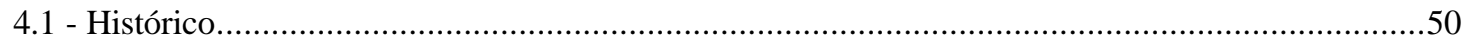

4.2 - Sinais de Rádio Utilizados ………………………………………………………...51

4.3 - Princípio Básico...………………………………………………………………………….52

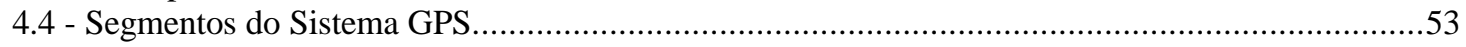

4.5 - Posicionamento de Pontos..............................................................................................54

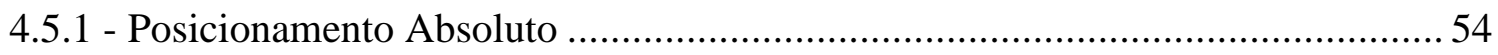

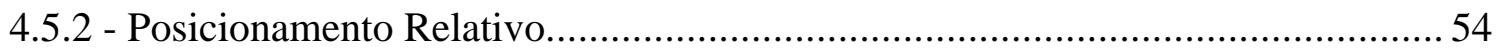

4.6 - Métodos de Levantamento …………………………………………………………...5

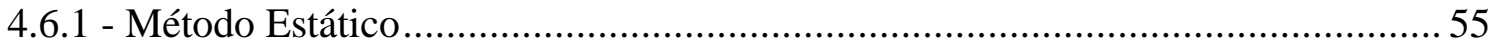

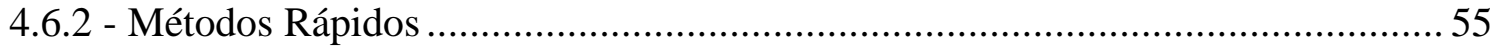

4.6.2.1 - Cinemático ……………………………………………………………………...5

4.6.2.2 - Levantamento Cinemático "stop-and-go" (semi-cinemático) ..........................................56

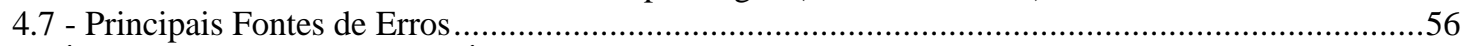

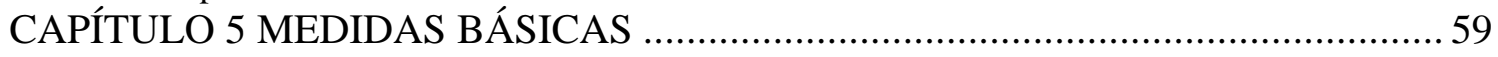

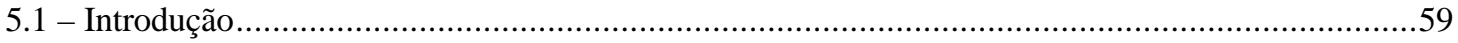

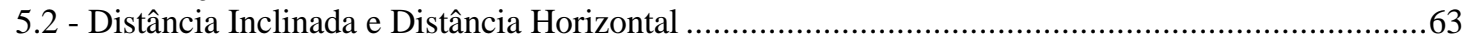

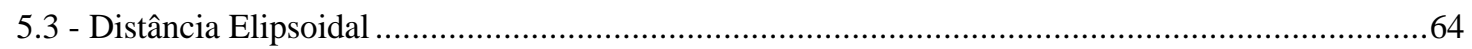

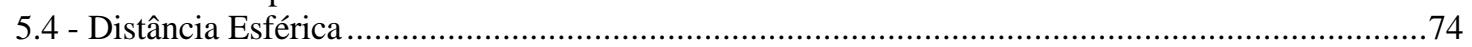

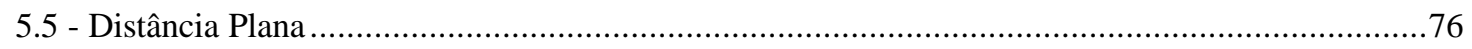

5.6 - Relação entre Distância Esférica e Horizontal...……………………………………………....77 
5.7 - Redução de Distâncias Inclinadas em Distâncias Esféricas...........................................................79

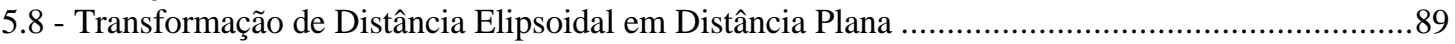

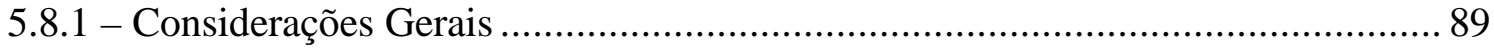

5.8.2 - Transformação das coordenadas Geodésicas Cartesianas em Geodésicas

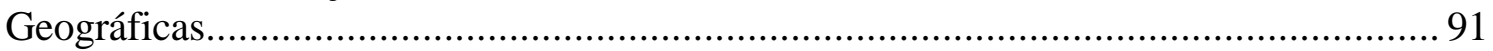

5.8.3 - Transformação das coordenadas Geodésicas Geográficas em Planas UTM....... 93

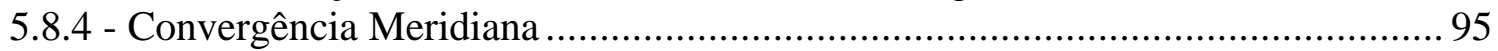

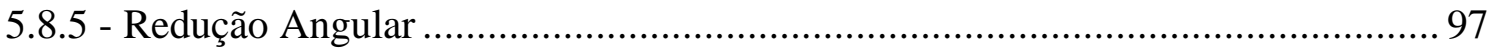

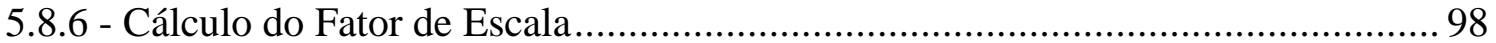

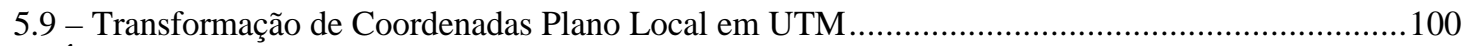

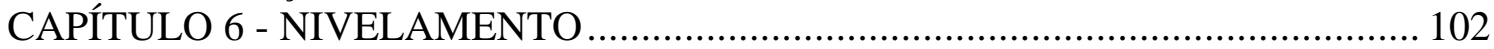

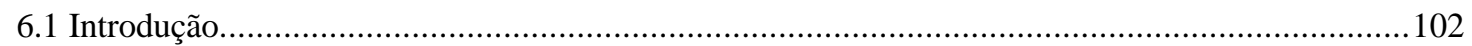

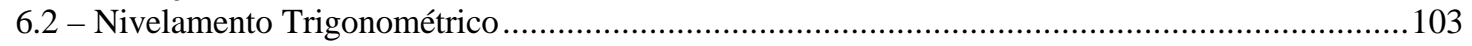

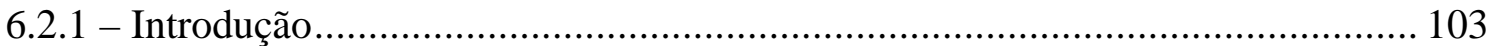

6.2.2 - O nivelamento trigonométrico no processo da poligonação eletrônica............. 104

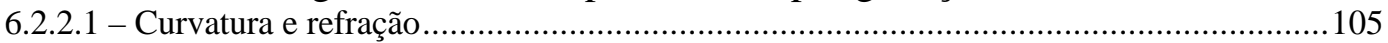

CAPÍTULO 7 - AJUSTAMENTO ............................................................... 110

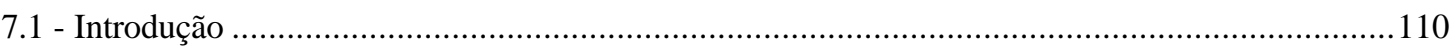

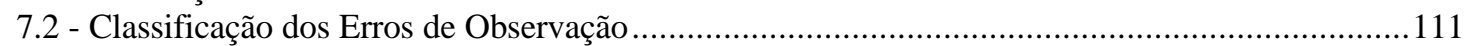

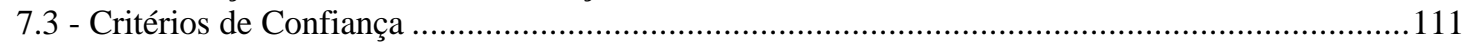

7.4 - O Princípio do Ajustamento Baseado no Princípio dos Erros ...................................................112

7.4.1 - O Método dos Mínimos Quadrados (M.M.Q.)......................................... 112

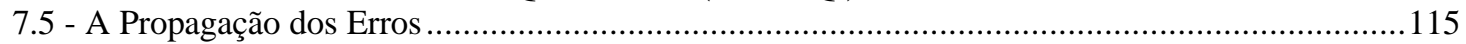

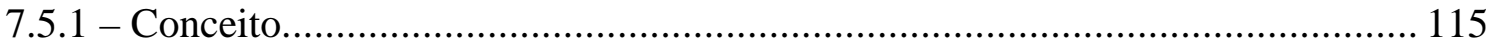

7.5.2 - Propagação dos Erros para Observações não Correlacionadas ....................... 116

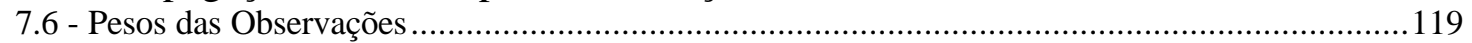

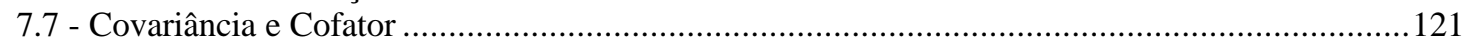

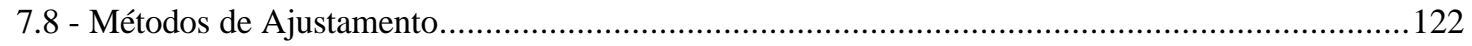

7.8.1 - Ajustamento de Observações Diretas .......................................................... 122

7.8.1.1 - Ajustamento de Observações de Igual Confiança ............................................................122

7.8.1.2 - Ajustamento de Observações de Diferentes Confianças .................................................125

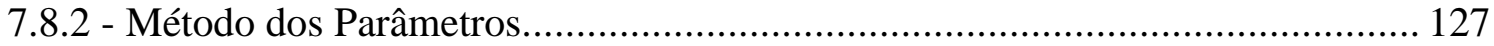

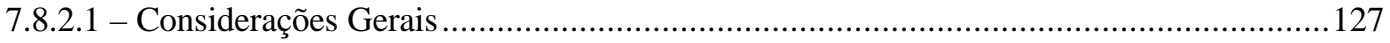

7.8.2.2 - Equações Normais ...............................................................................................130

7.8.2.3 - Cálculo dos Erros Através das Matrizes de Variância e Covariância ...............................131

7.8.3 - Método das Equações de Condição ou dos Correlatos ................................... 133

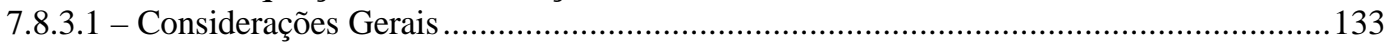

7.8.3.2 - Equações Normais .............................................................................................136

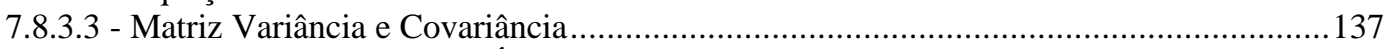

CAPÍTULO 8 - MATERIAIS E MÉTODOS ...................................................... 140

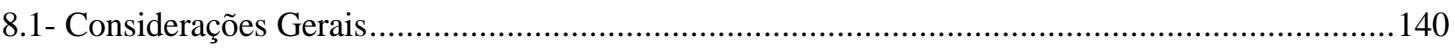

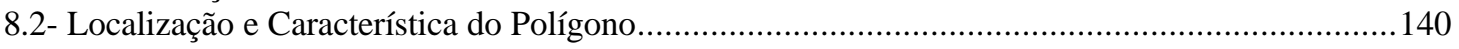

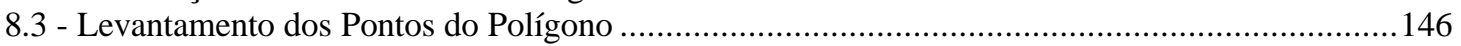

8.3.1 - Levantamento Utilizando Receptores GPS .............................................. 146

8.3.2 - Levantamento Utilizando Estação Total ...................................................... 147

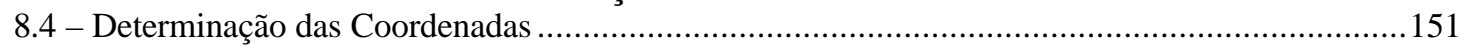

8.4.1 - Correção das Observações................................................................. 152 


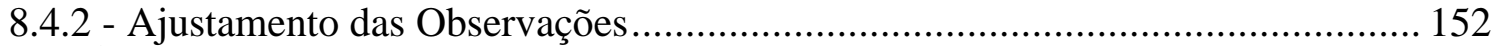

CAPÍTULO 9 - RESULTADOS E DISCUSSÕES ............................................ 154

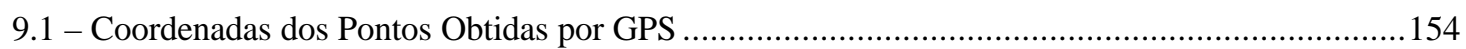

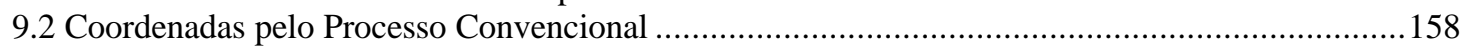

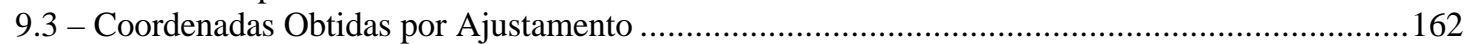

9.4 - Distâncias Horizontais da Poligonal Reduzidas nas Diferentes Superfícies de Referência ..........164

9.5 - Cotas do Nivelamento Trigonométrico Ajustadas e as Cotas do Nivelamento Geométrico .........166

10 - CONCLUSÕES E RECOMENDAÇÕES .................................................... 168

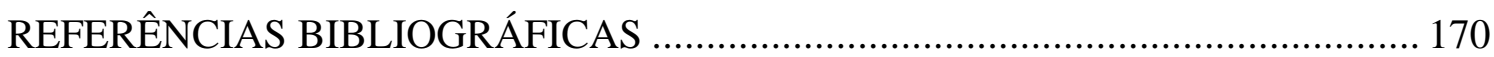

\section{ANEXO I 1}

Programa para Transformação de Coordenadas Geodésicas Geográficas para UTM SAD-69 ...............2

Programa para Transformar UTM SAD-69 para Geodésicas Geográficas ...........................................6

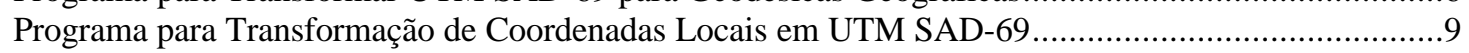

Programa para Cálculo de Distância Elipsóidica a partir das Distâncias Horizontais .............................10

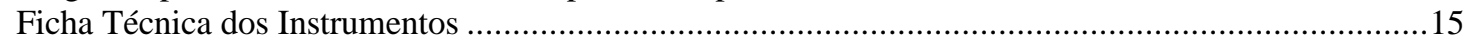




\section{LISTA DE FIGURAS}

Figura 2.1: Princípio da técnica do contador de pulso (Timed-pulse) para medidor de

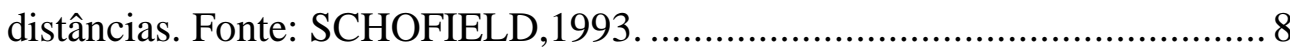

Figura 2.2: Determinação de distâncias usando MED, por caminho duplo, método da diferença de fase. Adaptado de KENNIE et al (1993). ................................. 9

Figura 2.3: Esquema de um medidor digital de fase. Fonte: SCHOFIELD, 1993......... 11

Figura 2.4: Componentes básicos de um MED. Fonte: BURNISIDE, 1991_............... 12

Figura 2.6: Modulação por amplitude do diodo GaAs. Adaptado de PRICE \& UREN (1989).

Figura 3.1: Ilustração de um dispositivo de medição (MED) acoplado a um teodolito. 24

Figura 3.2: Apresentação de um teodolito mecânico e um eletrônico, respectivamente.

Figura 3.3: Estação Total da série de compensadores eletrônicos e prumos laser.

Cortesia d Leic do Brasil S/A 26

Figura 3.4: Sistema de leitura angular incremental usando comparador de fase (KAHMEN et al, 1988).

Figura 3.5: Sistema de leitura angular incremental usando interpolação matemática (KAHMEN et al, 1988). 28

Figura 3.6: Sistema de leitura angular absoluto (COOPER, 1987). 29

Figura 3.7: Detalhe do sensor de inclinação que permite a horizontalização automática. Adaptada de KENNIE et al (1993)........................................................... 30

Figura 3.8: Eixos esquemáticos do teodolito (KAHMEN et al, 1988)......................... 31

Figura 3.9: Representação do erro horizontalidade do eixo secundário. Adaptada de MOREIRA (1998). 
Figura 3.10: Representação do erro de colimação horizontal. Adaptada de MOREIRA (1998).

Figura 3.11: Representação do erro de verticalidade do eixo principal. Adaptada de MOREIRA (1998)...

Figura 3.12: Representação dos erros de excentricidade dos círculos. Adaptada de MOREIRA (1998)

Figura 3.13: Representação das leituras em dois pontos diametralmente opostos. Adaptada de MOREIRA (1998).

Figura 3.15: Esquema do sensor de verificação do nivelamento e verticalidade dos eixos. Adaptada de ZEISK (1999).

Figura 3.16: Gráfico demonstrando a temperatura em função da frequiência. Fonte, MANUAL DE SERVIÇO DI 1600/TC 1600 (1990).

Figura 3.17: Representação do sinal misturado no receptor. Fonte, MANUAL DE SERVIÇO DI 1600/ TC 1600.

Figura 3.18: Esquema do sistema de filtro. Fonte Manual de serviço DI 1600/DI2002 (1990).

Figura 3.19: Esquema da posição de filtro, , Manual de serviço DI 1600/DI2002 (1990).

Figura 3.14: Representação da repetição na medição de um ângulo

Figura 4.1: Estrutura básica do sinal GPS. Adaptada de MONICO apud CHAVES (1996).

Figura 4.2: Princípio básico do GPS. Adaptada de MORAES et al (1998). 52

Figura 4.3: Representação de incertezas na interseção de órbitas dos satélites conforme as diferentes geometrias. Adaptada de HURN (1999). .56

Figura 4.4: Efeito do multicaminhamento. Adaptada de HOFFMANN-WELLENHOF et al (1997). 57

Figura 4.5: Representação do atraso da ionosfera. Fonte: SEGANTINE (1998). 57

Figura 5.1: Esquema de medição na superfície terrestre e projeção seguindo os vetores gravidade dos pontos no geóide e no plano horizontal. 60

Figura 5.2: Projeção em uma superfície plana. Fonte SCHOFIELD (1993) 61 
Figura 5.3: Distorção entre distâncias no plano tangente ao geóide e na superfície esférica.

Figura 5.4: Distância inclinada e horizontal entre dois pontos topográficos. 63

Figura 5.5: Redução de distância espacial para elipsoidal. Adaptada de TORGE (1980).

Figura 5.6: Representação dos sistemas de coordenadas Local e Geodésico Geográfico e Cartesiano. 68

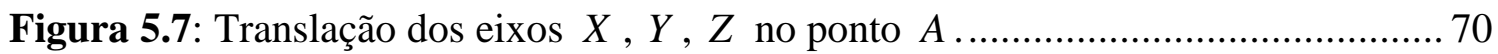

Figura 5.8: Rotação dos eixos Z e Y. Adaptada de RAPP (1989). ............................. 71

Figura 5.9: Coordenadas dos pontos levantados na superfície e projetados na superfície

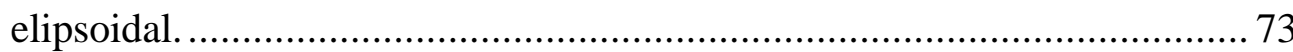

Figura 5.10: Representação da determinação da distância esférica. .......................... 74

Figura 5.11: Sistema de projeção Universal Transverso de Mercator (UTM). Fonte MOFFITT et al (1987)...................................................................... 77

Figura 5.12: Representação da relação entre distância esférica e horizontal................. 78

Figura 5.13: Relacionamento entre distância inclinada esférica. ............................. 80

Figura 5.14: Redução da Figura 5.12 em um quadrilátero. ...................................... 81

Figura 5.15: Diferenças entre ângulos devido a refração. ........................................ 82

Figura 5.16: Representação da distância esférica resultante entre $P$ e $Q$................. 87

Figura 5.17: Projeção Transverso de Mercator Adaptada de MOFFITT et al (1987).... 90

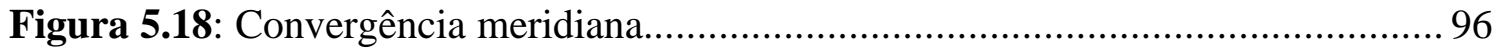

Figura 5.19: Curvatura das linhas geodésicas na projeção Transverso de Mercator. Adaptada de MOFFITT (1987).

Figura 5.20: Redução de um ângulo dado pela linha curva à corda. Adaptada de MOFFITT (1987). 98

Figura 6.1: Elementos básicos do nivelamento. Adaptada de ELFICK et al (1994). .. 102

Figura 6.2: Elementos do nivelamento trigonométrico. 104

Figura 6.3: Representação da refração e esfericidade da terra no nivelamento trigonométrico. Adaptada de MUELLER \& RAMSAYER (1979). 105

Figura 8.1: Croqui da área onde foi criada a poligonal. 141 
Figura 8.2: Representação das visadas recíprocas utilizando-se dois teodolitos com visadas coincidindo fio superior, médio e inferior, respectivamente, com o centro ótico do outro instrumento.

Figura 8.3: Representação da medida da altura do instrumento usando trena e pino graduado.

Figura 9.1: Pontos ajustados da Poligonal Contorno. 155

Figura 9.2: Pontos ajustados da Poligonal triangulação. 156

Figura 9.3: Diferenças entre as coordenadas dos pontos UTM (WGS-84) nas poligonais Contorno e Triangulação

Figura9.4: Representação das coordenadas ajustadas pelo método condicional poligonal tipo 1 .

Figura 9.5: Representação das diferenças entre coordenadas das poligonais tipo 1, 2, 3 .

Figura 9.5: Representação da diferença das distâncias nas diversas superfícies de referência em relação a distância horizontal medida no plano local. 165

Figura 9.6 : Diferenças entre cotas nivelamento trigonométrico e geométrico. 167 
LISTA DE TABELAS

TABELA 2.1: ESPECTRO DE FREQÜÊNCIAS DAS ONDAS ELETROMAGNÉTICAS. ADAPTADA DE DOUBEK(1974),.............. 6

TABELA 2.2: COMPONENTES BÁSICOS DE UM MED. FONTE: BURNSIDE, 1991 13

TABELA 2.3: PRINCÍPIO DE RESOLUÇÃO DA DISTÂNCIA POR MUDANÇA DE COMPRIMENTO DE ONDA. FONTE: KENNIE ET AL (1993) .......... 15

TABELA 2.4: APRESENTA AS CARACTERÍSTICAS TÉCNICAS DOS INSTRUMENTOS QUE UTILIZAM MICROONDAS. FONTE: DOUBEK, 1984. 16

TABELA 2.5: CARACTERÍSTICAS TÉCNICAS DE EQUIPAMENTOS QUE UTILIZAM INFRAVERMELHO. FONTE: DOUBEK, 1984. 19

TABELA 2.6: PRECISÕES EM MEDIDÇÕES DA TEMPERATURA, PRESSÃO E UMIDADE ENTRE OS DIVERSOS MED PARA OBTER UM 1 PPM DE PRECISÃO NO ÍNDICE DE REFRAÇÃO. KENNIE ET AL (1993).

TABELA 5.1: VARIAÇÃO DAS DISTÂNCIAS EM RELAÇÃO ÀS ALTITUDES.. 76

TABELA 5.2: DIFERENÇAS ENTRE CORDA E O ARCO .79

TABELA 8.1: REDE DE REFERÊNCIA CADASTRAL MUNICIPAL - POLIGONAIS 142

Tabela 9.1: Coordenadas da poligonal contorno no sistema WGS-84 154

Tabela 9.2: Coordenadas da poligonal triangulação em WGS-84 156 Coordenadas dos pontos das poligonais descritas acima no sistema SAD-69:

Tabela 9.3: Coordenadas dos pontos da poligonal contorno no sistema SAD-69 157

Tabela 9.4: Coordenadas dos pontos da poligonal triangulação no sistema SAD-69 .. 158

Tabela 9.5: Coordenadas corrigidas para a poligonal tipo 1 158

Tabela 9.6: Coordenadas corrigidas para a poligonal tipo 2 ……............................... 160

Tabela 9.7: Coordenadas corrigidas para a poligonal tipo 3 160 
Tabela 9.9: Diferença de fechamento nos eixos coordenados X e Y no ajustamento.. 162

Tabela 9.11: distância horizontal reduzida nas diversas superfícies de referência. ..... 164

Tabela 9.12: Cotas dos pontos dadas por nivelamento trigonométrico e geométrico .. 166 


\section{LISTA DE ABREVIATURAS E SIGLAS}

\begin{tabular}{|c|c|}
\hline $\mathrm{AD}$ & Analógico-Digital \\
\hline ADC & Conversor Analógico Digital \\
\hline $\mathrm{C} / \mathrm{A}$ & Coarse or Clear/Aquisition-code \\
\hline $\mathrm{CPU}$ & Unidade Central de Processamento \\
\hline DATUM & Sistema de Referência \\
\hline EPROM & Eraseble Prograamble Memory \\
\hline FM & Freqüência Média \\
\hline GPS & Global Positioning System \\
\hline $\mathrm{HF}$ & Alta Freqüência \\
\hline IBGE & Instituto Brasileiro de Geografia e Estatística \\
\hline IR & Infra-Vermelho \\
\hline L1 e L2 & Freqüência da portadora \\
\hline LASER & Ligth Amplification by Stimulation Emission of Radiaton \\
\hline LED & Diodo Infra-Vermelho \\
\hline LF & Baixa Freqüência \\
\hline $\mathrm{MC}$ & Meridiano Central \\
\hline MED & Medidor Eletrônico de Distância \\
\hline MMQ & Método do Mínimos Quadrados \\
\hline MVC & Matriz de Variância e Covariância \\
\hline NAVSTAR & NAVigation System using Time And Ranging \\
\hline NBR 13.133 & Norma Brasileira 13.133 \\
\hline OEM & Ondas Eletro-Magnéticas \\
\hline $\mathrm{P}$ & Precision ou Protect-mode \\
\hline
\end{tabular}




$\begin{array}{ll}\text { PPS } & \text { Precise Positioning Service } \\ \text { SGB } & \text { ao Sistema Geodésico Brasileiro } \\ \text { UHF } & \text { Ultra High Frequency } \\ \text { UTM } & \text { Sistema de Projeção Universal Transverso de Mercator } \\ \text { WGS } & \text { World Geodetic System } \\ \text { WGS-72 } & \text { World Geodetic System de } 1972 \\ \text { WGS-84 } & \text { World Geodetic System de } 1984\end{array}$




\section{LISTA DE SÍMBOLOS}

$\begin{array}{ll}a & \text { erro médio angular da rede de apoio } \\ a & \text { semi-eixo maior do elipsóide } \\ a^{T} & \text { matriz transposta } \\ A & \text { coeficientes de determinação do arco elipsóidico } \\ A^{T} & \text { vetor coluna dos termos unitários } \\ A^{\prime} 6 & \text { coeficiente UTM } \\ A z_{A B} & \text { azimute do alinhamento plano local } \\ A z_{\text {in. }} & \text { azimute inicial } \\ A z_{\text {fin. }} & \text { azimute final } \\ A z^{a}{ }_{\text {alinham.i }} & \text { azimute ajustado do alinhamento } \\ b & \text { coeficiente de tolerância para o erro de medição angular } \\ b & \text { semi-eixo menor do elipsóide } \\ B & \text { coeficiente de determinação do arco elipsóidico } \\ B & \text { matriz das derivadas parciais } \\ b_{i n} & \text { coeficiente de determinação do arco elipsóidico } \\ B^{\prime} 5 & \text { um elemento da matriz dos coeficientes } \\ c & \text { coeficiente UTM } \\ c & \text { ângulo inclinado da linha de colimação } \\ c & \text { corda }\end{array}$




\begin{tabular}{|c|c|}
\hline$C$ & convergência meridiana \\
\hline$C$ & velocidade do sinal eletromagnético (EM) no vácuo \\
\hline corr & correção de esfericidade \\
\hline$c_{P Q}$ & distância espacial entre pontos \\
\hline$C^{\prime} 5$ & coeficiente UTM \\
\hline$d$ & coeficiente de tolerância para o erro de fechamento linear \\
\hline$d_{A B}$ & distância plana UTM do alinhamento \\
\hline$d h_{A B}$ & distância horizontal \\
\hline$d_{i}^{a}$ & distância observada ajustada do alinhamento \\
\hline$D$ & distância entre instrumento e alvo. \\
\hline$D^{\prime}$ & distância inclinada \\
\hline$D$ & distância horizontal \\
\hline$D$ & coeficiente de determinação do arco elipsóidico \\
\hline$D_{A}^{B}$ & distância horizontal da estação A, vante B \\
\hline$e$ & coeficiente de tolerância para o erro transversal \\
\hline$e$ & excentricidade do círculo graduado \\
\hline$e$ & primeira excentricidade do elipsóide \\
\hline$e$ & vetor unitário \\
\hline$e^{\prime}$ & segunda excentricidade do elipsóide \\
\hline$e_{r}$ & erro relativo tolerável linear após a compensação angular \\
\hline$E$ & coeficiente de determinação do arco elipsóidico \\
\hline$E$ & coordenada leste UTM \\
\hline$E$ & pressão do vapor de água \\
\hline$E^{\prime}$ & diferença de coordenada leste UTM em relação a origem \\
\hline Esf & esfericidade \\
\hline$f$ & coeficiente de tolerância para o erro longitudinal \\
\hline$f$ & freqüência modulada \\
\hline$F$ & fuso \\
\hline
\end{tabular}




$\begin{array}{ll}F & \text { matriz das funções } \\ F & \text { coeficiente de determinação do arco elipsóidico } \\ F^{T} & \text { matriz das funçães transposta } \\ h_{P} & \text { altura geométrica do ponto } \\ H_{P} & \text { altitude do ponto } \\ i & \text { ângulo de inclinação } \\ i_{A} e i_{B}: & \text { alturas dos instrumentos em A e B } \\ k & \text { coeficiente médio de refração } \\ k & \text { coeficiente de refração } \\ k & \text { fator de escala UTM no ponto } \\ k_{i} & \text { multiplicadores de Lagrange ou os "correlatos" } \\ k_{0} & \text { fator de escala no meridiano central } \\ k_{1} & \text { erro de escala ou constante de multiplicação; } \\ k_{2} & \text { erro de zero do instrumento ou constante aditiva; } \\ k_{3} & \text { erro cíclico do instrumento; } \\ K & \text { vetor dos multiplicadores de Lagrange (ou correlatos) } \\ K & \text { coeficiente de determinação do arco elipsóidico } \\ l & \text { observações } \\ \tilde{l}_{i i} & \text { valor mais provável } \\ L & \text { vetor das observações } \\ L & \text { coeficiente de determinação do arco elipsóidico } \\ L & \text { perímetro } \\ L_{a} & \text { vetor dos valores observados ajustados } \\ L_{b} & \text { vetor dos valores observados } \\ L_{0} & \text { vetor dos valores em função dos parâmetros aproximados } \\ M & \text { coeficiente de determinação do arco elipsóidico } \\ M C & \text { raio de curvatura da seção meridiana } \\ & \end{array}$


$n_{t}$

$n_{s}$

$n_{a}$

N

$N$

$N$

$N$

$N$

N

$N$

$N$

$N Q$

$N G$

$p$

$p$

$P$

$P$

$P$

$q$

$q_{i i}$

$q_{i j}$

$Q$

$\bar{Q}$

$Q_{f f}$

índice de refração da atmosfera

matriz do somatório dos coeficientes pelos erros com seus pesos

número de medições

índice de refração corrente

índice de refração do ar

índice de refração da atmosfera;

coeficiente de determinação do arco elipsóidico

coordenada norte UTM

matriz do somatório dos coeficientes ao quadrado com seus pesos

número de vértices

número inteiro de comprimento de onda

número inteiro de revoluções de um vetor

ondulação geoidal

raio de curvatura da seção transversa $\left(1^{\mathrm{a}}\right.$ vertical $)$

norte da quadrícula

norte geográfico

coeficiente UTM

peso da observação

matriz quadrada dos pesos

coeficiente de determinação do arco elipsóidico

pressão durante a observação

coeficiente UTM

cofator da observação

covariância relativa entre observações

coeficiente de determinação do arco elipsóidico

matriz utilizada para representar multiplicação de matrizes

matriz dos cofatores da função 


\begin{tabular}{|c|c|}
\hline$r$ & raio do círculo \\
\hline$\vec{r}^{i}$ & posição do i-ésimo satélite \\
\hline$R$ & matriz de rotação \\
\hline $\operatorname{Ref}$ & refração \\
\hline$R_{\alpha}$ & raio de curvatura do arco $s$ com um azimute $\alpha$ \\
\hline$R_{m}$ & raio curvatura médio \\
\hline$R_{0}$ & raio médio da esfera terrestre \\
\hline$\vec{R}_{u}$ & posição do usuário \\
\hline$R_{A B}$ & rumo do alinhamento plano local \\
\hline Red & redução ao nível do mar \\
\hline$s$ & distância elipsoidal \\
\hline$s$ & distância horizontal \\
\hline$s$ & erro padrão médio impírico \\
\hline$s^{\prime}$ & distância inclinada \\
\hline$s_{A} e s_{B}:$ & alturas dos alvos em A e B \\
\hline$S_{i}$ & precisão de cada observação \\
\hline$s_{0}, s_{P}, s_{Q} s_{m}$ & distância esférica ao nível do geóide, $P, Q$, médio \\
\hline$s_{\tilde{x}}$ & precisão da média \\
\hline$s_{x 1}$ & precisão da observação \\
\hline$S_{x 1 x 2}$ & correlação entre variáveis \\
\hline$s_{y}$ & precisão da função \\
\hline$s_{0}$ & precisão a priori \\
\hline$S$ & distância elipsoidal do Equador ao meridiano central \\
\hline$t$ & erro médio quadrado \\
\hline$t$ & tempo de propagação da onda \\
\hline$t$ & temperatura durante a observação \\
\hline$t$ & tempo \\
\hline
\end{tabular}




\begin{tabular}{|c|c|}
\hline$T_{t}$ & erro tolerável transversal antes da compensação angular \\
\hline$T_{l}$ & erro tolerável longitudinal antes da compensação angular \\
\hline$T_{\alpha}$ & tolerância angular \\
\hline$T_{p}$ & tolerância linear após a compensação angular \\
\hline$u$ & número das incógnitas \\
\hline$u, v, w$ & eixos coordenados no plano local \\
\hline$v$ & ângulo de inclinação do eixo vertical \\
\hline$v$ & erros residuais \\
\hline$v$ & velocidade média da luz (atmosfera) \\
\hline$V$ & ângulo de altura (contado a partir do plano horizontal) \\
\hline$V$ & matriz dos erros residuais \\
\hline$x$ & média aritmética \\
\hline$\tilde{x}$ & média aritmética das observações \\
\hline$x, y, z$ & coordenadas cartesiana do ponto no eixo X, Y,Z; \\
\hline$x^{\prime}, y^{\prime}, z^{\prime}$ & eixos coordenados paralelo ao sistema Cartesiano Geodésico; \\
\hline$x^{\prime \prime}, y^{\prime \prime}, z^{\prime \prime}$ & eixos coordenados paralelos ao plano local \\
\hline$X$ & vetor dos acréscimos (correção) \\
\hline$X_{a}$ & vetor dos parâmetros ajustados \\
\hline$X_{0}$ & vetor dos valores aproximados dos parâmetros \\
\hline$X_{\text {in. }}$ & abscissa do ponto inicial \\
\hline$X_{f i n .}$ & abscissa do ponto final \\
\hline$X_{u}, Y_{u}, Z_{u}$ & coordenadas cartesianas do usuário \\
\hline$X, Y, Z$ & coordenadas cartesianas \\
\hline$y=f\left(x_{1}, x_{2}, \ldots, x_{n}\right)$ & função de variáveis \\
\hline$y_{0}$ & função das variáveis no ponto estimado \\
\hline$Y_{\text {in. }}$ & ordenada do ponto inicial \\
\hline$Y_{\text {fin. }}$ & ordenada do ponto final \\
\hline
\end{tabular}




\begin{tabular}{|c|c|}
\hline$Z$ & ângulo zenital; \\
\hline$Z_{r e}$ & ângulo zenital a rè \\
\hline$Z_{\text {médio }}$ & ângulo zenital médio \\
\hline$Z_{\text {vante }}$ & ângulo zenital a vante \\
\hline$Z_{A}^{x}$ & ângulo zenital corrigido da estação A \\
\hline$Z_{\text {média }}^{x}$ & ângulo zenital médio corrigido \\
\hline$Z_{A}^{B}$ e $Z_{B}^{A}:$ & ângulos zenitais em A e B \\
\hline$W$ & vetor dos "erros de fechamento" \\
\hline$\alpha$ & azimute da seção normal \\
\hline$\alpha$ & azimute geodésico da linha de visada. \\
\hline$\alpha$ & ângulo vertical \\
\hline$\alpha, \alpha^{\prime}$ & ângulos centrais do círculo graduado \\
\hline$\alpha_{i}^{a}$ & ângulo horizontal observado ajustado do alinhamento \\
\hline$\beta$ & ângulo da linha de visada \\
\hline$\beta_{2}, \beta_{1}$ & ângulos entre os raios dos diferentes centros \\
\hline$\beta^{\prime}$ & ângulo de altura da linha; \\
\hline $\bar{\beta}$ & ângulo de altura corrigido da linha \\
\hline$\gamma$ & ângulo central \\
\hline$\delta "$ & redução angular à corda \\
\hline$\varepsilon_{i}$ & erro da direção horizontal \\
\hline$\varepsilon_{i}$ & erro verdadeiro pertencentes as medidas individuais da série \\
\hline$\varepsilon_{c}$ & erro de colimação \\
\hline$\varepsilon_{v}$ & erro de verticalidade do eixo \\
\hline$\Delta h$ & diferença de alturas geométricas \\
\hline$\Delta h, \Delta H$ & diferença de nível \\
\hline$\Delta X, \Delta Y, \Delta Z$ & diferença de coordenadas cartesianas \\
\hline
\end{tabular}




\begin{tabular}{ll}
$\Delta Z$ & correção do Ângulo zenital \\
$\Delta Z_{r e}$ & correção zenital a ré \\
$\Delta Z_{\text {vante }}$ & correção zenital vante \\
$\Delta h_{A}^{B}$ & diferença de nível estação A, vante B \\
$\Delta \lambda$ & parte fracional do comprimento de onda \\
$\Delta \lambda$ & diferença de longitude \\
$\eta$ & componente da primeira vertical \\
$\theta_{X}, \theta_{Y}, \theta_{Z}$ & rotações \\
$\lambda$ & longitude do ponto referente ao elipsóide \\
$\lambda$ & comprimento de onda eletromagnética \\
$\lambda_{0}$ & comprimento de onda do sinal no vácuo \\
$\lambda_{0}$ & longitude do meridiano central \\
$\mu$ & o erro médio quadrado caracterizando cada medida \\
$\mu_{1}, \mu_{2}$ & coeficientes de redução angular \\
$\mu_{0}$ & precisão a priori \\
$\vec{\rho}^{i}$ & posição do usuário em relação ao i-ésimo satélite \\
$\sigma_{x y}$ & covariância entre observações \\
$\sigma$ & erro padrão médio verdadeiro \\
$\tau$ & ângulo de refração \\
$\phi$ & ângulo de fase \\
$\phi$ & latitude do ponto referente ao elipsóide \\
$\phi_{0}$ & aungulo enão que caracteriza o modelo matemático condicionado arco de eixo inclinado e vertical \\
$\phi\left(\tilde{L}_{1}, \tilde{L}_{2}, \ldots, \tilde{L}_{n}\right)$ & \\
\hline$f_{m}$ & \\
$\partial x_{1}$ &
\end{tabular}




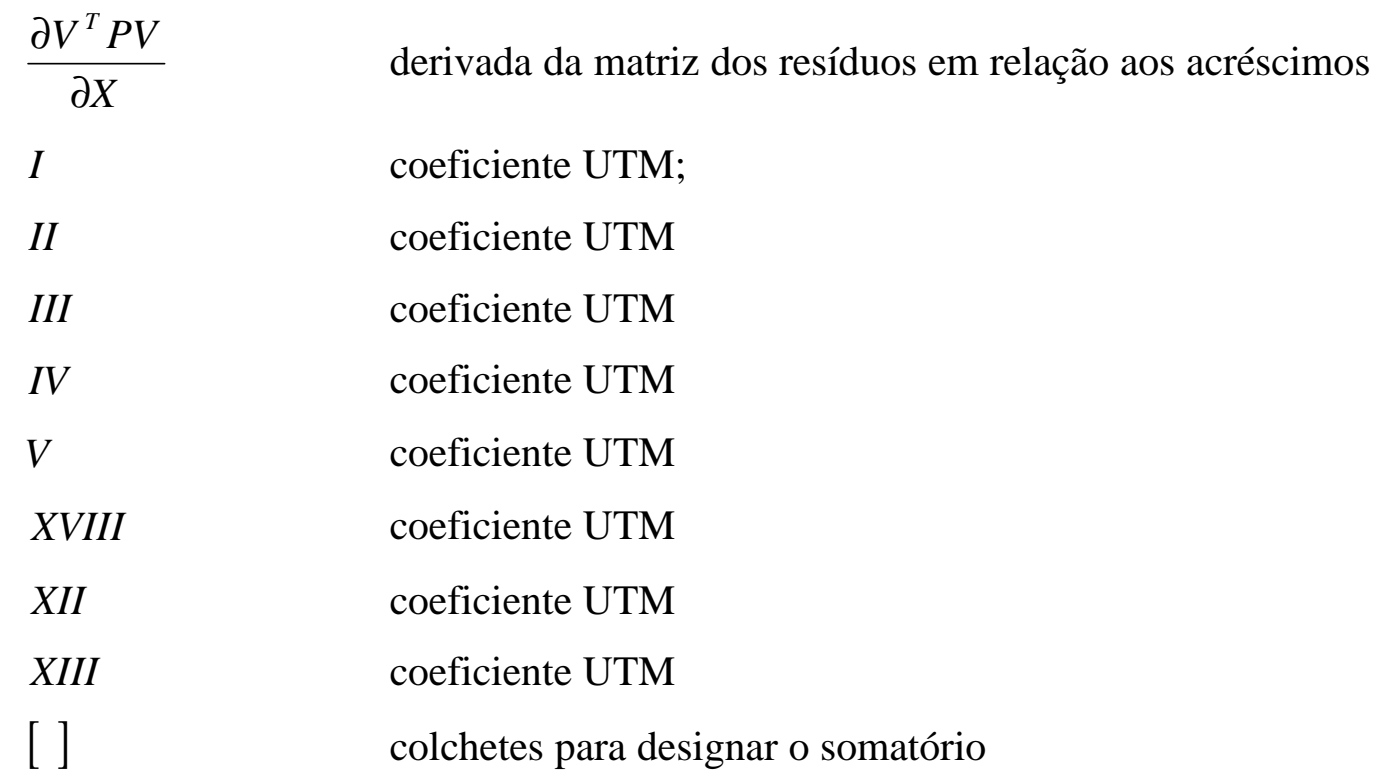




\section{RESUMO}

MAIA, T.C.B. (1999). Estudo e análise de poligonais segundo a NR 13.133 e o Sistema Posicionamento Global. São Carlos, 1999. 176p. Dissertação (Mestrado) - Escola de Engenharia de São Carlos, Universidade de São Paulo.

Com o desenvolvimento de novas tecnologias, os instrumentos utilizados para levantamentos na Mensuração sofreram profundas modificações. Muitos equipamentos e técnicas foram substituídos e outros até se tornaram obsoletos. $\mathrm{O}$ aparecimento de novas opções e técnicas de medições criam sempre dificuldades na vinculação entre levantamentos. Atualmente se utilizam as estações totais e o GPS (Global Positioning System) para levantamentos de pontos e áreas criando diferentes superfícies de referência e de projeção, tornando difícil a análise dos dados observados em conjunto das diferentes técnicas. Para tanto é necessário transformar as observações de um sistema de referência para outro, tornando-as compatíveis. Como não se tem uma descrição da maneira de proceder ao

ajustamento dos dados das diferentes técnicas, este trabalho tem por objetivo o ajustamento destas observações (GPS e estação total) combinados e em separado e comparar os resultados das coordenadas e precisões com as precisões estabelecidas pela NBR 13.133 de 1994.

Palavras-chaves: transformação, sistema de referência, coordenadas, ajustamento, nivelamento. 


\section{ABSTRACT}

MAIA, T.C.B. (1999). Study and analyse of transverse with NR 13.133 and the Global Position System. São Carlos, 1999. 176p. Dissertação (Mestrado) - Escola de Engenharia de São Carlos, Universidade de São Paulo.

The development of new tecnologies brought deep modifications in the instruments used for surveying in the measuration. Many equipaments and techinics were substituted and others became obsolete. The new options and technics of measuring always bring dificulties in the link among surveying nowadays it is used Total Stations and GPS (Global Positioning System) to surveying of points and areas creating different surface of reference and projections; making the analyse of observed data difficult considering the set of different technics. For this, it is necessary to change the observations of a system to another, making them compatible. As we do not have a detailed descriptions of the way to proceed the adjustament of the data from different technics, the aim of this work is to adjust these aobservations (GPS and Total Station) combined and apart to comper the results of the coordinates and precisions stablished by NBR13.133 of 1994.

Keywords: transformation, reference system, coordinates, adjustament, leveling. 


\section{CAPÍTULO 1 - INTRODUÇÃO}

\subsection{Generalidades}

Os empreendimentos da engenharia civil, desde a construção de edifícios, execução de barragens, estradas de rodagem e ferrovias, túneis, sistemas de abastecimento de água e esgotos sanitários, irrigação, levantamento cadastral urbano e rural, projetos de implantação de obras, telecomunicações, redes elétricas etc necessitam de levantamentos plani-altimétricos topográficos ou geodésicos das áreas envolvidas.

$\mathrm{Na}$ execução de levantamentos terrestres de poligonais topográficas indica-se a utilização de instrumentos eletrônicos de medidas de ângulos e distâncias, chamados Estações Totais. Estes tipos de instrumentos apresentam inúmeras vantagens sobre os processos tradicionais de medições; tais como, economia de tempo e custo, facilidade de operação, precisão, confiabilidade. "Acabou-se o tempo da Topografia árdua e trabalhosa" (CINTRA, 1995). Com as opções e facilidades oferecidas, alguns processos tradicionais tornaram-se mais simples e viáveis; outros se tornaram obsoletos.

Outra forma de executar levantamentos de pontos em uma área é a utilização do sistema de posicionamento NAVSTAR/GPS (NAVigation System using Time And Ranging/Global Positioning System) ${ }^{1}$. Este sistema se baseia no princípio da triangulação espacial, segundo o qual o observador conhece a posição de um conjunto de satélites (em relação a um referencial inercial) e a sua posição em relação a este conjunto de satélites, e obtém a sua própria posição em um sistema de referência. O sistema vem

\footnotetext{
${ }^{1}$ Por simplicidade, será adotado neste trabalho o termo GPS (Global Positioning System) para designar o sistema de posicionamento global.
} 
provando ao longo dos anos que é uma tecnologia efetiva para posicionamento, proporcionando obtenção de coordenadas com precisão.

O posicionamento via GPS, apesar de sua pouca idade, vem modernizando-se ao longo dos últimos anos. Atualmente, há vários estudos em desenvolvimento nas várias áreas de suas aplicações e, neste trabalho vamos destacar a aplicação no cadastro rural e urbano. Segundo CUNHA (1997), diversos países já utilizam no cadastro a técnica GPS, isolada ou combinada às outras. Em alguns casos a aplicação ainda limita-se ao levantamento de pontos de controle cadastral, cita-se (Somers e Sngh, 1992; Slonecker e Groskinsky, 1993; Thompson, Podgorki e Campbell, 1994; Muniz et al., 1996). Em outros, a aplicação é direta, ou seja, o GPS utilizado efetivamente na captura de coordenadas dos pontos a cadastrar "in loco" (Marques et al., 1996; Gillone, 1996).

Os pontos obtidos por GPS estão servindo de apoio para poligonais topográficas, vinculando desta forma, levantamentos topográficos via Estação Total com posicionamento GPS. Deve-se salientar que os sistemas de referência, para cada um dos instrumentos envolvidos no levantamento de dados, topográficos e geodésicos, se diferem quanto a forma e origem.

Tradicionalmente, um sistema de referência arbitrário tem sido adotado nos cálculos envolvidos numa poligonal topográfica a partir do qual são estimadas as coordenadas dos pontos levantados. Esta metodologia não se aplica aos levantamentos com o sistema GPS, pois o mesmo está relacionado a uma superfície elipsoidal que se aproxima da forma real da terra.

\subsection{Justificativa do Trabalho}

Com o advento de novas tecnologias, dentre elas o Sistema de Informação Geográfica (SIG), que dá suporte a várias atividades de desenvolvimento, surgiu a necessidade de adotar um sistema de referência único. Face a isso, a comunidade envolvida com a Mensuração no Brasil, passou a vincular os levantamentos cartográficos e geodésicos ao Sistema Geodésico Brasileiro (SGB). O Instituto 
Brasileiro de Geografia e Estatística (IBGE) preconiza o Sistema de Projeção Universal de Mercator (UTM), para os levantamentos cartográficos em escalas maiores que 1:25.000. Assim, sem dúvida, a vinculação dos levantamentos topográficos ao Sistema Geodésico Brasileiro facilita a integração de todos os trabalhos topográficos, permitindo, também, amarrações entre si. Porém, se nessa integração os cálculos não forem realizados de forma correta, a tolerância dos erros de fechamento linear e angular pode não atender a prescrição do levantamento. Há bastante questionamento de vários profissionais a cerca desta problemática, pelo fato de não ter uma descrição clara dos procedimentos de cálculo para obtenção das coordenadas ajustadas. Daí, a necessidade de elaborar uma sistemática para os cálculos dos dados, topográficos e geodésicos, combinados e separados; e verificar os desvios obtidos em cada processo.

MONICO (1998), conclui que levantamentos topográficos convencional e com GPS, podem ser integrados sem maiores problemas. Ressalta-se a necessidade de executar reduções lineares e angulares, visando a compatibilização com o sistema de referência e de projeção.

\subsection{Objetivos deste trabalho}

Neste trabalho, propõe-se a análise de ajustamento dos dados (Convencionais e GPS), combinados e em separado, elaborando os programas de transformação de coordenadas entre os sistemas utilizados para o SGB e, de ajustamento das observações obtidas dos processos convencional e GPS comparando com as tolerâncias indicadas pela NBR 13.133. Assim, considera-se os fatores causadores de erros no cálculo das distâncias por processos eletrônicos.

Dentre os fatores causadores de erros, destacam-se os fatores externos que são representados pelas condições atmosféricas que através da refração que afeta a propagação dos raios eletromagnéticos. Esta refração pode ser estimada pela fórmula empírica de Barrel e Sears, em função da pressão, umidade e temperatura. Em seguida destacam-se os erros inerentes aos componentes do equipamento, e por último as 
correções geométricas que dependem do elipsóide de referência adotado e do sistema de coordenadas planas adotado.

Em adição, apresenta-se como objetivo secundário a análise do erro de fechamento altimétrico de uma poligonal levando-se em consideração a tolerância preconizada pela NBR 13133 para nivelamentos geométricos. É importante citar que esta norma não apresenta o uso de nivelamento trigonométrico para levantamentos de precisão.

\subsection{Organização do Trabalho}

No segundo capítulo, descreve-se a evolução dos equipamentos de medição eletrônica, tais como, microondas, luz e infravermelho; demonstrando as características inerentes a cada um, e limites de operação; desta forma, possibilitando a melhor utilização do instrumento para um determinado trabalho.

No terceiro capítulo, apresenta-se os teodolitos detalhando os erros inerentes que afetam as medições de ângulos e as formas de evitá-los.

No quarto capítulo, apresenta-se um breve resumo a respeito Sistema de Posicionamento Global - GPS.

No quinto capítulo, apresenta-se os diferentes sistemas de referência, dos métodos utilizados para levantamentos das observações, suas características; as diferentes distâncias obtidas em cada superfície; e as transformações destas distâncias de um sistema para outro.

No sexto capítulo, apresenta-se o método do nivelamento trigonométrico e suas correções; no sétimo capítulo apresenta-se os métodos de ajustamento.

No oitavo e nono capítulos são apresentados os métodos utilizados e os resultados finais dos dados, respectivamente. 


\section{CAPÍTULO 2 MEDIDORES ELETRÔNICOS}

\section{1 - Propagação de Ondas Eletromagnéticas}

A forma e a velocidade de propagação de uma onda eletromagnética dependem da frequiência do sinal e da natureza da atmosfera. Portanto, as condições atmosféricas da passagem da onda devem ser consideradas de maneira a referi-la às suas propriedades no vácuo (DOUBEK, 1974).

A teoria dos fenômenos eletromagnéticos, apresentada por Maxwell em 1865, mostra que qualquer perturbação no campo eletromagnético se propaga no espaço com a velocidade da luz no vácuo.

Mais tarde, experiências realizadas por Hertz, comprovaram que as ondas hertzianas, de origem eletromagnética, têm as mesmas propriedades luminosas, estabelecendo-se desta forma uma identidade entre os fenômenos luminosos e eletromagnéticos (PACILEO, 1990).

Embasados na teoria eletromagnética, surgiram os $\mathrm{MED}^{2}$, instrumentos que permitem medir distâncias utilizando como unidade básica de medida a metade do comprimento de uma onda utilizada como portadora.

Como os instrumentos eletrônicos utilizam uma variedade de comprimentos de onda, a maneira de propagação difere entre si. Na Tabela 2.1, apresenta-se a classificação das ondas eletromagnéticas de acordo com suas freqüências.

\footnotetext{
${ }^{2}$ MED - Medidores Eletrônicos de Distâncias.
} 
Tabela 2.1: Espectro de freqüências das ondas eletromagnéticas. Adaptada de DOUBEK (1974).

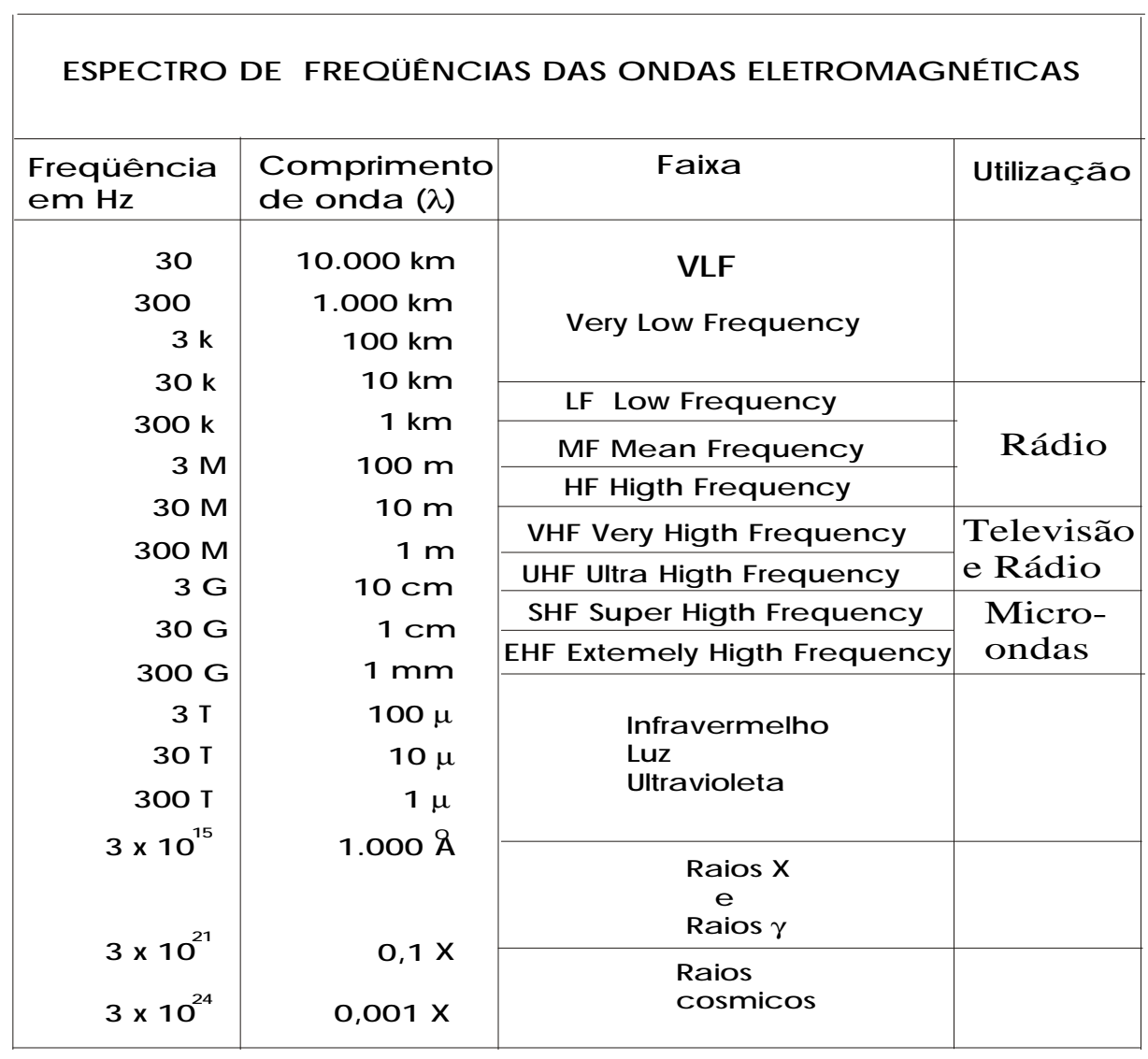

Na propagação das ondas eletromagnéticas podemos considerar dois casos:

1) Freqüências abaixo de $\approx 30 \mathrm{MHz}$, baixa freqüência;

2) Freqüências acima de $\approx 30 \mathrm{MHz}$, alta frequiência.

\subsection{1 - Ondas de Baixa Freqüência}

A propagação de ondas com freqüências inferiores $a \approx 30 \mathrm{MHz}$, ocorre em três diferentes modos:

1- Onda direta sobre a pequena faixa de intervisibilidade;

2- $\quad$ Uma onda superficial (MF) ou terrestre (LF);

3- Uma onda refletida pela ionosfera. 


\subsection{2 - Ondas de Altas Freqüências}

A propagação de ondas com freqüências superiores $\mathrm{a} \approx 30 \mathrm{MHz}$, também ocorre em três modos diferentes:

1- Uma onda direta sobre uma pequena faixa de intervisibilidade;

2- Uma onda refletida da superfície do solo;

3- Um sinal disperso causado por fenômenos na troposfera e ionosfera.

A reflexão no terreno é uma nuança e é uma possível fonte de erro em medições e, esta fonte é freqüentemente referida como "ground swing". Os sinais que se dispersam encontram aplicações em sistemas de comunicação. Todos os métodos de propagação mencionados, exceto onda direta, são resultados da reflexão, difração ou retração de onda, causada pela variação do índice refração da troposfera ou ionosfera.

Os instrumentos de medições eletrônica de distância (MED) que utilizam altas frequiências (micro ondas) usam sempre o sinal direto, limitando seu alcance de medição para ordem de $100 \mathrm{~km}$. Esta limitação, pode ser contornada realizando o aero-transporte do equipamento, (BURNSIDE, 1991). Nestes equipamentos a difração aumenta com o comprimento de onda, causado principalmente pela superfície da terra.

\section{2 - Princípios de Medições com Ondas Eletro-Magnéticas (OEM)}

Atualmente, existe uma grande variedade de instrumentos MED disponíveis no mercado e existem basicamente dois métodos de medição de comprimento de ondas: método do pulso e o método de diferença de fase; este último, é considerado o mais popular (SCHOFIELD, 1993). 


\subsection{1 - Método do Pulso (Timed-Pulse)}

Um curto e intensivo pulso de radiação é emitido pelo transmissor ao refletor, que reflete o sinal de volta, em um caminho paralelo, até o receptor (Figura 2.1). A distância é calculada pela velocidade do sinal multiplicado pelo tempo que este fez para completar o percurso.

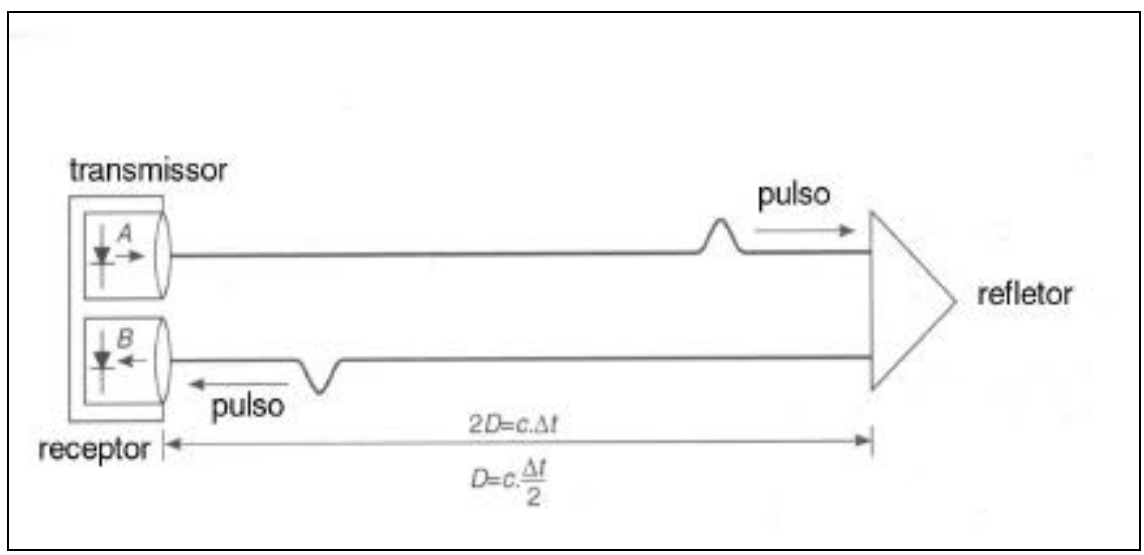

Figura 2.1: Princípio da técnica do contador de pulso (Timed-pulse) para medidor de distâncias. Fonte: SCHOFIELD,1993.

$$
\begin{aligned}
& 2 D=c \cdot \Delta t \\
& D=c \cdot \frac{\Delta t}{2}
\end{aligned}
$$

onde:

$t$ tempo de propagação da onda entre o transmissor e o refletor, considerando o caminho de ida e volta do sinal;

$c$ velocidade da luz no meio em que se propaga;

$D$ distância entre o instrumento e o alvo.

Esta técnica surgiu, primeiramente, em instrumentos hidrográficos, usando microondas. Mas, com o passar dos anos, tornou-se disponível para os sistemas que utilizam sistemas laser de propagação de ondas eletromagnéticas. 


\subsection{2 - Método da Diferença de Fase}

A maioria dos instrumentos MED, que usam infravermelho, luz visível ou microondas, aplicam essa forma de medição. A medida de diferença de fase, entre os sinais transmitidos e refletidos, da parte fracional do comprimento total, é menor que o valor da parte inteira do comprimento de onda modulada. A Figura 2.2 representa graficamente a medida da distância AB.

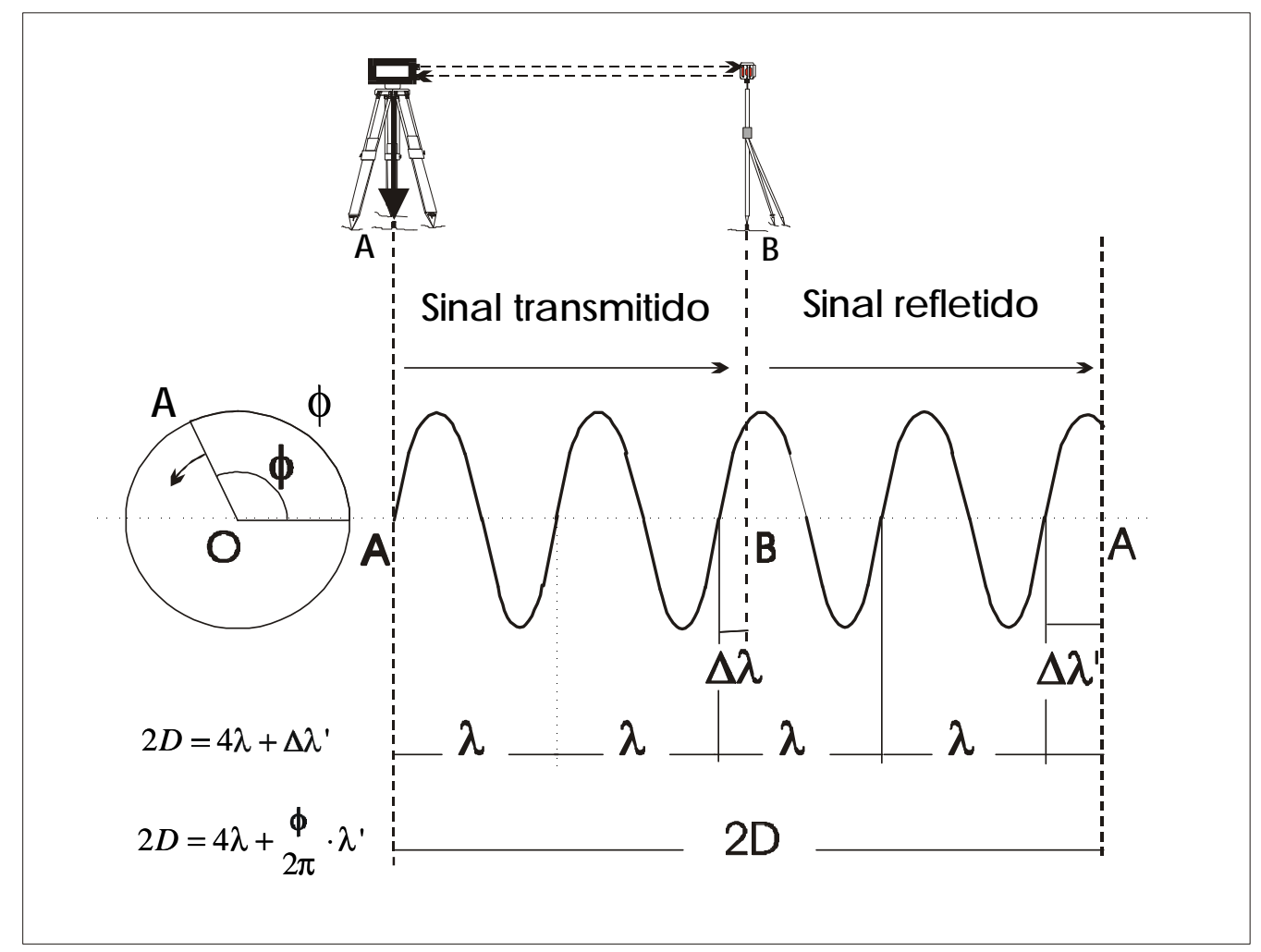

Figura 2.2: Determinação de distâncias usando MED, por caminho duplo, método da diferença de fase. Adaptado de KENNIE et al (1993).

$$
D=M \lambda+\Delta \lambda
$$

onde:

$M$ é o número inteiro de comprimento de onda (neste caso igual a 2); 
$\Delta \lambda$ é a parte fracional do comprimento de onda.

Como o sinal é refletido de volta ao instrumento (transmissor), a distância entre os pontos é dada por:

$$
2 D=N \lambda+\Delta \lambda
$$

onde:

$N$ é o número inteiro de revoluções do vetor OA (4 neste caso);

$\Delta \lambda$ é a parte fracional dada pelo ângulo de fase.

Na Figura 2.2, tem-se que $\Delta \lambda=\frac{\phi}{2 \pi} \cdot \lambda$; substituindo esta expressão em (2.4 ), obtem-se:

$$
\begin{aligned}
& 2 D=N \lambda+\frac{\phi}{2 \pi} \cdot \lambda \\
& D=N \frac{\lambda}{2}+\frac{\phi}{2 \pi} \cdot \frac{\lambda}{2}
\end{aligned}
$$

A diferença de fase $\Delta \lambda$ pode ser medida por métodos analógicos ou digitais. A Figura 2.3 ilustra a medida digital de diferença fase $\Delta \lambda$. 


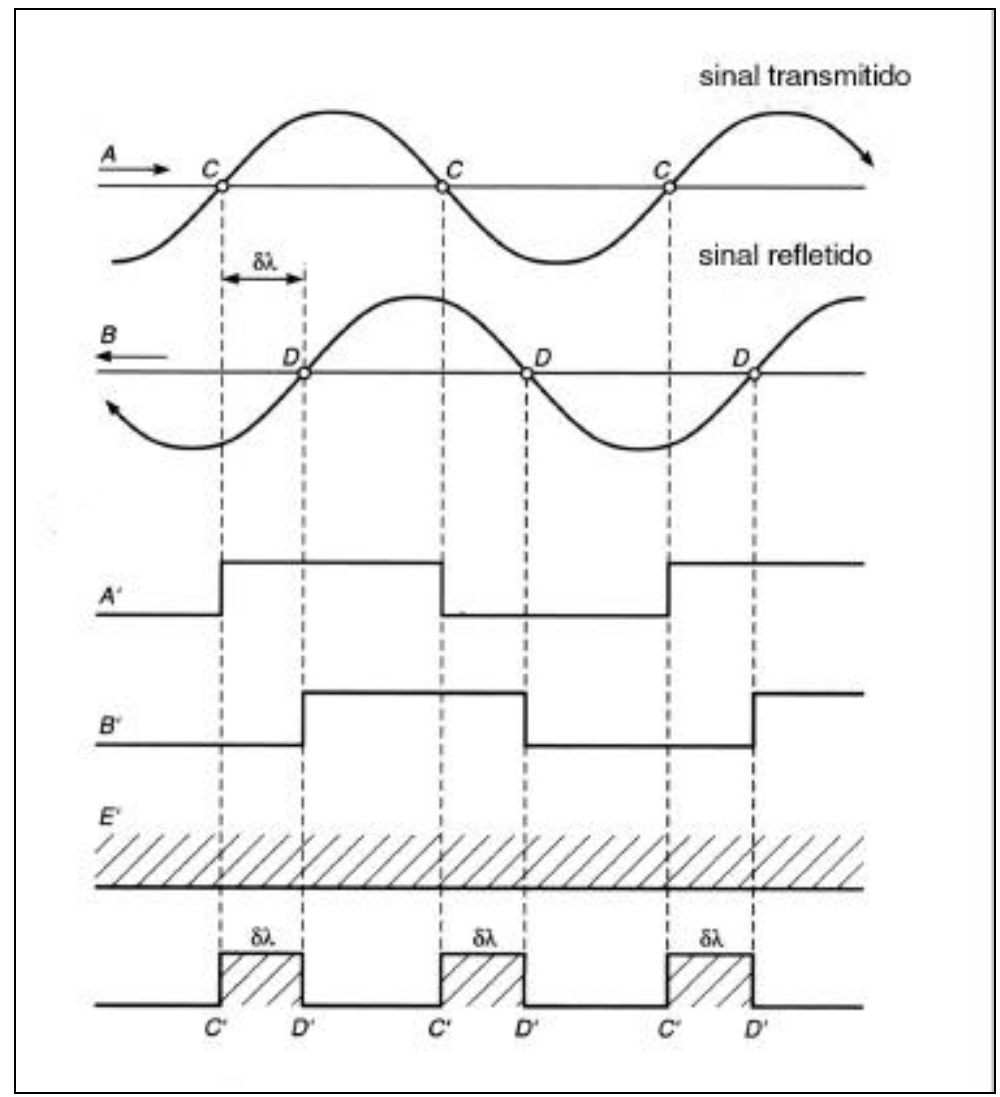

Figura 2.3: Esquema de um medidor digital de fase. Fonte: SCHOFIELD, 1993.

Deste modo, podemos idealizar uma equação que descreve a situação de maneira mais adequada.

$$
D=N \frac{C}{2 f n_{a}}+\left[\frac{\phi}{2 \pi} \times \frac{C}{2 f n_{a}}\right]+k_{2}+k_{3}
$$

onde:

$C$ é a velocidade do sinal eletromagnético (EM), no vácuo;

$f$ é a frequiência modulada (assumida sem erros);

$n_{a}$ é o índice de refração da atmosfera;

$k_{2}$ é o erro de zero do instrumento, ou constante aditiva;

$k_{3}$ é o erro cíclico do instrumento. 


\section{3- Constituição dos Medidores Eletrônicos de Distâncias (MED)}

De acordo com PACILEO (1990), podemos esquematicamente enquadrar os MED na seguinte constituição básica (Figura 2.4 e Tabela 2.2):

- Gerador de onda portadora (grupo ótico ou luz e microondas);

- Oscilador cuja função é gerar freqüências precisas e estáveis;

- Modulador capaz de transformar a onda contínua portadora em onda moduladora, com amplitude de zero a um máximo, no mesmo ritmo da freqüência fornecida pelo oscilador;

- Emissor, cuja função é enviar o feixe de onda modulada, até atingir o refletor no ponto destino;

- Refletor, que reenvia o feixe de luz ao medidor;

- Receptor, que recebe a onda portadora, detecta a onda moduladora e a amplifica para compará-la em fase com o sinal oscilador;

- Comparador de Fase, que compara a fase do sinal do oscilador (onda emitida) com a fase da onda detectada pelo receptor (onda recebida);

- Dispositivo de Leitura de Fase, ou da distância.

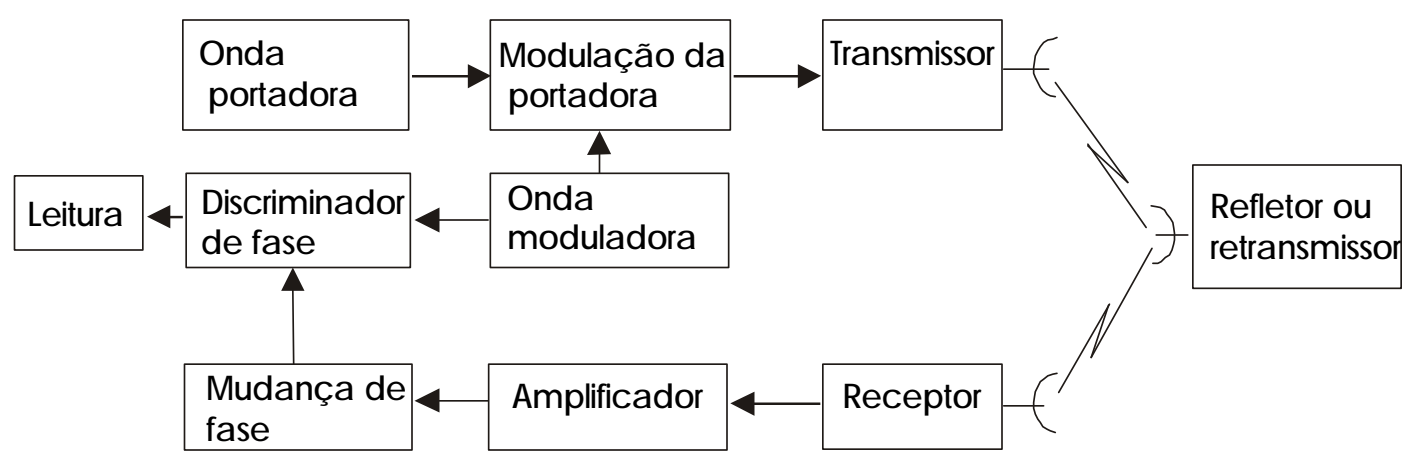

Figura 2.4: Componentes básicos de um MED. Fonte: BURNISIDE, 1991. 
Tabela 2.2: Componentes básicos de um MED. Fonte: BURNSIDE, 1991.

\begin{tabular}{|c|c|c|c|}
\hline $\begin{array}{l}\text { Onda } \\
\text { portadora }\end{array}$ & Transmissão & $\begin{array}{l}\text { Métodos de } \\
\text { modulação }\end{array}$ & $\begin{array}{l}\text { Medida } \\
\text { de fase }\end{array}$ \\
\hline $\begin{array}{l}\text { Ondaslongas } \\
\text { de rádio }\end{array}$ & Nenhum & $\begin{array}{l}\text { Antena } \\
\text { vertical }\end{array}$ & $\begin{array}{l}\text { Circuito discrimina dor } \\
\text { com indicador de fase }\end{array}$ \\
\hline Microondas & $\begin{array}{l}\text { Modulação direta } \\
\text { de freqüência }\end{array}$ & $\begin{array}{l}\text { Dipolo e } \\
\text { refletor }\end{array}$ & $\begin{array}{l}\text { Métodos de ponto nulo } \\
\text { usando: } \\
\text { 1) linha de atraso } \\
\text { 2) resolvedor } \\
\text { 3)caminho de luz variável }\end{array}$ \\
\hline Infra vermelho & $\begin{array}{l}\text { Modulação direta } \\
\text { de intensidade }\end{array}$ & $\begin{array}{l}\text { Sistema de } \\
\text { espelhos / } \\
\text { lentes }\end{array}$ & $\begin{array}{l}\text { Método digital de } \\
\text { contagem de pulso }\end{array}$ \\
\hline Luz visível & $\begin{array}{l}\text { Modulação em } \\
\text { intensidade pela } \\
\text { célula Kerrou } \\
\text { equipamento } \\
\text { similar }\end{array}$ & $\begin{array}{l}\text { Sistema de } \\
\text { espelhos / } \\
\text { lentes }\end{array}$ & $\begin{array}{l}\text { Nota: todos acima não } \\
\text { limitados a algum tipo } \\
\text { particular de instrumento }\end{array}$ \\
\hline
\end{tabular}

\section{4 - Tipos de Medidores Eletrônicos de Distâncias}

Dependendo da freqüência da onda portadora, podemos ter um maior ou menor alcance bem como limitações de precisão das medições. Podemos separar as freqüências em três grupos de medidas precisas, que dão origem a três grupos de diferentes tipos de equipamentos:

1- Microondas, com comprimento de onda $1<\lambda<10 \mathrm{~cm}$;

2- Luz visível, com comprimento de onda médio de $0,5 \mu \mathrm{m}$;

3- Infra vermelho, com comprimento de onda entre $0,72<\lambda<0,94 \mu \mathrm{m}$.

Os equipamentos descritos nos itens 2 e 3, estão inclusos na faixa LASER (Ligth Amplification by Stimulation Emission of Radiaton), que segundo PRICE \& UREN (1989) esta faixa se estende do infravermelho, passando pela luz visível, até a região do ultravioleta. 
Ainda existe a possibilidade do uso de ondas de rádio com comprimento entre $150 \mathrm{~m}<\lambda<2 \mathrm{~km}$. Estes tipos, são usadas principalmente na navegação.

\subsection{1 - Microondas}

\subsubsection{1 - Características dos Instrumentos}

Os instrumentos que utilizam microondas usam o percurso direto devido ao curto comprimento de onda. Como o sinal é direto, o alcance do instrumento é limitado para linhas de visada com distâncias menores que $100 \mathrm{~km}$. Podem ser utilizadas em satélites artificiais ou em aeronaves, mas estes são casos especiais. O equipamento pode ser operado durante o dia e a noite, mesmo com fraca visibilidade, uma vez que a pontaria não é crítica. As medições são bastante afetadas pelas condições atmosféricas.

Os instrumentos com microondas utilizam a modulação em freqüência da onda portadora, e utilizam diversas freqüências para resolver a ambigüidade. A freqüência mais alta define o limite de precisão. Como é possível medir 1/1.000 partes do ciclo, temos uma resolução do comprimento da onda entre $1 \mathrm{~mm}$ e $1 \mathrm{~cm}$.

Nas medições de distâncias com tais equipamentos, os erros instrumentais estão mais presentes e com maior peso em linhas bases curtas. Todavia, em bases longas, as condições atmosféricas têm maior influência. Estes instrumentos foram concebidos para medidas geodésicas, em bases de triangulações, poligonações de precisão ou trilateração de lados curtos, com necessidades de precisão da ordem de $1 / 10.000$ a $1 / 20.000$.

\subsubsection{2 - Princípios de Funcionamento}

Os instrumentos microondas são chamados $M E D$ ativos, em que o sinal que retorna é gerado por um segundo instrumento. O sinal é transmitido pela estação principal, chamada Master, até um segundo instrumento, dito remoto, instalado no ponto final da linha, que o retransmite a estação Master. O sinal refletido é 
enfraquecido durante o percurso de retorno. Deste modo, o sinal é amplificado (dentro da estação Master) e comparado em fase com a onda transmitida. A diferença de fase entre os dois sinais, segundo BURNSIDE (1991), é obtido usando um ponto de zero aproximado, em que a diferença de fase entre os dois sinais é levada a zero, ao introduzir uma diferença de fase adicional usando as seguintes maneiras:

1) Um circuito de indutância - atraso de linha;

2) Um circuito eletromecânico - discriminador de fase.

A solução da equação da distância (2.6), não pode ser resolvida por uma simples medição devido a não resolução da ambigüidade $(N)$. Para a solução da ambigüidade, é necessário introduzir sucessivas mudanças de comprimento de onda $(\lambda)$. Nos instrumentos que utilizam microondas, a solução da equação (2.6) é obtida por medição de $\Delta \lambda$ usando cinco valores de comprimento de onda $(\lambda)$ que é incrementado progressivamente por um fator de 10 , e esta operação de troca é feita manualmente. $\mathrm{O}$ exemplo na Tabela 2.3 ilustra este princípio.

Tabela 2.3: Princípio de resolução da distância por mudança de comprimento de onda. Fonte: KENNIE et al (1993)

\begin{tabular}{|r|c|c|}
\hline$\lambda$ & $\frac{\lambda}{2}$ & $\Delta \lambda \frac{\phi}{2 \pi} \cdot \frac{\lambda}{2}$ \\
\hline 2 & 1 &, 1243 \\
20 & 10 & 6,124 \\
200 & 100 & 76,12 \\
2.000 & 1.000 & 376,1 \\
20.000 & 10.000 & $2.376,0$ \\
\hline \multicolumn{2}{|c|}{ Distância $=2.376,1243 \mathrm{~m}$} \\
\hline
\end{tabular}


Tabela 2.4: Apresenta as características técnicas dos instrumentos que utilizam microondas. Fonte: DOUBEK, 1984.

\begin{tabular}{|c|c|c|c|c|c|c|c|}
\hline \multirow{2}{*}{ Nome } & \multirow{2}{*}{$\begin{array}{l}\text { Comprimento } \\
\text { de onda } \\
\text { portadora }\end{array}$} & \multicolumn{2}{|c|}{ Alcance } & \multirow{2}{*}{$\begin{array}{l}\text { Sistema } \\
\text { de leitura }\end{array}$} & \multirow{2}{*}{ Precisão } & \multirow{2}{*}{ Peso } & \multirow{2}{*}{ Observações } \\
\hline & & Mín & Máx & & & & \\
\hline $\begin{array}{l}\text { Tellurometer } \\
\text { MRA-4 }\end{array}$ & $\begin{array}{l}9 \mathrm{~mm} \\
\text { feixe } 2^{\circ}\end{array}$ & $\begin{array}{r}50 \\
\mathrm{~m}\end{array}$ & $\begin{array}{l}50 \\
\mathrm{k} \mathrm{m}\end{array}$ & $\begin{array}{l}\text { Medidor } \\
\text { de nulo 3 } \\
\text { dígitos }\end{array}$ & $\begin{array}{l} \pm 3 \mathrm{~mm} \\
\pm 3 \mathrm{ppm}\end{array}$ & $18 \mathrm{~kg}$ & $\begin{array}{l}\text { Trabalha nas } \\
\text { temperaturas } \\
-55^{\circ} \text { até }+55^{\circ}\end{array}$ \\
\hline $\begin{array}{l}\text { Cubic } \\
\text { E letrotape } \\
\text { D M -20 }\end{array}$ & $\begin{array}{l}30 \mathrm{~cm} \\
\text { feixe } 6^{\circ}\end{array}$ & $\begin{array}{l}10 \\
\mathrm{~m}\end{array}$ & $\begin{array}{l}50 \\
\mathrm{k} \mathrm{m}\end{array}$ & $\begin{array}{l}\text { Medidor } \\
\text { de nulo } 3 \\
\text { dígitos }\end{array}$ & $\begin{array}{c} \pm 1 \mathrm{~cm} \\
\pm 3 \times 10^{-5} \\
m\end{array}$ & $15 \mathrm{~kg}$ & $\begin{array}{l}\text { Similar ao } \\
\text { MRA-3 }\end{array}$ \\
\hline $\begin{array}{l}\text { Wild } \\
\text { Distomat } \\
\text { DI-50 }\end{array}$ & $\begin{array}{l}3 \mathrm{~cm} \\
\text { feixe } 6^{\circ}\end{array}$ & $\begin{array}{c}100 \\
\mathrm{~m}\end{array}$ & $\begin{array}{l}50 \\
\mathrm{k} \mathrm{m}\end{array}$ & $\begin{array}{l}\text { Semi-auto } \\
\text { mático } 7 \\
\text { dígitos }(\mathrm{cm})\end{array}$ & $\begin{array}{c} \pm 2 \mathrm{~cm} \\
\pm 0,5 \times 10^{-5} \\
m\end{array}$ & $25 \mathrm{~kg}$ & $\begin{array}{l}\text { Medida } \\
\text { automática } \\
\text { de fase }\end{array}$ \\
\hline $\begin{array}{l}\text { Tellurometer } \\
\text { M R B-2 } \\
\text { H ydrodist }\end{array}$ & $\begin{array}{l}10 \mathrm{~cm} \\
\text { feixe } 20^{\circ}\end{array}$ & & $\begin{array}{l}50 \\
\mathrm{k} \mathrm{m}\end{array}$ & $\begin{array}{l}\text { TRC com } \\
100 \\
\text { divisões }\end{array}$ & $\pm 1,5 \mathrm{~m}$ & $15 \mathrm{~kg}$ & $\begin{array}{l}\text { Antena pode fi- } \\
\text { car } 5 \mathrm{~m} \text { separada } \\
\text { do instrumento }\end{array}$ \\
\hline
\end{tabular}

\subsection{2 - Luz Visível}

Os instrumentos dessa categoria usam luz visível como portadora, por exemplo, o Geodímetro tem um comprimento de onda da ordem de $5600 A^{0}$ (isto é, $\left.0,56 \times 10^{-6} \mathrm{~m}\right)$. O modo de propagação é na forma de raio direto, reflexões são incomuns, devido ao fato que na natureza não se encontram muitas superfícies que produzem fortes reflexões para este tipo de onda. Por outro lado, durante parte do dia, sempre há a possibilidade de entrada de luz no sistema ótico aumentando o ruído, que reduz a sensibilidade do instrumento no processo de medição. $O$ feixe de luz é altamente colimado, com uma divergência de apenas frações do grau, razão pela qual o receptor ótico tem um diâmetro bastante pequeno e, portanto pequeno ângulo de recepção. Devido a pequena divergência do feixe, o alinhamento de visada torna-se crítico.

O alcance é em geral menor que os instrumentos que usam microondas, sendo que a noite o alcance é maior e as condições atmosféricas, tais como chuviscos ou 
neblina, diminuem consideravelmente o alcance. O índice de refração é pouco afetado pelas condições atmosféricas para o curto comprimento de onda usado, e a umidade relativa causa pequena influência nesses instrumentos, o que não ocorre com os instrumentos com microondas. Por essas razões, o erro externo é considerado com um valor da ordem de 1 ppm (parte por milhão).

Em geral os instrumentos eletro-óticos são mais apropriados para medir distâncias curtas obtendo-se alta precisão, sendo o erro de zero o fator mais importante de limitação de sua precisão.

O uso destes instrumentos é bastante amplo, sendo que na engenharia têm sido usados na abertura de túneis ou minas, barragens, pontes, instalação de máquinas; no levantamento de bases de triangulação, poligonais de precisão ou trilateração de lados curtos.

\subsection{3 - Infra-Vermelho}

\subsubsection{1 - Características dos instrumentos}

Os instrumentos dessa categoria usam radiação infra-vermelho como portadora, com comprimento de onda em torno de $0,9 \mu \mathrm{m}$. Na região do infravermelho, a atmosfera tem uma grande absorção com exceção da região 0,72 $0,94 \mu \mathrm{m}$, que é chamada de "janela do I.V.". Isto implica no uso dessa região para todos equipamentos; para evitar a perda por dispersão. Em condições combinando alta umidade, alta temperatura; o vapor d'água presente na atmosfera causa mais absorção. Com o feixe estreito e o curto comprimento de onda usado, existem poucos

problemas com ondas refletidas. Neste caso, a pontaria é crítica, pois o feixe de luz é de $1 / 4$ do grau, e sendo a precisão da ordem de milímetros.

O processo de modulação da freqüência é usado nestes instrumentos para que possa usar como unidade de medida um comprimento de onda em torno de $10 \mathrm{~m} \mathrm{e}$ transmitir o sinal na atmosfera de forma eficiente. A primeira vista poderia se pensar em diminuir o comprimento da onda para que se possa utilizar antenas de 
transmissão, já que as mesmas devem ter o tamanho da ordem de $10 \lambda$ (comprimento da onda de medição). Sabe-se que não é recomendado este procedimento de diminuição do comprimento de onda pela dificuldade de se resolver a ambigüidade para uma medida longa, onde os ciclos são muito próximos e o processo de medição de fase é extremamente instável para altas freqüências. Assim sendo, as antenas seriam muito grandes, já que o comprimento de onda $\lambda$ é em torno de $10 \mathrm{~m}$, inviabilizando seu uso no processo de medição.

O tipo de modulação nos instrumentos infravermelho com sistema eletroóticos, segundo PRICE \& UREN (1989), é a modulação em amplitude na qual a onda de medição é usada para variar a onda portadora (Figura 2.5). O raio infravermelho, pode ser controlado usando pequenos componentes tais como lentes de modo que um raio altamente colimado seja transmitido pelo instrumento.

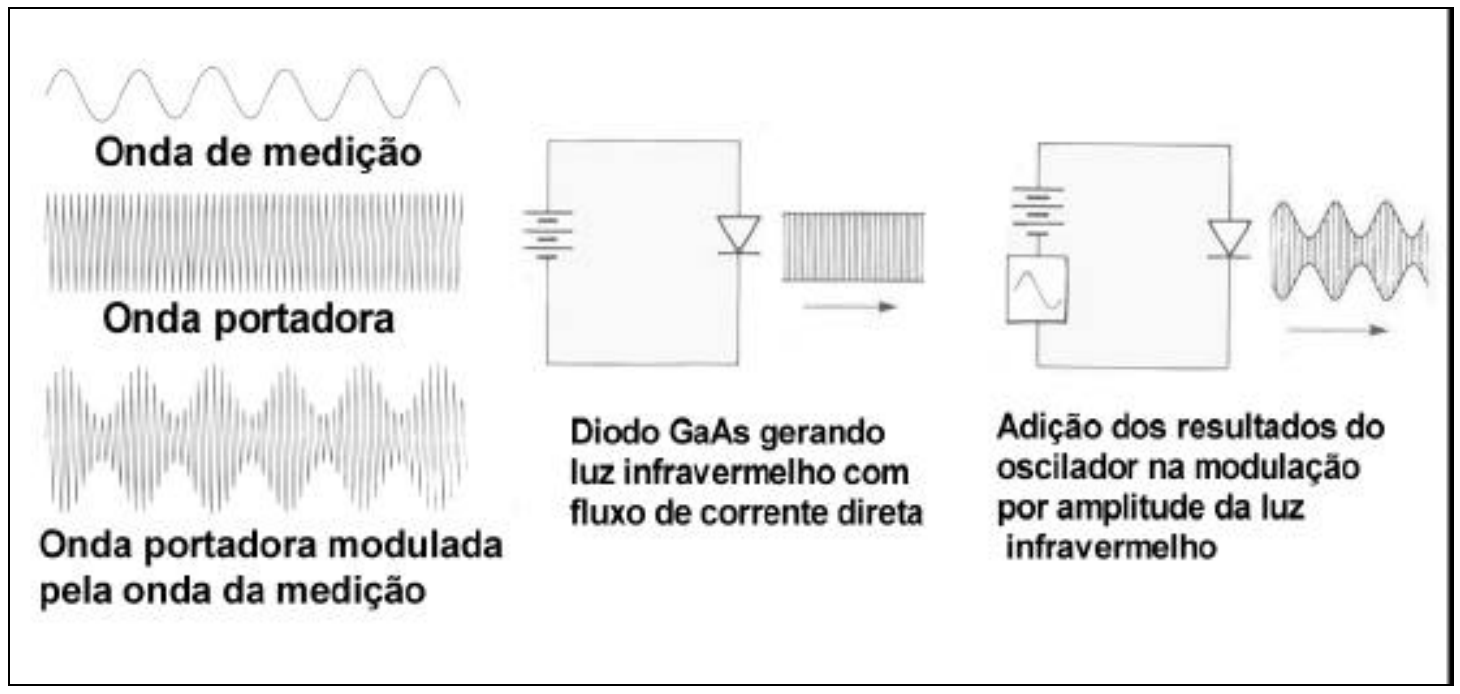

Figura 2.6: Modulação por amplitude do diodo GaAs. Adaptado de PRICE \& UREN (1989).

O diodo de arseniato de gálio (GaAs) é a fonte de onda utilizada na maioria dos instrumentos dessa categoria, sendo que sua principal vantagem é que a saída pode ser modulada diretamente em intensidade. A saída de radiação é sempre linearmente relacionada a estimulada corrente aplicada e o tempo de resposta é na 
verdade muito pequeno. A Tabela 2.5 apresenta as características técnicas dos equipamentos que utilizam o infravermelho.

Tabela 2.5: Características técnicas de equipamentos que utilizam infravermelho. Fonte: DOUBEK, 1984.

\begin{tabular}{|c|c|c|c|c|c|c|}
\hline Instrumento & Fonte & $\begin{array}{l}\text { Comprimen- } \\
\text { to de onda }\end{array}$ & Alcance & Precisão & Peso & $\begin{array}{l}\text { Sistema } \\
\text { de leitura }\end{array}$ \\
\hline $\begin{array}{l}\text { Tellurometer } \\
\text { M A-100 }\end{array}$ & $0,93 \mu \mathrm{m}$ & $4 \mathrm{~m}$ & $2 \mathrm{k} \mathrm{m}$ & $\begin{array}{l} \pm 1,5 \mathrm{~mm} \\
\pm 2 \mathrm{ppm}\end{array}$ & $17,3 \mathrm{~kg}$ & $\begin{array}{l}\text { Medida digital } \\
\text { de fase, } 4 \text { dígitos }\end{array}$ \\
\hline $\begin{array}{l}\text { Wild } \\
\text { Distomat } \\
\text { DI-10 }\end{array}$ & $0,875 \mu \mathrm{m}$ & $20 \mathrm{~m}$ & $2 \mathrm{k} \mathrm{m}$ & $\pm 1 \mathrm{~cm}$ & $20 \mathrm{~kg}$ & $\begin{array}{l}\text { Mudança contínua } \\
\text { de frequiência, } \\
\text { leitura automática, } \\
4 \text { dígitos }\end{array}$ \\
\hline $\begin{array}{l}\text { Zeiss } \\
\text { SM -11 }\end{array}$ & $0,92 \mu \mathrm{m}$ & $20 \mathrm{~m}$ & $2 \mathrm{k} \mathrm{m}$ & $\pm 1 \mathrm{~cm}$ & $20,5 \mathrm{~kg}$ & $\begin{array}{l}\text { Medida digital } \\
\text { de fase, } 5 \text { dígitos. } \\
\text { Medida de ângulos } \\
\text { em cristal graduado }\end{array}$ \\
\hline $\begin{array}{l}\text { Zeiss J ena } \\
\text { EOK } 2000\end{array}$ & $0,91 \mu \mathrm{m}$ & $10 \mathrm{~m}$ & $2,5 \mathrm{k} \mathrm{m}$ & $\begin{array}{c} \pm 1 \mathrm{~cm} \\
\pm 1,5 \times 10^{-5} \\
m\end{array}$ & $12 \mathrm{~kg}$ & $\begin{array}{l}\text { Leitura automática } \\
\text { digital } 6 \text { dígitos }\end{array}$ \\
\hline $\begin{array}{l}\text { Hewlett } \\
\text { Packard }\end{array}$ & $0,91 \mu \mathrm{m}$ & 20 pés & 7.500 pés & $\begin{array}{l} \pm 1 \mathrm{~cm} \\
\pm 0,01 \text { pé } \\
\times 10^{-5} \mathrm{~m}\end{array}$ & $7,5 \mathrm{~kg}$ & Leitura digital \\
\hline $\begin{array}{l}\text { Zeiss R eg } \\
\text { Elta }\end{array}$ & $0,92 \mu \mathrm{m}$ & $20 \mathrm{~m}$ & $2 \mathrm{k} \mathrm{m}$ & $\pm 1 \mathrm{~cm}$ & $20 \mathrm{~kg}$ & $\begin{array}{l}\text { Mede também os } \\
\text { ângulos, registra } \\
\text { em fita, medida } \\
\text { automática, preci- } \\
\text { são de } \pm 10\end{array}$ \\
\hline
\end{tabular}

\subsection{5 - Erros Sistemáticos em Medições com MED}

Os erros que afetam os MED são de natureza randômica e sistemática, e que podem ser evitados ou fortemente reduzidos através de boas técnicas de medição, mas se alguns erros sistemáticos permanecem, há o processo de calibração com o propósito de avaliá-los e corrigi-los. 
Segundo KENNIE et al (1993), são muitos as diferentes fontes de erros sistemáticos que podem afetar os instrumentos MED, incluindo aqueles causados pelo operador do instrumento, a atmosfera e instrumento mau ajustado.

\subsubsection{1 - Erros do Operador do instrumento}

Em particular, o cuidado deveria acontecer nas seguintes operações:

- é importante regular, com precisão, o centro com o eixo principal do instrumento verificando o prumo ótico do teodolito (se o MED é montado no teodolito), ou por um prumo ótico integral;

- fazer uma pontaria de forma cuidadosa ao ponto da posição do alvo refletor. É importante pelo fato das facilidades para a redução automática da distância inclinada; a não observância do ponto do alvo a ser colimado, pode evidenciar erros na leitura do ângulo vertical;

- verificar as configurações automáticas de valores da correção (umidade, pressão, temperatura etc). É essencial entrar esses valores corretos para prevalecer as condições em que os instrumentos estão sendo usados

\subsubsection{2 - Erros Atmosféricos}

Variações nas condições atmosféricas daquelas que são assumidas pelo instrumento quando de sua fabricação, podem causar incremento ou redução na medida de comprimento de onda e conduz a um erro sistemático se a correção não for aplicada.

Normalmente, o efeito da atmosfera é definida pela mudança no índice de refração $(n)$, onde $n$ é definido como: 


$$
n=\frac{c}{v}
$$

onde:

$c$ é a velocidade das ondas eletromagnéticas no vácuo $(c=299.792,5$ $\mathrm{km} / \mathrm{s})$;

$v$ é a velocidade média (atmosfera).

O valor de $n$ é normalmente próximo da unidade e é assumido por muitos instrumentos MED como sendo igual a 1,000320. No espectro de onda eletromagnética (EM) de luz visível e infravermelho, $n$ é calculado usando a fórmula de Barrel e Sears:

$$
\left(n_{t}-1\right)=\left(n_{s}-1\right) \cdot \frac{273}{273+t} \cdot \frac{P}{760}-\frac{15,02 \cdot E}{273+t} \times 10^{-6}
$$

onde:

$$
\left(n_{s}-1\right) \times 10^{-6}=287,604+\frac{1,6288}{\lambda_{0}^{2}}+\frac{0,0136}{\lambda_{0}^{4}}
$$

$n_{t}$ índice de refração corrente;

$n_{s}$ índice de refração do ar a $0^{\circ} \mathrm{C}$ e $760 \mathrm{mmHg}$ de pressão, contendo $0,03 \%$ de $\mathrm{CO}_{2}$;

$t$ temperatura durante a observação $\left({ }^{\circ} \mathrm{C}\right)$;

$P$ pressão durante a observação $(\mathrm{mmHg})$;

$E$ pressão do vapor de água $(\mathrm{mmHg})$;

$\lambda_{0}$ comprimento de onda do sinal no vácuo. 
Tabela 2.6: Precisões em medições da temperatura, pressão e umidade entre os diversos MED para obter um 1 ppm de precisão no índice de refração. KENNIE et al (1993).

\begin{tabular}{|llll|}
\hline & \multicolumn{3}{c|}{ Precisão em medidas } \\
\hline Onda portadora & $\begin{array}{l}\text { T } \\
\text { (oC) }\end{array}$ & $\begin{array}{l}\text { P } \\
\text { (mmH g) }\end{array}$ & $\begin{array}{l}\text { H umidade } \\
\text { (mmH g) }\end{array}$ \\
\hline Microondas & 0,8 & $\pm 2,9$ & $\pm 0,17$ \\
Luz visivel/Infravermelho & 1,0 & $\pm 2,7$ & \pm 20 \\
\hline
\end{tabular}

\subsubsection{3 - Erros Instrumentais}

Dispositivos MED, como outros instrumentos topográficos, requerem cuidados no uso e uma regular calibração, para fornecer segurança e acurácia às medições. Os erros sistemáticos causados pelo instrumento mau ajustado são: Erro de escala $\left(K_{1}\right)$ ou constante de multiplicação, Erro de índice $\left(k_{2}\right)$; Erro cíclico $\left(k_{3}\right)$, descritos a seguir.

\subsubsection{1 - Erro de Escala $\left(k_{1}\right)$ ou Constante de Multiplicação}

Ocorre se a freqüência modulada dos instrumentos MED não corresponde exatamente com o valor da freqüência projetada para o instrumento. É um erro linear proporcional à distância a ser medida e podem surgir de fontes internas ou externas. Este erro pode ser freqüentemente expresso em partes por milhão (ppm) da distância medida. Se o oscilador não gera a frequiência de medida requerida, então o erro de escala poderá ser introduzido. Os osciladores controlados por um cristal são influenciados pelas condições de temperatura ambiente e estão expostos a um processo de envelhecimento lento. Devem ser calibrados anualmente, sempre que possível. Os instrumentos que trabalham com alcance mais longo, como os equipamentos de microondas, tem maiores riscos de apresentarem estes tipos de erros que os equipamentos de alcance curto, tais como os instrumentos infravermelho (IR). 


\subsubsection{2 - Erro de Zero ou de Índice $\left(k_{2}\right)$}

Segundo SILVA et al (1999), Erro de Zero ou de Índice é também chamado de Erro de Constante de Adição. Esse erro representa a diferença entre a distância medida, pelo instrumento MED, entre os dois pontos e a distância conhecida dos mesmos, sem erros de escala, cíclico e atmosférico. É causado quando o centro interno de medida do instrumento e o refletor não coincidem com o centro físico do instrumento/refletor, que é colocado verticalmente sobre o ponto a ser medido. A constante de adição varia de acordo com a combinação instrumento/prisma. Na maioria dos casos ela é igual a zero.

\subsubsection{3 - Erro Cíclico $\left(k_{3}\right)$}

São erros periódicos e, podem ter um efeito sistemático, particularmente em pequenas distâncias. É caracterizado por ser uma função periódica do comprimento de onda medido e a diferença de fase entre medida e sinal de referência. Este efeito é cíclico sobre o comprimento de onda modulada.

Estes são os menores das três fontes de erros instrumentais e são causados por “contaminação" eletrônica interna entre o transmissor e o receptor (circuito elétrico). O efeito dessa fonte de erro é reduzido pelos fabricantes de instrumentos por isolantes elétricos e proteção dos componentes dentro do equipamento. 


\section{CAPÍTULO 3 - TEODOLITOS ELETRÔNICOS}

\section{1 - Considerações Gerais}

Pelo fato das distâncias medidas estarem associadas a alinhamentos, freqüentemente os dispositivos de medição eletrônicos de distâncias (MED) são ligados a um teodolito para facilitar a pontaria do alvo, e no caso de alinhamentos consecutivos que se ligam, determinar o ângulo horizontal entre os mesmos para posterior estimativa da orientação e cálculo das coordenadas (Figura 3.1).

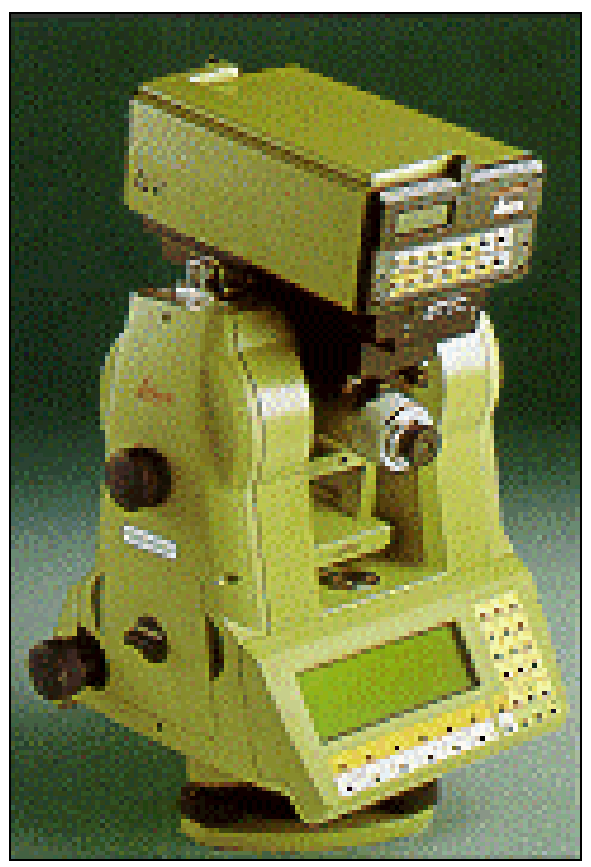

Figura 3.1: Ilustração de um dispositivo de medição (MED) acoplado a um teodolito. 
Segundo SILVA (1993), na década de 70 a área de levantamentos topográficos sofreu profundas modificações com o aparecimento dos teodolitos eletrônicos em substituição aos instrumentos ótico-mecânicos (Figura 3.2).

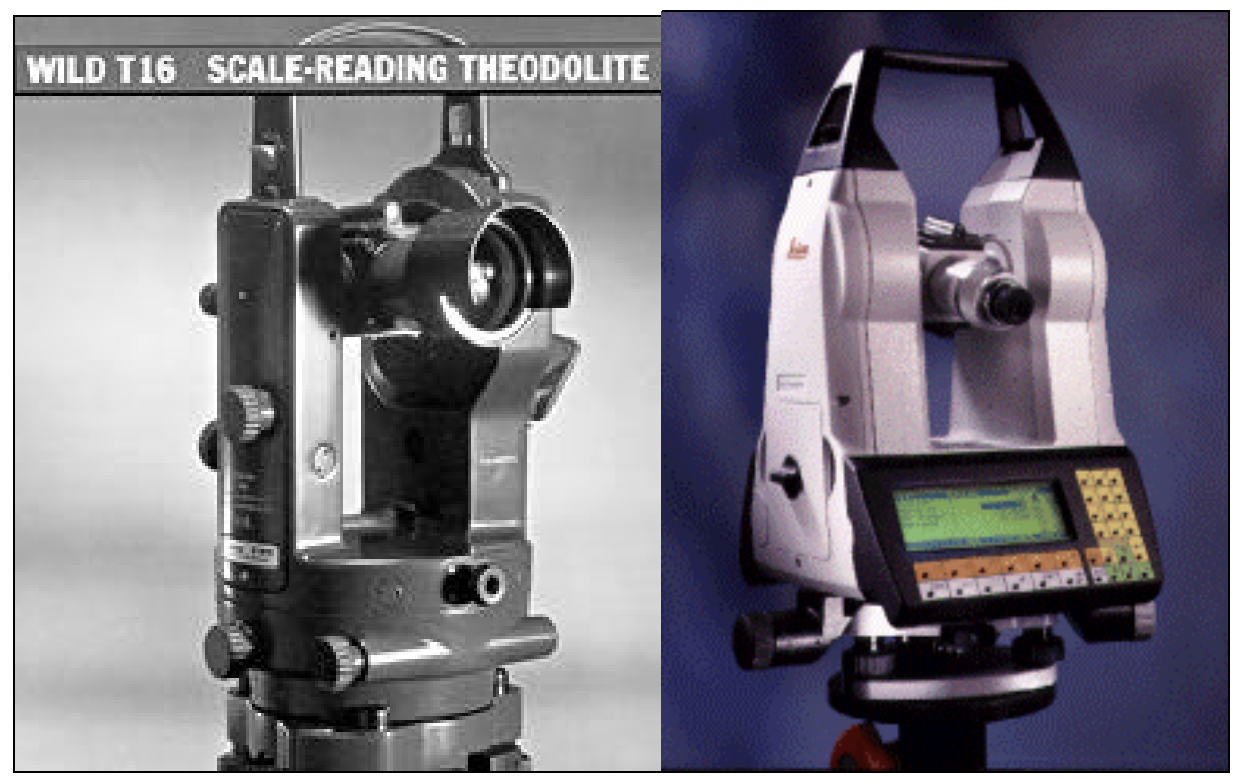

Figura 3.2: Apresentação de um teodolito mecânico e um eletrônico, respectivamente.

Os teodolitos eletrônicos são instrumentos que permitem a medição eletrônica de ângulos horizontal e vertical. Estes instrumentos possuem as mesmas características construtivas de um teodolito clássico. Algumas novas soluções foram adotadas para determinados grupos de elementos, o que determinou uma maior confiabilidade nos instrumentos. A maior mudança foi no sistema de leitura de ângulo que é eletrônico e no sistema de calagem que é usado um sensor eletrônico de inclinação.

Nos últimos anos aparece a nova geração de instrumentos de medições topográficas que conjuga os teodolitos eletrônicos com os dispositivos de medição eletrônica de distâncias, dando origem às estações totais (Figura 3.3). 


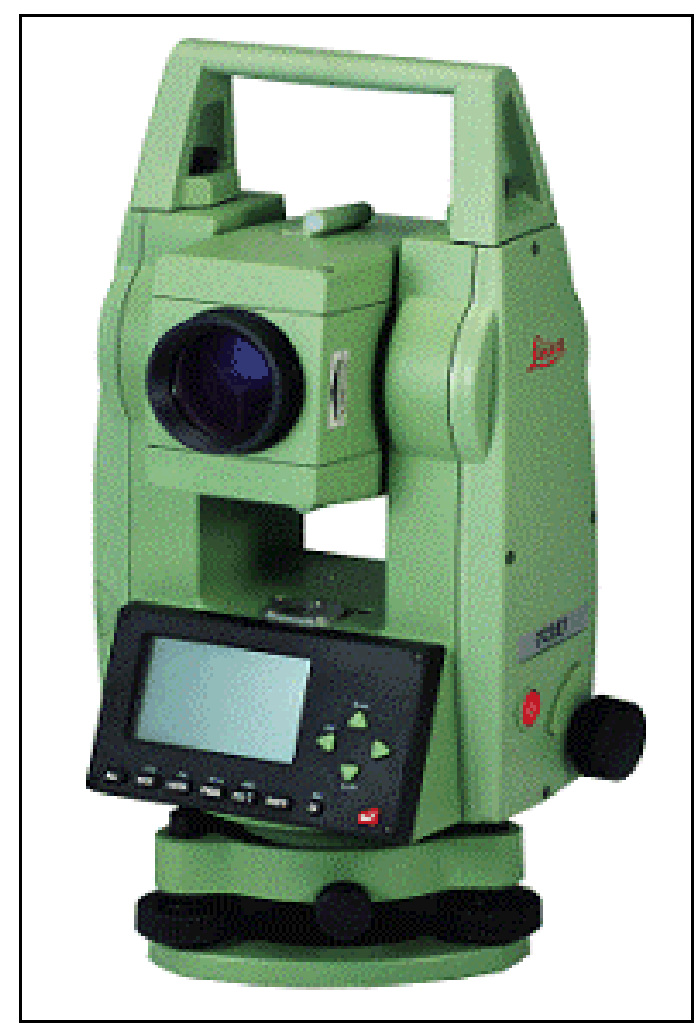

Figura 3.3: Estação Total da série de compensadores eletrônicos e prumos laser. Cortesia da Leica do Brasil S/A.

\section{2 - Princípios da Medição Eletrônica de Ângulos}

Para CINTRA (1995) os principais componentes físicos de um sistema de medição eletrônica de ângulos são dois:

1- Um círculo de cristal com regiões claras e escuras (transparentes e opacas) codificadas através de um processo de fotolitografia;

2- Fotodiodos detectores de luz que atravessa esse círculo graduado.

Existem basicamente dois princípios de codificação e medição, o absoluto que fornece o valor angular para cada posição do círculo, e o incremental que fornece o valor com relação a uma posição inicial. 


\subsection{1 - Modelo Incremental}

Para entender o princípio de funcionamento do modelo incremental pode-se pensar, de maneira simplificada, num círculo de vidro com uma série de traços opacos e transparentes igualmente espaçados. Colocando uma fonte de luz de um lado do círculo e um fotodetector do outro, é possível "contar" o número de pulsos (“claro/escuro") que ocorrem quando o teodolito é girado, de uma posição a outra, para medir o ângulo (Figuras 3.4 e 3.5). Esse número de pulsos pode ser convertido e mostrado de forma digital em um visor.

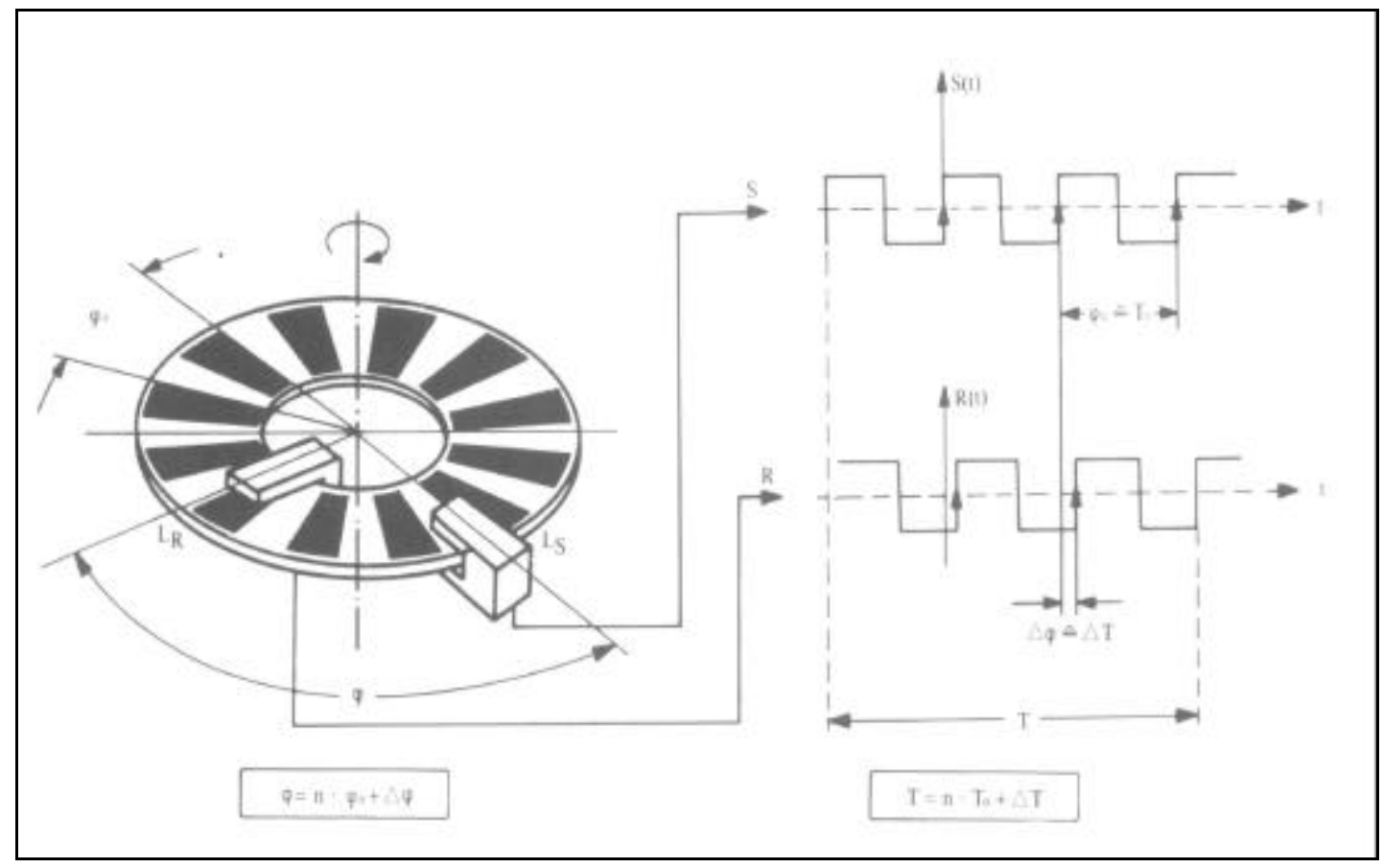

Figura 3.4: Sistema de leitura angular incremental usando comparador de fase (KAHMEN et al, 1988). 


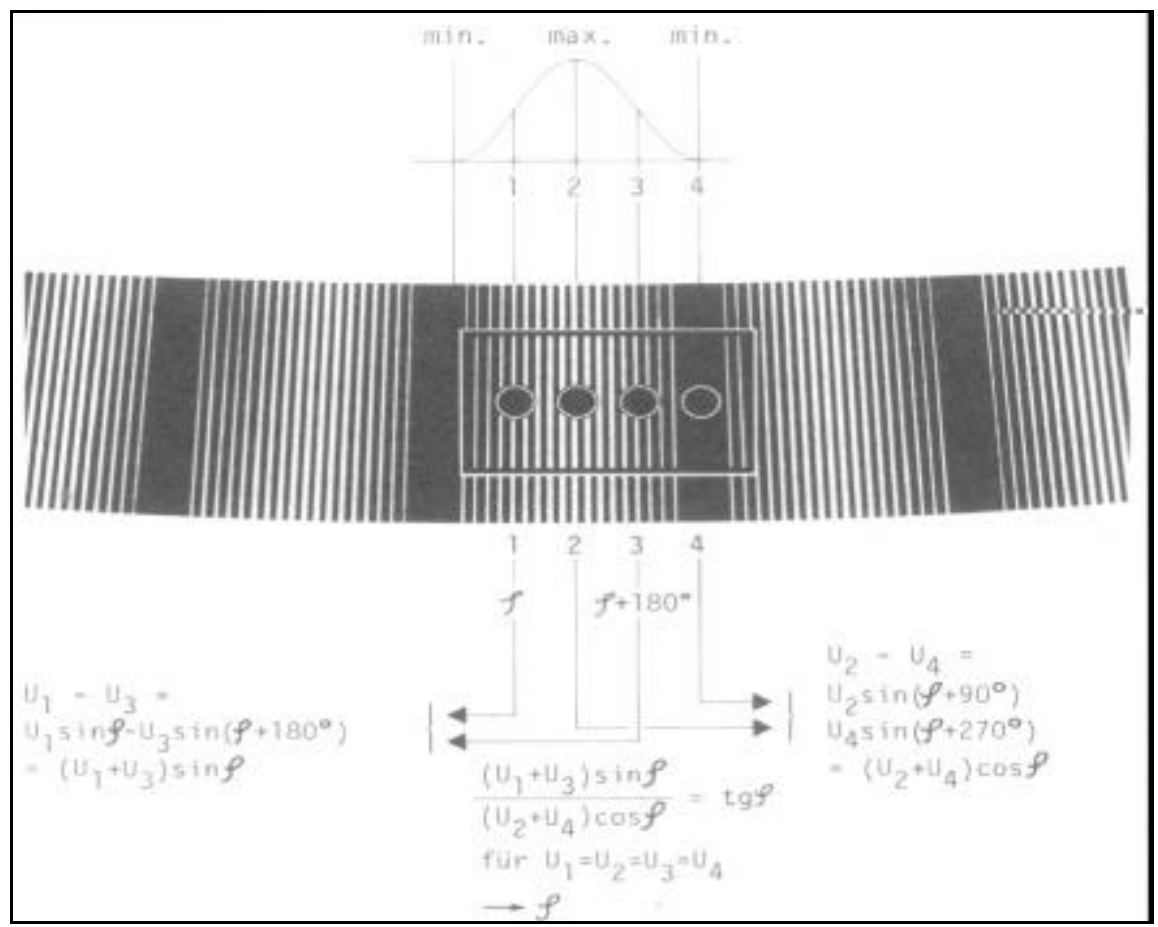

Figura 3.5: Sistema de leitura angular incremental usando interpolação matemática (KAHMEN et al, 1988).

\subsection{2 - Modelo Absoluto}

No modelo absoluto pode-se pensar em trilhas opacas dispostas concentricamente não mais na direção radial, conforme a Figura 3.6. O limite do número de trilhas vem dado agora pelo raio e não pelo perímetro.

Associando o valor 0 (zero) quando a luz não atravessa e 1 (um) quando isso ocorre, e dispondo uma série de diodos de forma radial, podemos associar cada posição do círculo a um código binário de zeros e uns numa determinada seqüência, este é manipulado e mostrado na forma decimal. 


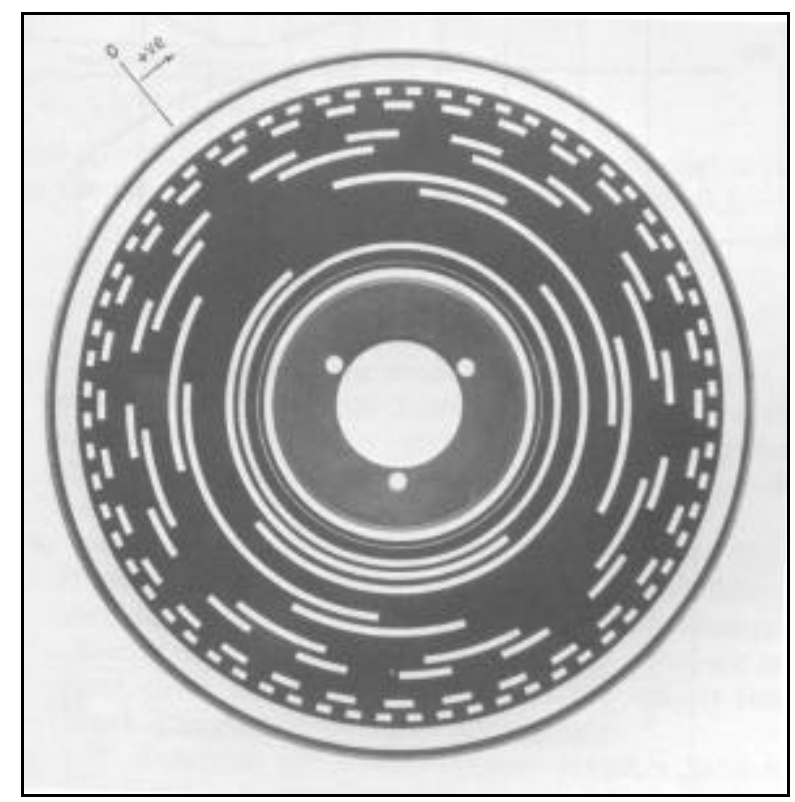

Figura 3.6: Sistema de leitura angular absoluto (COOPER, 1987).

\section{3 - Sensor Eletrônico de Inclinação}

O sensor eletrônico de inclinação, além de facilitar a tarefa do operador e aumentar a precisão, permite corrigir diretamente uma visada simples de ângulos verticais, sem ter que conjugar pares de leituras nas posições direta e inversa, segundo KENNIE et al (1993). É um dos dispositivos que os teodolitos eletrônicos incorporaram que não aparecem nos mecânicos, destinado a horizontalização automática dos mesmos, compensando as inclinações residuais do eixo vertical.

Segundo CINTRA (1995) o sistema, mostrado na Figura 3.7 é baseado na reflexão de uma luz sobre uma superfície líquida, que permanece sempre horizontal e por isso pode ser usada como referencial. Uma luz gerada em A é refletida na superfície líquida $\mathrm{B}$, e após através de alguns componentes óticos atinge um fotodiodo $\mathrm{C}$. $\mathrm{O}$ valor da corrente, induzida neste, permite determinar a posição da luz com relação ao ponto zero $\mathrm{Z}$ em um quadrante e qual o deslocamento com relação a esse ponto central, ou seja, a inclinação do teodolito na direção do eixo de colimação e na sua perpendicular. 


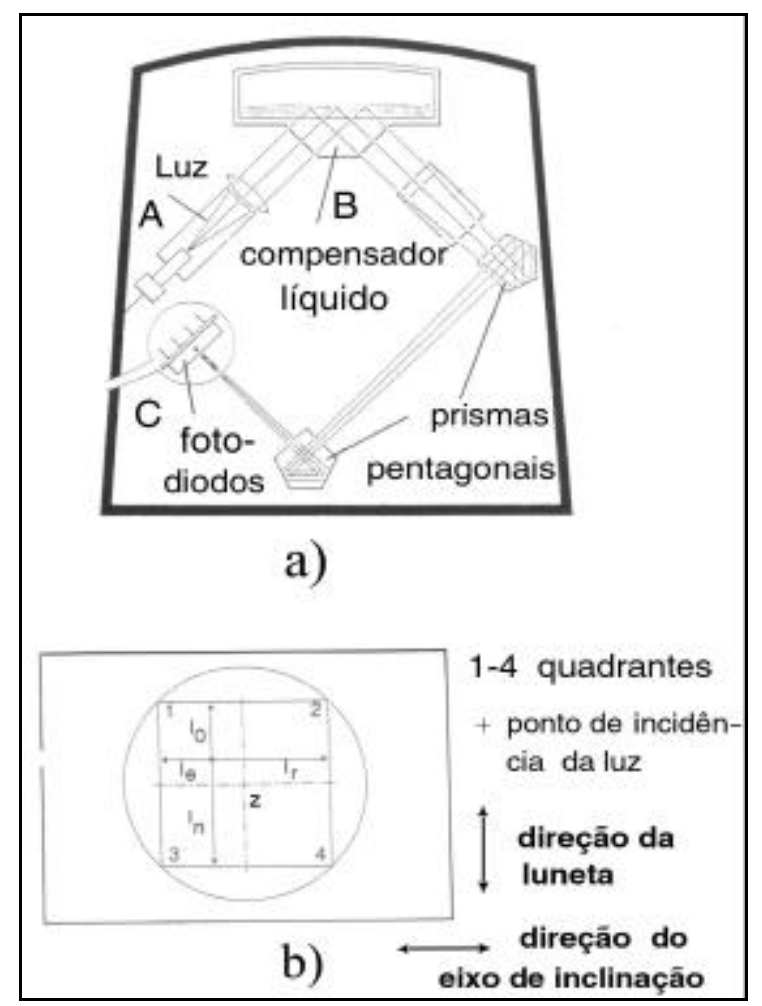

Figura 3.7: Detalhe do sensor de inclinação que permite a horizontalização automática Adaptada de KENNIE et al (1993).

\section{4 - Erros Instrumentais de um Teodolito}

\subsection{1 - Introdução}

$\mathrm{Na}$ fabricação dos teodolitos há alguns erros inevitáveis de ajustamento do instrumento que permanecem após a construção, e quando detectados devem ser corrigidos.

Segundo MOREIRA (1998), os eixos de um teodolito devem satisfazer as seguintes condições:

1- o eixo secundário $(\mathrm{HH})$ deve ser perpendicular ao eixo principal;

2- o eixo de visada (ZZ) deve ser perpendicular ao eixo secundário;

3- o eixo principal deve estar vertical (VV) após a calagem;

4- os três eixos devem ser concorrentes em um mesmo ponto. 


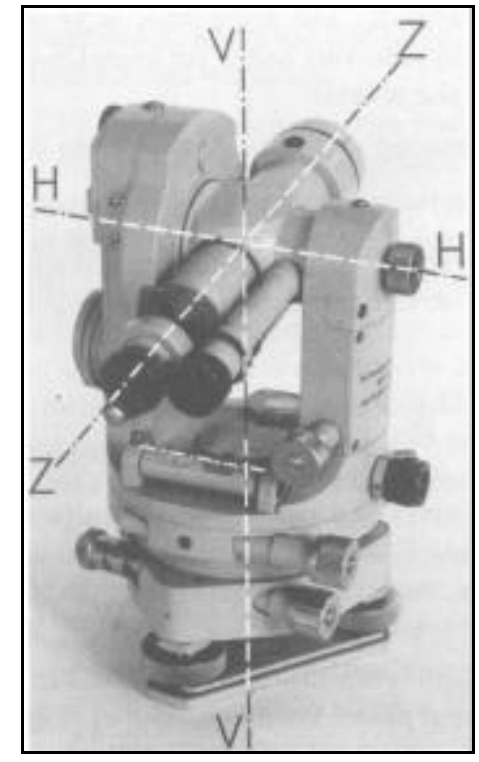

Figura 3.8: Eixos esquemáticos do teodolito (KAHMEN et al, 1988).

Entretanto, quando estas não são completamente satisfeitas acarretam os erros de eixo do teodolito, cujos erros não podem ser desprezados nas medidas angulares. Além disso, o centro do círculo horizontal deve coincidir com o centro do eixo principal e o centro do círculo vertical deve coincidir com o centro do eixo secundário.

\subsection{2 - Erros de Eixo de um Teodolito}

Estes erros podem ser eliminados pela medida dos ângulos nas duas posições da luneta, tomando-se a média (reiteração) para os dois primeiros itens.

Os erros de eixo de um teodolito são:

1- erro de perpendicularidade do eixo secundário em relação ao eixo principal, que se traduz por um erro de horizontalidade do eixo secundário ou do basculamento;

2- erro de perpendicularidade do eixo de visada em relação ao eixo secundário, denominado erro de colimação horizontal;

3- erro de calagem do instrumento, ou seja, o erro de verticalidade do eixo principal. 


\subsubsection{1 - Erro de Horizontalidade do Eixo Secundário ou Erro do Basculamento}

Segundo MOREIRA (1998), se o eixo secundário de um teodolito não for perpendicular ao eixo principal, quando este último estiver vertical ao eixo secundário não estará horizontal, tem-se então:

\section{$\mathbf{i}=$ erro de horizontalidade}

Neste caso o erro de visada descreverá um plano inclinado durante o basculamento da luneta, de acordo com Figura 3.9.

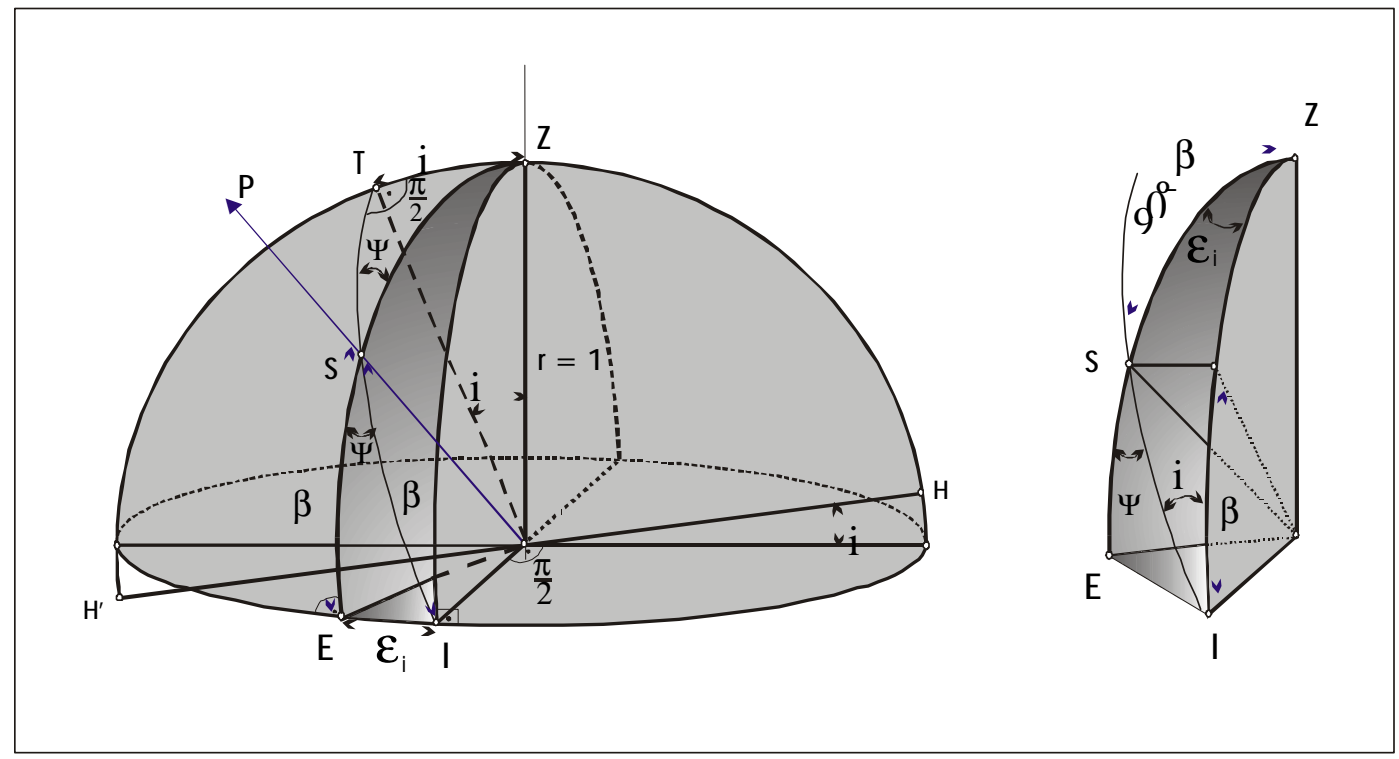

Figura 3.9: Representação do erro horizontalidade do eixo secundário, adaptado de MOREIRA (1998).

Para visada $O P$, o erro da direção horizontal é o arco $I E=\varepsilon_{i}$. Tem-se, então:

$$
\begin{aligned}
& \frac{\sin \varepsilon_{i}}{\sin \psi}=\frac{\sin \beta}{\sin \left(\frac{\pi}{2}\right)} \\
& \frac{\sin \psi}{\sin i}=\frac{\sin \left(\frac{\pi}{2}\right)}{\sin \left(\frac{\pi}{2}-\beta\right)}
\end{aligned}
$$


substituindo, vem:

$$
\sin \varepsilon_{i}=\sin i \cdot \operatorname{tg} \beta
$$

Como os ângulos $i$ e $\varepsilon_{i}$ são pequenos, faz-se:

$$
\varepsilon_{i}=i \cdot \operatorname{tg} \beta
$$

\subsubsection{2 - Erro de Colimação Horizontal}

Segundo COOPER (1987), se a linha de colimação é inclinada em um ângulo $c$ à normal do eixo de giro, a linha de visada descreve um cone em torno do eixo de giro, como na Figura 3.10:

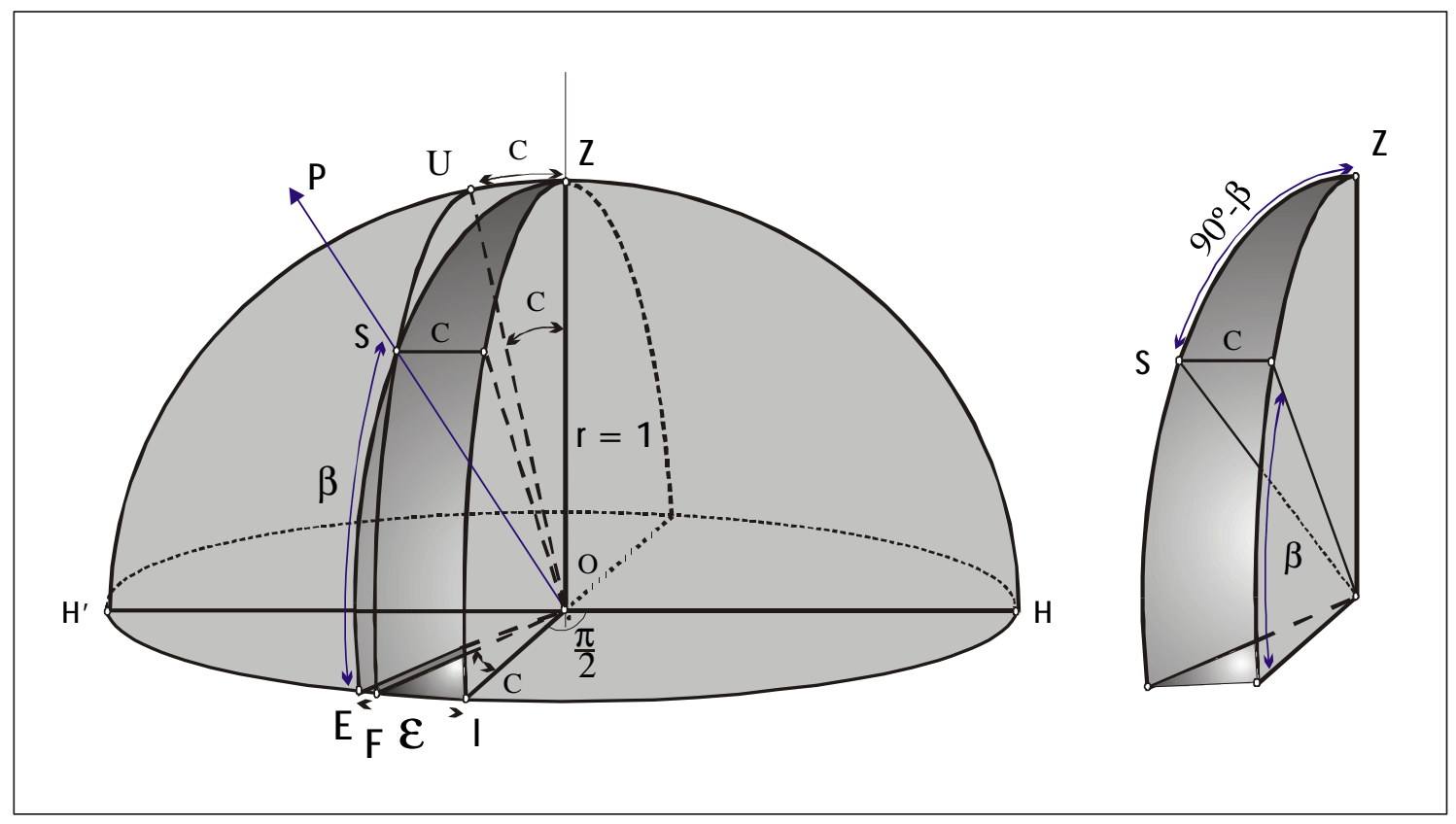

Figura 3.10: Representação do erro de colimação horizontal, adaptada de MOREIRA (1998). 
De acordo com MOREIRA (1998), o erro de colimação horizontal é dado como a seguir:

$$
\begin{gathered}
\frac{\sin \varepsilon_{c}}{\sin \left(\frac{\pi}{2}\right)}=\frac{\sin c}{\sin \left(\frac{\pi}{2}-\beta\right)} \\
\sin \varepsilon_{c}=\frac{\sin c \cdot \sin \left(\frac{\pi}{2}\right)}{\sin \left(\frac{\pi}{2}-\beta\right)} \\
\sin \varepsilon_{c}=\frac{\sin c}{\cos \beta}
\end{gathered}
$$

Como $\varepsilon_{c}$ e $c$ são pequenos, tem-se:

$$
\varepsilon_{c}=c \frac{1}{\cos \beta} \quad \text { ou } \quad \varepsilon_{c}=c \sec \beta
$$

\subsubsection{3 - Erro de Verticalidade do Eixo Principal}

A origem do erro $(v)$ vem da concepção que o círculo horizontal permanece horizontal, enquanto que o eixo vertical é inclinado em relação à vertical, segundo COOPER (1987). A inclinação do eixo secundário varia de $+v$ a $-v$ segundo a orientação da visada. 


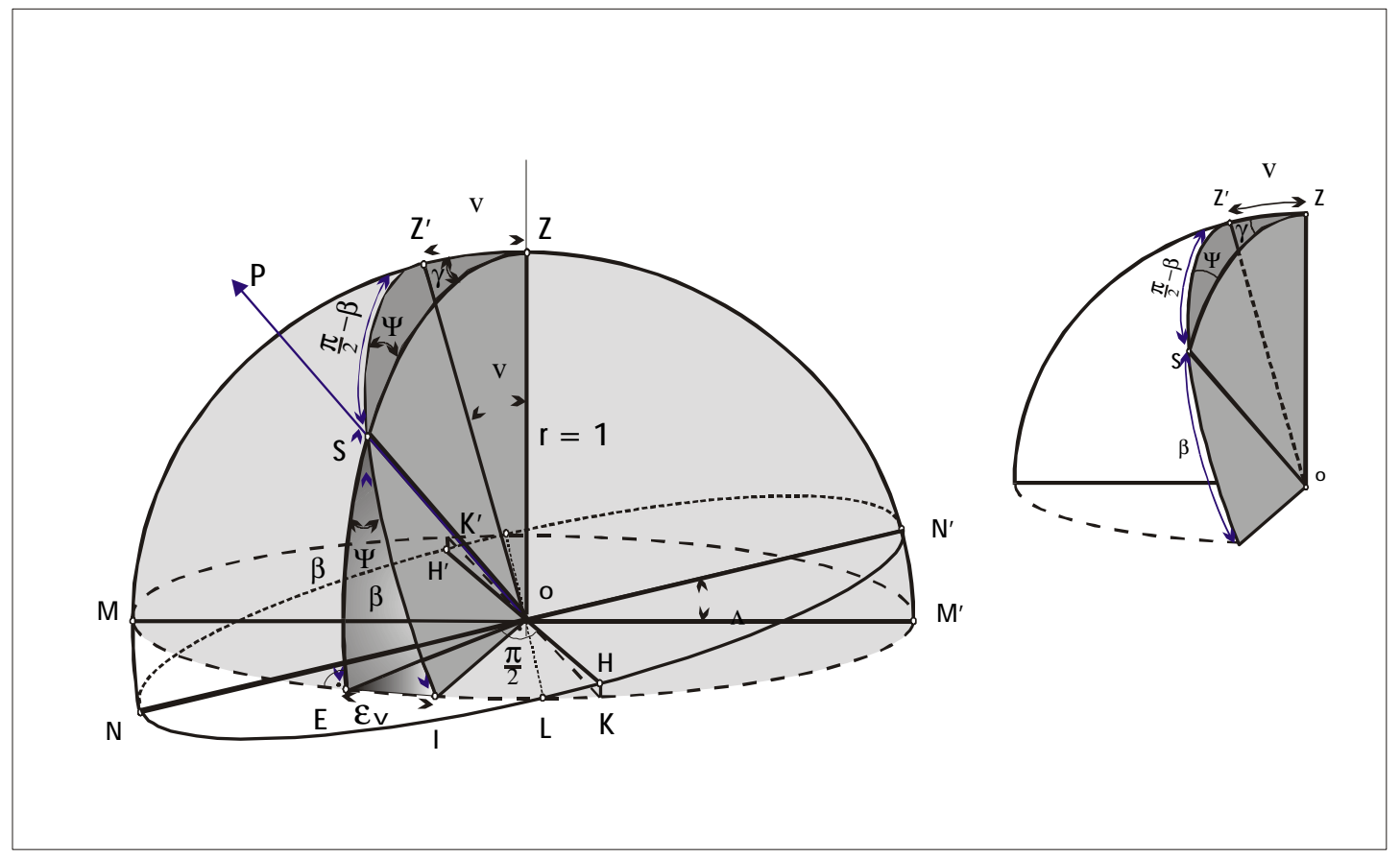

Figura 3.11: Representação do erro de verticalidade do eixo principal, adaptada de MOREIRA (1998).

Para visada $O P$, o erro da direção horizontal é o arco $I E=\varepsilon_{v}$. Tem-se, então:

$$
\begin{gathered}
\frac{\sin \varepsilon_{v}}{\sin \psi}=\frac{\sin \beta}{\sin \left(\frac{\pi}{2}\right)} \\
\frac{\sin \psi}{\sin v}=\frac{\sin \gamma}{\sin \left(\frac{\pi}{2}-\beta\right)}
\end{gathered}
$$

substituindo, vem:

$$
\sin \varepsilon_{v}=\sin v \cdot \sin \gamma \cdot \operatorname{tg} \beta
$$

Como os ângulos $v$ e $\varepsilon_{v}$ são pequenos, faz-se:

$$
\varepsilon_{v}=v \cdot \sin \gamma \cdot \operatorname{tg} \beta
$$




\subsection{3 - Erros de Excentricidade dos Círculos}

Os teodolitos em vez de ter seu círculo horizontal montado sobre o centro, este está deslocado lateralmente em relação ao eixo de giro. O círculo vertical, da mesma forma, deve estar centrado sobre o eixo secundário. Caso isso não ocorra, tem-se uma excentricidade como mostrado seguir (Figura 3.12):

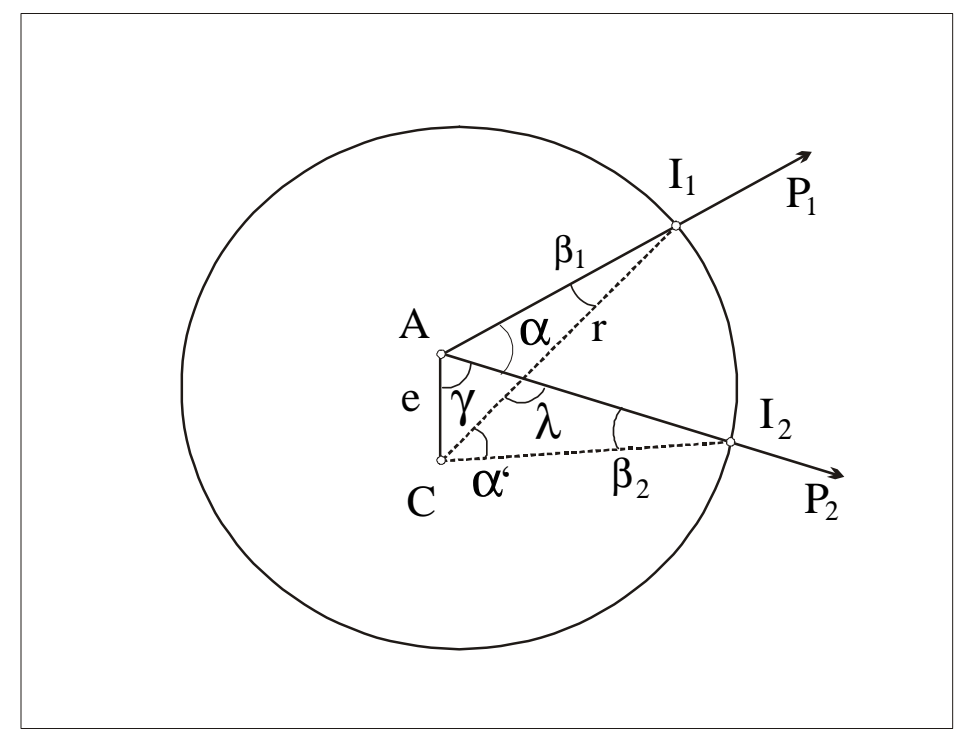

Figura 3.12: Representação dos erros de excentricidade dos círculos, adaptada de MOREIRA (1998).

Considerando-se os ângulos $\beta_{1}, \beta_{2}$ e $\lambda$, somando os ângulos de cada triângulo, temos:

$$
\alpha^{\prime}+\beta_{2}+\lambda=180^{\circ} \quad \text { e } \quad \alpha+\beta_{1}+\lambda=180^{\circ}
$$

Substituindo, vem:

$$
\alpha-\alpha^{\prime}=\beta_{2}-\beta_{1}
$$

Assim:

$$
\varepsilon=\alpha-\alpha^{\prime}=\beta_{2}-\beta_{1}
$$


Considerando que os ângulos $\beta_{1}$ e $\beta_{2}$ são pequenos, pode-se dizer que:

$$
\begin{gathered}
\sin \beta_{1} \cong \beta_{1}=\frac{e}{r} \sin (\alpha+\gamma) \text { e } \quad \sin \beta_{2} \cong \beta_{2}=\frac{e}{r} \sin \gamma \\
\varepsilon=\beta_{2}-\beta_{2}=\frac{e}{r}[\sin \gamma-\sin (\alpha+\gamma)]
\end{gathered}
$$

Na prática não se conhece a excentricidade e nem a orientação da linha dos centros AC. Por isso não é possível avaliar a grandeza do erro de um ângulo medido. Segundo MOREIRA (1998), a solução para o problema consiste em eliminar o erro lendo-se a medida em dois índex de pontos diametralmente opostos do círculo e calcular a média dos dois valores. A Figura 3.13 mostra esta situação:

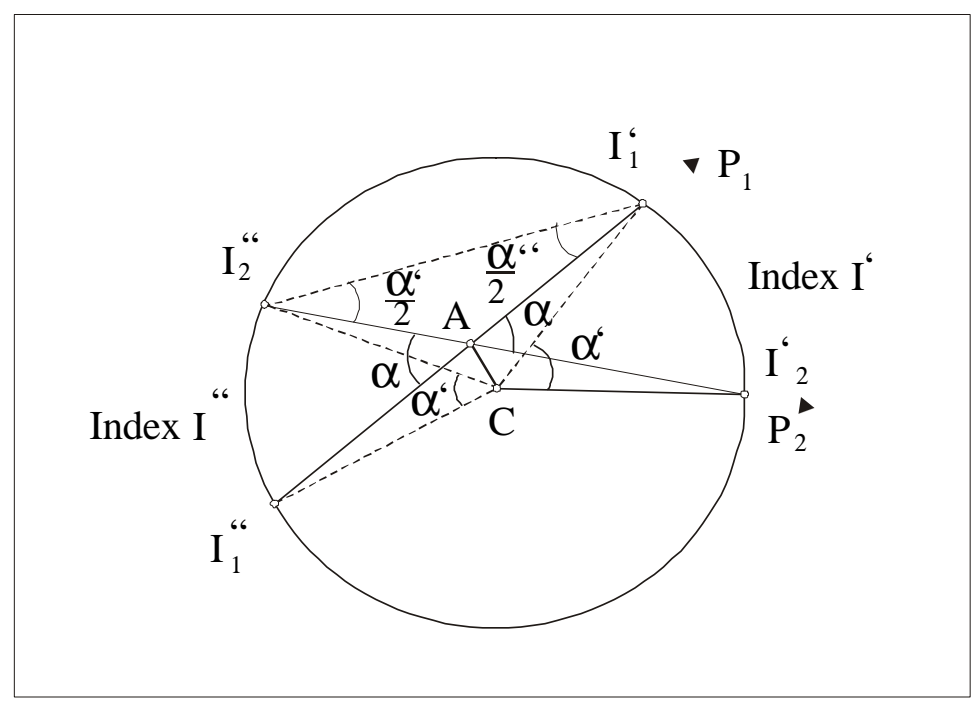

Figura 3.13: Representação das leituras em dois pontos diametralmente opostos, adaptada de MOREIRA (1998).

Assim, tem-se:

$$
\begin{aligned}
& \frac{\alpha^{\prime}}{2}+\frac{\alpha^{\prime \prime}}{2}=\alpha \\
& \alpha=\frac{\alpha^{\prime}+\alpha^{\prime \prime}}{2}
\end{aligned}
$$




\subsection{4 - Erros de Graduação dos Círculos}

Os erros de graduação dos círculos são acarretados pela imprecisão dos traços que constituem a graduação do círculo. Segundo MOREIRA (1998) são eles:

1- erros acidentais: são erros existentes no posicionamento de cada traço individualmente, são indiferentemente positivos e negativos;

2- erros sistemáticos: são erros que ocorrem devido a imperfeição da máquina de gravar, eles são negativos ou positivos em regiões distintas do círculo.

Segundo JORDAN (1944), procura-se atenuar as conseqüências dos erros de graduação sobre as medidas angulares fazendo para cada ponto de visada leituras em partes distintas da graduação do círculo e calcular a média dos resultados; e para diminuir os efeitos dos erros sistemáticos é necessário repartir as medidas regularmente sobre toda a porção da graduação.

\subsection{5 - Erros do Índice do Círculo Vertical - Colimação Vertical}

Para MOREIRA (1998), o erro do índice do círculo vertical é o erro de colimação do círculo vertical em relação ao horizonte ou ao zênite.

Se o instrumento estiver isento do erro de índice do círculo vertical, a leitura do ângulo zenital deve ser igual a $90^{\circ} 00^{\prime} 00^{\prime \prime}$, na posição I, sempre que a luneta estiver orientada no horizonte. Essa condição deve ser verificada seguindo os seguintes passos: visar um ponto bem definido em posição I da luneta e ler o valor do ângulo do círculo vertical. Repetir a mesma operação na posição II da luneta. A soma das duas leituras deve ser igual a $360^{\circ} 00^{\prime} 00^{\prime}$. Uma eventual diferença corresponderá ao duplo valor do índice vertical. A eliminação do erro do índice vertical é dada pela média das duas leituras do círculo vertical nas duas posições da luneta. 


\section{5 - Correções das Medidas dos Ângulos Lidos com um Teodolito Eletrônico}

Estes aparelhos possuem a capacidade para corrigir, automaticamente, os erros instrumentais através de processadores eletrônicos e de compensadores mecânicoeletrônicos. Segundo SILVA (1996), em certos instrumentos, os erros de índice vertical e de colimação horizontal são compensados através da calibração do instrumento, que pode ser feita pelo próprio usuário fazendo leituras nas posições direta e inversa da luneta para um alvo bem definido. Os erros calculados através da calibração são armazenados no instrumento e compensados durante as medições de campo. O erro de verticalidade do eixo principal é compensado, automaticamente, através de um compensador eletrônico para os dois eixos do teodolito. Este compensador opera através do princípio da incidência de um raio luminoso sobre uma célula de foto-diodos e leitura das coordenadas do ponto de incidência. A resolução de um compensador desse tipo, segundo MOREIRA (1998), é da ordem de $1 \mu \mathrm{m}$ e permite detectar um defeito de calagem do instrumento da ordem de 1".

\section{6 - As Estações Totais Modernas e a Leitura de Ângulos e Distâncias}

\subsection{1 - Considerações Gerais}

A aplicação de novas tecnologias e implementação dos desejos dos usuários de todas partes do mundo trouxe apreciável desenvolvimento no conceito de operação e funcionalidade das Estações Totais. Estas se tornaram menores, mais leves e seus procedimentos de medição tem sido acelerado. Os sistemas de medição de ângulos, de distância sem refletor, o reconhecimento automático do alvo, e o prumo laser com o "spot" de iluminação ajustável às condições ambientais são todos componentes disponíveis nestes instrumentos. 


\subsection{2 - Medição de Ângulos}

A leitura do círculo de vidro de graduação com códigos é realizada óticaeletronicamente, conforme Figura 3.14, usando o sistema absoluto de leitura do círculo.

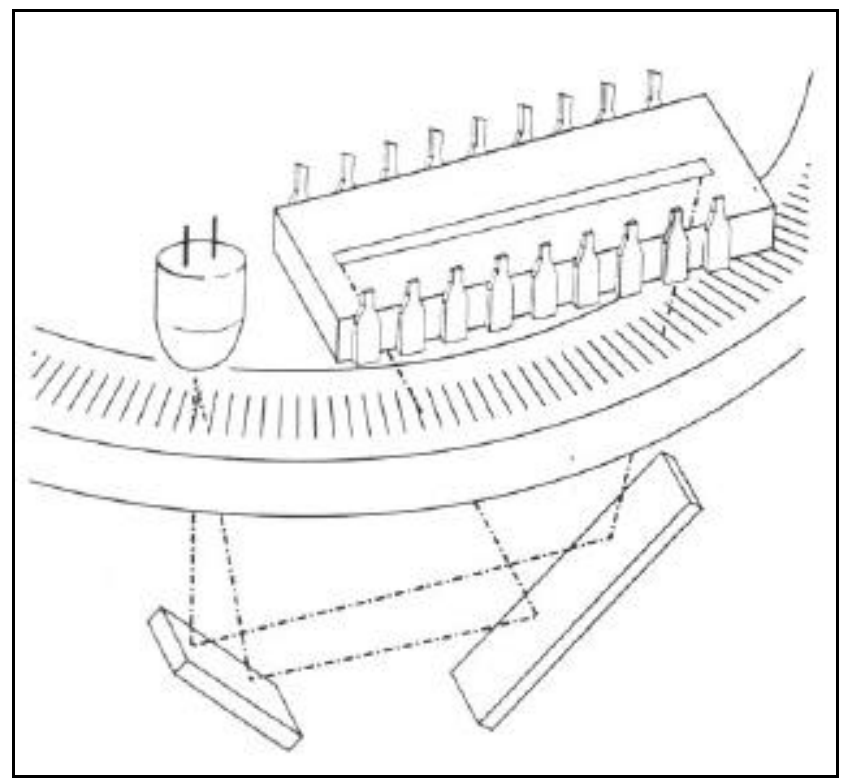

Figura 3.14: Princípio de leitura ótica-eltrônica do círculo de vidro, adaptada de ZEISK (1999).

O sistema da LEICA, ao contrário dos principais sistemas de medidas de ângulo absoluto onde as posições tem que ser decodificadas por várias linhas paralelas, o círculo transporta apenas uma linha de graduação, com códigos que contém todas informações posicionais, e são lidos por meio de uma câmera CCD e um conversor de 8 bit A/D, para fornecer a posição aproximada com uma precisão em torno de 1 segundo.

A medida fina é realizada por um algoritmo apropriado que encontra o meio termo entre as posições de centro de cada linha de código projetada na série que é capturada pela câmera. Um mínimo de 10 linhas de códigos devem ser capturados para determinar a posição. Entretanto uma simples medida envolve cerca de 60 linhas de código, fornecendo a precisão de interpolação, a redundância e a reprodutibilidade.

O valor da direção horizontal é obtido por leituras nas duas posições do círculo de maneira a eliminar a excentricidade e posteriormente é corrigido por parâmetros em 
função do ângulo vertical lido, antes de apresentar os valores em um visor. Os parâmetros são:

- o último erro de colimação, e de nivelamento e verticalidade dos eixos armazenados no instrumento;

- a componente momentânea da falta de verticalidade do eixo principal, transverso à linha de sinal.

O ângulo vertical é corrigido por todos os erros de índice armazenado e pela componente do erro de verticalidade do eixo principal na direção da linha de sinal. Um sensor de verificação da verticalidade do eixo principal monitora as duas componentes do desvio do eixo principal. O princípio do sensor é mostrado na Figura 3.15, em que o espelho do líquido forma uma referência horizontal.

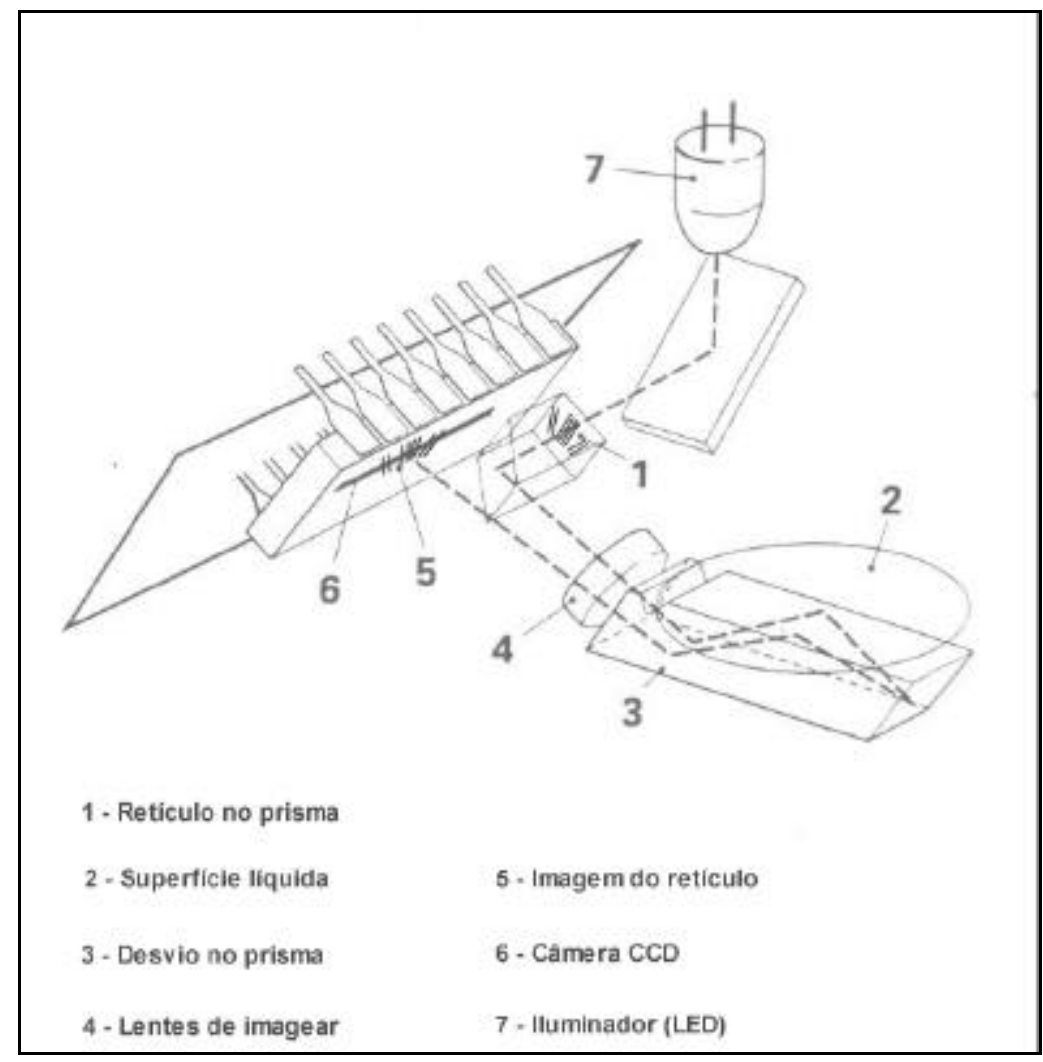

Figura 3.15: Esquema do sensor de verificação do nivelamento e verticalidade dos eixos, adaptada de ZEISK (1999). 
De acordo com ZEISK (1999), o retículo (1) localizado no prisma é iluminado (7), e é imageado (5) na câmera CCD (6) por meio de lentes de imagear (4) após a dupla reflexão na superfície líquida (2). O modelo de linha triangular dos retículos possibilita capturar as duas componentes do desvio do eixo principal por meio de somente um receptor unidirecional. O desvio longitudinal altera o espaço entre as linhas diferentemente orientadas; desvio transversal altera o centro da linha padrão ao longo da câmera CCD.

Este arranjo capacita o sensor de desvio ser produzido tão pequeno que pode ser locado centralizadamente sobre o eixo vertical e o espelho líquido de nível apenas sairia da posição de horizontalidade momentaneamente, sempre durante uma rotação rápida da alidade. Também; o desvio de medição pode não ser muito afetado por outros fatores tais como a temperatura específica de deformação padrão do teodolito.

\subsection{3 - Medição de Distâncias}

\subsubsection{1 - Considerações Gerais}

As Estações Totais é a associação de um teodolito eletrônico com um medidor eletrônico de distância. Portanto, o princípio de medição de distâncias segue o princípio dos MED onde a luz infravermelho, modulada em intensidade, é projetada em um prisma refletor posicionado no ponto final a ser medida a distância. A porção refletida da luz infravermelha é influenciada por mudanças de fase que é proporcional a duas vezes a mudança de fase da distância entre o transmissor e o prisma refletor. Esta mudança de fase é avaliada por um procedimento de processamento do sinal.

Alguma mudança de fase pode somente ser medido dentro de um período de $2 \pi$. Portanto para se medir uma distância acima de $6 \mathrm{~km}$, o comprimento de onda da freqüência modulada deve maior ou igual a $12 \mathrm{~km}$, o que resulta em uma freqüência acima de $25 \mathrm{kHz}$. Por outro lado uma precisão menor do que $1 \mathrm{~mm}$ pode ser obtida apenas com o uso de comprimento de onda de $6 \mathrm{~m}$, que corresponde a uma modulação de freqüência de $50 \mathrm{MHz}$. 


\subsubsection{2 - Frequiência de Referência}

A precisão de um medidor de distâncias é diretamente dependente da qualidade referente do oscilador. Alguma diferença na frequiência fixada resultará em um erro ppm proporcional.

A temperatura característica do oscilador de quartzo referente é expressa por uma função polinomial, conforme Figura 3.16. Estes coeficientes são armazenados em uma EPROM do microprocessador.

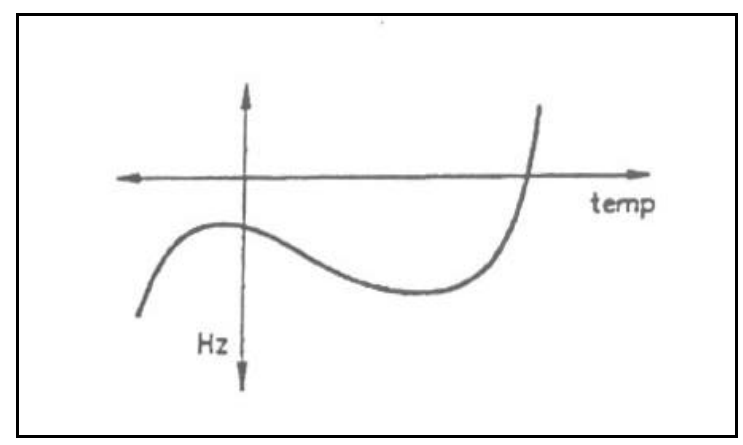

Figura 3.16: Gráfico demonstrando a temperatura em função da freqüência. Fonte, MANUAL DE SERVIÇO DI 1600/TC 1600 (1990).

A medição da temperatura do quartzo, e o cálculo da frequiência real são realizados por conta do instrumento quando a distância é estimada. Assim a freqüência do sinal HF transmitido altera com a temperatura interior do instrumento e pode ser comparada com a calculada usando informações armazenadas nos instrumentos em funções específicas. Os desvios permitidos devem ser:

$$
\begin{array}{lc} 
\pm 5 \mathrm{ppm} & \pm 250 \mathrm{~Hz} \\
\pm 2 \mathrm{ppm} & \pm 100 \mathrm{~Hz} \\
\pm 1 \mathrm{ppm} & \pm 50 \mathrm{~Hz}
\end{array}
$$

Com o exposto acima torna-se desnecessário se preocupar com a constante de multiplicação que é usada para definir a freqüência de referência, já que os desvios são testados pelo próprio instrumento. 
O contador de freqüência usado para verificação, tem que ter na verdade uma precisão que não pode ser menor do que $1 \times 10^{-7} \mathrm{~Hz}$. Esta estabilidade e precisão requerida é somente obtida com contadores de frequiência equipado com quartzo estabilizado a altas temperaturas. O desvio de freqüência de tais contadores é especificado em 1 ppm/ano, que é justamente o envelhecimento. Portanto o contador de frequiência tem que ser calibrado anualmente.

\subsubsection{3 - Freqüência de Medição Fina}

Para o instrumento DI-1600/TC-1600 o raio de luz infravermelho transmitido é modulado com a freqüência de $50 \mathrm{MHz}$, que resulta em um comprimento de onda de 6 m e uma resolução de ambigüidade de $3 \mathrm{~m}(\lambda / 2)$.

O sinal HF recebido é misturado com 49.993.896 Hz no receptor, caindo a um sinal LF resultante de $6104 \mathrm{~Hz}$, igual a diferença das duas freqüências, e este sinal é afetado pela mesma quantidade de mudança de fase como do sinal HF referente à frequiência de referência do instrumento, no caso $50 \mathrm{MHz}$ (Figura 3.17), o que facilita a medição do comprimento de onda pelos componentes eletrônicos pelo fato desta ser mais estável.

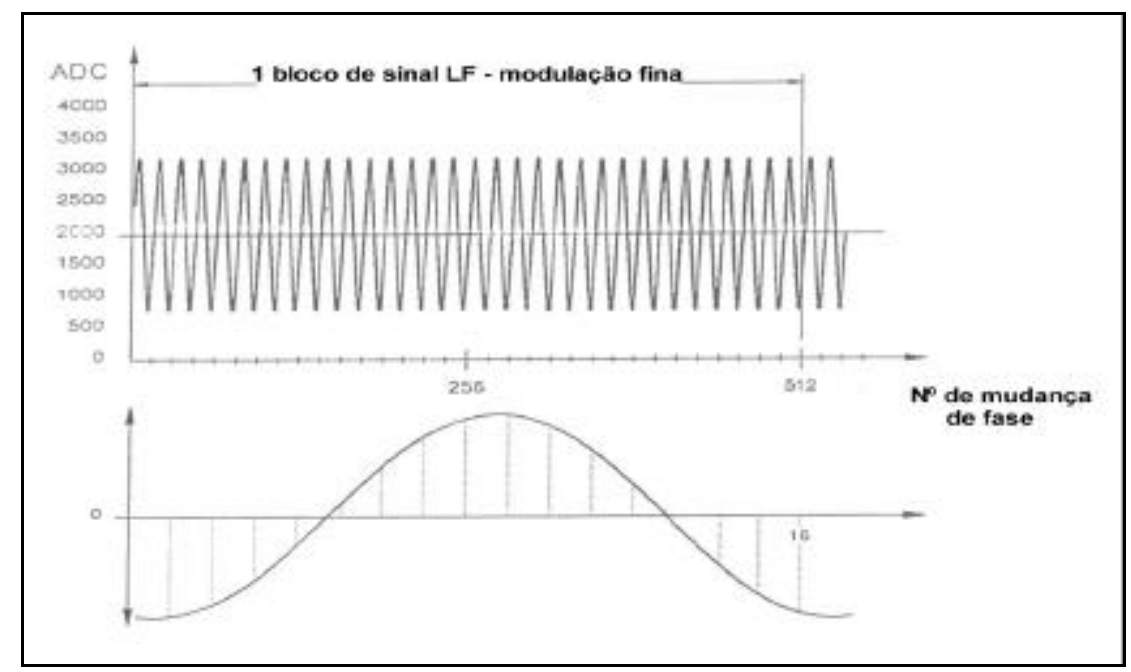

Figura 3.17: Representação do sinal misturado no receptor. Fonte, MANUAL DE SERVIÇO DI 1600/ TC 1600. 
De acordo com a Figura 3.17, 16 vezes por período a forma senoidal é digitada em um conversor $\mathrm{AD}$ em configuração com um circuito de controle. A posição real de fase é avaliada matematicamente e convertida em uma distância fina.

\subsubsection{3 - Freqüência de Medição Grosseira}

Uma resolução de $3 \mathrm{~m}$ é obtida com a medição fina, assim a medição grosseira tem que ter uma acurácia de $\pm 1,5 \mathrm{~m}$ no mínimo. De maneira a executar uma medição grosseira, as três frequiências podem ser selecionadas:

$\begin{array}{lrlr}f_{96 m} & 1.562 .500 \mathrm{HZ} & \Rightarrow & 96 \mathrm{~m} \\ f_{3 K m} & 48.170 \mathrm{HZ} & \Rightarrow & 3072 \mathrm{~m} \\ f_{6 K \mathrm{~m}} & 24.319 \mathrm{HZ} & \Rightarrow & 6.104 \mathrm{~m}\end{array}$

Contudo somente duas, $f_{96 m}$ e $f_{6 K m}$ são usadas para obter a acurácia da medição.

Da mesma forma como durante a medição fina, o raio de luz infravermelho é modulado pela freqüência de referência de $50 \mathrm{MHz}$ que misturado no receptor com $49.993 .896 \mathrm{~Hz}$ gera um sinal baixa frequiência de $6104 \mathrm{~Hz}$ que é modulado em fase pelas bandas de sinal de 191 HZ locada a partir da freqüência grosseira transmitida de acordo com a distância a ser medida. A curva envelopada da modulação em amplitude tem forma triangular com $191 \mathrm{HZ}$. Da mesma forma como durante a medida fina, os períodos do sinal de baixa freqüência de $6104 \mathrm{HZ}$ são digitalizados em 32 períodos (que representa 1.5 m cada intervalo da onda de $96 \mathrm{~m}$ ). A posição real de fase de $191 \mathrm{HZ}$ do sinal de forma triangular é avaliada matematicamente e convertida em distância grosseira.

\subsubsection{4 - Processo de Medição de Distâncias}

Cada uma das três medições, fina e as grosseiras de $96 \mathrm{~m}$ e $6 \mathrm{~km}$, são produzidas através de um processo de medição interno de maneira a avaliar a rotação de fase 
interna. Esta rotação de fase interna é devido a várias influências físicas e eletrônicas como temperatura, resposta de freqüência, ação e tolerâncias de componentes tão bem como dos parâmetros óticos. A distância bruta encontrada pelas medições externas são corrigidas pela distância medida através do procedimento de medição interna e que representa assim o 0 (Zero) de referência do instrumento.

Para as Estações Totais de última geração, são incorporados dois distanciômetro de medição coaxiais; um para distâncias com uso do refletor e outro sem o uso do refletor. Ambos operam no princípio da medição de fase descrito anteriormente.

O raio laser infravermelho para a medição com o uso de refletores (prismas) tem um comprimento de onda de $780 \mathrm{~nm}$, mede distâncias cerca de $3.000 \mathrm{~m}$ com um único prisma, com acurácia de $2 \mathrm{~mm}+2 \mathrm{ppm}$.

A luz visível do raio laser vermelha tem um comprimento de onda de $670 \mathrm{~nm}$ e mede distâncias até $80 \mathrm{~m}$ com uma acurácia de $3 \mathrm{~mm}+2$ ppm sem uso do refletor.

Esta combinação de dois distanciômetros em uma única Estação Total oferece grandes vantagens onde os pontos a serem medidos alternam entre pontos de fácil e difícil acesso, e inacessíveis como em controles de estruturas metálicas, determinação de comprimento de condutos.

\subsubsection{3 - Sistema de Filtro}

De maneira a prevenir a saturação do receptor causada por um forte sinal de retorno (distância próxima), o raio infravermelho pode ser atenuado variavelmente por meio de um disco de filtro que é posicionado por um motor e controlado por um processador através de uma interface.

Dois filtros cobrem o disco e atenua os sinais transmitidos e recebidos, cada um $50 \%$ de toda atenuação. No fim da trilha do disco, uma parada mecânica limita o movimento do motor do disco.

Um detector de posição é usado para uma rápida configuração da amplitude dos sinais recebidos e também para o sistema antiboomerangue, de maneira a fixar a atenuação desejada. 
O detector de posição é uma barreira de luz consistindo de um IR-Diodo (LED) e um fotodiodo. A luz ilumina o fotodiodo através de um diafragma em forma de cunha que é locado na borda da circunferência do disco de filtro, conforme Figura 3.18. Esta barreira de luz é variável de instrumento para instrumento.

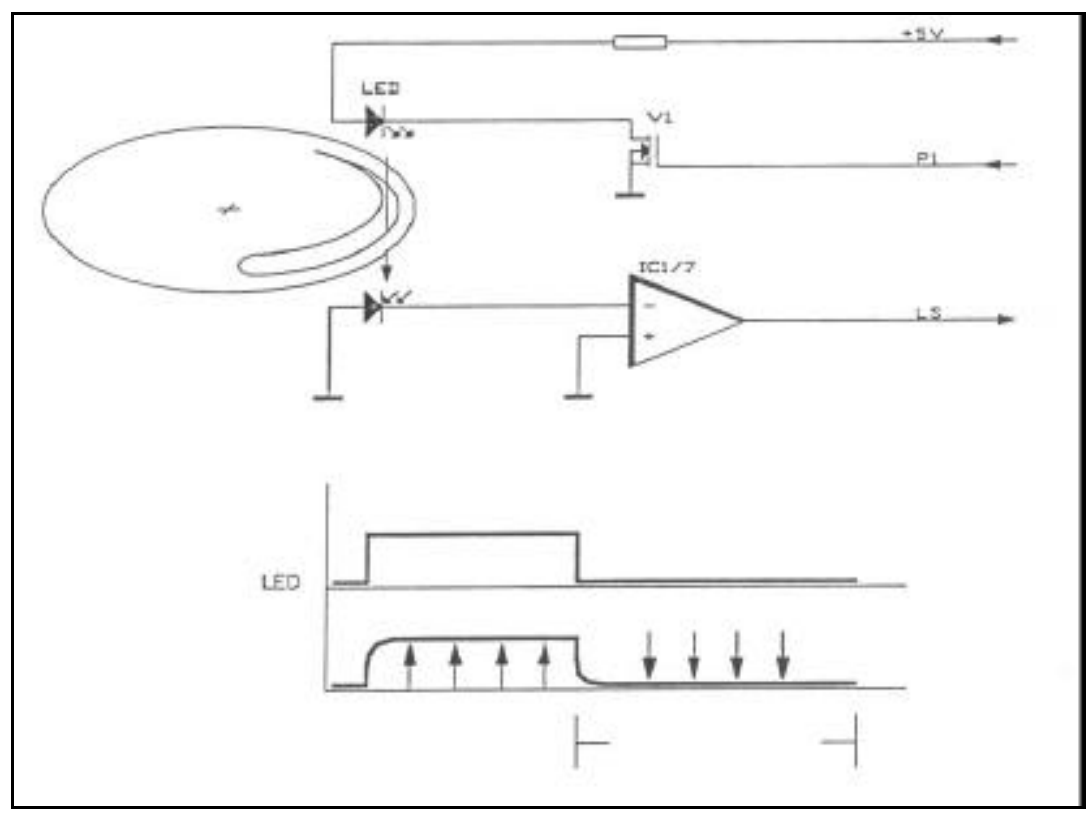

Figura 3.18: Esquema do sistema de filtro. Fonte Manual de serviço DI 1600/DI2002 (1990).

A corrente através do fotodiodo, causada pela luz recebida, é controlada em uma voltagem de corrente contínua. Esta magnitude é proporcional à posição do disco de filtro. Por meio de um conversor $\mathrm{AD}$ a voltagem é lida pela $\mathrm{CPU}$.

Quando o sistema de filtro é inicializado a CPU lê os valores limites e aloca a faixa de atenuação para uma área de posição de 0-255 (Figura 3.19). Esta padronização é feita de forma a compensar as tolerâncias da barreira de luz se um dos valores limite desviar por mais do que \pm 7 de 0 a 255 , a padronização é feita automaticamente e os valores são escritos em uma EPROM do microprocessador. Logo em seguida, é verificada a acurácia do local de posição do filtro. Comparando alguma posição preestabelecida com a real, a diferença deve ser \pm 6 ou menor. Se esta é maior, o motor e barreira de luz devem ser inicializados novamente. 


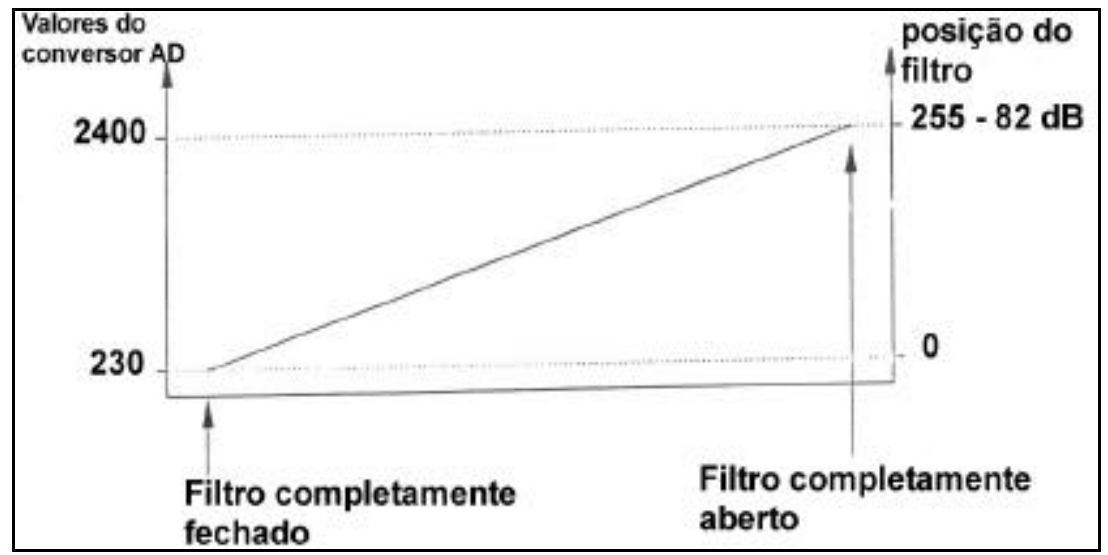

Figura 3.19: Esquema da posição de filtro, , Manual de serviço DI 1600/DI2002 (1990).

Quando um sinal percorre mais do que uma vez o percurso entre o transmissor ótico, refletor e receptor ótico, este é chamado sinal bomerangue, e pode ser adicionado ao sinal de medição, resultando em um erro de distância. De maneira a limitar o sinal bomerangue, o raio infravermelho é atenuado por um filtro graduado, que é selecionado de acordo com o nível de ruído e o sinal é reduzido possivelmente pelo mesmo fator de nível de ruído.

Para os modelos DI 1600 e DI 2002 o sistema antibomerangue é ativado na faixa de 0 a $100 \mathrm{~m}$.

Os sistemas antibomerangue são ineficazes contra reflexos dos componentes óticos dos teodolitos. Especialmente tipos mais antigos que não são equipados com filtros de absorção que poderia produzir fortes reflexos. Se tal problema é detectado, é recomendado cobrir a objetiva do teodolito, durante a medição de distâncias. As menores distâncias e a maior imprecisão de pontaria no prisma, proporcionará uma maior probabilidade de ocorrer os efeitos bomerangue.

\section{7 - Impacto das Estaçães Totais e dos Teodolitos Eletrônicos nos Processos de Medição}

Para obter uma determinada precisão nos levantamentos, o trabalho é bem menos oneroso que nos equipamentos óticos. 
A reiteração que é um processo cuja função era variar o limbo para obter melhores médias tornou-se obsoleta, sabendo-se que cada leitura que aparece no painel já é uma média de várias leituras, levando em conta diferentes regiões da graduação, e em tempos inferiores a 0,5 segundos.

A repetição se tornou mais simples pelo fato de não exigir complicado jogo de movimentos do limbo e dos parafusos de travar e destravar os movimentos particular e geral, e sendo esta disponível em todos os teodolitos eletrônicos. A repetição trata-se de ir combinando valores de um mesmo ângulo várias vezes. Visa-se A e B alternadamente, levando o valor da leitura de B para A, como mostra a Figura 3.14.

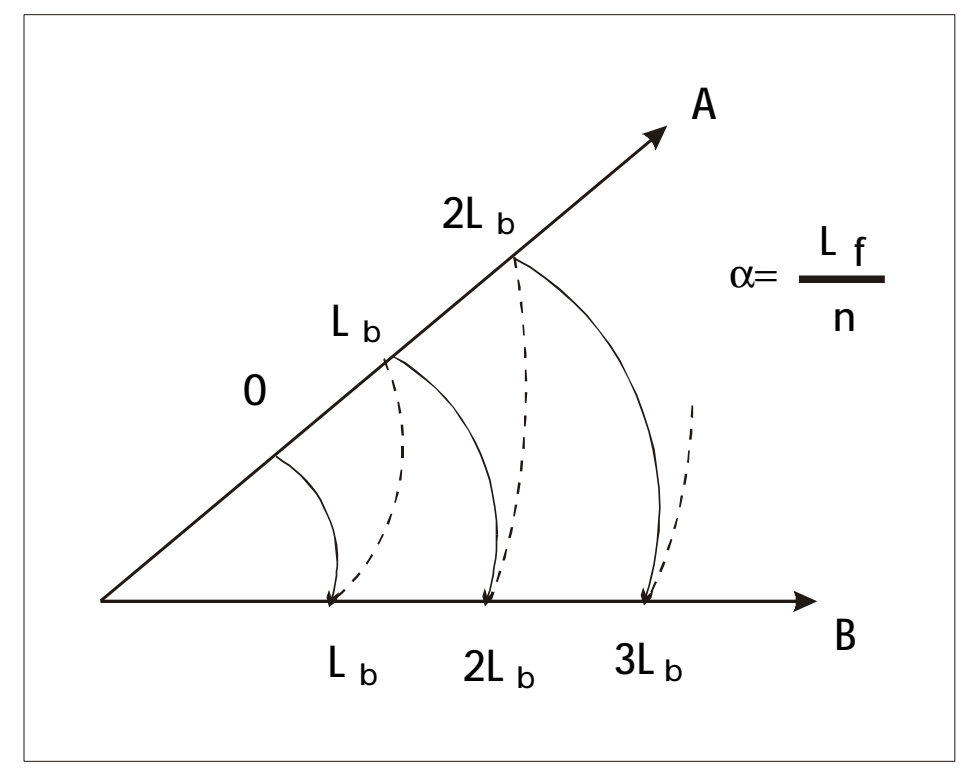

Figura 3.14: Representação da repetição na medição de um ângulo 


\section{CAPÍTULO 4 - SISTEMA DE POSICIONAMENTO GLOBAL (GPS)}

\section{1 - Histórico}

Segundo MORAES et al (1998), desde os primórdios tempos o homem procura corpos celestes para a navegação, e ao que tudo indica continuará utilizandoos para se orientar. Mas, agora utiliza além de corpos celestes naturais, os corpos dispostos convenientemente no espaço e sob seu controle.

A navegação astronômica depende da observação de astros que precisam estar à disposição do usuário no momento da realização da operação. Assim pode ser imprópria para a obtenção, em tempo real, da posição de usuários, pelo fato de não estar acessível nas 24 horas do dia.

Outros sistemas de navegação modernos que utilizam ondas de rádio também possuem limitações: as ondas de rádio de alta freqüência proporcionam posição de navegação precisa, mas apresentam limitações na precisão vertical; e as ondas de baixa freqüência são pobres em precisão (horizontal e vertical) e os equipamentos de difícil aquisição aos usuários. Nas décadas de 60 e 70, a utilização de satélites artificiais introduziu novos sistemas de navegação (Transit, Timation, System 621B, NTS), que resolveram alguns desses problemas, mas não todos simultaneamente.

O caminho para a solução foi dado através de pesquisas realizadas nas décadas de 70 e 80, pela força aérea dos Estados Unidos, que levaram ao desenvolvimento de um sistema de navegação por satélites NAVSTAR/GPS (NAVigation System using Time And Ranging/Global Positioning System) ${ }^{3}$.

\footnotetext{
${ }^{3}$ Por simplicidade, será adotado neste trabalho o termo GPS (Global Positioning System) para designar o sistema de posicionamento global.
} 
Os objetivos do GPS são:

$\stackrel{4}{4}$ auxiliar à radionavegação com elevada precisão nos cálculos de posição, mesmo com usuários sujeitos a altas dinâmicas;

$\stackrel{4}{\rightarrow}$ propiciar navegação em tempo real;

$\leftrightarrow$ propiciar alta imunidade a interferências;

$\rightarrow$ proporcionar cobertura global, 24 horas por dia;

$\rightarrow$ obter de forma rápida as informações transmitidas pelos satélites.

\section{2 - Sinais de Rádio Utilizados}

São utilizados dois tipos de sinais: um para a determinação de posição dos usuários e outro para eventuais correções necessárias nas configurações dos satélites. Os satélites GPS, também chamados de "veículos espaciais" ou SV (Space Vehicle) transmitem em duas frequiências, na comunicação com os usuários, na faixa UHF (Ultra High Frequency, sendo que seus valores são 1575,42 MHz e 1227,60 MHz) (FREITAS, 1997). Estas freqüências portadoras são designadas por L1 e L2, são obtidas a partir da freqüência fundamental (10,23 MHz) multiplicada por 154 e 120, respectivamente. O comprimento de onda de L1 é cerca de $19 \mathrm{~cm}$, enquanto o comprimento de onda de L2 é cerca de $24 \mathrm{~cm}$.

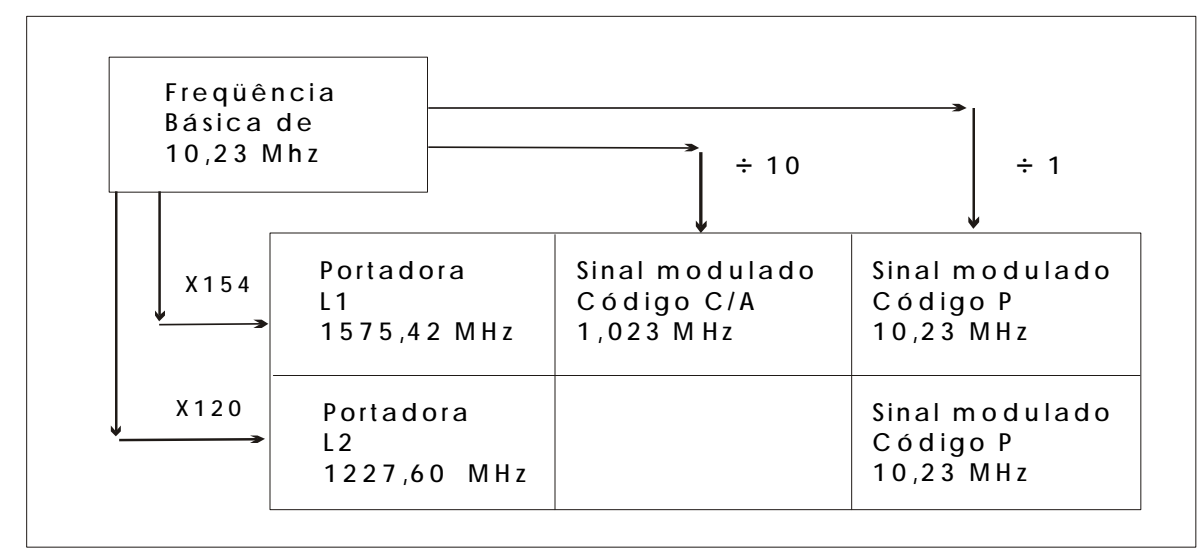

Figura 4.1: Estrutura básica do sinal GPS. Adaptada de MONICO apud CHAVES (1996). 


\section{3 - Princípio Básico}

Para MORAES et al (1998), o funcionamento do sistema GPS se baseia no princípio da triangularização, segundo o qual o observador conhece a posição de um conjunto de satélites em relação a um referencial inercial e a sua posição em relação a este conjunto de satélites, e obtém a sua própria posição no sistema de referência. $\mathrm{O}$ sistema de referência utilizado pelo sistema GPS é o WGS ${ }^{4}$ (WGS-72 até 1986 e WGS-84 a partir de 1987). A Figura 4.2 apresenta os parâmetros básicos utilizados pelo GPS na determinação da posição pelo usuário; definindo:

$$
\begin{array}{ll}
\vec{R}_{u} & \text { posição do usuário; } \\
\vec{r}^{i} & \text { posição do i-ésimo satélite; } \\
\vec{\rho}^{i} & \text { posição do usuário em relação ao i-ésimo satélite }
\end{array}
$$

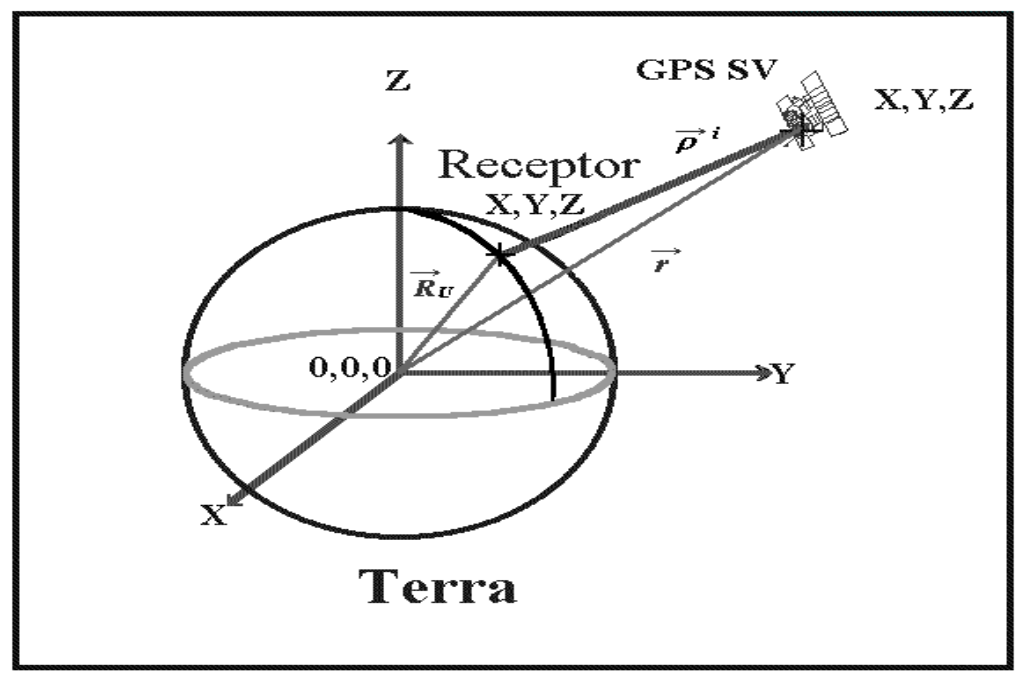

Figura 4.2: Princípio básico do GPS. Adaptada de MORAES et al (1998).

Assim, admitindo $\vec{R}_{u}=\left(X_{u}, Y_{u}, Z_{u}\right)$, temos a relação:

$$
\left(X_{U}-X^{i}\right)^{2}+\left(Y_{U}-Y^{i}\right)^{2}+\left(Z_{U}-Z^{i}\right)^{2}=\vec{\rho}^{i^{2}} ;
$$

\footnotetext{
${ }^{4}$ WGS: World Geodetic System.
} 
cada satélite $i$ transmite sua posição e o instante de transmissão $t_{0}$.

\section{4 - Segmentos do Sistema GPS}

O sistema GPS pode ser dividido em 3 segmentos principais:

o: Segmento espacial composto pelo conjunto de satélites que emitem os sinais;

o: O segmento de controle terrestre, composto pelas estações de rastreamento e monitoramento;

o: O segmento do usuário utilizando qualquer tipo de receptor.

Apenas o segmento do usuário será descrito neste trabalho pelo fato do maior interesse na discriminação dos receptores utilizados para os diversos levantamentos. E este segmento consiste dos receptores GPS e a comunidade civil e militar.

Os receptores GPS localizados na superfície terrestre, converte os sinais dos satélites em posição, velocidade e tempo estimado. Quatro satélites, no mínimo, são requeridos para calcular as posições $X, Y, Z$ e o tempo $t$.

A navegação é a função primária do GPS, e é usada por usuários de aeronaves, navios, veículos, e por quaisquer indivíduos que portem um receptor portátil. Segundo CUNHA et al (1997), atualmente os receptores GPS são utilizados nas mais variadas áreas profissionais, como por exemplo: em todos os tipos de levantamento de áreas; pontos de controle cadastral; controles geodésicos no estabelecimento de apoio para a fotogrametria, no monitoramento do vôo e posição de tomada de foto; controle de desastres ecológicos e outros.

Segundo RIBAS et al (1997), existem três tipos de receptores GPS, o de navegação com uma precisão na horizontal da ordem 100 metros e na vertical de 150 metros; o topográfico que atinge uma precisão de 1 a 5 metros e o geodésico com precisão de $1 \mathrm{~cm} \pm 0,3$ a $2 \mathrm{ppm}$ (parte por milhão). 


\section{5 - Posicionamento de Pontos}

\subsection{1 - Posicionamento Absoluto}

No posicionamento absoluto de ponto, segundo MONICO et al (1997), é usual ter como observável principal a pseudodistância (código), a qual é igual a diferença entre o tempo do relógio do receptor, no instante de recepção do sinal, e o tempo do relógio do satélite, no instante de transmissão do sinal, multiplicado pela velocidade da luz no vácuo.

Segundo MONICO et al (1997) as coordenadas do satélite estão implícitas na distância geométrica $\rho$ e, são obtidas a partir das efemérides transmitidas. As incógnitas da equação são as coordenadas X, Y, Z e o erro do relógio do receptor. Para a resolução do sistema de equações, então, é necessário um mínimo de quatro satélites, disponíveis numa época.

\subsection{2 - Posicionamento Relativo}

No posicionamento relativo estático a fase da portadora é o método mais usado, a qual é dada pela diferença de fase entre o sinal recebido, pelo receptor, com a fase do sinal gerado pelo receptor.

Neste caso aparece a ambigüidade, que é uma incógnita a determinar, advinda da falta de conhecimento da soma dos ciclos completos do sinal corrente. Para BURNSIDE (1991), este é um problema familiar nos MED, e é usualmente resolvido por técnica similar, isto é, por resolver a ambigüidade inerente em um método do uso de medidas menos precisas em escala grosseira. Segundo SCHOFIELD (1993), o valor da ambigüidade pode ser obtido, também, de ajustamento de redes GPS, ou de dupla diferença ou eliminando-a por tripla diferença. 


\section{6 - Métodos de Levantamento}

\subsection{1 - Método Estático}

O método de posicionamento estático consiste em posicionar um receptor em um marco geodésico, no qual são conhecidas as suas coordenadas, e um segundo receptor no ponto onde se quer determiná-las. Rastreando simultaneamente as estações por um intervalo de tempo recomendado, são calculadas as coordenadas tridimensionais (latitude, longitude e altitude geométrica) para o ponto desconhecido. Esse processo é o mais empregado e o que atinge maiores precisões e é usado em levantamento de pontos de apoio á restituição (RIBAS et al, 1997).

No presente trabalho utilizou-se este método para realizar todo o levantamento

de campo. Apresenta-se no capítulo 8 a metodologia aplicada para a realização dos trabalhos de campo.

\subsection{2 - Métodos Rápidos}

\subsubsection{1 - Cinemático}

Para SEGANTINE (1998), o levantamento cinemático puro é aquele em que, inicialmente, um dos receptores é colocado sobre um ponto de coordenadas conhecidas e um segundo receptor é colocado sobre um ponto qualquer. A partir daí, as duas antenas receptoras passam a coletar dados simultaneamente por alguns minutos com o objetivo de resolver as ambigüidades. Depois, a antena que estava sobre o ponto desconhecido move-se por um percurso selecionado, sendo possível determinar com bastante precisão a trajetória feita por esta antena móvel. A grande limitação do deste método está na obrigatoriedade de se manter constante a recepção dos sinais, nas duas antenas receptoras, emitidos pelos satélites. 


\subsubsection{2 - Levantamento Cinemático "stop-and-go" (semi-cinemático)}

Este método é uma derivação do cinemático puro, visto que, o usuário tem a opção de registrar pontos específicos do levantamento ao longo do deslocamento da antena remota. A grande vantagem deste método em relação ao cinemático puro é o aumento de precisão no posicionamento devido ao registro de um certo número de épocas no ponto desejado, SEGANTINE, 1998.

\section{7 - Principais Fontes de Erros}

As principais fontes de erro do GPS são as seguintes:

(1) erro devido a geometria dos satélites com relação ao observador;

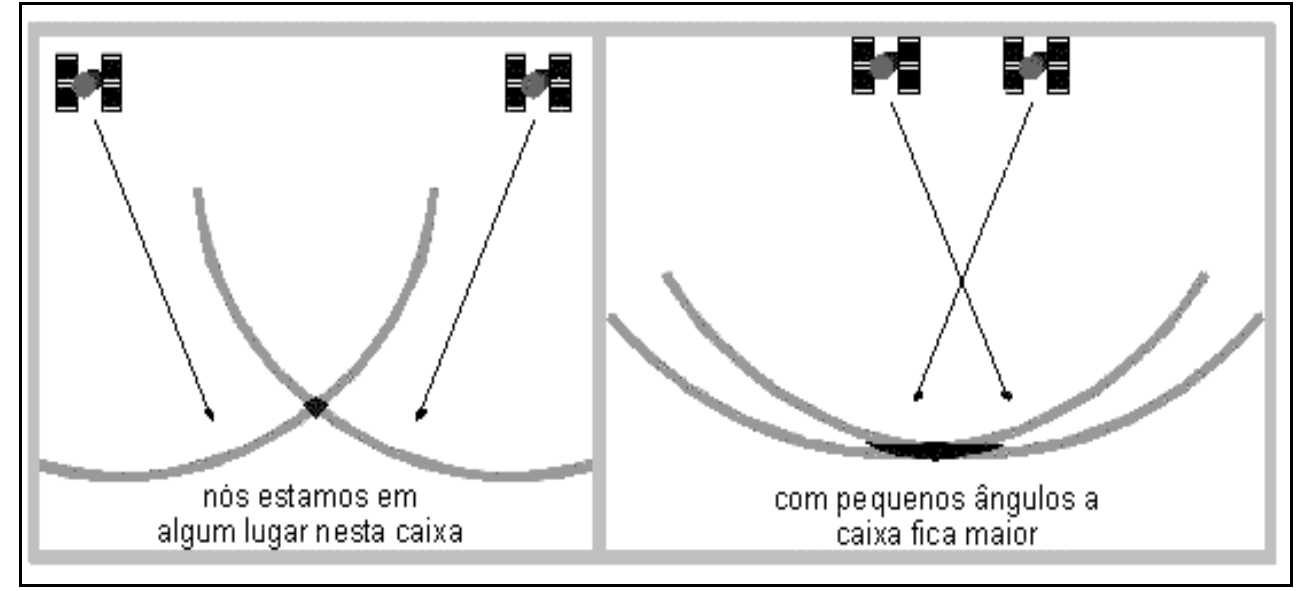

Figura 4.3: Representação de incertezas na interseção de órbitas dos satélites conforme as diferentes geometrias. Adaptada de HURN (1999).

2 desvios dos relógios dos satélites;

(3) atraso de propagação e processamento dos sinais pelos circuitos dos satélites;

(4) erros devido a trajetórias múltiplas dos sinais (multicaminhamento); 


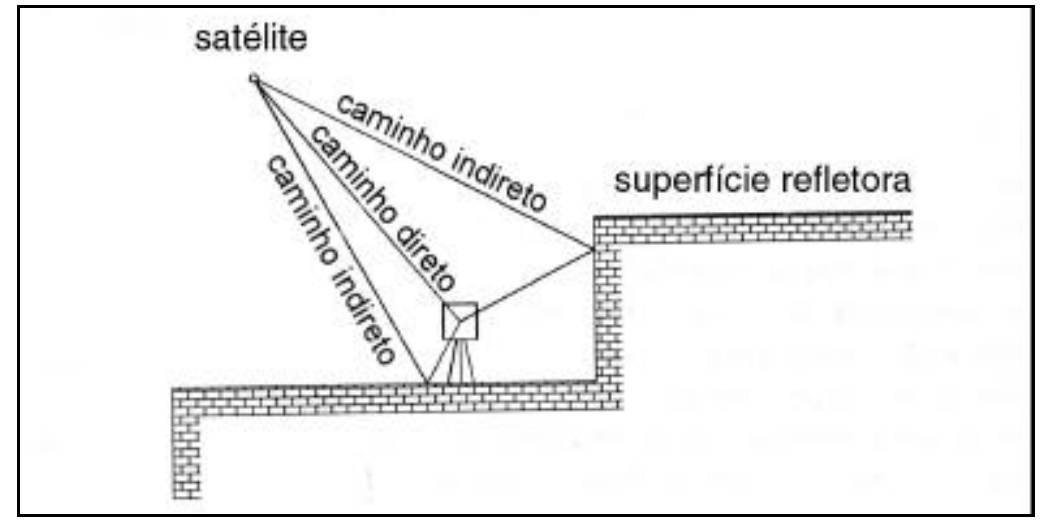

Figura 4.4: Efeito do multicaminhamento. Adaptada de HOFFMANNWELLENHOF et al (1997).

5 efeitos da atmosfera ( ionosfera e troposfera) sobre a velocidade e a trajetória de propagação dos sinais transmitidos;

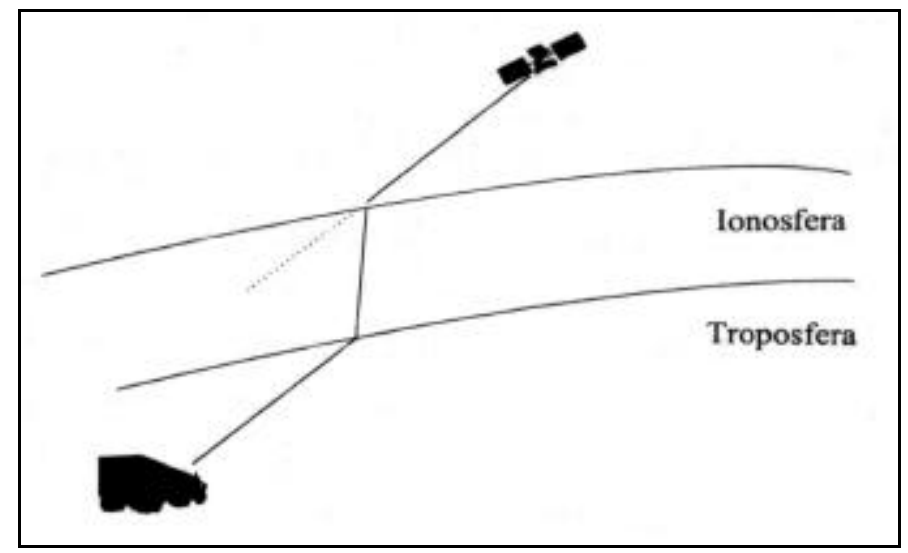

Figura 4.5: Representação do atraso da ionosfera. Fonte: SEGANTINE (1998).

6 erros devidos à resolução e ruído do receptor do usuário;

$\boldsymbol{\nabla}$ erro devido ao centro de fase da antena receptora que pode não coincidir com o seu centro geométrico;

8 erro devido a perda de ciclos por obstrução temporária do sinal (árvores, edifícios);

(9) erro na determinação da posição dos satélites (erro de efeméride, nominal e adicional). 
MORAES et al (1998) comenta que, alguns erros na determinação das efemérides, são devidos as perturbações que as órbitas dos satélites GPS estão submetidas, dadas suas características. Estas perturbações são: potencial terrestre, atração lunissolar, pressão de radiação solar (incluindo os efeitos da sombra da Terra) e a ressonância devido à comensurabilidade do período do satélite com o período de rotação da Terra. 


\section{CAPÍTULO 5 MEDIDAS BÁSICAS}

\section{1 - Introdução}

As medidas em levantamentos, na Mensuração, são realizados na superfície física da terra, mas esta não serve como sistema de referência (Datum) para calcular uma posição.

Uma alternativa é considerar a superfície de nível, formada pela posição média dos oceanos, assumindo ela livre de todas forças internas, tais como, marés, correntes, ventos. Esta superfície é chamada geóide e é a superfície equipotencial ao nível médio do mar; onde os instrumentos instalados, estão com seu eixo vertical na direção da força da gravidade daquele ponto.

$\mathrm{Na}$ verdade, os pontos levantados na superfície física da terra são freqüentemente reduzidos à sua posição equivalente no geóide por projeção ao longo dos seus vetores de gravidade, linha de prumo e plano ortogonal considerado horizontal (Figura 5.1), de acordo com as alturas medidas acima ou abaixo do geóide. Entretanto, o geóide também é uma superfície irregular, devido a variações na distribuição de massa da terra, e que não pode ser usado para posição e locação matemática de pontos. 


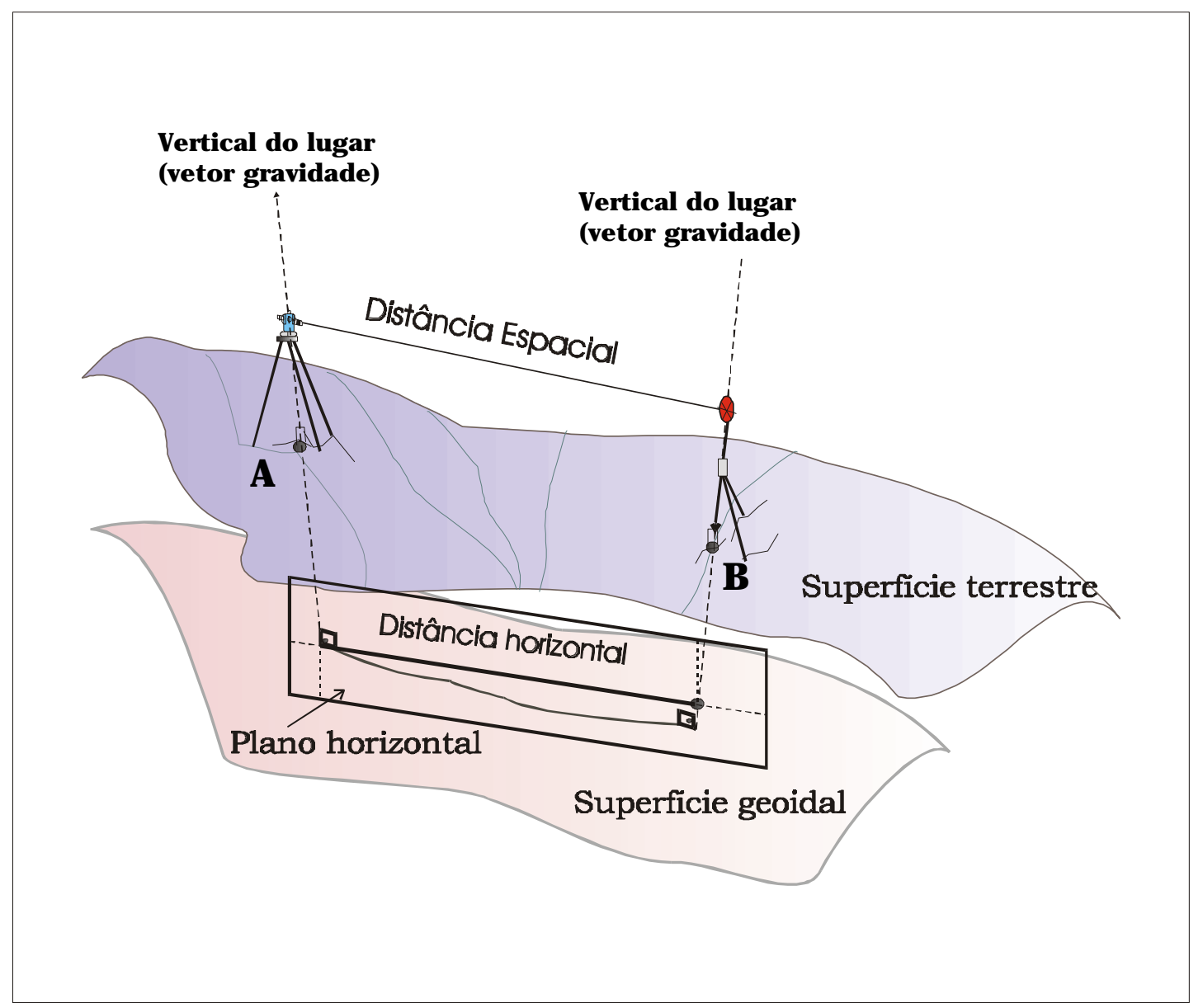

Figura 5.1: Esquema de medição na superfície terrestre e projeção seguindo os vetores gravidade dos pontos no geóide e no plano horizontal

Como a maioria dos levantamentos na engenharia são realizados em áreas de extensões limitadas, neste caso a superfície de referência pode ser feita como um plano tangente ao geóide, ou seja, horizontal, e as regras usadas como levantamento plano. Em outras palavras, a curvatura da terra é ignorada e todos os pontos na superfície física são ortogonalmente projetados em um plano horizontal como ilustrado na Figura 5.2. 


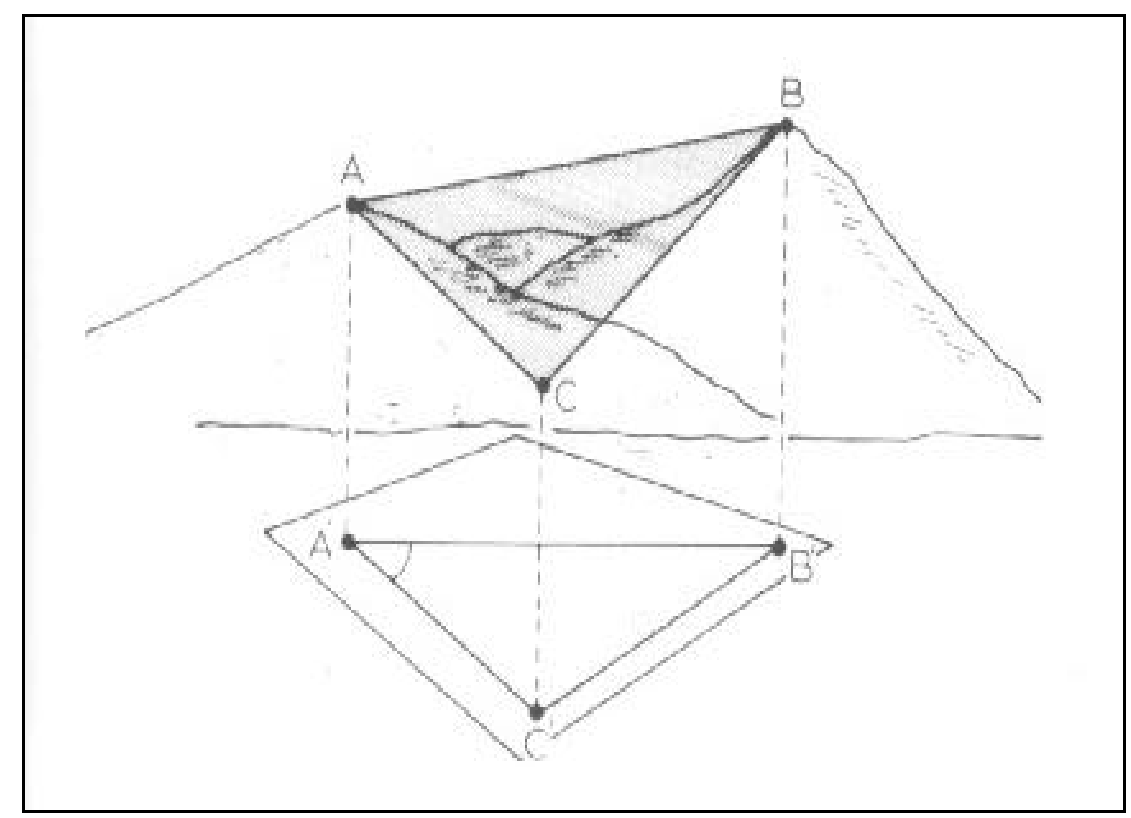

Figura 5.2: Projeção em uma superfície plana. Fonte SCHOFIELD (1993).

Segundo SCHOFIELD (1993), para áreas menores do que $10 \mathrm{~km}^{2}$ a concepção da Terra plana é perfeitamente aceitável, onde as considerações que em um triângulo de aproximadamente $200 \mathrm{~km}^{2}$, a diferença entre a soma dos ângulos esféricos poderiam ser da ordem 1 segundo de arco, ou que a diferença no comprimento de arco de aproximadamente $20 \mathrm{~km}$, na superfície da terra, seja equivalente a $10 \mathrm{~mm}$, conforme Figura 5.3. Entretanto estas concepções não são aceitas para elevações do geóide que podem desviar do plano tangente cerca de $80 \mathrm{~mm}$ por $\mathrm{km}$. Este é um dos limites propostos para a representação de áreas com a concepção da Terra plana, para evitar grandes deformações. Segunda a NBR 13.133 o plano de projeção, para plano topográfico local, tem sua dimensão máxima limitada a $80 \mathrm{~km}$ a partir da origem de maneira que erro relativo decorrente da desconsideração da curvatura terrestre, não ultrapasse 1/35.000 nesta dimensão e 1/5.000 nas imediações da extremidade desta dimensão. Este estudo do limite para o plano topográfico não será abordado neste trabalho, cabendo a análise para um outro trabalho. 


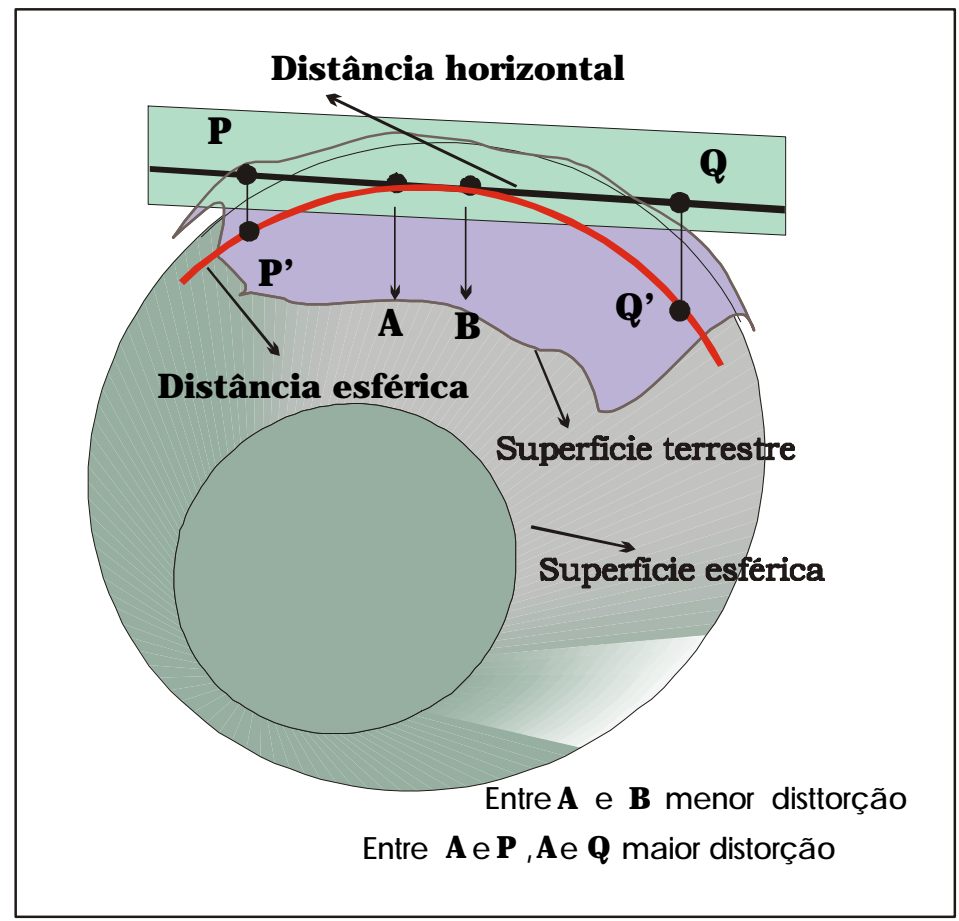

Figura 5.3: Distorção entre distâncias no plano tangente ao geóide e na superfície esférica.

A melhor superfície, matematicamente definida, que se adapta à forma do geóide é um elipsóide formado pela rotação de uma elipse sobre seu eixo menor e, a esta superfície dá-se o nome de elipsóide.

Outra consideração, de superfície matematicamente definida, utilizada que representa a forma da terra é a esfera de aproximação local ao elipsóide, que simplifica os cálculos, comparando-se com a superfície elipsoidal. Segundo SILVA et al (1999), nos cálculos rotineiros realizados em relação a uma esfera e não em relação ao elipsóide, as diferenças são desprezíveis na mensuração e são absolutamente aceitáveis, o que deve ser comprovado neste documento.

Podemos considerar diversas distâncias na mensuração, de acordo com as diferentes superfícies de referência. São elas:
a) distância inclinada;
b) distância horizontal; 
c) distância elipsoidal;

d) distância esférica;

e) distância plana.

\section{2 - Distância Inclinada e Distância Horizontal}

$\mathrm{Na}$ maioria dos casos, devido a superfície irregular do terreno, não existem condições de efetuar uma leitura de distância paralela ao plano tangente ao geóide (ou normal em relação a vertical do lugar), dita distância horizontal. Por isso efetua-se uma distância inclinada, em que a mira do ponto de visada pode estar em uma altura, acima ou abaixo do geóide; anotando a medida do ângulo de inclinação ou mesmo a diferença de nível entre os referidos pontos (Figura 5.4).

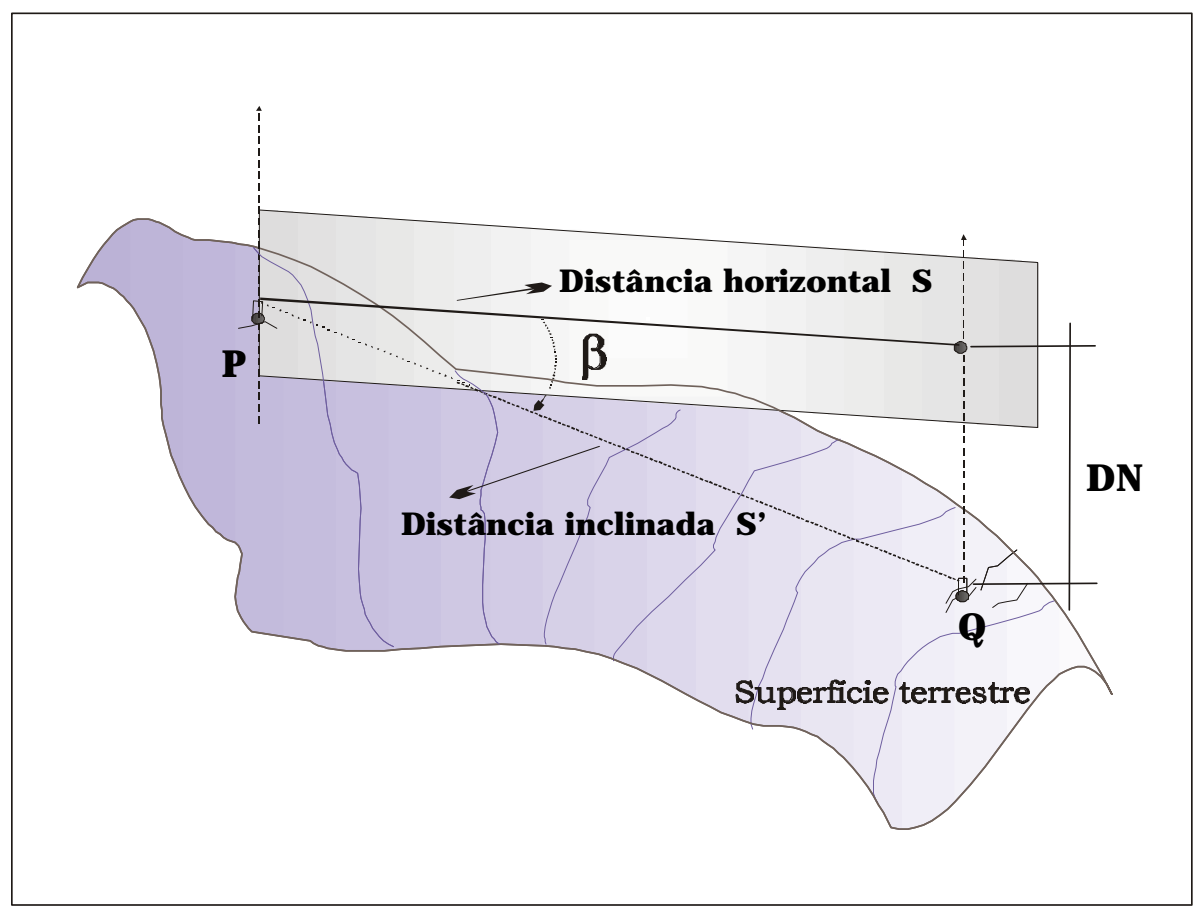

Figura 5.4: Distância inclinada e horizontal entre dois pontos topográficos. 
Para realizar a transformação desta distância inclinada em uma distância horizontal, deve-se manter os pontos suficientemente próximos para que se possa desconsiderar a curvatura da terra, conforme justificativa no item anterior. A equação de transformação entre distâncias é dada a seguir:

$$
s=s^{\prime} \cdot \cos \beta
$$

onde:

$s^{\prime}$ distância inclinada entre $P$ e $Q$;

$s$ distância horizontal entre $P$ e $Q$;

$\beta$ ângulo de altura da direção $P Q$.

\section{3 - Distância Elipsoidal}

A distância elipsoidal, entre dois pontos, situa-se na superfície de referência elipsoidal, dada pela rotação de uma elipse em torno de seu semi-eixo menor. Na redução de observações, primeiro devemos aplicar as correções atmosféricas, que é a refração, dada a posição em que elas foram obtidas. Na redução da distância espacial ao elipsóide há dois grupos de efeitos a ser considerado: efeitos geométricos e efeitos do campo de gravidade da terra.

Os efeitos geométricos aparecem de peculiaridades da geometria de um elipsóide biaxial. O campo de gravidade deve ser considerado porque instrumentos usados na medição são alinhados à linha do prumo local, enquanto os cálculos são realizados em um espaço geométrico. As várias reduções são em função da posição a ser resolvida. A redução das observações em distância espacial considerando a trajetória de visada um arco esférico, de acordo com TORGE (1980), é obtida pela equação abaixo (Figura 5.5): 


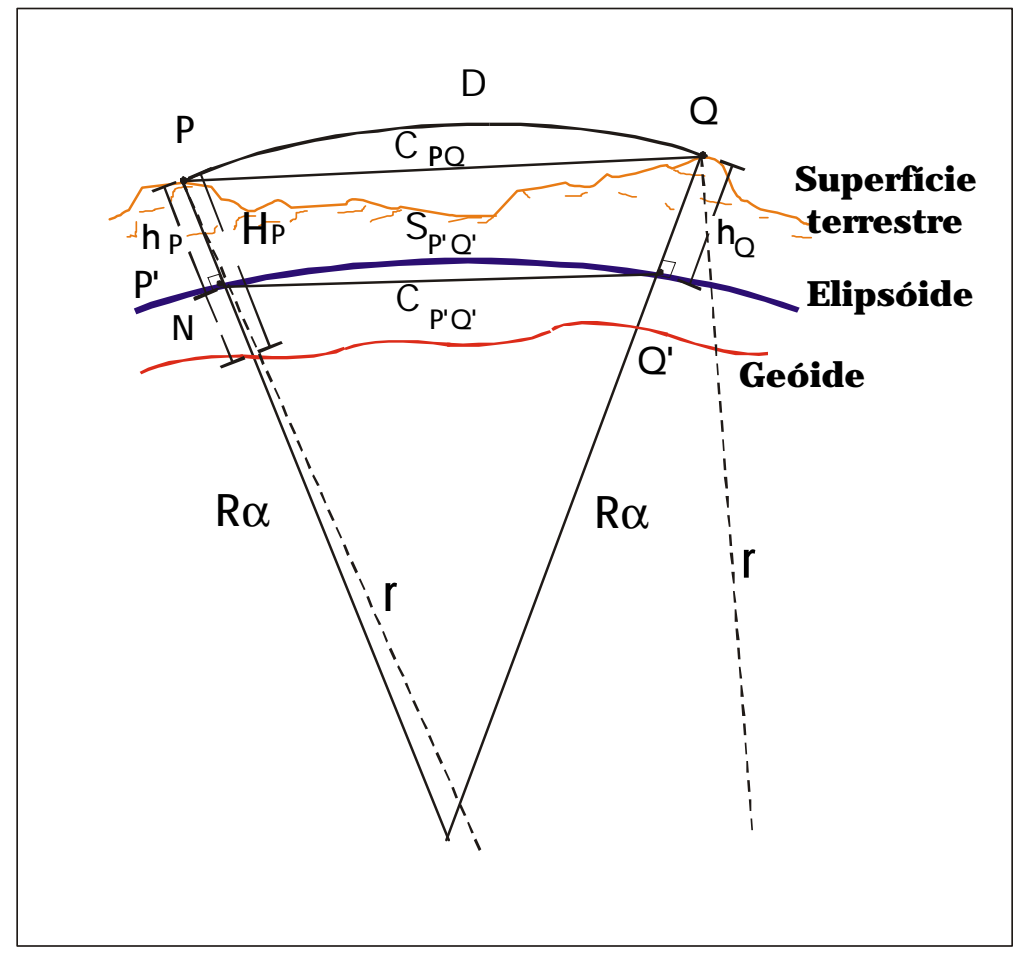

Figura 5.5: Redução de distância espacial para elipsoidal. Adaptada de TORGE (1980).

$$
c_{P Q}=D-k^{2} \cdot \frac{D^{3}}{24 R_{\alpha}^{2}}
$$

onde:

$c_{P Q} \quad$ distância espacial entre $P$ e $Q$;

$D \quad$ observação entre $P$ e $Q$;

$k \quad$ coeficiente de refração;

$R_{\alpha} \quad$ raio de curvatura do arco $s_{P^{\prime} Q^{\prime}}$ com um azimute $\alpha$.

Segundo VANICEK et al (1986), TORGE (1980) e LEICK (1980), o desenvolvimento das equações de redução da distância espacial em distância elipsoidal, que na verdade é uma forma simplificada baseada na aproximação esférica do arco elipsoidal, é dada conforme seguir: 


$$
\begin{array}{ll}
s_{P^{\prime} Q^{\prime}}=R_{m} \cdot \gamma & \\
\sin \left(\frac{\gamma}{2}\right)=\frac{c_{P^{\prime} Q^{\prime}}}{2 R_{m}} & \frac{\gamma}{2}=\sin \left(\frac{c_{P^{\prime} Q^{\prime}}}{2 R_{m}}\right)
\end{array}
$$

Substituindo 5.4 em 5.3; tem-se a distância elipsoidal através da corda entre os pontos no elipsóide:

$$
S_{P^{\prime} Q^{\prime}}=2 R_{m} \cdot \arcsin \left(\frac{c_{P^{\prime} Q^{\prime}}}{2 R_{m}}\right)
$$

Determinando a corda $c_{P^{\prime} Q^{\prime}}$ que ainda é desconhecida em 5.3, que de acordo com a Figura 5.5 é dada por:

$$
\begin{aligned}
& D^{2}=\left(R_{m}+h_{P}\right)^{2}+\left(R_{m}+h_{Q}\right)^{2}-2\left(R_{m}+h_{P}\right)^{2} \cdot\left(R_{m}+h_{Q}\right)^{2} \cdot \cos (\gamma) \\
& \cos (\gamma)=1-2 \operatorname{sen}^{2}\left(\frac{\gamma}{2}\right)
\end{aligned}
$$

Substituindo 5.7 em 5.6 e, arranjando tem-se:

$$
D^{2}=\left(h_{P}-h_{Q}\right)^{2}+4 R_{m}^{2}\left(1+\frac{h_{P}}{R_{m}}\right) \cdot\left(1+\frac{h_{Q}}{R_{m}}\right) \cdot \operatorname{sen}^{2}\left(\frac{\gamma}{2}\right)
$$

Fazendo a diferença de altura entre os pontos observados $P$ e $Q$, vem:

$$
\begin{aligned}
\Delta h & =h_{Q}-h_{P} \\
D^{2} & =\Delta h^{2}+\left(1+\frac{h_{P}}{R_{m}}\right) \cdot\left(1+\frac{h_{Q}}{R_{m}}\right) \cdot c_{P^{\prime} Q^{\prime}}^{2} \\
c_{P^{\prime} Q^{\prime}} & =\sqrt{\frac{D_{P Q}^{2}-\left(h_{P}-h_{Q}\right)^{2}}{\left(1+\frac{h_{P}}{R_{m}}\right) \cdot\left(1+\frac{h_{Q}}{R_{m}}\right)}}
\end{aligned}
$$




$$
\begin{aligned}
& R_{m}=\frac{1}{2} \cdot\left(R_{P}(\alpha)+R_{Q}(\alpha)\right) \\
& R_{P}=\frac{M_{P} N_{P}}{M_{P} \sin ^{2} \alpha+N_{P} \cos ^{2} \alpha} \quad\left(\alpha=\alpha_{P Q}\right)
\end{aligned}
$$

onde:

$S_{P^{\prime} Q^{\prime}} \quad$ distância elipsoidal entre os pontos $P^{\prime}$ e $Q^{\prime}$;

$D$ distância espacial entre os pontos $P$ e $Q$ situados na superfície da Terra;

$c_{P^{\prime} Q^{\prime}} \quad$ corda entre os pontos $P^{\prime}$ e $Q^{\prime}$ situados na superfície elipsoidal;

$R_{m} \quad$ raio médio do elipsóide na direção $(\alpha)$ da linha visada;

$R_{P} \quad$ raio do elipsóide no plano da primeira vertical;

$R_{Q} \quad$ raio do elipsóide no ponto final;

$M \quad$ raio de curvatura da seção meridiana;

$N$ raio de curvatura da seção transversa ( $1^{\mathrm{a}}$ vertical);

$h_{P} \quad$ altura elipsoidal em $P$;

$h_{Q} \quad$ altura elipsoidal em $Q$;

$\alpha \quad$ azimute geodésico da linha de visada.

Em alguns casos as magnitudes das correções acima são pequenas, e há uma tentação em não aplicá-las. Este tipo de erro sistemático pode ter efeito nocivo, sempre que negligenciadas as correções, conduzindo a uma acumulação significativa de distorções em uma série de pontos levantados. Cabe ao geodesista julgar se estas correções são significantes para um dado projeto.

De acordo com LEICK (1980), as equações acima podem ser utilizadas na redução de distâncias nos trabalhos usuais de redes de triângulação/trilateração proporcionando suficiente precisão, e os resultados desta redução de distâncias serão comparados com os resultados obtidos pelas equações descritas no item $\mathbf{5 . 4}$ - Distância 
Esférica. Entretanto, em caso de maiores precisões ou em distâncias longas pode ser usada alternativamente a formulação tridimensional apresentada a seguir. Para tal considere dois pontos A e B locados na superfície terrestre representados em um plano tangente ao geóide no ponto A (plano local), com o eixo $w$ na direção da normal ao elipsóide, o eixo $u$ perpendicular ao eixo $w$ na direção norte definida pelo meridiano geodésico e com o eixo $v$ na direção Leste (positiva) perpendicular ao plano $u w$ como mostrado na Figura 5.6.

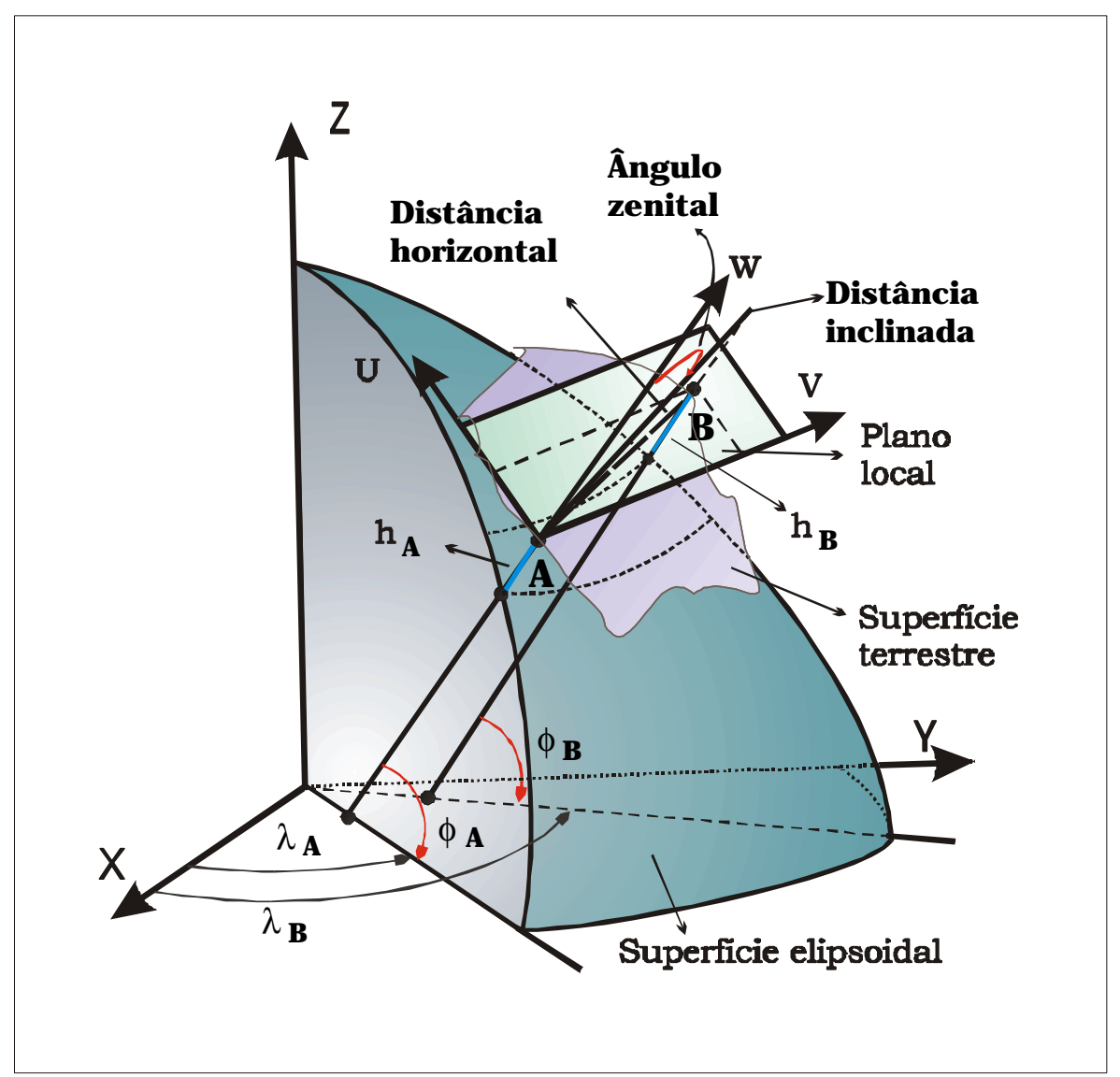

Figura 5.6: Representação dos sistemas de coordenadas Locais e Geodésico Geográfico e Cartesiano.

A partir das observações que são a distância inclinada, o ângulo zenital e o azimute da seção normal pode-se obter as projeções em cada um dos eixos coordenados com o uso das equações abaixo: 


$$
\begin{aligned}
& u=s^{\prime} \cos V \cos \alpha \\
& v=s^{\prime} \cos V \operatorname{sen} \alpha \\
& w=s^{\prime} \operatorname{sen} V \\
& V=Z-90^{\circ}
\end{aligned}
$$

onde:

$$
\begin{array}{ll}
s^{\prime} & \text { distância inclinada; } \\
V & \text { ângulo de altura (contado a partir do plano horizontal); } \\
Z & \text { ângulo zenital; } \\
\alpha & \text { azimute da seção normal. }
\end{array}
$$

As coordenadas cartesianas geodésicas destes pontos podem ser calculadas a partir das equações abaixo, segundo RAPP (1989) conhecendo-se a latitude, longitude, altura geográfica e ondulação geoidal:

$$
\begin{aligned}
& X=(N+h) \cos \phi \cos \lambda \\
& Y=(N+h) \cos \phi \operatorname{sen} \lambda \\
& Z=\left(N\left(1-e^{2}\right)+h\right) \operatorname{sen} \phi
\end{aligned}
$$

onde:

$$
\begin{array}{ll}
N & \text { ondulação geoidal; } \\
h & \text { altura geométrica geográfica; } \\
\phi & \text { latitude do ponto; } \\
\lambda & \text { longitude do ponto. }
\end{array}
$$

Como se deseja expressar as coordenadas locais em termos das coordenadas cartesianas geodésicas para a obtenção da distância nesta superfície, aplica-se primeiro a translação dos eixos $X, Y, Z$ para um outro conjunto de eixos paralelos que tem a origem no ponto $A$, como mostrado na Figura 5.7. 


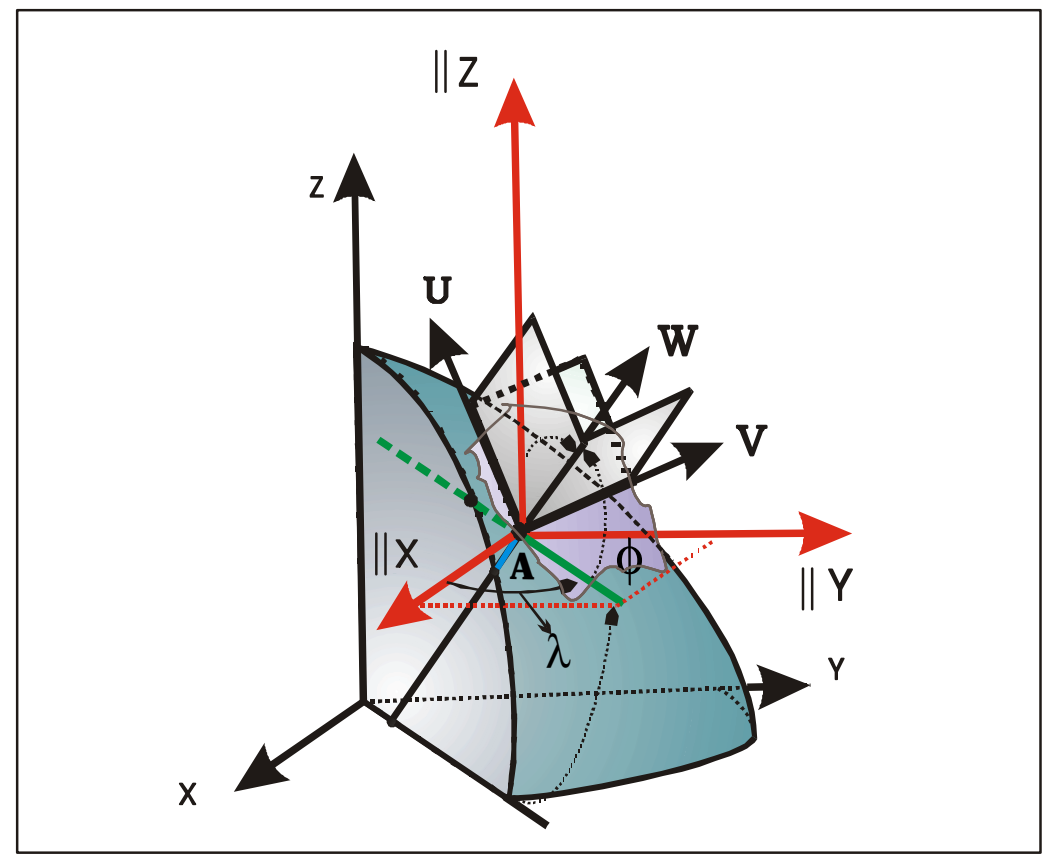

Figura 5.7: Translação dos eixos $X, Y, Z$ no ponto $A$.

Os eixos dos dois sistemas que agora possuem a mesma origem em $A$ não são paralelos entre si, sendo necessária a rotação entre os mesmos, e esta pode ser escrita na forma geral como a seguir:

$$
\left(\begin{array}{c}
x^{\prime \prime} \\
y^{\prime \prime} \\
z^{\prime \prime}
\end{array}\right)=R_{1}\left(\theta_{X}\right) R_{2}\left(\theta_{Y}\right) R_{3}\left(\theta_{Z}\right)\left(\begin{array}{l}
x^{\prime} \\
y^{\prime} \\
z^{\prime}
\end{array}\right)
$$

onde:

$$
\theta_{X}, \theta_{Y}, \theta_{Z}, \text { são as rotações em } x^{\prime}, y^{\prime}, z^{\prime} \text {; }
$$

No caso específico do sistema demonstrado na Figura 5.7, o sistema $x^{\prime}, y^{\prime}, z^{\prime}$ se refere ao sistema Cartesiano Geodésico, e o sistema $x^{\prime \prime}, y^{\prime \prime}, z^{\prime \prime}$ se refere ao sistema $u,-v, w$, conforme Figura 5.8, que forma o sistema destrógeno. As rotações podem ser primeiro $-\left(180^{\circ}-\lambda_{A}\right)$ em torno do eixo ||$Z$ e em seguida a rotação de $-\left(90^{\circ}-\phi_{A}\right)$ em 
torno do novo eixo ||$Y$, alterado pela primeira rotação aplicada. Os sinais negativos são devidos o sentido contrário ao relógio dos ângulos de rotação. Desta forma tem-se:

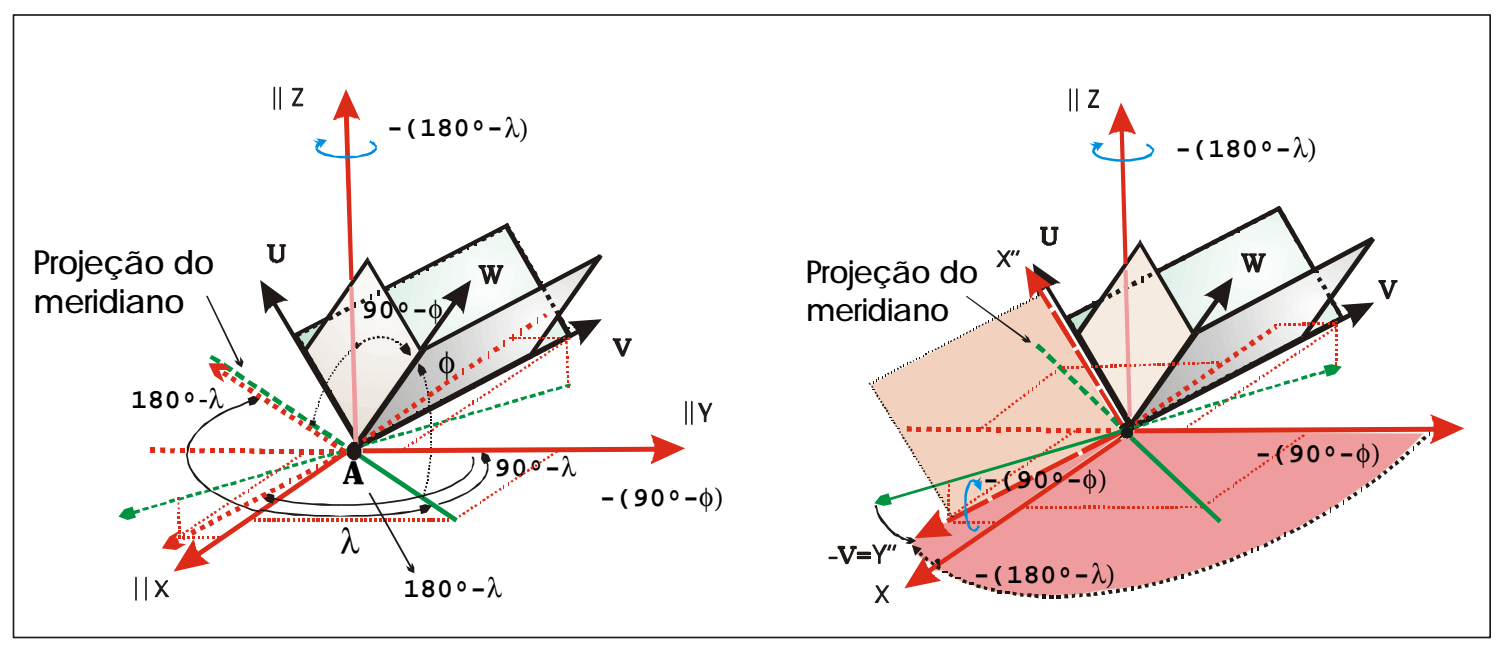

Figura 5.8: Rotação dos eixos Z e Y. Adaptada de RAPP (1989).

$$
\begin{gathered}
\left(\begin{array}{c}
u \\
-v \\
w
\end{array}\right)=R_{2}\left(-\left(90^{\circ}-\phi_{A}\right)\right) R_{3}\left(-\left(180^{\circ}-\lambda_{A}\right)\right)\left(\begin{array}{c}
\Delta X \\
\Delta Y \\
\Delta Z
\end{array}\right) \\
\Delta X=X_{2}-X_{1}, \Delta Y=Y_{2}-Y_{1}, \Delta Z=Z_{2}-Z_{1} \\
\cos \left[-\left(90^{\circ}-\phi_{A}\right)\right]=\operatorname{sen}\left(\phi_{A}\right) \\
\operatorname{sen}\left[-\left(90^{\circ}-\phi_{A}\right)\right]=-\cos \left(\phi_{A}\right) \\
\cos \left[-\left(180^{\circ}-\lambda_{A}\right)\right]=-\cos \left(\lambda_{A}\right) \\
\operatorname{sen}\left[-\left(180^{\circ}-\lambda_{A}\right)\right]=-\operatorname{sen}\left(\lambda_{A}\right)
\end{gathered}
$$

Fazendo o caminho inverso, trazendo o plano local com seus eixos paralelos ao sistema Geodésico Cartesiano, tem-se $\Delta X, \Delta Y, \Delta Z$ :

$$
\begin{aligned}
& \left(\begin{array}{c}
\Delta X \\
\Delta Y \\
\Delta Z
\end{array}\right)=R^{-1}(\phi, \lambda)\left(\begin{array}{c}
u \\
-v \\
w
\end{array}\right) \\
& R^{-1}(\phi, \lambda)=R^{T}(\phi, \lambda)
\end{aligned}
$$


Multiplicando as matrizes de rotação e invertendo o sinal de $v$, tem-se:

$$
\left(\begin{array}{c}
\Delta X \\
\Delta Y \\
\Delta Z
\end{array}\right)=\left(\begin{array}{ccc}
-\operatorname{sen} \phi_{A} \cos \lambda_{A} & -\operatorname{sen} \lambda_{A} & \cos \phi_{A} \cos \lambda_{A} \\
-\operatorname{sen} \phi_{A} \operatorname{sen} \lambda_{A} & \cos \lambda_{A} & \cos \phi_{A} \operatorname{sen} \lambda_{A} \\
\cos \phi_{A} & 0 & \operatorname{sen} \phi_{A}
\end{array}\right)\left(\begin{array}{c}
u \\
v
\end{array}\right)
$$

Resolvendo a multiplicação e substituindo $u, v, w$ por 5.14:

$$
\begin{aligned}
& \Delta X=s^{\prime}\left[\cos \lambda_{A}\left(\cos \phi_{A} \operatorname{sen} V_{A}-\operatorname{sen} \phi_{A} \cos \alpha_{A} \cos V_{A}\right)-\operatorname{sen} \lambda_{A} \cos \alpha_{A} \cos V_{A}\right] \\
& \Delta Y=s^{\prime}\left[\operatorname{sen} \lambda_{A}\left(\cos \phi_{A} \operatorname{sen} V_{A}-\operatorname{sen} \phi_{A} \cos \alpha_{A} \cos V_{A}\right)+\cos \lambda_{A} \operatorname{sen} \alpha_{A} \cos V_{A}\right] \\
& \Delta Z=s^{\prime}\left[\cos \phi_{A} \cos V_{A} \cos \alpha_{A}+\operatorname{sen} \phi_{A} \operatorname{sen} V_{A}\right]
\end{aligned}
$$

A corda $c$ no espaço pode ser dada por:

$$
c=\sqrt{\Delta X^{2}+\Delta Y^{2}+\Delta Z^{2}}
$$

As coordenadas cartesianas do ponto no espaço é dada pela coordenada inicial conhecida e suas projeções como a seguir:

$$
\begin{gathered}
X_{B}=X_{A}+\Delta X_{A B} \\
Y_{B}=Y_{A}+\Delta Y_{A B} \\
Z_{B}=Z_{A}+\Delta Z_{A B}
\end{gathered}
$$

Para o cálculo das coordenadas do ponto na superfície do elipsóide basta subtrair as projeções da altura geométrica $h$ do ponto em cada um dos eixos coordenados dadas pela equação 5.15. A Figura 5.9 mostra as coordenadas espaciais e as coordenadas na superfície do elipsóide. 


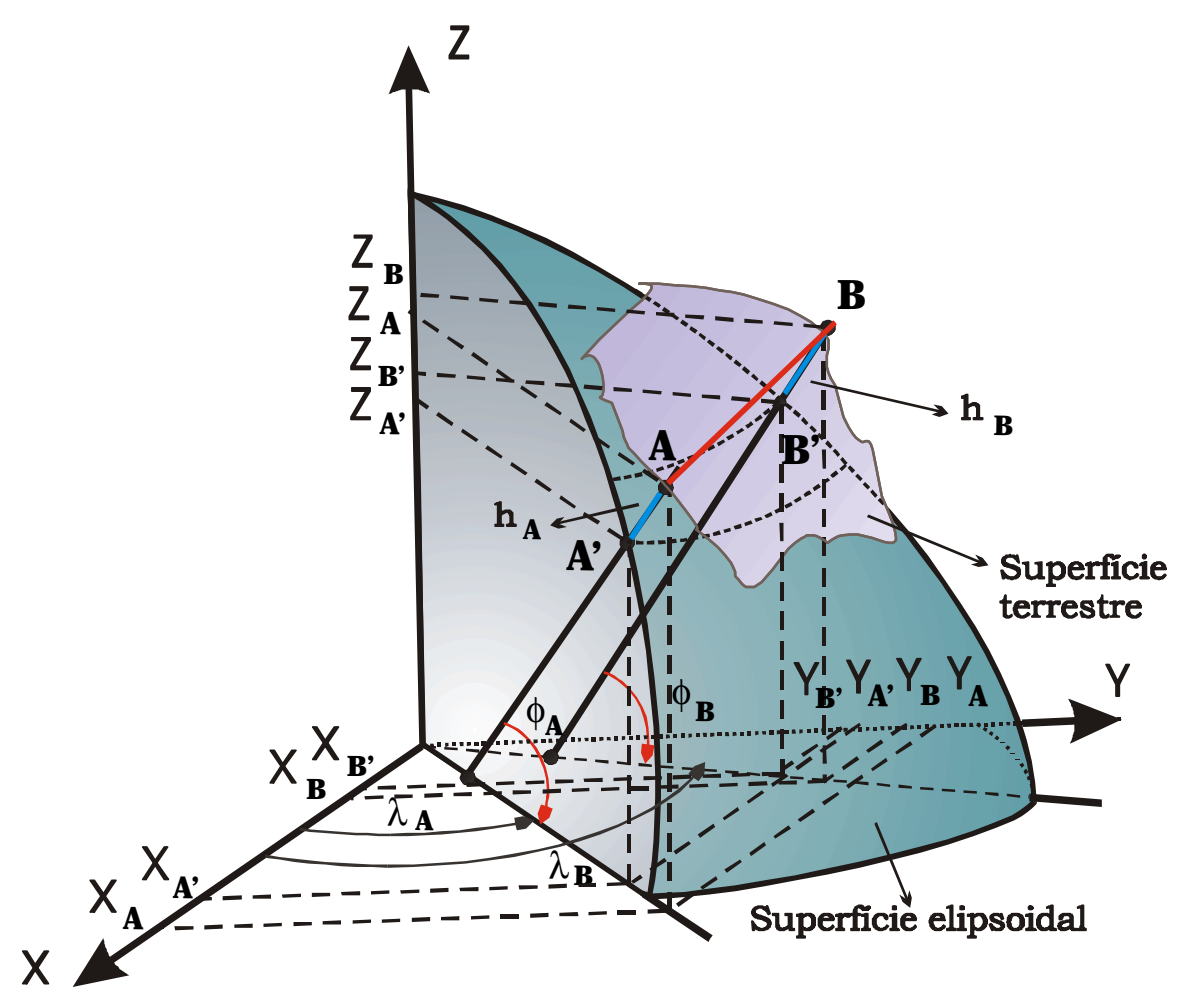

Figura 5.9: Coordenadas dos pontos levantados na superfície e projetados na superfície elipsoidal.

A distância na seção normal em $A$, segundo BAGRATUNI (1967) apud RAPP (1989) é:

$$
\begin{gathered}
s=c\left(1+\frac{1}{6}\left(\frac{c}{2 R}\right)^{2}+\frac{3}{40}\left(\frac{c}{2 R}\right)^{4}+\frac{5}{112}\left(\frac{c}{2 R}\right)^{6}+\frac{\mu_{1}}{2}\left(\frac{c}{2 R}\right)^{3}+\frac{3}{5} \mu_{2}\left(\frac{c}{2 R}\right)^{4}+\ldots\right) \\
R^{2}=X_{A}^{2}+Y_{A}^{2}+Z_{A}^{2} \\
\mu_{1}=\frac{e^{\prime 2}\left(\operatorname{sen} 2 \phi_{A} \cos \alpha_{A B}\right)}{1+\eta_{A}^{2} \cos ^{2} \alpha_{A B}} \\
\mu_{2}=\frac{e^{\prime 2}\left(\operatorname{sen} 2 \phi_{A}-\cos ^{2} \phi_{A} \cos ^{2} \alpha_{A B}\right)}{1+\eta_{A}^{2} \cos ^{2} \alpha_{A B}} \\
\eta^{2}=e^{\prime 2} \cos ^{2} \phi_{a}
\end{gathered}
$$


onde:

$R \quad$ raio da seção normal geodésica do primeiro ponto;

$e^{\prime} \quad$ segunda excentricidade;

$\eta \quad$ uma das componentes do desvio da vertical, chamada de componente da primeira vertical (projeção no plano vertical) no sentido Leste-Oeste.

\section{4 - Distância Esférica}

A distância esférica, entre dois pontos, situa-se na superfície de referência esférica que passa pelo ponto inicial, até o ponto final. Evidentemente, se os pontos inicial e final não estiverem na mesma altitude, haverá superfícies de nível esféricas concêntricas, de acordo com a Figura 5.10, que permitem equacioná-las como a seguir:

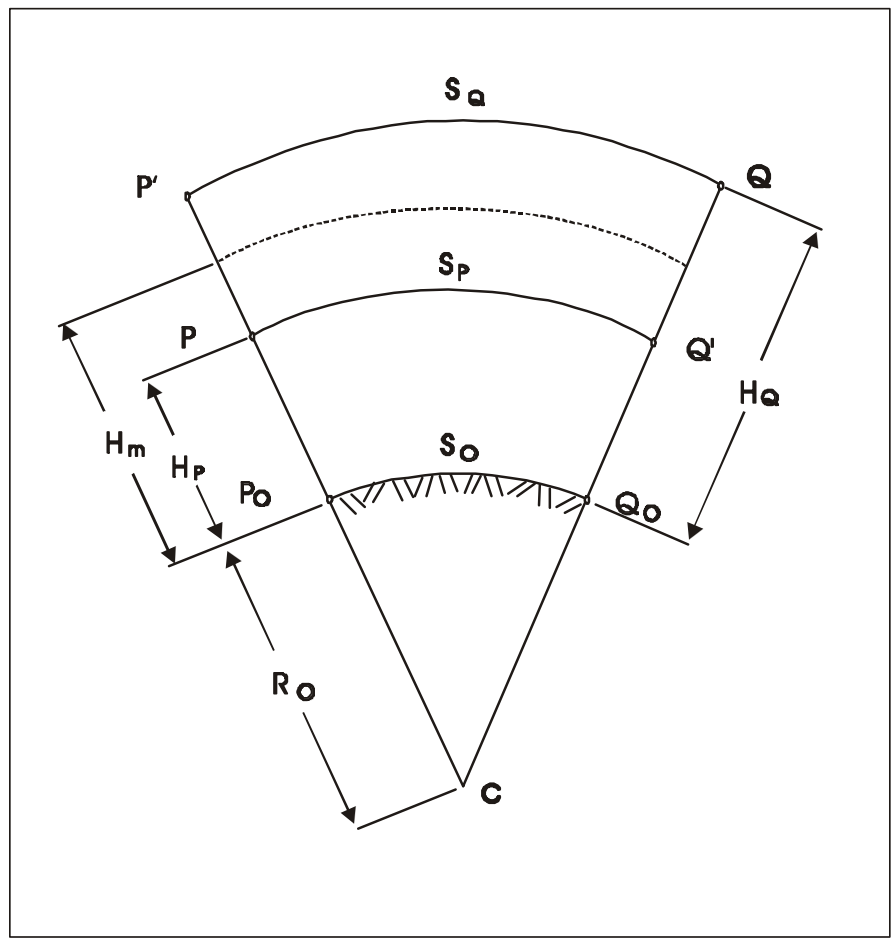

Figura 5.10: Representação da determinação da distância esférica.

$$
\frac{s_{0}}{R_{0}}=\frac{s_{P}}{R_{0}+H_{P}}=\frac{s_{Q}}{R_{0}+H_{Q}}
$$


onde:

$s_{0}$ distância esférica ao nível do geóide;

$s_{P}$ distância esférica do nível $P$;

$s_{Q}$ distância esférica do nível $Q$;

$R_{0}$ raio médio da esfera terrestre;

$H_{P}$ altitude do ponto $P$;

$H_{Q}$ altitude do ponto $Q$.

A generalização da distância esférica ao nível de um ponto é dada pela equação a seguir:

$$
\begin{aligned}
& s=\frac{R_{0}+H}{R_{0}} \cdot s_{0}=\left(1+\frac{H}{R_{0}}\right) \cdot s_{0} \\
& s_{0}=\frac{s}{\left(1+\frac{H}{R_{0}}\right)}
\end{aligned}
$$

Segundo SILVA et al (1999), para cálculos práticos pode-se operar com valores em ppm (partes por milhão), adotando-se na altitude média para a região de cálculo. Tem-se assim que, a redução e o comprimento ao nível do mar podem ser dados por:

$$
\begin{aligned}
& \operatorname{Re} d=-\frac{H}{R_{0}+H} \cdot 10^{6} p p m \\
& s_{0}=s-s \cdot \operatorname{Re} d
\end{aligned}
$$

onde:

$\operatorname{Re} d$ redução ao nível do mar;

$s_{0} \quad$ distância esférica do nível do geóide (nível do mar);

$R_{0} \quad$ raio médio da esfera terrestre; 
$S \quad$ distância esférica na altitude do ponto em questão;
$H \quad$ altitude do ponto em que se tem a distância esférica.

Este método de redução das observações, que utiliza a esfera de aproximação local ao elipsóide é recomendado para distâncias curtas.

A Tabela 5.1 abaixo apresenta a variação das distâncias $(\operatorname{Re} d)$, em relação à variação das altitudes, para diversos valores de $H\left(\right.$ para $R_{0}=6356,758 \mathrm{~km}$ ).

Tabela 5.1: Variação das distâncias em relação às altitudes

\begin{tabular}{|c|c|c|c|c|}
\hline $\mathrm{H}(\mathrm{m}) \backslash \mathrm{s}_{\mathrm{H}}(\mathrm{m})$ & 1000 & 2000 & 5000 & 10000 \\
\hline 5000 & 0,786 & 1,752 & 3,930 & 7,859 \\
2000 & 0,315 & 0,629 & 1,573 & 3,145 \\
1000 & 0,157 & 0,315 & 0,786 & 1,573 \\
500 & 0,079 & 0,157 & 0,393 & 0,786 \\
0 & 0 & 0 & 0 & 0 \\
\hline
\end{tabular}

\section{5 - Distância Plana}

$\mathrm{Na}$ Mensuração, os cálculos relativos à determinação de coordenadas de pontos, podem ser realizados segundo um plano de projeção, a partir do qual define-se o sistema de coordenadas XY. Neste caso, opera-se com distâncias planas, deformadas, que variam evidentemente de acordo com o tipo de relação de projeção adotada. Existem uma infinidade de sistemas de projeções que foram desenvolvidos ao longo dos anos e, cada país usa aquela que mais adapta às suas condições. No Brasil é adotado o sistema de projeção Universal Transverso de Mercator (UTM) (Figura 5.11).

A projeção UTM, originada a partir da projeção conforme de Gauss, tem como sua principal vantagem o fato de que ela permite representar grandes áreas da superfície terrestre, sobre um plano, em um sistema de coordenadas retangulares com poucas deformações. 


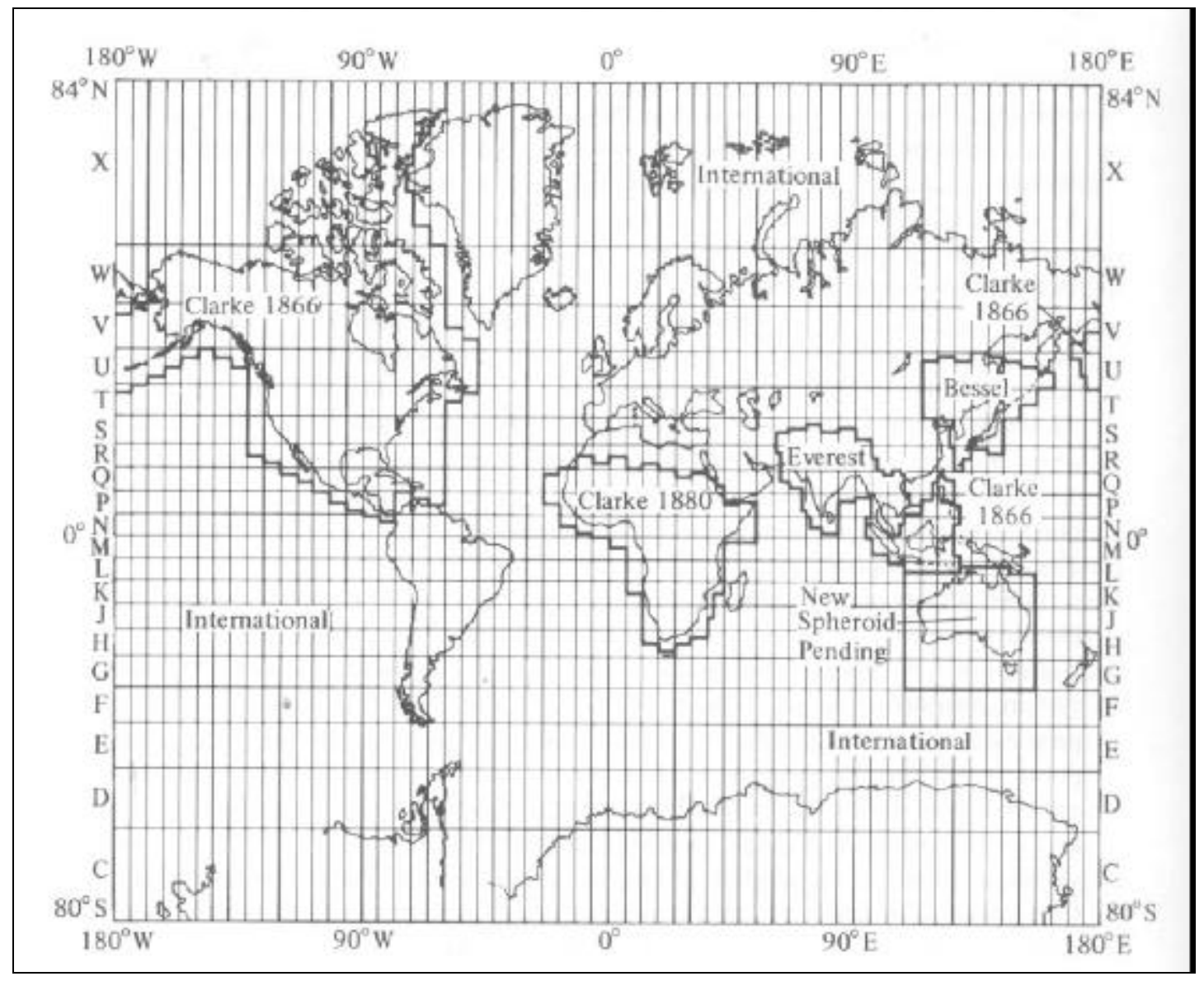

Figura 5.11: Sistema de projeção Universal Transverso de Mercator (UTM). Fonte MOFFITT et al (1987).

\section{6 - Relação entre Distância Esférica e Horizontal}

Como abordado anteriormente, a distância horizontal entre dois pontos, situa-se no plano horizontal e a distância esférica entre dois pontos, situa-se na superfície esférica que passa pelo ponto inicial (Figura 5.12). Têm-se, desta forma, as seguintes relações: 


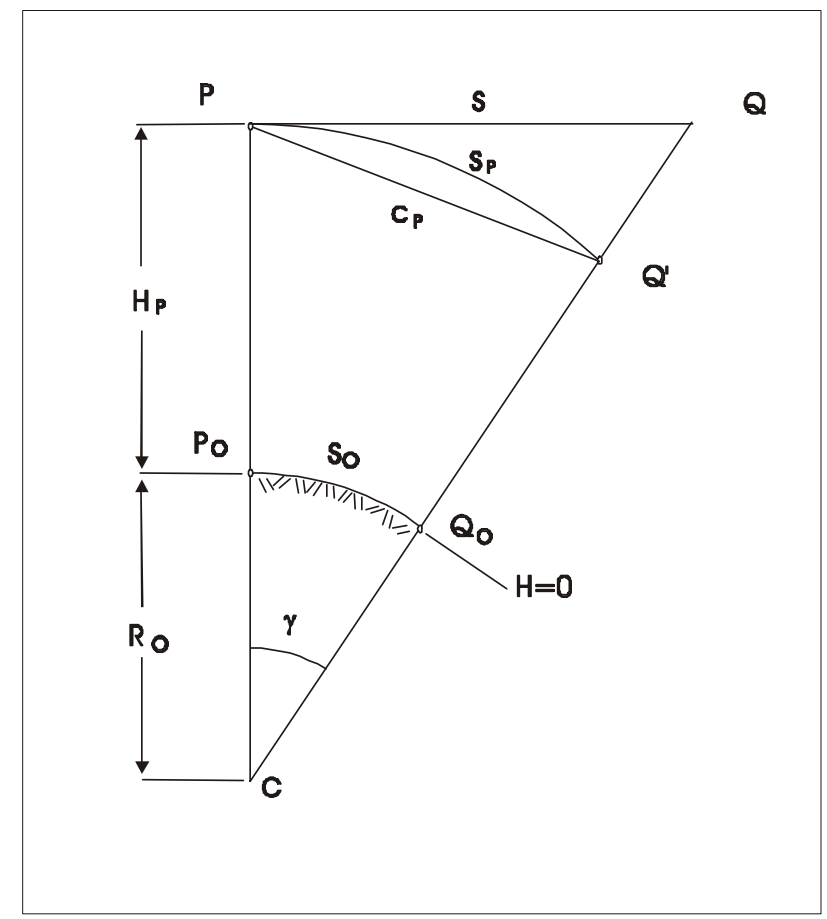

Figura 5.12: Representação da relação entre distância esférica e horizontal.

$$
\begin{aligned}
& s_{p}=\left(R_{0}+H_{p}\right) \cdot \gamma(\gamma \text { em radianos }) \\
& s=\left(R_{0}+H_{p}\right) \cdot \operatorname{tag}(\gamma) \\
& s=\left(R_{0}+H_{p}\right) \cdot \sin \left(\frac{\gamma}{2}\right)
\end{aligned}
$$

onde:

$Q^{\prime} \quad$ projeção de $Q$ sobre a superfície esférica;

$s \quad$ distância horizontal entre $P$ e $Q$;

$S_{P} \quad$ distância esférica ao nível de $P$;

$c_{P} \quad$ corda $P Q^{\prime}$;

$\gamma \quad$ ângulo no centro da terra;

$R_{0} \quad$ raio médio da esfera terrestre para a região do levantamento;

A Tabela 5.2 apresenta as diferenças entre a corda $c_{P}$ e o arco $s_{P}$, a tangente $s$ e o $\operatorname{arco} s_{P}$, ao nível do mar $(H=0)$. 
Tabela 5.2: Diferenças entre corda e o arco

\begin{tabular}{|c|l|r|r|c|c|}
\hline Valores do & $\begin{array}{c}\text { Valores do } \\
\text { arco } s_{P}(\mathrm{~m})\end{array}$ & $\begin{array}{c}\text { Valores da } \\
\text { arco } \gamma \\
\text { corda } c_{P}(\mathrm{~m})\end{array}$ & $\begin{array}{c}\text { Valores da } \\
\text { tangente } s \\
(\mathrm{~m})\end{array}$ & $\begin{array}{c}\text { Diferença } \\
c_{P}-s_{P} \\
(\mathrm{~mm})\end{array}$ & $\begin{array}{c}\text { Diferença } \\
s-s_{P}(\mathrm{~mm})\end{array}$ \\
\hline 1.000 & $0^{\circ} 00^{\prime} 32,45 "$ & 999,999999 & $1.000,000008$ & $-0,001$ & 0,008 \\
2.000 & $0^{\circ} 01^{\prime} 04,90 "$ & $1.999,999992$ & $2.000,000066$ & $-0,008$ & 0,066 \\
5.000 & $0^{\circ} 02^{\prime} 42,24 "$ & $4.999,999871$ & $5.000,001031$ & $-0,129$ & 1,031 \\
10.000 & $0^{\circ} 05^{\prime} 24,48^{\prime \prime}$ & $9.999,998969$ & $10.000,008249$ & $-1,031$ & 8,249 \\
\hline
\end{tabular}

Analisando os resultados, da Tabela 5.2, constata-se que para distâncias menores que $10 \mathrm{~km}$, a diferença entre corda e o arco é desprezível; o que não ocorre entre a tangente e o arco. Quando os pontos $P$ e $Q$ não estiverem na mesma altitude haverá uma diferença de distância conforme se adote o plano horizontal passando por $P$ ou $Q$ e, essa diferença na maioria dos casos pode ser desprezada.

\section{7 - Redução de Distâncias Inclinadas em Distâncias Esféricas}

Reduzir uma distância inclinada em distância esférica significa calcular a projeção desta distância inclinada sobre uma superfície de referência esférica. A Figura 5.13 mostra os diferentes elementos a serem considerados na redução das distâncias inclinadas. 


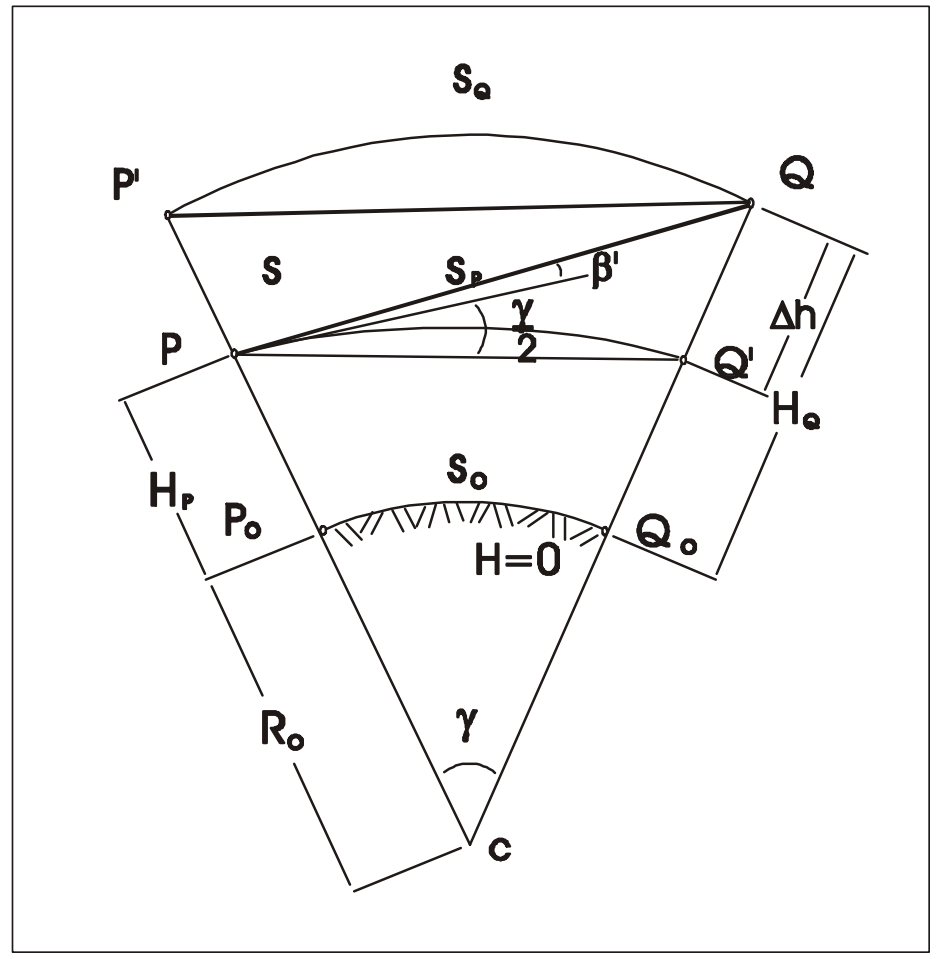

Figura 5.13: Relacionamento entre distância inclinada esférica.

Onde:

$R_{0} \quad$ raio médio da terra;

c centro da terra;

$\gamma \quad$ ângulo no centro da terra para $P Q$;

$s^{\prime} \quad$ distância inclinada;

$\beta^{\prime} \quad$ ângulo de altura da linha $P Q$;

$s_{P} \quad$ arco $P Q^{\prime}$ igual à corda $P Q^{\prime}$;

$s_{Q} \quad \operatorname{arco} P^{\prime} Q$ igual à corda $P^{\prime} Q ;$

$H_{P} \quad$ altitude do ponto $P$;

$H_{Q} \quad$ altitude do ponto $Q$;

$\Delta h$ diferença de nível entre $P Q\left(H_{Q}-H_{P}\right)$. 
Para melhor compreensão, se fará uma redução da Figura 5.13 em um quadrilátero conforme Figura 5.14.

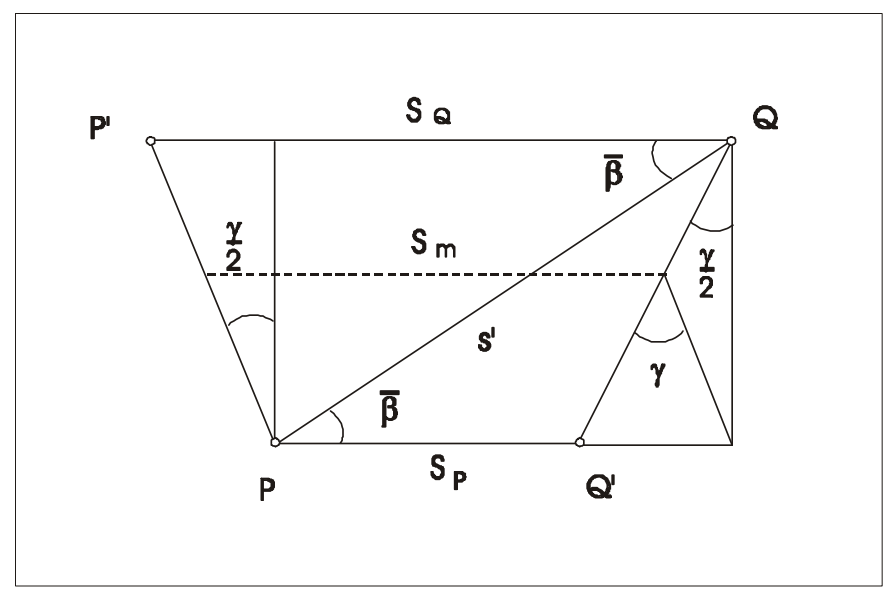

Figura 5.14: Redução da Figura 5.12 em um quadrilátero.

De acordo com a Figura 5.14 nota-se que:

$$
\bar{\beta}=\beta^{\prime}+\frac{\gamma}{2}
$$

E considerando que o ângulo $\gamma$ é extremamente pequeno, obtém-se:

a) distância ao nível de $P$

$$
\begin{aligned}
& s_{P}=s^{\prime} \cos \bar{\beta}-\Delta h \cdot \operatorname{sen} \frac{\gamma}{2} \\
& s_{P}=s^{\prime} \cos \bar{\beta}-\Delta h \cdot \frac{\gamma}{2}
\end{aligned}
$$

b) distância ao nível de $Q$

$$
\begin{gathered}
s_{Q}=s^{\prime} \cos \bar{\beta}+\Delta h \cdot \operatorname{sen} \frac{\gamma}{2} \\
s_{Q}=s^{\prime} \cos \bar{\beta}+\Delta h \cdot \frac{\gamma}{2}
\end{gathered}
$$


c) distância ao nível médio entre $P$ e $Q$

$$
s_{m}=s^{\prime} \cdot \cos \bar{\beta}
$$

Na realidade o ângulo medido com um teodolito é o ângulo de altura $\beta$, que é um ângulo diferente dos ângulos $\bar{\beta}$ e $\beta^{\prime}$. Essa diferença ocorre devido ao efeito da refração atmosférica, que transforma a visada retilínea $P Q$ em uma visada esférica, conforme mostra a Figura 5.15.

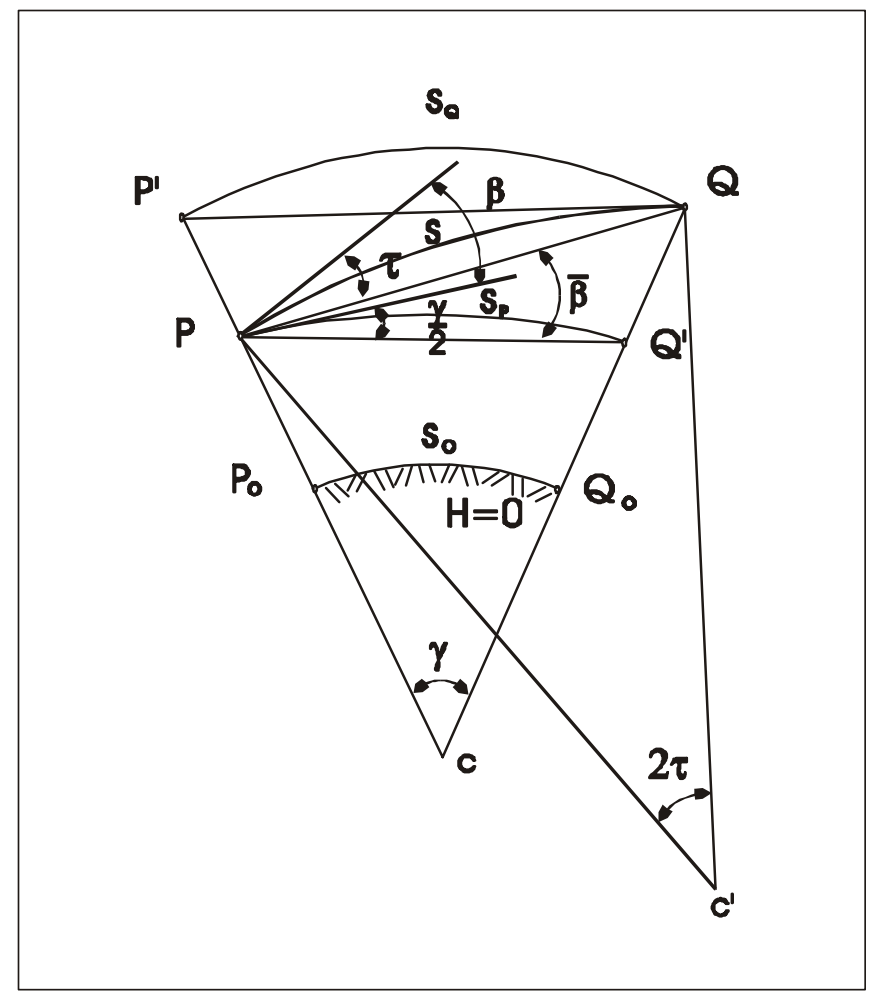

Figura 5.15: Diferenças entre ângulos devido a refração.

Onde:

$\beta \quad$ é o ângulo de altura efetivamente medido com o teodolito;

$\tau \quad$ é o ângulo de refração. 
Para calcular o ângulo de refração conforme Figura 5.15 faz-se as seguintes considerações: o raio $R^{\prime}$ do arco $P Q$ se supõe constante, e mediante um coeficiente $k$ se refere ao raio médio terrestre como a seguir.

$$
\begin{gathered}
R_{P}=k R^{\prime} \\
\frac{1}{R^{\prime}}=k \cdot \frac{1}{R_{P}}
\end{gathered}
$$

Pode-se admitir que os arcos $P Q$ e $P Q^{\prime}$ são iguais a $s_{P}$ pelo fato do ângulo $\gamma$ ser pequeno. Partindo desta suposição, tem-se:

$$
\begin{aligned}
& \tau=\frac{1}{2} \cdot \frac{s_{P}}{R^{\prime}} \\
& \operatorname{sen} \frac{\gamma}{2}=\frac{s_{P}}{2 \cdot R_{P}} \\
& \operatorname{sen} \frac{\gamma}{2}=\frac{\gamma}{2}
\end{aligned}
$$

substituindo 5.34 em 5.35 e 5.37 em 5.36 tem-se:

$$
\begin{gathered}
\tau=\frac{k}{2} \frac{s_{P}}{R_{P}} \\
\frac{\gamma}{2}=\frac{s_{P}}{2 \cdot R_{P}}
\end{gathered}
$$

Substituindo 5.39 em 5.38 tem-se:

$$
\tau=k \frac{\gamma}{2}
$$

Segundo JORDAN (1944), o coeficiente médio de refração $k$ achado por Gauss é 0,1306 . Em números arredondados se toma para este coeficiente o valor $k=0,13$.

Para o cálculo do ângulo medido, pela figura tem-se a relação: 


$$
\beta=\bar{\beta}-\frac{\gamma}{2}+\tau
$$

Substituindo 5.40 em 5.41 tem-se:

$$
\begin{aligned}
& \beta=\bar{\beta}-\frac{\gamma}{2}+k \cdot \frac{\gamma}{2} \\
& \beta=\bar{\beta}-(1-k) \cdot \frac{\gamma}{2}
\end{aligned}
$$

Considerando-se o ângulo de altura $\beta$ efetivamente medido, obtém-se a distância reduzida $s_{r}$, pela relação abaixo:

$$
s_{r}=s^{\prime} \cdot \cos \beta
$$

Considerando o valor de $\beta$ como indicado na equação $5.42, s_{r}$ em 5.43 pode ser dado em função de $\bar{\beta}$ por:

$$
\cdot \cos \left\lceil\bar{\beta}-(1 \quad) \cdot \frac{\gamma}{2}\right\rceil
$$

Desenvolvendo a diferença da função

$$
\operatorname{sen}(1-k) \frac{\gamma}{2}=(1-k) \frac{\gamma}{2} \mathrm{e}
$$

$$
\cos (1-k) \frac{\gamma}{2}=1
$$

$$
s_{r}=s^{\prime} \cdot \cos \bar{\beta}-s^{\prime} \cdot \operatorname{sen} \bar{\beta} \cdot\left[(1-k) \cdot \frac{\gamma}{2}\right]
$$

Da Figura $5.13 \Delta h^{\prime}$ é dado em função do ângulo $\frac{\gamma}{2}$, pela relação a seguir:

$$
\Delta h^{\prime}=\Delta h \cdot \cos \frac{\gamma}{2}
$$




$$
\Delta h^{\prime}=s^{\prime} \cdot \operatorname{sen} \bar{\beta}
$$

Substituindo 5.46 em 5.47, tem-se:

$$
s^{\prime} \cdot \operatorname{sen} \bar{\beta}=\Delta h \cdot \cos \frac{\gamma}{2}
$$

5.48 em 5.44:

$$
s_{r}=s^{\prime} \cdot \cos \bar{\beta}-\Delta h \cdot \cos \frac{\gamma}{2} \cdot(1-k) \cdot \frac{\gamma}{2}
$$

Ainda considerando $\cos \frac{\gamma}{2}=1$, e substituindo $\frac{\gamma}{2}=\frac{s_{P}}{2 \cdot R_{0}}$ (ângulo central em função da corda e raio, Figura 5.15) em 5.49 obtém-se:

$$
s_{r}=s^{\prime} \cdot \cos \bar{\beta}-\Delta h \cdot(1-k) \cdot \frac{s}{2 \cdot R_{0}}
$$

Comparando as distâncias reduzida esférica com as distâncias esféricas nos pontos e esférica média, as diferenças podem ser dadas por:

Em relação a $s_{P}$ (no ponto $P$ )

$$
\begin{aligned}
& \varepsilon_{P}=s_{r}-s_{P} \\
& \varepsilon_{P}=s^{\prime} \cdot \cos \bar{\beta}-\Delta h \cdot(1-k) \cdot \frac{s}{2 \cdot R_{0}}-s^{\prime} \cdot \cos \bar{\beta}+\Delta h \cdot \frac{s}{2 R_{0}} \\
& \varepsilon_{P}=\Delta h \cdot s \cdot \frac{k}{2 R_{0}}
\end{aligned}
$$

Em relação a $s_{Q}($ no ponto $Q)$

$$
\varepsilon_{Q}=s_{r}-s_{Q}
$$




$$
\begin{aligned}
\varepsilon_{Q} & =s^{\prime} \cdot \cos \bar{\beta}-\Delta h \cdot(1-k) \cdot \frac{s}{2 R_{0}}-s^{\prime} \cdot \cos \bar{\beta}-\Delta h \cdot \frac{s}{2 R_{0}} \\
\varepsilon_{Q} & =-\Delta h \cdot s \cdot \frac{(2-k)}{2 R_{0}}
\end{aligned}
$$

Em relação a $s_{m}$ :

$$
\begin{aligned}
& \varepsilon_{m}=s_{r}-s_{m} \\
& \varepsilon_{m}=s^{\prime} \cdot \cos \bar{\beta}+\Delta h \cdot(1-k) \cdot \frac{s}{2 R_{0}}-s^{\prime} \cdot \cos \bar{\beta} \\
& \varepsilon_{m}=\Delta h \cdot s \cdot \frac{(1-k)}{2 R_{0}}
\end{aligned}
$$

Os erros em função da diferença de altitude $\Delta h$ e a distância esférica $s$, para $k=0,13$ e $R_{0}=6.356 .778 m$ (região de São Carlos) é:

$$
\begin{aligned}
& \varepsilon_{P}(m)=0,102 \cdot 10^{-7} \cdot \Delta h \cdot s \\
& \varepsilon_{Q}(m)=-1,47 \cdot 10^{-7} \cdot \Delta h \cdot s \\
& \varepsilon_{m}(m)=0,684 \cdot 10^{-7} \cdot \Delta h \cdot s
\end{aligned}
$$

De acordo com a Figura 5.16, deve-se calcular a altitude $H_{r}$ da distância reduzida $s_{r}$, para que posteriormente possa reduzi-la ao nível médio do mar, assim sendo, é necessário aplicar as seguintes relações: 


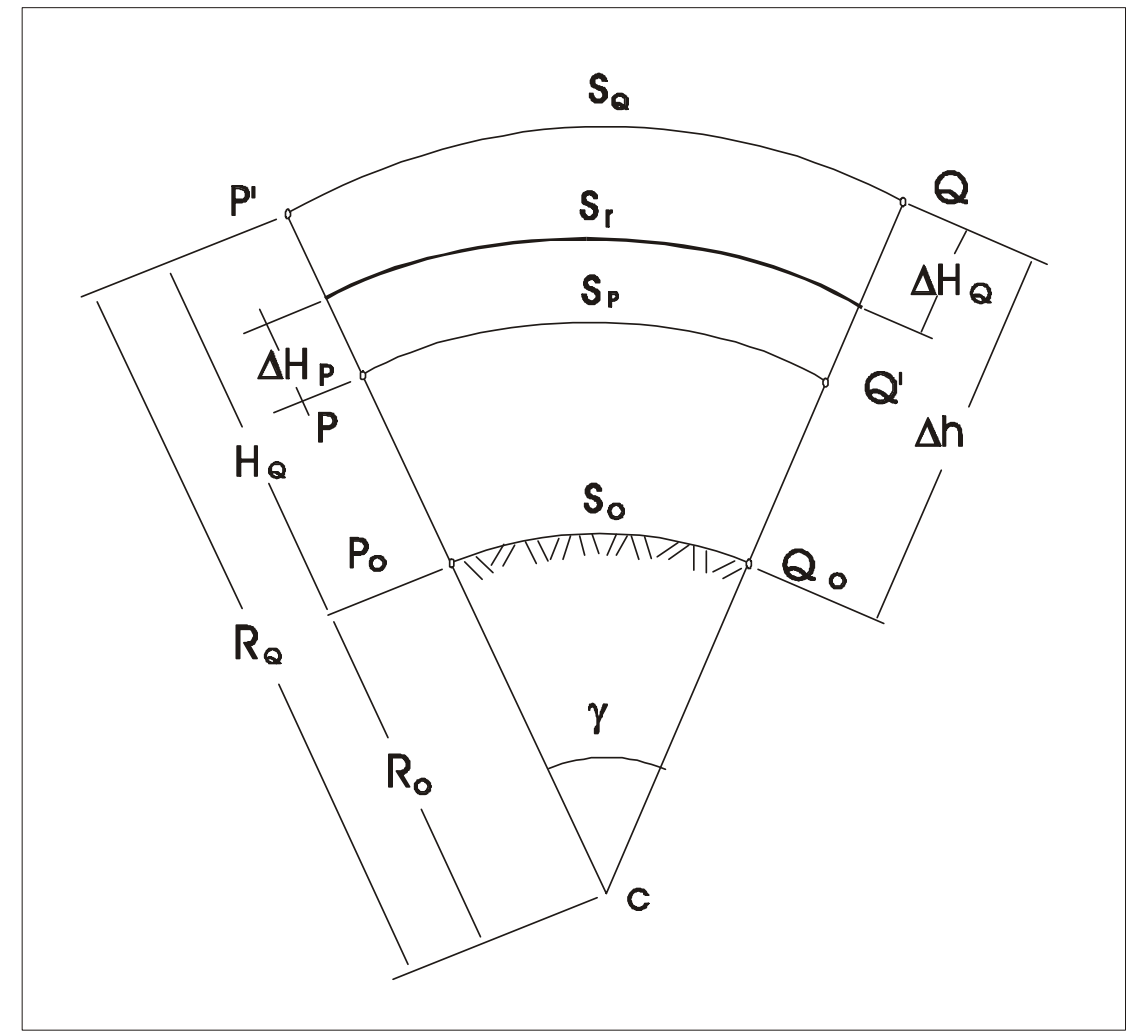

Figura 5.16: Representação da distância esférica resultante entre $P$ e $Q$.

A partir de $P$ :

$$
\begin{aligned}
& \frac{R_{r}}{s_{r}}=\frac{R_{P}}{s_{P}} \\
& R_{r}=R_{P}+\Delta H_{P}
\end{aligned}
$$

5.53 em 5.54 e $s_{r}=s_{P}+\varepsilon_{P}$ dado por 5.49, tem-se:

$$
\begin{aligned}
& R_{P}+\Delta H_{P}=\frac{R_{P}}{s_{P}} \cdot\left(s_{P}+\varepsilon_{P}\right) \\
& \Delta H_{P}=\frac{R_{P}}{s_{P}} \cdot \varepsilon_{P}
\end{aligned}
$$

Substituindo 5.51 em 5.57, tem-se: 


$$
\Delta H_{P}=\frac{R_{P}}{s_{P}} \cdot \Delta h \cdot s \cdot \frac{k}{2 R_{0}}
$$

Admitindo $\frac{R_{P}}{S_{P}}=\frac{R_{0}}{S}$, obtém-se finalmente:

$$
\begin{aligned}
& \Delta H_{P}=H_{r}-H_{P}=\frac{k}{2} \cdot \Delta h \\
& H_{r}=H_{P}+\frac{k}{2} \cdot \Delta h
\end{aligned}
$$

Para o ponto $Q$ faz-se o mesmo procedimento sabendo que $\Delta H_{Q}\langle 0$ :

$$
\begin{aligned}
\Delta H_{Q} & =H_{r}-H_{Q}=\frac{2-k}{2} \cdot \Delta h \\
H_{r} & =H_{Q}+\frac{2-k}{2} \cdot \Delta h
\end{aligned}
$$

Assim, resumindo, para reduzir uma distância inclinada em distância esférica pode-se usar:

a) o ângulo vertical medido $\beta$

$$
\begin{aligned}
& s_{r}=s^{\prime} \cdot \cos \beta \\
& H_{r}=H_{P}+\frac{k}{2} \cdot \Delta h=H_{Q}+\frac{2-k}{2} \cdot \Delta h
\end{aligned}
$$

b) o ângulo vertical corrigido $\bar{\beta}$

$$
\begin{aligned}
& s_{m}=s^{\prime} \cdot \cos \bar{\beta} \\
& H_{m}=H_{P}+\frac{1}{2} \Delta h
\end{aligned}
$$




\section{8 - Transformação de Distância Elipsoidal em Distância Plana}

\subsection{1 - Considerações Gerais}

$\mathrm{Na}$ transformação de uma distância elipsoidal em uma distância plana é necessária apenas a aplicação do fator de escala entre as duas superfícies, dada a posição em que se encontra esta distância elipsoidal no elipsóide de referencia (coordenadas) e o elipsóide em relação ao cilindro secante Equatorial, ou seja, basta projetá-la neste cilindro secante equatorial ao elipsóide impondo as condições de conformidade, fazendo a abertura e planificação do mesmo (Figura 5.17).

A vista a da Figura 5.17 mostra a superfície elipsoidal, que representa a terra e que se aproxima da superfície do mar, interceptada por uma superfície cilíndrica ao longo das duas elipses AE'A' e BE'B', que são eqüidistantes ao meridiano central PES.

Esta interseção ao longo das duas elipses é afetada por uma diminuição de comprimento em relação a um outro cilindro que por sua vez seria tangente a terra ao longo do meridiano central.

A vista b da Figura 5.17 mostra a porção da superfície cilíndrica desenvolvida na superfície plana em que os meridianos e paralelos da superfície da terra tem sido projetado matematicamente. No desenvolvimento de cada elipse aparece como uma linha reta paralela e eqüidistante ao meridiano central. Ao longo dessas duas linhas de projeção, a distância é a mesma como a correspondente na superfície elipsoidal, entre as duas linhas é menor, dos lados exteriores às duas linhas a distância na projeção é maior. A discrepância entre essas distâncias correspondentes depende da posição da linha considerada em relação ao meridiano central. $\mathrm{O}$ fator de escala de uma linha projetada na direção Leste-Oeste varia de ponto a ponto, enquanto na projeção paralela ao meridiano central tem uma escala constante por todo o seu comprimento, e o comprimento pode ser maior, igual ou menor do que a linha correspondente ao elipsóide. 


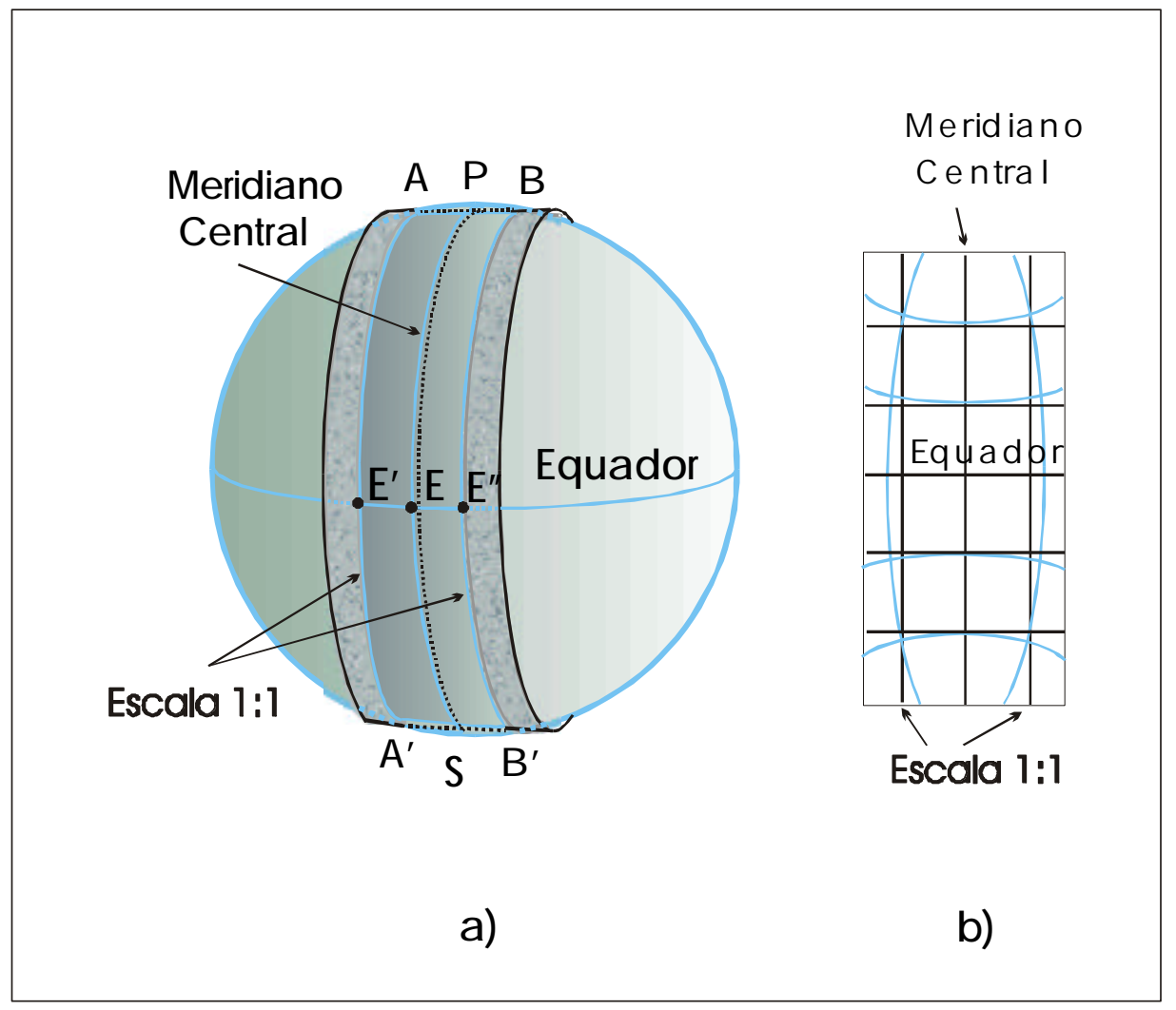

Figura 5.17: Projeção Transverso de Mercator, adaptada de MOFFITT et al (1987).

Para o caso do fator de redução variável de ponto a ponto para uma linha é necessário calcular o fator de redução de um arco de meridiano que passa por cada ponto extremo da linha e as coordenadas para a determinação da distância plana. Em casos especiais, para as linhas no sentido Leste-Oeste o fator de escala de redução entre superfícies pode ser calculado por média ponderada dos pontos extremos e médio do alinhamento e em trabalhos que não se exige grandes precisões pode-se aplicar fatores de escala aproximados que serão discutidos a seguir.

Para o cálculo do fator de escala e a localização de uma distância plana no seu sistema de referência, deve-se ter a fixação do ponto inicial e final da distância elipsoidal em relação ao seu sistema Geodésico. Com isto garante-se as coordenadas no sistema geográfico, conhecendo-se latitude, longitude e altitude, ou em relação ao sistema cartesiano XYZ, conhecendo-se as coordenadas X, Y e Z. Dada a direção, através das coordenadas iniciais e finais do alinhamento, pode-se determinar o Meridiano Central e 
a superfície elipsoidal que é interceptada por esta distância elipsoidal. Assim esta superfície elipsoidal será projetada em um cilindro secante ao Meridiano Central correspondente.

No sistema UTM o globo terrestre é divido em 60 fusos dado pela adoção de 60 cilindros de eixo transverso, obtidos através da rotação do mesmo no plano do Equador de maneira que cada um cubra $6^{\circ}$ de longitude ( $3^{\circ}$ para cada lado do meridiano central) mantendo as deformações em limites aceitáveis. Os fusos são numerados a partir do antimeridiano de Greenwich; sendo para o nosso território representado de 18 a 25 . As latitudes para o nosso território não têm limites de uso já que estas se situam do Equador (latitude $0^{\circ}$ ) até o paralelo $32^{\circ} \mathrm{S}$, dentro do limite máximo de $80^{\circ}(\mathrm{N}, \mathrm{S})$. Pela simetria do elipsóide de revolução, os cálculos são idênticos para todos os fusos ou cilindros e os resultados são válidos para toda a terra (CINTRA, 1989).

Para o cálculo do meridiano central (MC) de um ponto, podemos proceder de duas formas, como a seguir:

a- em função da longitude $(\lambda)$ de um ponto

$$
M C=6 \cdot \operatorname{int}\left(\frac{\lambda}{6}\right)+3
$$

b- em função do fuso $(F)$ em que se encontra o ponto

$$
M C=183-6 \cdot F
$$

\subsection{2 - Transformação das coordenadas Geodésicas Cartesianas em Geodésicas Geográficas}

Se acontecer de se ter as coordenadas geodésicas no sistema cartesiano XYZ, deve-se transformá-las para o sistema geográfico geodésico, para obtenção das latitudes e longitudes. A transformação pode ser realizada pelas equações abaixo, segundo VANICEK et al (1986), HOFMAN-WELLENHOF (1994) e TORGE (1984): 


$$
\begin{aligned}
e & =\sqrt{\frac{a^{2}-b^{2}}{a^{2}}} \\
e^{\prime} & =e \cdot \frac{a}{b} \\
\phi_{0} & =\arctan \left[\left(\frac{z}{\left(x^{2}+y^{2}\right)^{\frac{1}{2}}}\right) \cdot\left(1-e^{2}\right)^{-1}\right] \\
\phi & =\arctan \left[\frac{z+\left(e^{\prime 2} \cdot b \cdot\left(\operatorname{sen} \phi_{0}\right)^{3}\right)}{\left(x^{2}+y^{2}\right)^{\frac{1}{2}}-\left(e^{2} \cdot a \cdot\left(\cos \phi_{0}\right)^{3}\right)}\right] \\
\lambda & =\arctan \frac{y}{x} \\
N & =\frac{a}{\left(1-e^{2} \cdot(\operatorname{sen} \phi)^{2}\right)^{\frac{1}{2}}} \\
h & =\frac{\sqrt{x^{2}+y^{2}}}{\cos \phi}-N
\end{aligned}
$$

onde:

e primeira excentricidade do elipsóide;

$e^{\prime} \quad$ segunda excentricidade do elipsóide;

$a \quad$ semi-eixo maior do elipsóide;

$b \quad$ semi-eixo menor do elipsóide;

$\phi_{0} \quad$ latitude provisória fazendo $h=0$;

$\phi \quad$ latitude do ponto referente ao elipsóide;

$\lambda \quad$ longitude do ponto referente ao elipsóide;

$x \quad$ coordenada cartesiana do ponto no eixo $\mathrm{X}$;

$y \quad$ coordenada cartesiana do ponto no eixo Y;

$z \quad$ coordenada cartesiana do ponto no eixo $\mathrm{Z}$;

$N \quad$ raio de curvatura na primeira vertical; 
$h \quad$ altura do ponto na superfície do terreno até o elipsóide medida na seção normal ( altitude geográfica).

\subsection{3 - Transformação das coordenadas Geodésicas Geográficas em Planas UTM}

A seguir as fórmulas matemáticas dos coeficientes usados para as transformações das coordenadas geográficas geodésicas em coordenadas planas UTM, de acordo com TABELA PARA CÁlCULO NO SISTEMA DE PROJEÇÃO UNIVERSAL TRANSVERSO DE MERCATOR (UTM) (ELIPSÓIDE INTERNACIONAL DE 1967) (1986) e GRIPP JR. \& SILVA (1987):

$$
\begin{aligned}
& (I)=S \cdot k_{0} \\
S & =a\left(1-e^{2}\right) \cdot\left(A \cdot K-\frac{1}{2} B \cdot L+\frac{1}{4} C \cdot M^{\prime}-\frac{1}{6} D \cdot N^{\prime}+\frac{1}{8} E \cdot P-\frac{1}{10} F \cdot Q\right) \\
A & =1+\frac{3}{4} e^{2}+\frac{45}{64} e^{4}+\frac{175}{256} e^{6}+\frac{11025}{16384} e^{8}+\frac{43659}{65536} e^{10} \\
B & =\frac{3}{4} e^{2}+\frac{15}{16} e^{4}+\frac{525}{512} e^{6}+\frac{2205}{2048} e^{8}+\frac{72765}{65536} e^{10} \\
C & =\frac{15}{64} e^{4}+\frac{105}{256} e^{6}+\frac{2205}{4096} e^{8}+\frac{10395}{16384} e^{10} \\
D & =\frac{35}{512} e^{6}+\frac{315}{2048} e^{8}+\frac{31185}{131072} e^{10} \\
E & =\frac{315}{16384} e^{8}+\frac{3465}{65536} e^{10} \\
F & =\frac{639}{131072} e^{10} \\
K & =\left(\phi_{P}-\phi\right)^{\prime \prime} \cdot \operatorname{sen} 1^{\prime \prime} \\
L & =\operatorname{sen}\left(2 \phi_{P}\right)-\operatorname{sen}(2 \phi) \\
M^{\prime} & =\operatorname{sen}\left(4 \phi_{P}\right)-\operatorname{sen}(4 \phi) \\
N^{\prime} & =\operatorname{sen}\left(6 \phi_{P}\right)-\operatorname{sen}(6 \phi) \\
& \\
&
\end{aligned}
$$




$$
\begin{aligned}
& P=\operatorname{sen}\left(8 \phi_{P}\right)-\operatorname{sen}(8 \phi) \\
& Q=\operatorname{sen}\left(10 \phi_{P}\right)-\operatorname{sen}(10 \phi) \\
& I I=\frac{N \cdot \operatorname{sen} \phi_{P} \cos \phi_{P}}{2} \cdot k_{0} \cdot 10^{8} \\
& I I I=\frac{\operatorname{sen}^{4} 1^{\prime \prime} \cdot N \cdot \operatorname{sen} \phi_{P} \cdot \cos ^{3} \phi_{P}}{24} \cdot\left(5-\tan ^{2} \phi_{P}+9 e^{\prime 2} \cdot \cos ^{2} \phi_{P}+4 e^{\prime 4} \cdot \cos ^{4} \phi_{P}\right) \cdot k_{0} \cdot 10^{16} \\
& I V=N \cdot \cos \phi_{P} \operatorname{sen} 1^{\prime \prime} \cdot k_{0} \cdot 10^{4} \\
& V=\frac{\operatorname{sen}^{3} 1^{\prime \prime} \cdot N \cdot \cos ^{3} \phi_{P}}{6} \cdot\left(1-\tan ^{2} \phi_{P}+e^{\prime 2} \cdot \cos ^{2} \phi_{P}\right) \cdot k_{0} \cdot 10^{12} \\
& X V I I I=\frac{1+e^{\prime 2} \cdot \cos ^{2} \phi_{P}}{2 N^{2}} \cdot\left(\frac{1}{k_{0}^{2}}\right) \cdot 10^{12} \\
& \quad A^{\prime} 6=\frac{\operatorname{sen}^{6} 1^{\prime \prime} \cdot N \cdot \operatorname{sen}_{P} \cdot \cos ^{5} \phi_{P}}{720} \cdot\left(61-58 \tan ^{2} \phi_{P}+\tan ^{4} \phi_{P}+270 e^{\prime 2} \cdot \cos ^{2} \phi_{P}+\right. \\
& \left.\quad-330 e^{\prime 2} \cdot \operatorname{sen}^{2} \phi_{P}\right) \cdot k_{0} \cdot 10^{24} \\
& B^{\prime} 5=\frac{\operatorname{sen}^{5} 1^{\prime \prime} \cdot N \cdot \cos ^{5} \phi_{P}}{120} \cdot\left(5-18 \tan ^{2} \phi_{P}+\tan ^{4} \phi_{P}+14 e^{\prime 2} \cdot \cos ^{2} \phi_{P}-58 e^{\prime 2} \cdot \operatorname{sen}^{2} \phi_{P}\right) \cdot k_{0} \cdot 10^{20}
\end{aligned}
$$

onde:

$\phi_{P} \quad$ latitude do ponto;

$N \quad$ raio de curvatura da $1^{\mathrm{a}}$ vertical;

$S \quad$ arco do meridiano contado a partir do equador sobre o meridiano central;

$e^{\prime} \quad$ segunda excentricidade;

$k_{0} \quad$ fator de escala no meridiano central.

Equações de transformação das coordenadas geodésicas em planas:

a) para o eixo $X$ :

Para o hemisfério norte 


$$
N=(I)+(I I) \cdot p^{2}+(I I I) \cdot p^{4}+\left(A^{\prime} 6\right) \cdot p^{6}
$$

para o hemisfério sul

$$
N=(I)+(I I) \cdot p^{2}+(I I I) \cdot p^{4}+\left(A^{\prime} 6\right) \cdot p^{6}+10.000 .000
$$

b) para o eixo $\mathrm{Y}$

$$
E=500.000+(I V) \cdot p+(V) \cdot p^{3}+\left(B^{\prime} 5\right) \cdot p^{5}
$$

onde:

$$
\begin{aligned}
& p=0.0001 \cdot \Delta \lambda " \\
& \Delta \lambda=\lambda_{P}-\lambda_{0} \\
& \lambda_{P} \quad \text { longitude de um ponto } P ; \\
& \lambda_{0} \quad \text { longitude do meridiano central. }
\end{aligned}
$$

\subsection{4 - Convergência Meridiana}

Os azimutes, na projeção UTM, estão referidos ao Norte da Quadrícula $(N Q)$, linha de orientação formada por um sistema de coordenadas retangular, com o eixo $\mathrm{X}$ descrevendo a direção Leste-Oeste e o eixo Y descrevendo a direção Norte-Sul. Já no sistema geodésico os ângulos medidos estão referidos ao Norte Geográfico $(N G)$, cuja representação na projeção UTM, é dada por uma linha curva, côncava em relação ao meridiano central. As duas linhas formam um ângulo variável para cada ponto, denominado convergência meridiana conforme Figura 5. 18. 


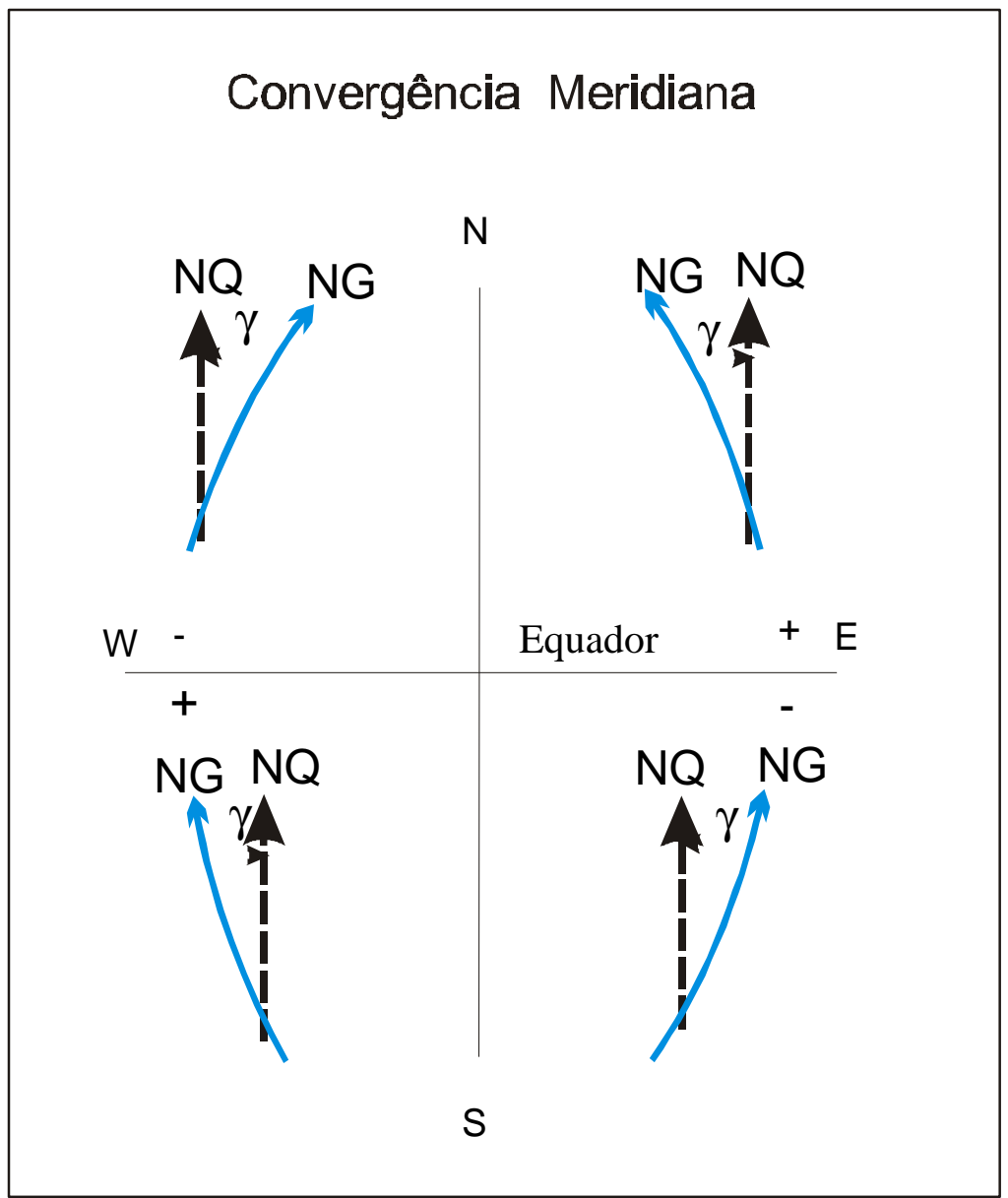

Figura 5.18: Convergência meridiana.

Fórmulas para a transformação em convergência meridiana:

a) em função das coordenadas geodésicas

$$
C=(X I I) \cdot p+(X I I I) \cdot p^{3}+\left(C^{\prime} 5\right) \cdot p^{5}
$$

b) em função das coordenadas UTM

$$
\begin{aligned}
& q=0.000001 \times(E-500.000) \\
& C=(X V) \cdot q+(X V I) \cdot q^{3}+\left(F^{\prime} 5\right) \cdot q^{5}
\end{aligned}
$$




\subsection{5 - Redução Angular}

Pequenas correções devem ser aplicadas a cada ângulo geodésico de maneira a converte-lo em ângulo plano. O ângulo geodésico é dado pela linha geodésica (arco) unindo dois pontos na superfície de referência elipsoidal e sua projeção no sistema UTM também é uma linha curva que tem concavidade sempre voltada para o meridiano central (GRIPP \& SILVA, 1987), conforme a figura 5.19.

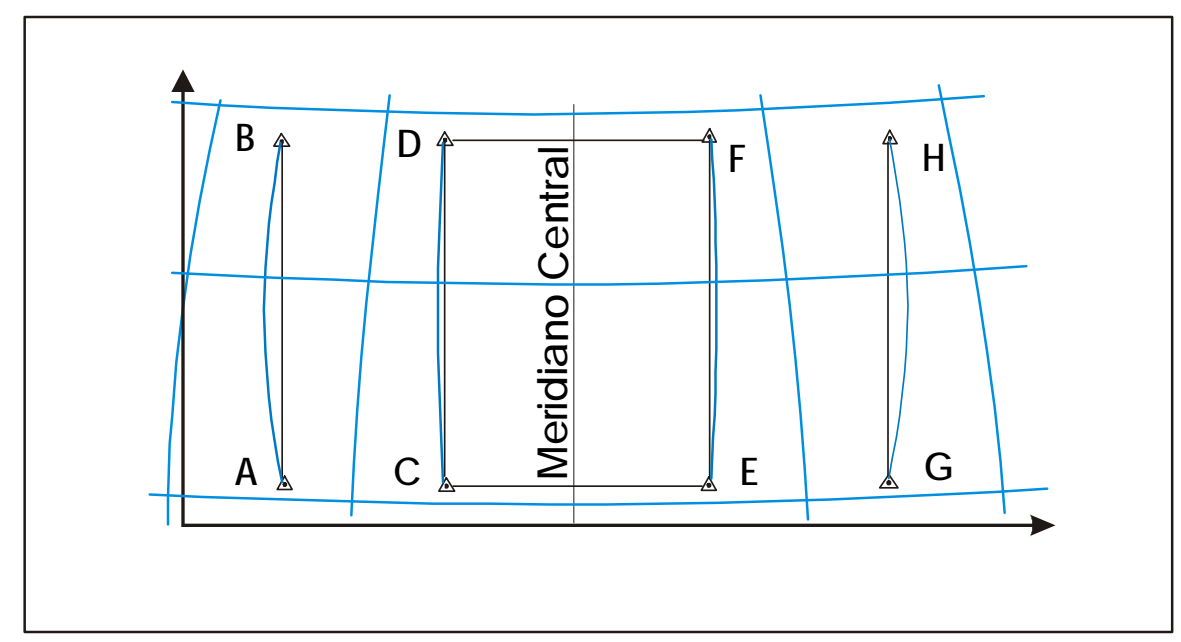

Figura 5.19: Curvatura das linhas geodésicas na projeção Transverso de Mercator. Adaptada de MOFFITT (1987).

O Ângulo formado pela tangente à curva e a corda é denominado ângulo de redução angular, e é representado pela letra $\delta$. Entretanto, para as dimensões dos trabalhos topográficos, segundo SILVA et al (1999), a curvatura dessa linha é muito pequena, e em muitos casos pode ser desconsiderada, aceitando a corda que une os dois pontos como a referencia para o cálculo da distância e o azimute entre eles.

As fórmulas para a obtenção do ângulo $\delta$ são obtidas a partir das coordenadas planas UTM considerando dois vértices $A$ e $B$, que segundo GRIPP \& SILVA (1987) são: 


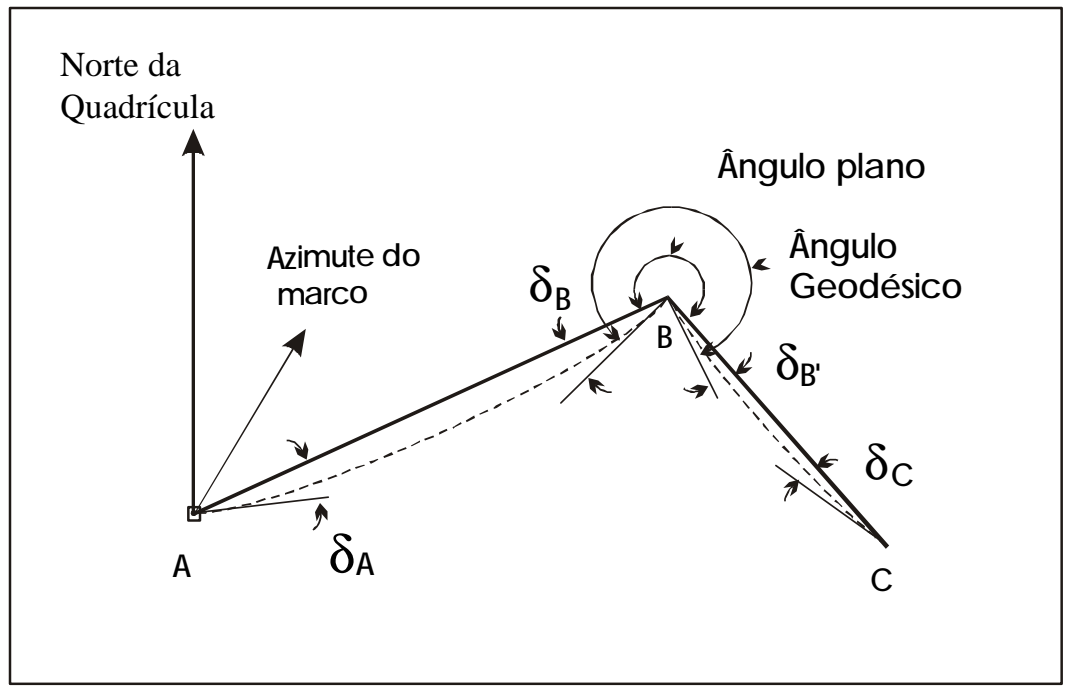

Figura 5.20: Redução de um ângulo dado pela linha curva à corda. Adaptada de MOFFITT (1987).

$$
\begin{gathered}
\delta_{A}{ }^{\prime \prime}=6,8755 \cdot 10^{-8} \cdot(X V I I I) \cdot\left(N_{B}-N_{A}\right) \cdot\left(2 E_{A}^{\prime}+E_{B}^{\prime}\right) \\
\delta_{B}{ }^{\prime \prime}=6,8755 \cdot 10^{-8} \cdot(X V I I I) \cdot\left(N_{A}-N_{B}\right) \cdot\left(2 E_{B}^{\prime}+E_{A}^{\prime}\right) \\
E_{A}^{\prime}=E_{A}-500.000 \\
E_{B}^{\prime}=E_{B}-500.000
\end{gathered}
$$

O cálculo acima indica o valor absoluto de $\delta$. Para conhecer o sinal de $\delta$ é conveniente analisar a situação de cada vértice, como mostra a Figura 5.20.

\subsection{6 - Cálculo do Fator de Escala}

a) a partir das coordenadas Geodésicas (LEICK , 1995)

$$
\begin{aligned}
k= & k_{0}\left[1+\frac{\lambda^{2}}{2} \cos ^{2} \phi_{p}\left(1+\eta^{2}\right)+\frac{\lambda^{4}}{24} \cos ^{4} \phi_{p}\left(5-4 \tan ^{2} \phi_{P}+14 \eta^{2}+13 \eta^{4}-28 \eta^{2} \tan ^{2} \phi_{P}\right.\right. \\
& \left.\left.+4 \eta^{6}-48 \eta^{4} \tan ^{2} \phi_{P}-24 \eta^{6} \tan ^{2} \phi_{P}\right)+\frac{\lambda^{6}}{720} \cos ^{6} \phi_{p}\left(61-148 \tan ^{2} \phi_{P}+16 \tan ^{4} \phi_{P}\right)\right]
\end{aligned}
$$




$$
\eta^{2}=\frac{e^{2}}{1-e^{2}} \cos \phi_{P}
$$

onde:

$k \quad$ fator de escala no ponto;

$k_{0} \quad$ fator de escala no meridiano central;

$\lambda_{P} \quad$ longitude do ponto;

$\phi_{P} \quad$ latitude do ponto.

b) a partir das coordenadas UTM

$$
k=k_{0} \cdot(1+(X V I I I)) \cdot q^{2}+0.00003 \cdot q^{4}
$$

De uma forma simplificada pode ser calculado através da seguinte expressão, segundo RICHARDUS apud GRIPP \& SIMÕES (1987):

$$
k=k_{0} \cdot\left(1+\frac{Y^{2}}{2 R_{0}{ }^{2}}\right) \quad R_{0}=\sqrt{M \cdot N}
$$

onde:

$Y \quad$ distância sobre a projeção (cilindro) do ponto $P$ ao meridiano central;

$M \quad$ raio de curvatura da seção meridiana no ponto $P$ de latitude geodésica;

$N \quad$ raio de curvatura da seção $1^{\text {a }}$ vertical no ponto $P$;

As formas aproximadas de obtenção do fator de escala para uma linha que não paralela ao meridiano central são apresentadas a seguir. Segundo MOFFITT (1986), para alinhamentos no sentido Leste-Oeste deve-se obter o fator de escala para os pontos finais e médio do alinhamento, e aplicar a equação abaixo, dada pela média ponderada:

$$
k_{L}=\frac{k_{P}+4 k_{m}+k_{Q}}{6}
$$


onde:

$k_{L}$ fator de escala para a redução da linha elipsoidal em distância plana;

$k_{A}$ fator de escala calculado para um dos pontos extremo do alinhamento $A$;

$k_{B}$ fator de escala calculado para um dos pontos extremo do alinhamento $B$;

$k_{m}$ fator de escala no ponto médio entre os pontos extremos do alinhamento

Segundo SILVA et al (1999) para alinhamentos inferiores a $15 \mathrm{~km}$, pode-se usar o fator de escala médio entre os pontos extremos, dados pela equação abaixo:

$$
k_{L}=\frac{k_{A}+k_{B}}{2}
$$

\section{9 - Transformação de Coordenadas Plano Local em UTM}

A transformação das coordenadas plano locais em UTM é realizada pelas seguintes fórmulas:

a) Cálculo da distância horizontal e o azimute a partir das coordenadas plano local dos pontos inicial e final do alinhamento

$$
\begin{aligned}
d h_{A B} & =\sqrt{\left(X_{B}-X_{A}\right)^{2}+\left(Y_{B}-Y_{A}\right)^{2}} \\
R_{A B} & =\operatorname{arctg}\left(\frac{X_{B}-X_{A}}{Y_{B}-Y_{A}}\right)
\end{aligned}
$$

Dado o rumo analisando o quadrante se determina o azimute

b) Transformar o azimute local em plano UTM

$$
\alpha_{A B}=A z_{A B}-C_{A}
$$


onde:

$A z_{A B}$ azimute do alinhamento em questão;

$C_{A} \quad$ convergência meridiana do ponto de partida

c) Transformar a distância horizontal em distância plana UTM.

$$
d_{A B}=d h_{A B} \cdot F C \cdot(1-\operatorname{Re} d)
$$

onde:

$d h_{A B}$ distância horizontal do alinhamento no plano local;

$d_{A B}$ distância plana UTM do referido alinhamento;

FC fator de escala para o alinhamento obtido pelas equações 5.92 ou 5.93, ou 5.94; dependendo da situação como descrito anteriormente;

Red redução ao nível do mar, equação 5.28, quando se reduzir distância horizontal em distância esférica.

Observação: pode-se também aplicar a redução da distância horizontal em distância elipsoidal evitando a aplicação do $\operatorname{Re} d$. 


\section{CAPÍTULO 6 - NIVELAMENTO}

\subsection{Introdução}

Nivelamento é um termo geral aplicado a algum tipo dos vários processos em que são determinadas as elevações dos pontos ou diferenças na elevação (alturas). Esta operação é de vital para a engenharia quando se fala em construção, produção de projetos, e mapeamento.

Alguns termos básicos são definidos a seguir, conforme ELFICK et al (1994), para melhor entendimento do processo. São eles de acordo com a Figura 6.1.

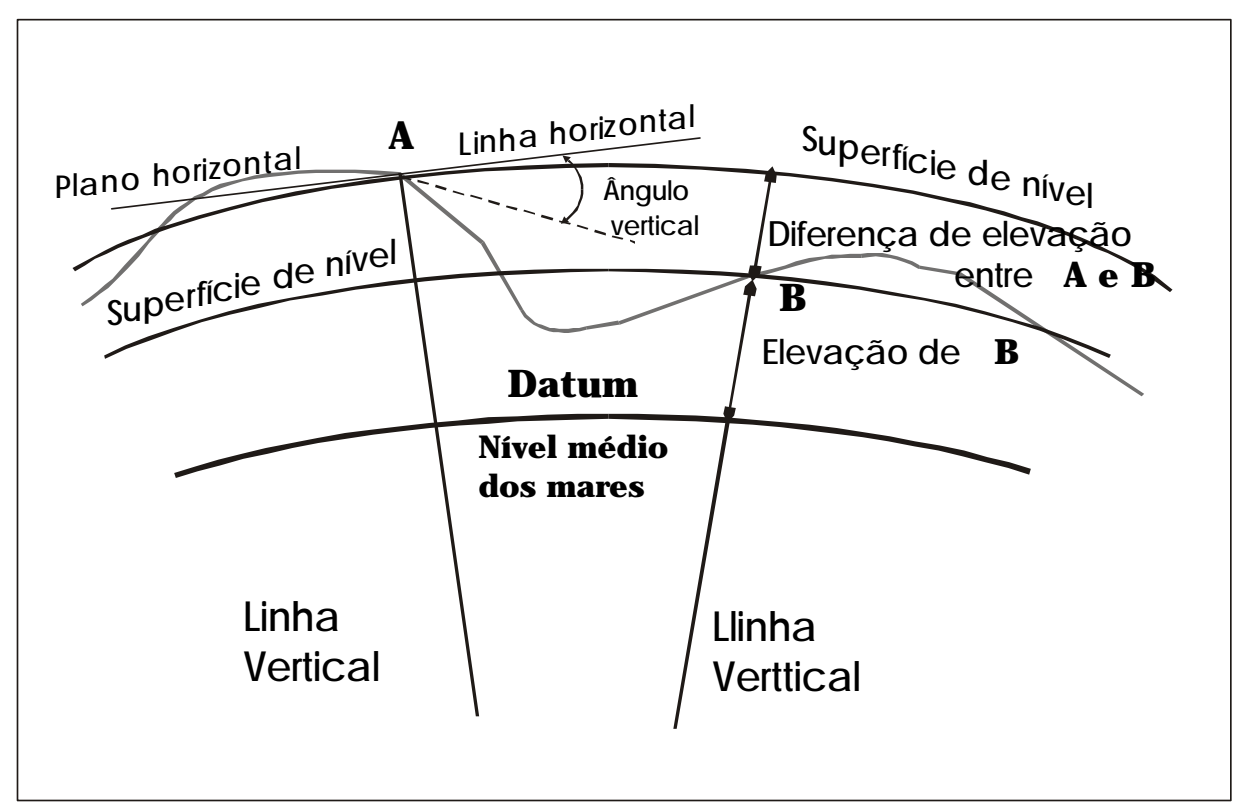

Figura 6.1: Elementos básicos do nivelamento. Adaptada de ELFICK et al (1994). 
$\diamond$ Linha vertical: linha que segue a direção da gravidade (linha de prumo).

$\checkmark$ Superfície de nível: superfície curva em que todos os pontos são perpendiculares a linha de prumo local. São aproximadamente elípticas. Para pequenas áreas, a superfície de nível é tratada como plana.

$\diamond \quad$ Linha de nível: uma linha na superfície de nível (linha curva).

$\diamond$ Plano horizontal: plano perpendicular à direção do vetor gravidade.

$\diamond$ Linha horizontal: linha no plano horizontal perpendicular ao vertical.

$\diamond$ Datum vertical: alguma superfície de nível em que as elevações são referidas (nível médio dos mares).

$\checkmark$ Nível Médio dos Mares (MSL): a altura média da superfície do mar para todos estágios da maré sobre um período de 19 anos.

$\diamond$ Convergência das superfícies de nível: um fenômeno devido ao achatamento da terra na direção polar de modo que as superfícies de nível em elevações diferentes não são paralelas. Esta condição requer uma correção ortométrica.

$\diamond \quad$ Elevação: a distância vertical do datum ao ponto.

\section{2 - Nivelamento Trigonométrico}

\subsection{1 - Introdução}

O método consiste em medidas do distância inclinada $\left(D^{\prime}\right)$ ou da distância horizontal $(D)$ juntamente com o ângulo vertical $(\alpha)$ ou zenital $(Z)$ com o uso de teodolito com um círculo vertical (Figura 6.2). 


\subsection{2 - O nivelamento trigonométrico no processo da poligonação eletrônica}

Pelas observações no campo obtém-se o ângulo vertical (ou ângulo zenital) de um lado da poligonal, duas vezes, pelas observações vante e ré (observações recíprocas).

Então, o desnível entre duas estações A e B calcula-se pelas fórmulas:

$$
\begin{aligned}
& \Delta h_{A}^{B}=i_{A}+\operatorname{ctg}\left(Z_{A}^{B}+\operatorname{corr}\right) \cdot D-s_{B} \\
& \Delta h_{B}^{A}=i_{B}+\operatorname{ctg}\left(Z_{B}^{A}+\operatorname{corr}\right) \cdot D-s_{A}
\end{aligned}
$$

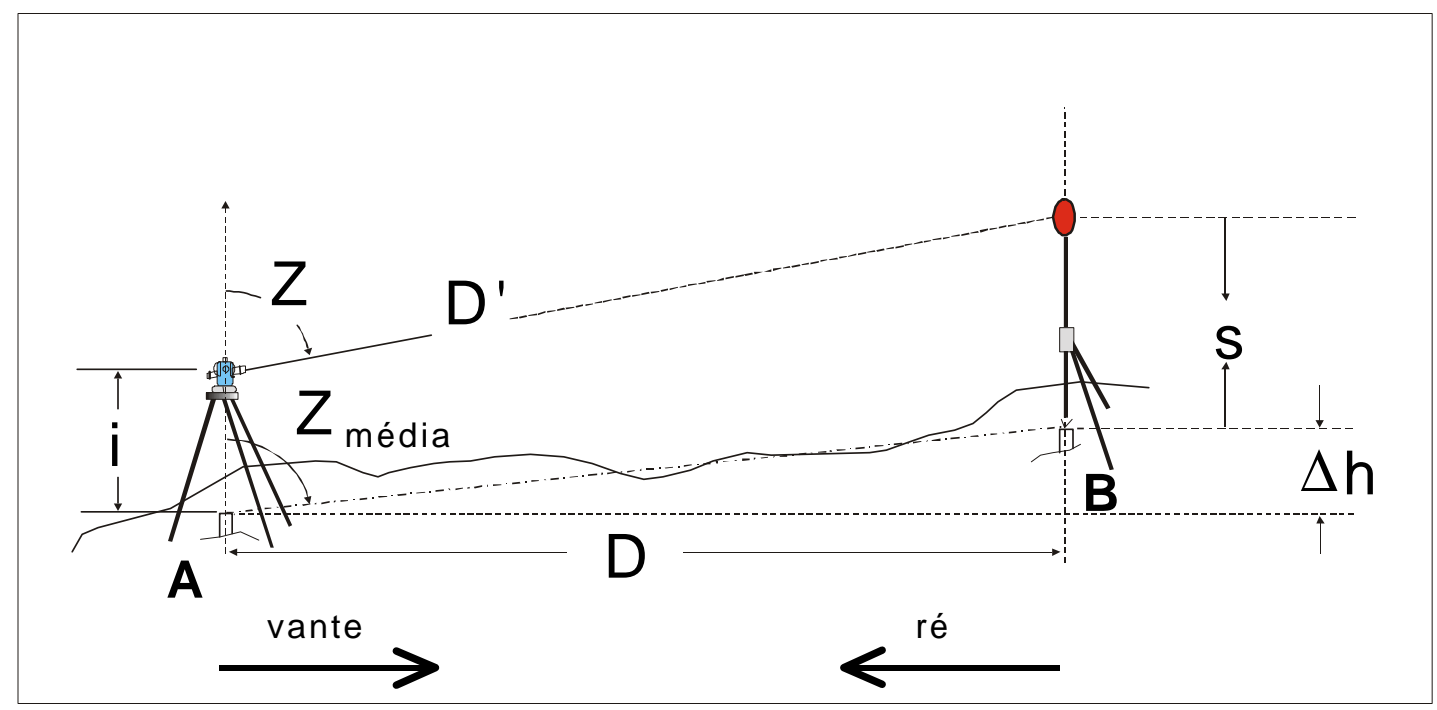

Figura 6.2: Elementos do nivelamento trigonométrico.

Onde:

$i_{A}$ e $i_{B}: \quad$ alturas dos instrumentos em A e B;

$s_{A}$ e $s_{B}: \quad$ alturas dos alvos em A e B;

$Z_{A}^{B}$ e $Z_{B}^{A}$ : ângulos zenitais em $\mathrm{A}$ e B;

D: distâncias horizontal;

corr: $\quad$ correção de esfericidade (Esf) e refração (Refr). 


\subsubsection{1 - Curvatura e refração}

O efeito de curvatura da terra é considerado como a diferença de altura entre as superfícies de nível passando pelo ponto $\mathbf{A}$, onde uma é tangente e a outra é curva conforme a superfície de curvatura da terra, estendida até o ponto $\mathbf{B}$ de visada (Figura 6.3). É um valor sempre positivo a ser corrigido na altura a determinar, segundo SHEFHERD (1981).

O raio de luz que parte de um ponto viaja através de camadas do ar com várias densidades óticas, e não se propaga em linha reta e sim em linha curva, com concavidade voltada para a terra. $O$ ângulo entre a linha curva e a tangente a ela no ponto de partida é chamada de refração terrestre. O coeficiente de refração $k$ depende da pressão e temperatura. Esta correção na altura é sempre negativa.

As demais correções devido ao uso de instrumentos são abordadas no capítulo 3 - Teodolitos.

A correção de esfericidade e de refração, conforme Figura 6.3, calcula-se pela fórmula a seguir:

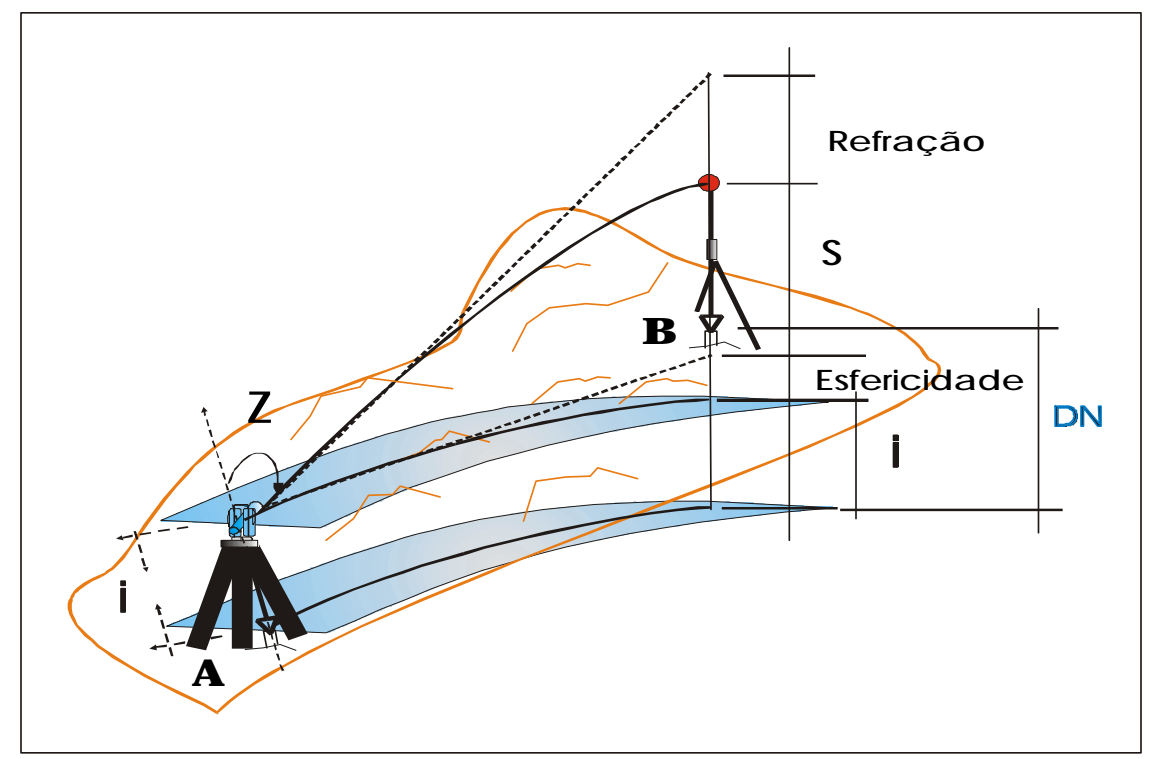

Figura 6.3: Representação da refração e esfericidade da terra no nivelamento trigonométrico. Adaptado de MUELLER \& RAMSAYER (1979). 


$$
(E s f+R e f)=[(1-k) / 2 r] \cdot D^{2} \times 10^{-12} \mathrm{em} \mathrm{m} .
$$

onde:

$k=0.13$, constante de refração média;

$r$ é o raio médio da Terra.

O processo de cálculo compara os dois ângulos verticais de um lado (vante e ré) centrados para os pontos no terreno, com a soma dos dois ângulos verticais, teoricamente, iguais a $180^{\circ}$. A diferença com $180^{\circ}$ indica imprecisões nas medições angulares ou de alturas de alvos e instrumentos, uma outra fonte de desvio de $180^{\circ}$ são as variações da refração ou do desvio vertical.

Então, o ângulo vertical de vante é corrigido pela metade da diferença com $180^{\circ}$.

Para os cálculos da centragem do ângulo zenital, utiliza-se a seguinte fórmula:

$$
\Delta Z=[i-s+(E s f .+R e f .)] \cdot \frac{206264,8}{D}
$$

O ângulo zenital para vante corrigido, calcula-se:

$$
Z_{\text {médio }}=\frac{1}{2}\left[\left(Z_{\text {vante }}-\Delta Z_{\text {vante }}\right)+\left(Z_{r e}-\Delta Z_{r e}\right)-180^{\circ}\right]+Z_{\text {vante }}
$$

\section{Exemplo:}

1) Na estação $\mathbf{A}=$ P1B foram medidos os seguintes valores:

Ângulo zenital $Z_{A}^{B}=90^{\circ} 12^{\prime} 31^{\prime}$,

Altura do instrumento $i_{A}=1,480 \mathrm{~m}$

Distância horizontal $D_{A}^{B}=230,452 \mathrm{~m}$

Altura do refletor $s_{B}=1,454 \mathrm{~m}$ 
2) $\mathrm{Na}$ estação $\mathbf{B}=\mathrm{P} 2 \mathrm{~B}$ foram medidos os seguintes valores:

Ângulo zenital $Z_{A}^{B}=89^{\circ} 47^{\prime} 54^{\prime}$,

Altura do instrumento $i_{B}=1,448 \mathrm{~m}$

Distância horizontal $D_{B}^{A}=D_{A}^{B}=230,452 \mathrm{~m}$

Altura do refletor $s_{A}=1,471 \mathrm{~m}$

3) A correção pela esfericidade e refração, calcula-se:

$$
(\text { Esf. }+ \text { Refr. })=68367 \cdot 10^{-12} \cdot 230,452^{2}=0,0036 \mathrm{~m} .
$$

4) Redução do ângulo zenital $Z_{A}$ na estação $\mathbf{A}$ ao ponto no chão:

$$
\begin{aligned}
\Delta Z_{A}= & {\left[i_{A}-s_{B}+(E s f .+\operatorname{Re} f r .)\right] \cdot \frac{\rho^{\prime \prime}}{D} } \\
= & (1,480-1,454+0,004) \cdot \frac{206264,8}{230,452} \\
& \Delta Z_{A}=26,8^{\prime \prime}
\end{aligned}
$$

Ângulo zenital corrigido $Z_{A}^{x}$ :

$$
\begin{gathered}
Z_{A}^{x}=Z_{A}-\Delta Z_{A} \\
=90^{\circ} 12^{\prime} 31,0^{\prime \prime}-26,8^{\prime}, \\
Z_{A}^{x}=90^{\circ} 12^{\prime} 04,2^{\prime},\left(Z_{\text {vante }}^{x}\right)
\end{gathered}
$$

5) Redução do ângulo zenital $Z_{B}$ na estação $\mathrm{B}$ ao ponto no terreno:

$$
\Delta Z_{B}=\left[i_{B}-s_{A}+(E s f .+\operatorname{Re} f r .)\right] \cdot \frac{\rho "}{D}
$$




$$
\begin{aligned}
= & (1,448-1,471+0,004) \cdot \frac{206264,8}{230,452} \\
& \Delta Z_{A}=-17,0 "
\end{aligned}
$$

Ângulo zenital corrigido $Z_{B}^{x}$ :

$$
\begin{aligned}
Z_{B}^{x} & =Z_{B}-\Delta Z_{B} \\
& =89^{\circ} 47^{\prime} 54,0^{\prime},+17,0^{\prime}, \\
Z_{B}^{x} & =89^{\circ} 48^{\prime} 11,0^{\prime},\left(Z_{r e}^{x}\right)
\end{aligned}
$$

6) Cálculo do ângulo zenital média para vante na estação A:

$$
\begin{gathered}
Z_{\text {média }}^{x}=-\frac{1}{2}\left(Z_{\text {vante }}^{x}+Z_{r e}^{x}-180^{\circ}\right)+Z_{\text {vante }}^{x} \\
\text { corr }=\frac{1}{2} \cdot\left(90^{\circ} 12^{\prime} 04,2^{\prime},+89^{\circ} 48^{\prime} 11,0^{\prime},-180^{\circ}\right)=-\frac{1}{2} \cdot 15,2^{\prime \prime} \\
Z_{\text {média }}^{x}=-7,6^{\prime},+90^{\circ} 12^{\prime} 04,2^{\prime}, \\
Z_{\text {média }}^{x}=90^{\circ} 11^{\prime} 56,6^{\prime},
\end{gathered}
$$

7) Cálculo do desnível $\Delta h$

$$
\begin{gathered}
\Delta h=D \cdot \operatorname{ctg}\left(Z_{\text {média }}^{x}\right)=230,452 \cdot \operatorname{ctg} 90^{\circ} 11^{\prime} 56,6^{\prime \prime} \\
=230,452 \cdot(-0,003474) \\
\Delta h=-0,801 \mathrm{~m}
\end{gathered}
$$

8) Ajuste das altitudes da poligonal calculada pelo processo de nivelamento trigonométrico:

A soma dos desníveis da poligonal deve ser igual $d$ diferença das altitudes de partida e de chegada. 


$$
\begin{aligned}
{[\Delta h]=H_{c} } & -H_{p} \\
H_{c} & =\text { altitude do ponto de chegada } \\
H_{p} & =\text { altitude do ponto de partida }
\end{aligned}
$$

então, o erro de fechamento do nivelamento trigonométrico é dado por:

$$
d_{H}=\left(H_{c}-H_{p}\right)-[\Delta h]
$$

Este erro $d_{H}$ pode ser distribuído em função das distâncias.

No presente trabalho, leva-se em conta toda a metodologia apresentada e será apresentado no capítulo 8 uma análise mais apurada e discussão dos resultados obtidos. 


\section{CAPÍTULO 7 - AJUSTAMENTO}

\section{1 - Introdução}

As observações realizadas pelo homem se caracterizam pela inevitável presença de erros nas medições. Erros que decorrem de falha humana; da imperfeição do equipamento e da influência das condições ambientais nas quais se efetua a mensuração.

Claramente se vê a necessidade da repetição nas leituras das observações face a desconfiança nas operações de medidas pela falibilidade humana e pelo uso da capacidade do dispositivo de medir. A partir da pluralidade de observações nos deparamos com dados redundantes e inexatos, com a incapacidade em determinar o valor verdadeiro das grandezas. Entretanto, tem-se que empenhar em dissolver as discrepâncias geométricas ocorrentes nas observações a extrair um resultado único que represente o valor mais próximo possível do valor verdadeiro e uma maior confiança desta grandeza medida.

O ajustamento de observações está presente na solução deste problema efetuando a avaliação desse valor e das estimativas de precisão da solução adotada e a correlação entre elas. É um meio indispensável para profissionais da área de Mensuração realizarem resultados confiáveis sobre as medições básicas obtidas no levantamento. Quanto melhor as precisões requeridas em medições, mais indispensável se torna o ajustamento.

O ajustamento pode ser aplicado em observações diretas onde a medida é realizada sobre a mesma por repetição ou em equações de condição que ligam as incógnitas, ou através de relações funcionais que vinculam a grandeza com a incógnita. 
Em quaisquer casos, o que se busca é o ajustamento das observações juntamente com seus parâmetros a um modelo matemático.

Podem surgir dificuldades quando se resolve ponderar as observações atribuindo mais peso àquelas de maior confiança, no caso em que se conhece as precisões com que as medições são efetuadas.

Na prática, o método de C.F. GAUSS (1777 - 1855) estabelecido nas bases da teoria da probabilidade é geralmente usado, e é chamado Método dos Mínimos Quadrados (MMQ). O método dos mínimos quadrados, segundo HAZAY (1970), foi primeiro publicado por A.M. LEGENDRE (1752 - 1833) em 1806. Sendo que este foi usado por GAUSS em 1794, embora seu método não tenha sido publicado até 1809. Até 1826 o método foi desenvolvido e tratado em seis publicações.

\section{2 - Classificação dos Erros de Observação}

Os erros de observações podem ser divididos em várias categorias de acordo com suas formas. Erros de várias formas afetam diferentemente as observações, e assim temse que seguir diferentes meios para considerar seus efeitos e deve-se empenhar em reduzi-los.

Os erros podem ser divididos em erros grosseiros; erros sistemáticos; erros acidentais. CAMIL (1994) apresenta uma descrição mais apurada e detalhada a respeito destes tipos de erros.

\section{3 - Critérios de Confiança}

Séries de medições com pequeno número de erros grandes e dentro dos limites mais restritos provam ser mais confiáveis.

LAPLACE introduziu o erro médio como um critério de confiança. Este é a média aritmética do valor absoluto dos erros: 


$$
v=\frac{\left[\left|\varepsilon_{i}\right|\right]}{n}
$$

onde:

$n$ é o número de medições inclusas numa série;

$\varepsilon_{i}$ representa o erro verdadeiro pertencentes as medidas individuais da série

[ ] Gauss usou colchetes para designar o somatório de uma dada grandeza.

O então erro médio quadrado foi introduzido por GAUSS e este é geralmente usado na Mensuração. O erro médio quadrado é igual a raiz quadrada da média quadrada dos erros verdadeiros:

$$
\mu=\sqrt{\frac{\varepsilon_{i} \varepsilon_{i}}{n}}
$$

onde:

$n$ é o número de medidas inclusas na série de medidas;

$\varepsilon_{i}$ representa o erro verdadeiro pertencente as medidas da série;

$\mu$ o erro médio quadrado caracterizando cada medida da série (erro médio quadrado de uma simples observação).

Também o duplo sinal \pm , surgido de uma extração de raiz quadrada, chama nossa atenção ao fato de que este critério tem efeito não corretivo.O erro médio quadrado é muito mais sensível que o erro médio.

\section{4 - O Princípio do Ajustamento Baseado no Princípio dos Erros}

\subsection{1 - O Método dos Mínimos Quadrados (M.M.Q.)}

A partir da condição de que os erros acidentais mudam as observações e obedecem a lei de erros, a demonstração da equação fundamental para o Método dos 
Mínimos Quadrados (M.M.Q.) é baseado na concepção que o valor mais provável das medidas de igual confiança é o valor da média aritmética das observações.

O valor médio aritmético não pode ser, é claro, considerado como o valor verdadeiro das quantidades procuradas, e assim nenhuma das diferenças resultante desta comparação com as medidas são os erros verdadeiros, mas sim os resíduos prováveis ou somente resíduos, designados por $v$.

Se medidas de iguais confiança são feitas para determinar a mesma quantidade, então a média aritmética é o valor mais provável $(x)$ de acordo ao princípio básico do Método dos Mínimos Quadrados (M.M.Q.). Assim, tem-se:

$$
x=\frac{[L]}{n}
$$

Ou na forma matricial

$$
x=\frac{e^{T} L e}{n}
$$

onde :

$L$ vetor das observações;

$n$ número de observações na série;

$e$ vetor unitário;

$x$ média aritmética.

Permita o valor verdadeiro da quantidade a ser determinada por $X$, e o valor mais provável $x$. As observações são:

$$
\begin{gathered}
L_{1}, L_{2}, \ldots ., L_{n} . \\
\varepsilon_{i}=X-L_{i} \\
v_{i}=x-L_{i} .
\end{gathered}
$$


O erro padrão médio verdadeiro e o erro padrão médio empírico, segundo KAHMEN (1988), são respectivamente:

$$
\begin{array}{ll}
\sigma= \pm \sqrt{\frac{\varepsilon^{T} \varepsilon}{n}} & s=\sqrt{\frac{V^{T} V}{n-1}} \\
n \rightarrow \infty & n<\infty
\end{array}
$$

Segundo CAMIL (1994), há quase dois séculos o geodesista fez sua opção, seguindo o caminho indicado por GAUSS e LEGENDRE: aceitar como melhor estimativa de $\mathrm{X}$ (valor verdadeiro) o valor que torna mínima a soma dos quadrados dos resíduos:

$$
\begin{aligned}
& x-l_{1}=v_{1} \\
& x-l_{2}=v_{2} \\
& \ldots \ldots \ldots \ldots . . \\
& x-l_{n}=v_{n} \\
& \sum_{i=1}^{n} v_{i}^{2}=\min
\end{aligned}
$$

Quando as observações não oferecem o mesmo grau de confiança são "homogeneizadas" através de pesos p:

$$
\sum_{i=1}^{n} p_{i} v_{i}^{2}=\min
$$

A notação original de GAUSS, é utilizada na forma abaixo:

$$
[v v]=\min ; \quad[p v v]=\min
$$

o colchete indica somatório, com variação subtendida de 1 a $n$, e sem utilizar expoentes. Modernamente prefere-se a linguagem matricial: 


$$
V^{T} V=\min
$$

sendo $V$ o vetor coluna dos resíduos:

$$
V=\left[\begin{array}{llll}
v_{1} & v_{2} & \ldots & v_{n}
\end{array}\right]^{T}
$$

ou no caso geral:

$$
V^{T} P V=\min
$$

sendo $P$ uma matriz quadrada da forma a seguir:

$$
P=\left[\begin{array}{cccc}
p_{1} & 0 & \ldots & 0 \\
0 & p_{2} & \ldots & 0 \\
\ldots & \ldots & \ldots & \ldots \\
0 & 0 & \ldots & p_{n}
\end{array}\right]
$$

Na teoria clássica a matriz pesos $P$ seria forçosamente diagonal; segundo na nulidade dos elementos não pertencentes à diagonal principal.

A concisão da linguagem matricial e o uso de computadores que tornou sentido da generalização do ajustamento de observações pelo M.M.Q.

\section{5 - A Propagação dos Erros}

Se um valor é obtido, em um relacionamento matemático, através de valores carregados de erros, este também será carregado com um erro. 
O conceito de propagação de erros implica, segundo HAZAY (1970), que os erros dos vários fatores expande sobre a quantidade a ser determinada, e este princípio expressa a maneira de propagação. Com o conhecimento dos erros médios quadrados dos valores determinados, a expressão da propagação de erros dá a confiança do valor determinado.

\subsection{2 - Propagação dos Erros para Observações não Correlacionadas}

Será desenvolvida a fórmula da propagação dos erros, para observações não correlacionadas, na determinação do valor esperado. Seja a função com várias variáveis:

$$
y=f\left(x_{1}, x_{2}, \ldots, x_{n}\right)
$$

para cada dos valores, várias quantidades de medidas foram realizadas. As observações são:

$$
\begin{aligned}
& \text { para } \quad x_{1}: x_{11}, x_{21}, \ldots, x_{n 1} \\
& x_{2}: x_{12}, x_{22}, \ldots, x_{n 2} \\
& \ldots \ldots \ldots \ldots \ldots \ldots \ldots \ldots \ldots \ldots \ldots \ldots \ldots \ldots \ldots \ldots \\
& x_{n}: x_{1 n}, x_{2 n}, \ldots, x_{n n}
\end{aligned}
$$

se cada uma das medidas são substituídas uma a uma na função, então valores diferentes serão obtidos para o valor de $y$, denotado por $y_{1}, y_{2}, \ldots, y_{n}$ :

$$
\begin{array}{lllllllll}
y_{1} & f & x_{11} & x_{12} & y_{2} & f & x_{21} & x_{22} & y_{n}=f\left(x_{n 1}, x_{n 2}, \ldots, x_{n n}\right)
\end{array}
$$

Caso a função não seja linear, esta deve ser linearizada. A linearização, segundo MIKAIL \& GRACIE (1981), é uma dedução matemática para eliminar a aproximação dos resultados de uma função não-linear, permitindo considerá-la linear em trechos por 
meio de derivadas. A base de linearização de uma função é a expansão em série por Taylor:

$$
\begin{gathered}
y_{1}+\varepsilon_{Y 1}=f\left(x_{11}, x_{12}, \ldots, x_{1 n}\right)+\frac{\partial f}{\partial x_{1}} \varepsilon_{x 1}+\frac{\partial f}{\partial x_{2}} \varepsilon_{x 2}+\ldots+\frac{\partial f}{\partial x_{n}} \varepsilon_{x n} \\
y_{2}+\varepsilon_{Y 2}=f\left(x_{21}, x_{22}, \ldots, x_{2 n}\right)+\frac{\partial f}{\partial x_{1}} \varepsilon_{x 1}+\frac{\partial f}{\partial x_{2}} \varepsilon_{x 2}+\ldots+\frac{\partial f}{\partial x_{n}} \varepsilon_{x n} \\
y_{m}+\varepsilon_{Y m}=f\left(x_{m 1}, x_{m 2}, \ldots, x_{m n}\right)+\frac{\partial f_{m}}{\partial x_{1}} \varepsilon_{x 1}+\frac{\partial f_{m}}{\partial x_{2}} \varepsilon_{x 2}+\ldots+\frac{\partial f_{m}}{\partial x_{n}} \varepsilon_{x n}
\end{gathered}
$$

na forma matricial:

$$
y=y_{0}+a^{T} x
$$

introduzindo valores verdadeiros, temos:

$$
\left[\begin{array}{c}
y_{1}+\varepsilon_{Y 1} \\
y_{2}+\varepsilon_{Y 2} \\
\ldots \\
y_{m}+\varepsilon_{Y m}
\end{array}\right]=\left[\begin{array}{c}
y_{1} \\
y_{2} \\
\cdots \\
y_{m}
\end{array}\right]+\left[\begin{array}{cccc}
\frac{\partial f_{1}}{\partial x_{1}} & \frac{\partial f_{1}}{\partial x_{2}} & \cdots & \frac{\partial f_{1}}{\partial x_{n}} \\
\frac{\partial f_{2}}{\partial x_{1}} & \frac{\partial f_{2}}{\partial x_{2}} & \cdots & \frac{\partial f_{2}}{\partial x_{n}} \\
\frac{\partial f_{m}}{\partial x_{1}} & \frac{\partial f_{m}}{\partial x_{2}} & \cdots & \frac{\partial f_{m}}{\partial x_{n}}
\end{array}\right] *\left[\begin{array}{c}
\varepsilon_{x 1} \\
\varepsilon_{x 2} \\
\ldots \\
\varepsilon_{x n}
\end{array}\right]
$$

Eliminando os termos da direita e da esquerda, elevando ao quadrado e somando, temos:

$$
\begin{aligned}
{\left[\varepsilon_{Y} \varepsilon_{Y}\right]=} & \left(\frac{\partial f}{\partial x_{1}}\right)^{2}\left[\varepsilon_{x 1} \varepsilon_{x 1}\right]+\left(\frac{\partial f}{\partial x_{2}}\right)^{2}\left[\varepsilon_{x 2} \varepsilon_{x 2}\right]+\ldots+\left(\frac{\partial f}{\partial x_{n}}\right)^{2}\left[\varepsilon_{x n} \varepsilon_{x n}\right]+2 \frac{\partial f}{\partial x_{1}} \frac{\partial f}{\partial x_{2}}\left[\varepsilon_{x 1} \varepsilon_{x 2}\right]+\ldots \\
& +2 \frac{\partial f}{\partial x_{1}} \frac{\partial f}{\partial x_{n}}\left[\varepsilon_{x 1} \varepsilon_{x n}\right]+\ldots+2 \frac{\partial f}{\partial x_{2}} \frac{\partial f}{\partial x_{3}}\left[\varepsilon_{x 2} \varepsilon_{x 3}\right]+\ldots+2 \frac{\partial f}{\partial x_{2}} \frac{\partial f}{\partial x_{n}}\left[\varepsilon_{x 2} \varepsilon_{x n}\right]+\ldots
\end{aligned}
$$




$$
+2 \frac{\partial f}{\partial x_{n-1}} \frac{\partial f}{\partial x_{n}}\left[\varepsilon_{x n-1} \varepsilon_{x n}\right]
$$

matricialmente:

$$
\begin{aligned}
& \varepsilon_{y}{ }^{T} \varepsilon_{y}=\left[\begin{array}{llll}
y_{1} & y_{2} & \ldots & y_{m}
\end{array}\right] *\left[\begin{array}{c}
y_{1} \\
y_{2} \\
\ldots \\
y_{m}
\end{array}\right] \\
& y_{1}=\frac{\partial f}{\partial x_{1}} \varepsilon_{x 11}+\frac{\partial f}{\partial x_{2}} \varepsilon_{x 12}+\ldots+\frac{\partial f_{m}}{\partial x_{n}} \varepsilon_{x 1 n} \\
& y_{2}=\frac{\partial f}{\partial x_{1}} \varepsilon_{x 21}+\frac{\partial f}{\partial x_{2}} \varepsilon_{x 22}+\ldots+\frac{\partial f_{m}}{\partial x_{n}} \varepsilon_{x 2 n} \\
& y_{m}=\frac{\partial f}{\partial x_{1}} \varepsilon_{x m 1}+\frac{\partial f}{\partial x_{2}} \varepsilon_{x m 2}+\ldots+\frac{\partial f_{m}}{\partial x_{n}} \varepsilon_{x m n}
\end{aligned}
$$

Dividindo a equação por $n$ (número das observações), e fazendo a consideração que:

$$
\begin{aligned}
& \frac{\left[\varepsilon_{y} \varepsilon_{y}\right\rfloor}{n}=s_{y}{ }^{2}, \frac{\left[\varepsilon_{x 1} \varepsilon_{x 1}\right]}{n}=s_{x 1}{ }^{2}, \frac{\left[\varepsilon_{x 2} \varepsilon_{x 2}\right]}{n}=s_{x 2}{ }^{2}, \ldots, \frac{\left[\varepsilon_{x n} \varepsilon_{x n}\right]^{2}}{n}=s_{x n}{ }^{2}, \frac{\left[\varepsilon_{x 1} \varepsilon_{x 2}\right]}{n}=s_{x 1 x 2}, \ldots \\
& \frac{\left[\varepsilon_{x n-1} \varepsilon_{x n}\right]}{n}=s_{x n-1 x n} \\
& s_{y}{ }^{2}=\left(\frac{\partial f}{\partial x_{1}}\right)^{2} s_{x 1}{ }^{2}+\left(\frac{\partial f}{\partial x_{2}}\right)^{2} s_{x 2}{ }^{2}+\ldots+\left(\frac{\partial f}{\partial x_{n}}\right)^{2} s_{x n}{ }^{2}+2 \frac{\partial f}{\partial x_{1}} \frac{\partial f}{\partial x_{2}} s_{x 1 x 2}+\ldots+2 \frac{\partial f}{\partial x_{1}} \frac{\partial f}{\partial x_{n}} s_{x 1 x n}+ \\
& \ldots+2 \frac{\partial f}{\partial x_{2}} \frac{\partial f}{\partial x_{3}} s_{x 2 x 3}+\ldots+2 \frac{\partial f}{\partial x_{2}} \frac{\partial f}{\partial x_{n}} s_{x 2 x n}+\ldots+2 \frac{\partial f}{\partial x_{n-1}} \frac{\partial f}{\partial x_{n}} s_{x n-1 x n}
\end{aligned}
$$

na forma matricial: 


$$
s_{y}{ }^{2}=\left[\begin{array}{llll}
\frac{\partial f_{1}}{\partial x_{1}} & \frac{\partial f_{2}}{\partial x_{2}} & \ldots & \frac{\partial f_{m}}{\partial x_{n}}
\end{array}\right] *\left[\begin{array}{cccc}
s_{x 1}{ }^{2} & s_{x 1 x 2} & \ldots & s_{x 1 x n} \\
s_{x 1 \times 2} & s_{x 2}^{2} & \ldots & s_{x 2 x n} \\
\ldots & \ldots & \ldots & \ldots \\
s_{x 1 \times n} & s_{x 2 x n} & \ldots & s_{x n}^{2}
\end{array}\right] *\left[\begin{array}{c}
\frac{\partial f_{1}}{\partial x_{1}} \\
\frac{\partial f_{2}}{\partial x_{2}} \\
\ldots \\
\frac{\partial f_{m}}{\partial x_{n}}
\end{array}\right]
$$

Para funções lineares e observações não correlacionadas, seguindo o raciocínio anterior, e sendo a função como a seguir, temos:

$$
y=a x_{1}+b x_{2}+\ldots+z x_{n}
$$

então:

$$
s_{y}{ }^{2}=a^{2} s_{x 1}{ }^{2}+b^{2} s_{x 2}{ }^{2}+\ldots+z^{2} s_{x n}{ }^{2}
$$

na formam matricial:

$$
s_{y}{ }^{2}=\left[\begin{array}{llll}
a & b & \ldots & z
\end{array}\right] *\left[\begin{array}{cccc}
s_{x 1}^{2} & 0 & \ldots & 0 \\
0 & s_{x 2}{ }^{2} & \ldots & 0 \\
\ldots & \ldots & \ldots & \ldots \\
0 & 0 & \ldots & s_{x n}{ }^{2}
\end{array}\right] *\left[\begin{array}{c}
a \\
b \\
\ldots \\
z
\end{array}\right]
$$

\section{6 - Pesos das Observações}

Segundo MIKAIL (1981), uma medida de alta precisão tem uma pequena variância porque repetidos valores se agrupariam proximamente, assim refletindo um alto grau de cuidados no procedimento e refinamento do instrumento. Ao contrário uma medição de baixa precisão tem uma larga variância. 
O erro médio quadrado é inversamente proporcional à confiança no cálculo prático, e tem sido comum introduzir tal critério que é uma taxa direta para a confiança. Este critério de confiança é o peso que é dado por:

$$
p=\frac{\mu_{0}{ }^{2}}{\mu^{2}}
$$

onde:

$\mu_{0} \quad$ é sempre um número positivo sem alguma dimensão chamado precisão a priori, segundo CAMIL (1994) e HAZAY (1970);

$\mu \quad$ é a precisão da observação.

O peso, portanto, é um valor positivo da mesma forma como o valor do quadrado do erro médio quadrado, e se o erro médio quadrado é dado em mm, então a dimensão do peso é $\mathrm{mm}^{-2}$, segundo HAZAY (1970).

Se o peso é igual a unidade, então:

$$
\text { valor numérico } \mu_{0}=\text { valor numérico } \mu
$$

neste caso $\mu_{0}$ é chamado de erro médio quadrado da unidade de peso $(p=1)$.

A diferença entre o erro médio quadrado da unidade de peso e do valor da unidade de peso consiste no fato que o erro médio quadrado da unidade de peso é um número adimensional; enquanto que do valor de unidade de peso é dimensional.

Se o erro médio quadrado da unidade de peso é conhecido, então os erros das demais observações desta série de medidas, de pesos conhecidos, podem ser calculados com base na seguinte fórmula:

$$
\mu_{i}=\frac{\mu_{0}}{\sqrt{p_{i}}}
$$

Dado o fato que o erro médio quadrado da unidade de peso é não dimensional e que do peso é dimensional, faz possível introduzir medidas de vários tipos na 
determinação do ajustamento de um ou mais valores desconhecidos (medidas de ângulos e distâncias); e determinar o erro médio quadrado para todas observações juntas.

De acordo com a definição de peso e a equação 7.33, a seguinte taxa é válida para o erro médio quadrado e o peso de duas quantidades arbitrárias conectadas com a série de medidas:

$$
p_{i}: p_{k}=\frac{1}{\mu_{i}{ }^{2}}: \frac{1}{\mu_{k}{ }^{2}}=\mu_{k}{ }^{2}: \mu_{i}{ }^{2}
$$

O efeito das observações no valor das medidas a ser determinadas por ajustamento é grandemente influenciadas pela proporção dos pesos das observações, dada pela taxa dos pesos. Na verdade, é a taxa dos pesos que tem importância no ajustamento e não seu valor numérico. Consequentemente, a quantidade a ser considerada como unidade de peso no ajustamento pode ser escolhida entre os pesos das observações sem nenhuma restrição.

\section{7 - Covariância e Cofator}

Covariância é basicamente um relacionamento somente entre duas variáveis aleatórias. Se três ou mais variáveis aleatórias são distribuídas conjuntamente, pode-se considerar as covariâncias para todos os pares. Assim, para três variáveis aleatórias, $X$, $Y$ e $Z$, refere-se especialmente a três covariâncias: $\sigma_{x y}$ para $X$ e $Y ; \sigma_{x z}$ para $X$ e $Z$;

$\sigma_{y z}$ para $Y$ e $Z$

Em aplicações práticas de ajustamento, segundo MIKAIL (1976), as variâncias e covariâncias são freqüentemente substituídas pelo que seria chamado de variâncias e covarâncias relativas. Para isto os termos "coeficiente de peso" ou "cofatores" são de uso comum. O termo "cofator", e as letras $q$ para um elemento e $Q$ para uma matriz, serão selecionados e serão usados como símbolos para designar este relacionamento.

Um cofator é relacionado a uma covariância por: 


$$
q_{i j}=\frac{\sigma_{i j}}{\sigma_{0}{ }^{2}} \quad \text { ou } \quad \sigma_{i j}=q_{i j} \sigma_{0}{ }^{2}
$$

A definição anterior inclui como um caso especial a relação entre cofator e a variância:

$$
q_{i i}=\frac{\sigma_{i}{ }^{2}}{\sigma_{0}{ }^{2}} \quad \text { ou } \quad \sigma_{i}{ }^{2}=q_{i i} \sigma_{0}{ }^{2}
$$

Pelo fato da simetria da matriz de covariância, a matriz dos cofatores também é uma matriz simétrica para este caso. Esta deve também ter somente elementos positivos na diagonal.

Para o caso de não correlação a matriz das covariâncias e dos cofatores, será diagonal, com todos os elementos fora da diagonal sendo igual a zero. Neste caso os elementos da diagonal podem ser representados pela equação abaixo:

$$
q_{i i}=\frac{1}{p_{i i}}
$$

Portanto, quando se tiver correlação deve-se usar a matriz de cofatores para a propagação dos erros, caso contrário pode-se tanto usar a matriz dos pesos como a matriz dos cofatores.

\section{8 - Métodos de Ajustamento}

\subsection{1 - Ajustamento de Observações Diretas}

\subsubsection{1 - Ajustamento de Observações de Igual Confiança}

Medida é dita ser direta, se o valor a ser determinado é medido diretamente sobre a grandeza procurada, isto é, se deseja conhecer a distância entre dois pontos procede-se a medida do comprimento com um diastímetro. As medidas seriam repetidas várias 
vezes, assim diferentes resultados seriam obtidos devido aos inevitáveis erros acidentais das medidas.

Se todas medidas são de igual confiança, de acordo com o princípio do Método dos Mínimos Quadrados o provável valor é a média aritmética das observações e o somatório dos resíduos ao quadrado é mínimo. Sejam as observações:

$$
\begin{aligned}
& l_{1}, l_{2}, \ldots, l_{n} \\
& \tilde{x}=\frac{1}{n} A^{T} L
\end{aligned}
$$

onde :

$\tilde{x} \quad$ é a média aritmética das observações;

$n \quad$ é o número de observações;

$A^{T} \quad$ é um vetor coluna dos termos unitários;

$L \quad$ é o vetor $n \times 1$ das observações.

Será denominado $\tilde{x}$ o valor mais provável do valor a ser determinado e $v$ os resíduos das observações, assim tem-se:

$$
\begin{gathered}
v_{1}=\tilde{x}-l_{1} \\
v_{2}=\tilde{x}-l_{2} \\
\ldots \ldots \ldots \ldots \ldots \\
v_{n}=\tilde{x}-l_{n}
\end{gathered}
$$

matricialmente:

$$
V=A X-L
$$




$$
\left[\begin{array}{c}
v_{1} \\
v_{2} \\
\cdots \\
v_{n}
\end{array}\right]=\left[\begin{array}{c}
\tilde{x} \\
\tilde{x} \\
\cdots \\
\tilde{x}
\end{array}\right]-\left[\begin{array}{l}
l_{1} \\
l_{2} \\
\ldots \\
l_{n}
\end{array}\right]
$$

controle:

$$
A^{T} V=0
$$

Segundo CAMIL (1994) a estimativa de precisão à posteriori é:

$$
s_{0}=\sqrt{\frac{V^{T} V}{n-1}}
$$

E a precisão das observações é:

$$
s_{i}=\frac{s_{0}}{\sqrt{p_{i}}}
$$

Como neste caso todas as observações tem o mesmo grau de confiança, então:

$$
s_{i}=\frac{s_{0}}{\sqrt{1}}=s_{0}
$$

é a precisão de cada observação;

$$
s_{\tilde{x}}=\frac{s_{0}}{n}=\sqrt{\frac{V^{T} V}{n(n-1)}}
$$

é a precisão do valor ajustado. 


\subsubsection{2 - Ajustamento de Observações de Diferentes Confianças}

Se medidas de diferentes confiança foram produzidas para determinar uma grandeza, então tem-se que fazer mínima a função $V^{T} V$. Sendo as medidas na determinação da grandeza igual a:

$$
l_{1}, l_{2}, \ldots, l_{n}
$$

E seus pesos são:

$$
p_{1}, p_{2}, \ldots, p_{n}
$$

Segundo CAMIL (1994), sendo $\tilde{x}$ (média ponderada) o valor mais provável a ser determinado, e observações não correlacionadas, tem-se:

$$
\begin{gathered}
\tilde{x}=\left(A^{T} P A\right)^{-1} A^{T} P L \\
A^{T} P A=\left[\begin{array}{llll}
1 & 1 & \ldots & 1
\end{array}\right] \cdot\left[\begin{array}{cccc}
p_{1} & 0 & \ldots & 0 \\
0 & p_{2} & \ldots & 0 \\
\ldots & \ldots & \ldots & \ldots \\
0 & 0 & \ldots & p_{n}
\end{array}\right] \cdot\left[\begin{array}{c}
1 \\
1 \\
\ldots \\
1
\end{array}\right]=\sum_{i=1}^{n} p_{i} \\
A^{T} P L=\left[\begin{array}{lllll}
1 & 1 & \ldots & 1
\end{array}\right] \cdot\left[\begin{array}{cccc}
p_{1} & 0 & \ldots & 0 \\
0 & p_{2} & \ldots & 0 \\
\ldots & \ldots & \ldots & \ldots \\
0 & 0 & \ldots & p_{n}
\end{array}\right] \cdot\left[\begin{array}{c}
l_{1} \\
l_{2} \\
\ldots \\
l_{n}
\end{array}\right]=\sum_{i=1}^{n} p_{i} l_{i} \\
v_{1}=\tilde{x}-l_{1} \quad \text { com peso } p_{1} \\
v_{2}=\tilde{x}-l_{2} \quad \text { com peso } p_{2} \\
\ldots \ldots \ldots \ldots . . \ldots \ldots \ldots \ldots \ldots \ldots . \\
v_{n}=\tilde{x}-l_{n} \quad \text { com peso } p_{n}
\end{gathered}
$$


Considerando os pesos, tem-se:

$$
\begin{aligned}
& \left(\tilde{x}-l_{1}\right) \sqrt{p_{1}}=v_{1} \sqrt{p_{1}}=v_{1}^{\prime} \\
& \left(\tilde{x}-l_{2}\right) \sqrt{p_{2}}=v_{2} \sqrt{p_{2}}=v_{2}^{\prime} \\
& \ldots \ldots \ldots \ldots \ldots \ldots \ldots \ldots \ldots \ldots \ldots \ldots \ldots \ldots \ldots \ldots \ldots \ldots \ldots \ldots \ldots \\
& \left(\tilde{x}-l_{n}\right) \sqrt{p_{n}}=v_{n} \sqrt{p_{n}}=v_{n}^{\prime}
\end{aligned}
$$

matricialmente:

$$
\begin{gathered}
V=A X-L \\
{\left[\begin{array}{c}
v_{1} \\
v_{2} \\
\cdots \\
v_{n}
\end{array}\right]=\left[\begin{array}{c}
\tilde{x} \\
\tilde{x} \\
\ldots \\
\tilde{x}
\end{array}\right]-\left[\begin{array}{l}
l_{1} \\
l_{2} \\
\ldots \\
l_{n}
\end{array}\right]}
\end{gathered}
$$

controle:

$$
A^{T} P V=0
$$

Segundo CAMIL (1994) a estimativa de precisão é:

$$
s_{0}=\sqrt{\frac{V^{T} P V}{n-1}}
$$

é a precisão à posteriori

$$
s_{i}=\frac{s_{0}}{\sqrt{p_{i}}}
$$

é a precisão de cada observação; 


$$
s_{\tilde{x}}=\frac{s_{0}}{\sum p}=\sqrt{\frac{V^{T} V}{\sum p(n-1)}}
$$

é a precisão do valor ajustado.

\subsection{2 - Método dos Parâmetros}

\subsubsection{1 - Considerações Gerais}

Este Método de ajustamento dito paramétrico, é também conhecido como Método de ajustamento de observações indiretas. Neste caso as medidas não se realizam sobre as grandezas procuradas; estas se vinculam matematicamente àquelas que se quer determinar. O relacionamento matemático que expressa o relacionamento entre a grandeza medida e a grandeza, ou grandezas, a serem determinadas são chamadas de equação da observação. Cada equação corresponde a uma observação. O ajustamento só pode ser realizado se o número de observações $n$ disponíveis para a determinação de cada incógnita é maior do que o número das incógnitas $u$ a ser determinadas $(n>u)$. $\mathrm{O}$ sistema acima não pode ser resolvido com os recursos usuais da álgebra, devido o fato dos erros acidentais estar presentes nos valores lidos, tornando-os incógnitas a serem determinadas. Assim tem se a necessidade de equações superabundantes ( em número superior às incógnitas) e aplicação da injunção $V^{T} P V=$ mínimo .

Sejam as observações não correlacionadas:

$$
l_{1}, l_{2}, \ldots, l_{n}
$$

Segundo CAMIL (1994), cada observação corresponderá a uma equação de erro: 


$$
\begin{aligned}
& \left(p_{1}\right) a_{1} x+b_{1} y+c_{1} z+l_{1}=v_{1} \\
& \left(p_{2}\right) a_{2} x+b_{2} y+c_{2} z+l_{2}=v_{2} \\
& \left(p_{n}\right) a_{n} x+b_{n} y+c_{n} z+l_{n}=v_{n}
\end{aligned}
$$

Se a relação matemática inicial entre a observação e as incógnitas não forem lineares deve-se linearizá-la.

Como não se conhece os valores das grandezas para solucionar o problema adota-se um valor provisório para cada incógnita. Assim, o valor mais provável da grandeza será calculado como a soma do valor provisório com o acréscimo deste; então:

$$
\tilde{x}=x_{0}+x, \quad \tilde{y}=y_{0}+y, \quad \tilde{z}=z_{0}+z
$$

A função das grandezas a determinar é:

$$
L_{i}=f_{i}(x, y, z)
$$

A forma linearizada da equação de observação por expansão em série é:

$$
L_{i}+v_{i}=f_{i}\left(x_{0}, y_{0}, z_{0}\right)+\frac{\partial f_{i}}{\partial x} x+\frac{\partial f_{i}}{\partial y} y+\frac{\partial f_{i}}{\partial z} z
$$

Onde os valores das derivadas parciais da função $f_{i}$ são calculados no lugar dos valores preliminares $x_{0}, y_{0}, z_{0}$.

Os valores dos primeiros termos de cada lado são conhecidos. Assim faz-se a diferença ser denotada por $l_{i}$ :

$$
l_{i}=L_{i}-f_{i}\left(x_{0}, y_{0}, z_{0}\right)
$$


E as derivadas parciais da função de incógnitas $x, y, z$ com as respectivas letras $a_{i}, b_{i}, c_{i}$ . Substituindo na equação tem-se na forma inicial dada por CAMIL (1994), apenas com a inversão do sinal de $l_{i}$ :

$$
\begin{aligned}
& a_{1} x+b_{1} y+c_{1} z-l_{1}=v_{1} \\
& a_{2} x+b_{2} y+c_{2} z-l_{2}=v_{2} \\
& a_{n} x+b_{n} y+c_{n} z-l_{n}=v_{n}
\end{aligned}
$$

\section{Utilizando a linguagem matricial}

Sejam:

$L_{b} \quad$ vetor $(n \times 1)$ dos valores observados;

$V \quad$ vetor $(n \times 1)$ dos resíduos;

$L_{a} \quad$ vetor $(n \times 1)$ dos valores observados ajustados;

$L_{0} \quad$ vetor $(n \times 1)$ dos valores em função dos parâmetros aproximados;

$L \quad$ vetor $(n \times 1)$ das diferenças entre $L_{0}$ e $L_{b}$;

$L_{a}=L_{b}+V$

$L=L_{b}-L_{0}$;

$X_{0} \quad$ vetor $(u \times 1)$ cujas componentes são os valores aproximados dos parâmetros;

$X \quad$ vetor dos acréscimos (correção);

$X_{a} \quad$ vetor dos parâmetros ajustados;

$X_{a}=X_{0}+X$

Os resíduos são:

$$
V=A X-L
$$




$$
\begin{aligned}
& A=\left[\begin{array}{ccc}
a_{1} & b_{1} & c_{1} \\
a_{2} & b_{2} & c_{2} \\
\cdots & \cdots & \cdots \\
a_{n} & b_{n} & c_{n}
\end{array}\right]_{n \times 3} \quad V=\left[\begin{array}{c}
v_{1} \\
v_{2} \\
\cdots \\
v_{n}
\end{array}\right]_{n \times 1} \quad L=\left[\begin{array}{c}
l_{1} \\
l_{2} \\
\cdots \\
l_{n}
\end{array}\right]_{n \times 1} \quad X=\left[\begin{array}{c}
x_{1} \\
x_{2} \\
\cdots \\
x_{u}
\end{array}\right]_{u \times 1}
\end{aligned}
$$

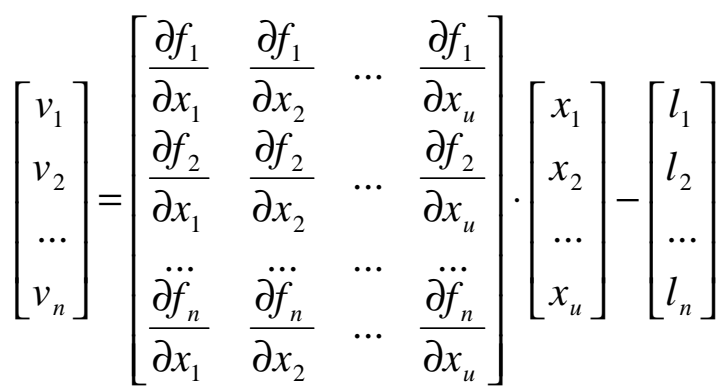

\subsubsection{2 - Equações Normais}

Segundo CAMIL (1994), minimizando a forma quadrática fundamental obtémse:

$$
\begin{gathered}
V^{T} P V=(A X-L)^{T} P(A X-L)=\min \\
V^{T} P V=\left(X^{T} A^{T} P-L^{T} P\right)(A X-L)=\min \\
V^{T} P V=X^{T} A^{T} P A X-X^{T} A^{T} P L-L^{T} P A X+L^{T} P L=\min
\end{gathered}
$$

pode-se verificar que os $2^{\circ}$ e $3^{\circ}$ termos são iguais, donde:

$$
X^{T} A^{T} P A X-2 L^{T} P A X+L^{T} P L=\min
$$

Fazendo a primeira derivada em relação a $X$ igual a zero, tem-se:

$$
\begin{gathered}
\frac{\partial V^{T} P V}{\partial X}=2 A^{T} P A X+2 A^{T} P L=0 \\
A^{T} P A X+A^{T} P L=0
\end{gathered}
$$




$$
\begin{gathered}
X=-\left(A^{T} P A\right)^{-1}+A^{T} P L \\
N=A^{T} P A \\
n=A^{T} P l
\end{gathered}
$$

Assim:

$$
X=-N^{-1} n
$$

Controle:

$$
A^{T} P V=0
$$

Precisão a posteriori:

$$
s_{0}=\sqrt{\frac{V^{T} P V}{n-u}}
$$

No caso de $s_{0}{ }^{2}$ a priori e $s_{0}{ }^{2}$ a posteriori serem significativamente diferentes, deve-se proceder a uma análise cuidadosa do ajustamento. Pode haver erros na Matriz de Variância e Covariância (MVC) dos valores observados, ou podem os resíduos estar excessivamente grandes em decorrência de erros grosseiros ou de erros sistemáticos, tornando o modelo matemático inconsistente com as observações.

\subsubsection{3 - Cálculo dos Erros Através das Matrizes de Variância e Covariância}

Além do cálculo das incógnitas é possível tirar todas as informações estatísticas do modelo através do conteúdo das matrizes de variância e covariância das incógnitas, das observações ajustadas e dos erros residuais.

Seja então: 


$$
\begin{gathered}
f=\left[\begin{array}{c}
L_{b} \\
X \\
\tilde{L} \\
V
\end{array}\right]=\left[\begin{array}{c}
I \\
N^{-1} A^{T} P \\
A N^{-1} A^{T} P \\
A N^{-1} A^{T} P-I
\end{array}\right] \cdot L \\
L=L_{b}-f_{0} \\
\bar{Q}=A N^{-1} A^{T}
\end{gathered}
$$

Assim:

$$
\begin{aligned}
& f=f_{0}+F^{T} L \\
& F=\left[\begin{array}{c}
I \\
N^{-1} A^{T} P \\
\bar{Q} P \\
\bar{Q} P-I
\end{array}\right] \\
& Q_{f f}=F^{T} Q_{l l} F \\
& Q_{f f}=\left[\begin{array}{cccc}
P^{-1} I & A N^{-1} & \bar{Q} & \bar{Q}-P^{-1} I \\
N^{-1} A^{T} I & N^{-1} A^{T} P A N^{-1} & N^{-1} A^{T} P \bar{Q} & N^{-1} A^{T}(P \bar{Q}-I) \\
\bar{Q} I & \bar{Q} P A N^{-1} & \bar{Q} P \bar{Q} & \bar{Q} P \bar{Q}-\bar{Q} I \\
\bar{Q} I-P^{-1} I & (\bar{Q} P-I) A N^{-1} & \bar{Q} P \bar{Q} \bar{Q} & \bar{Q} P \bar{Q}-\bar{Q} I-P^{-1} P \bar{Q}+P^{-1} I
\end{array}\right]
\end{aligned}
$$

Simplificando, tem-se:

$$
Q_{f f}=\left[\begin{array}{cccc}
P^{-1} & A N^{-1} & \bar{Q} & \bar{Q}-P^{-1} \\
N^{-1} A^{T} & N^{-1} & N^{-1} A^{T} & \{\} \\
\bar{Q} & A N^{-1} & \bar{Q} & \{\} \\
\bar{Q}-P^{-1} & \{\} & \{\} & P^{-1}-\bar{Q}
\end{array}\right]
$$

Os elementos da diagonal são as variâncias das observações (representada pelo primeiro elemento), das incógnitas (representadas pelo segundo elemento), das observações ajustadas (pelo terceiro elemento) e dos erros residuais (pelo último elemento da diagonal). 
A estimativa da precisão das observações é dada pela raiz quadrada dos elemento da diagonal (variâncias) da matriz $P^{-1}$ multiplicado pela precisão a posteriori. $s_{0}$ Os elementos fora da diagonal e diferentes de zero demonstram as covariâncias entre os pares de observações.

Para as incógnitas faz-se a mesma operação utilizando a matriz $N^{-1}$, para os valores ajustados das observações usa-se a matriz $\bar{Q}$ e para os erros a matriz $P^{-1}-\bar{Q}$.

\subsection{3 - Método das Equações de Condição ou dos Correlatos}

\subsubsection{1 - Considerações Gerais}

Neste método as grandezas a serem determinadas por ajustamento que são medidas direta ou indiretamente não são independentes uma das outras e o valor mais provável deve satisfazer as condições de relacionamento matemático ou geométrico entre as incógnitas, e o ajustamento tem que satisfazer a condição de $V^{T} P V$ mínimo.

O modelo matemático que caracteriza as observações condicionadas é dado por:

$$
\phi\left(\tilde{L}_{1}, \tilde{L}_{2}, \ldots, \tilde{L}_{n}\right)=0
$$

ou;

$$
\phi\left(L_{1}, L_{2}, \ldots, L_{n}\right)=\varpi
$$

Considerando o caso genérico de $r$ equações de condição naturais ligando $n$ incógnitas $\tilde{l}_{i}(n>r)$ :

$$
\begin{aligned}
& b_{10}+b_{11} \tilde{l}_{1}+b_{12} \tilde{l}_{2}+\ldots+b_{1 n} \tilde{l}_{n}=0 \\
& b_{20}+b_{21} \tilde{l}_{1}+b_{22} \tilde{l}_{2}+\ldots+b_{2 n} \tilde{l}_{n}=0 \\
& \ldots \ldots \ldots \ldots \ldots \ldots \ldots \ldots \ldots \ldots \ldots \ldots \ldots \ldots \ldots \ldots \ldots \ldots \ldots \ldots \ldots \ldots \ldots \ldots \ldots \ldots \ldots \ldots \ldots \\
& b_{r 0}+b_{r 1} \tilde{l}_{1}+b_{r 2} \tilde{l}_{2}+\ldots+b_{r n} \tilde{l}_{n}=0
\end{aligned}
$$

Fazendo $\tilde{l}_{i}=l_{i}+v_{i}$ e substituindo, tem-se: 


$$
\begin{aligned}
& b_{10}+b_{11}\left(l_{1}+v_{1}\right)+b_{12}\left(l_{2}+v_{2}\right)+\ldots+b_{1 n}\left(l_{n}+v_{n}\right)=0 \\
& b_{20}+b_{21}\left(l_{1}+v_{1}\right)+b_{22}\left(l_{2}+v_{2}\right)+\ldots+b_{2 n}\left(l_{n}+v_{n}\right)=0 \\
& b_{r 0}+b_{r 1}\left(l_{1}+v_{1}\right)+b_{r 2}\left(l_{2}+v_{2}\right)+\ldots+b_{r n}\left(l_{n}+v_{n}\right)=0
\end{aligned}
$$

Desenvolvendo os produtos, e designando $\varpi_{i}$ os "erros de fechamento", isto é, os valores numéricos obtidos de cada equação de condição:

$$
\begin{gathered}
\varpi_{1}=b_{10}+b_{11} l_{1}+b_{12} l_{2}+\ldots+l_{1 n} v_{n} \\
\varpi_{2}=b_{20}+b_{21} l_{1}+b_{22} l_{2}+\ldots+b_{2 n} l_{n} \\
\ldots \ldots \ldots \ldots \ldots \ldots \ldots \ldots \ldots \ldots \ldots \ldots \ldots \ldots \ldots \ldots \ldots \ldots \ldots \ldots \ldots \ldots \ldots \ldots \ldots \ldots \ldots \ldots \ldots \ldots \ldots \ldots \ldots \ldots \ldots \\
\varpi_{r}=b_{r 0}+b_{r 1} l_{1}+b_{r 2} l_{2}+\ldots+b_{r n} l_{n}
\end{gathered}
$$

Resulta:

$$
\begin{aligned}
& b_{10}+b_{11} v_{1}+b_{12} v_{2}+\ldots+b_{1 n} v_{n}+\varpi_{1}=0 \\
& b_{20}+b_{21} v_{1}+b_{22} v_{2}+\ldots+b_{2 n} v_{n}+\varpi_{2}=0 \\
& \ldots \ldots \ldots \ldots \ldots \ldots \ldots \ldots \ldots \ldots \ldots \ldots \ldots \ldots \ldots \ldots \ldots \ldots \ldots \ldots \ldots \ldots \ldots \ldots \ldots \ldots \ldots \ldots \ldots \ldots \ldots \ldots \ldots \ldots \ldots \ldots \ldots \\
& b_{r 0}+b_{r 1} v_{1}+b_{r 2} v_{2}+\ldots+b_{r n} v_{n}+\varpi_{r}=0
\end{aligned}
$$

As equações acima constituem; segundo CAMIL (1994), as equações de condição transformadas; as novas incógnitas que nelas aparecem, que são os resíduos $v_{i}$, ao contrário das primitivas, são funcionalmente independentes.

Os valores finais ajustados, devem satisfazer à injunção $V^{T} P V$ mínimo e também as equações de condição, como enfatizado anteriormente. Para garantir tais requisitos deve-se seguir a técnica do multiplicador de Lagrange (ou dos "correlatos").

Somando-se as $r$ equações de condição transformadas após multiplicá-las por:

$$
-2 k_{i}(i=1,2, \ldots, n)
$$


sendo $k_{i}$ os multiplicadores de Lagrange (desconhecidos) ou os "correlatos":

$$
U=-2 k_{1}\left[\sum_{i=1}^{n} b_{1 i} v_{i}+\Phi_{1}\right]-2 k_{2}\left[\sum_{i=1}^{n} b_{2 i} v_{i}+\Phi_{2}\right]-\ldots-2 k_{r}\left[\sum_{i=1}^{n} b_{r i} v_{i}+\varpi_{r}\right]
$$

Definindo-se a função:

$$
\Omega=V^{T} P V-U=\min
$$

As $n$ derivadas parciais de $\Omega$ em relação a $v_{i}$ deverão, obviamente ser nulas:

$$
\frac{\partial \Omega}{\partial v_{i}}=2 v_{i}-2 k_{1} b_{1 i}-2 k_{2} b_{2 i}-\ldots-2 k_{r} b_{1 r}=0
$$

Fazendo $i=1,2, \ldots, n$

$$
\begin{aligned}
& v_{1}=b_{11} k_{1}+b_{21} k_{2}+\ldots+b_{r 1} k_{r} \\
& v_{2}=b_{12} k_{1}+b_{22} k_{2}+\ldots+b_{r 2} k_{r} \\
& v_{n}=b_{1 n} k_{1}+b_{2 n} k_{2}+\ldots+b_{r n} k_{r}
\end{aligned}
$$

Substituindo em (7.96), tem-se:

$$
\begin{aligned}
& \left(\sum_{i=1}^{n} b_{1 i}{ }^{2}\right) k_{1}+\left(\sum_{i=1}^{n} b_{1 i} b_{2 i}\right) k_{2}+\ldots+\left(\sum_{i=1}^{n} b_{1 i} b_{r i}\right) k_{r}+\Phi_{1}=0 \\
& \left(\sum_{i=1}^{n} b_{1 i} b_{2 i}\right) k_{1}+\left(\sum_{i=1}^{n} b_{2 i}{ }^{2}\right) k_{2}+\ldots+\left(\sum_{i=1}^{n} b_{2 i} b_{r i}\right) k_{r}+\Phi_{2}=0 \\
& \left(\sum_{i=1}^{n} b_{r i} b_{1 i}\right) k_{1}+\left(\sum_{i=1}^{n} b_{r i} b_{2 i}\right) k_{2}+\ldots+\left(\sum_{i=1}^{n} b_{r i}{ }^{2}\right) k_{r}+\varpi_{r}=0
\end{aligned}
$$


Usando linguagem matricial

$$
B^{T} V+W=0
$$

\subsubsection{2 - Equações Normais}

Fazendo $V^{T} P V$ mínimo, tem-se:

$$
\phi=V^{T} P V-2 K^{T}(B V+W)=\text { mínimo }
$$

sendo:

$K \quad$ vetor dos multiplicadores de Lagrange (ou correlatos)

$W \quad$ vetor dos "erros de fechamento"

B matriz das derivadas parciais

Igualando as derivadas parciais em relação a $V$ e $K$ :

$$
\begin{gathered}
\frac{\partial \phi}{\partial V}=2 P V-2 K^{T} B=0 \\
P V-B^{T} K=0 \\
V=P^{-1} B^{T} K \\
V=Q B^{T} K \\
\frac{\partial \phi}{\partial K}=-2(B V+W)=0 \\
B V+W=0
\end{gathered}
$$

substituindo $V$ :

$$
B P^{-1} B^{T} K+W=0
$$




$$
K=-\left(B Q B^{T}\right)^{-1} W
$$

Fazendo:

$$
B Q B^{T}=N
$$

então:

$$
K=-N^{-1} W
$$

Valores ajustados:

$$
\tilde{L}=L+V
$$

Variância da observação de peso unitário a posteriori

$$
s_{0}{ }^{2}=\frac{V^{T} P V}{r}
$$

Para obter a forma quadrática de maneira mais simples:

$$
\begin{gathered}
V^{T} P V=\left(Q B^{T} K\right)^{T} P Q B^{T} K \\
V^{T} P V=K^{T} B Q P Q B^{T} K \\
V^{T} P V=K^{T} B Q B^{T} K
\end{gathered}
$$

substituindo 7.110:

$$
V^{T} P V=-K^{T} W
$$

\subsubsection{3 - Matriz Variância e Covariância}

Seja: 


$$
\begin{gathered}
{\left[\begin{array}{l}
l \\
\omega \\
k \\
v \\
\tilde{l}
\end{array}\right]=\left[\begin{array}{c}
0 \\
b_{0} \\
-N^{-1} b_{0} \\
-Q B^{T} N^{-1} b_{0} \\
-Q B^{T} N^{-1} b_{0}
\end{array}\right]+\left[\begin{array}{c}
I \\
B \\
-N^{-1} B \\
-Q B^{T} N^{-1} B \\
I-Q B^{T} N^{-1} B
\end{array}\right] \cdot l} \\
f=f_{0}+F^{T} l \\
Q_{f f}=F^{T} Q_{l l} F \\
I \\
B \\
Q_{f f}=\left[\begin{array}{c}
-N^{-1} B \\
-Q B^{T} N^{-1} B \\
I-Q B^{T} N^{-1} B
\end{array}\right] \cdot Q \cdot\left[\begin{array}{l}
I \quad B^{T}-B^{T} N^{-1}-B^{T} N^{-1} B Q \quad I-B^{T} N^{-1} B Q
\end{array}\right]
\end{gathered}
$$

Desenvolvendo o produto e agrupando os termos, tem-se:

$$
Q_{f f}=\left[\begin{array}{ccccc}
Q & Q B^{T} & -Q B^{T} N^{-1} & -Q B^{T} N^{-1} B Q & Q-Q B^{T} N^{-1} B Q \\
& N & -I & -B Q & \{\} \\
& & N^{-1} & N^{-1} B Q & -N^{-1} B Q+N^{-1} B Q \\
& & & Q B^{T} N^{-1} B Q & \{\} \\
& & & & Q-Q B^{T} N^{-1} B Q
\end{array}\right]
$$

Os elementos da diagonal representam as variâncias das observações, dos "erros de fechamento", dos correlatos, dos resíduos e das observações ajustadas; respectivamente.

Para a obtenção das precisões das observações, basta extrair a raiz quadrada dos elementos da diagonal da matriz $Q$ (matriz das variâncias e covariâncias das observações), primeiro elemento da matriz $Q_{f f}$, e multiplicar por $s_{0}$ a posteriori dada pela equação(4.114). Para a estimativa de precisão dos "erros de fechamento" deve-se usar o segundo elemento da diagonal da matriz $Q_{f f}$ que é a matriz $N$ e multiplicar 
também seus elementos da diagonal, após a extração da raiz quadrada, pela precisão $s_{0}$ à posteriori. Conseqüentemente, faz-se a mesma operação no terceiro elemento da diagonal $\left(N^{-1}\right)$ da matriz $Q_{f f}$ para a obtenção das precisões dos correlatos, no quarto elemento da diagonal $\left(Q B^{T} N^{-1} B Q\right)$ para a obtenção das precisões dos resíduos e por fim o quinto elemento da diagonal $\left(Q-Q B^{T} N^{-1} B Q\right)$ que dá as precisões das observações ajustadas. Os elementos fora da diagonal e diferentes de zero são as covariâncias entre os pares que compõem a matriz. 


\section{CAPÍTULO 8 - MATERIAIS E MÉTODOS}

\section{1- Considerações Gerais}

Neste capítulo apresenta-se a localização e as características do polígono (convencional e GPS) levantado, objeto de estudo nesta pesquisa, onde se procura o ajustamento das observações combinados e em separado. Também serão demonstrados os métodos de levantamento dos pontos do polígono, e os métodos empregados para o ajustamento. Assim sendo, o estudo será composto das seguintes etapas:

' $\gamma$ levantamento dos pontos do polígono pelo método convencional e GPS;

' $Y$ ' transformação das observações em coordenadas, associada ao sistema de referência de cada método de levantamento;

' $r$ ' transformação das coordenadas e ou distâncias para um sistema de referência único preconizado para o país;

' $\mathbf{Y}$ ' proposição e aplicação dos métodos de ajustamento das observações combinadas e em separado.

\section{2- Localização e Característica do Polígono}

A poligonal em estudo foi criada em uma área do campus da Universidade Federal de São Carlos (UFSCAR-SP), onde já se encontram instalados quatro pontos com coordenadas conhecidas, denominados FED1, FED2, FED3 e P6-A. A extensão total da poligonal é próxima de $2,5 \mathrm{~km}$, composto de treze pontos dispostos 
aleatoriamente de forma que não tenham obstrução da visão do alvo e de sinais remotos conforme Figura 8.1.

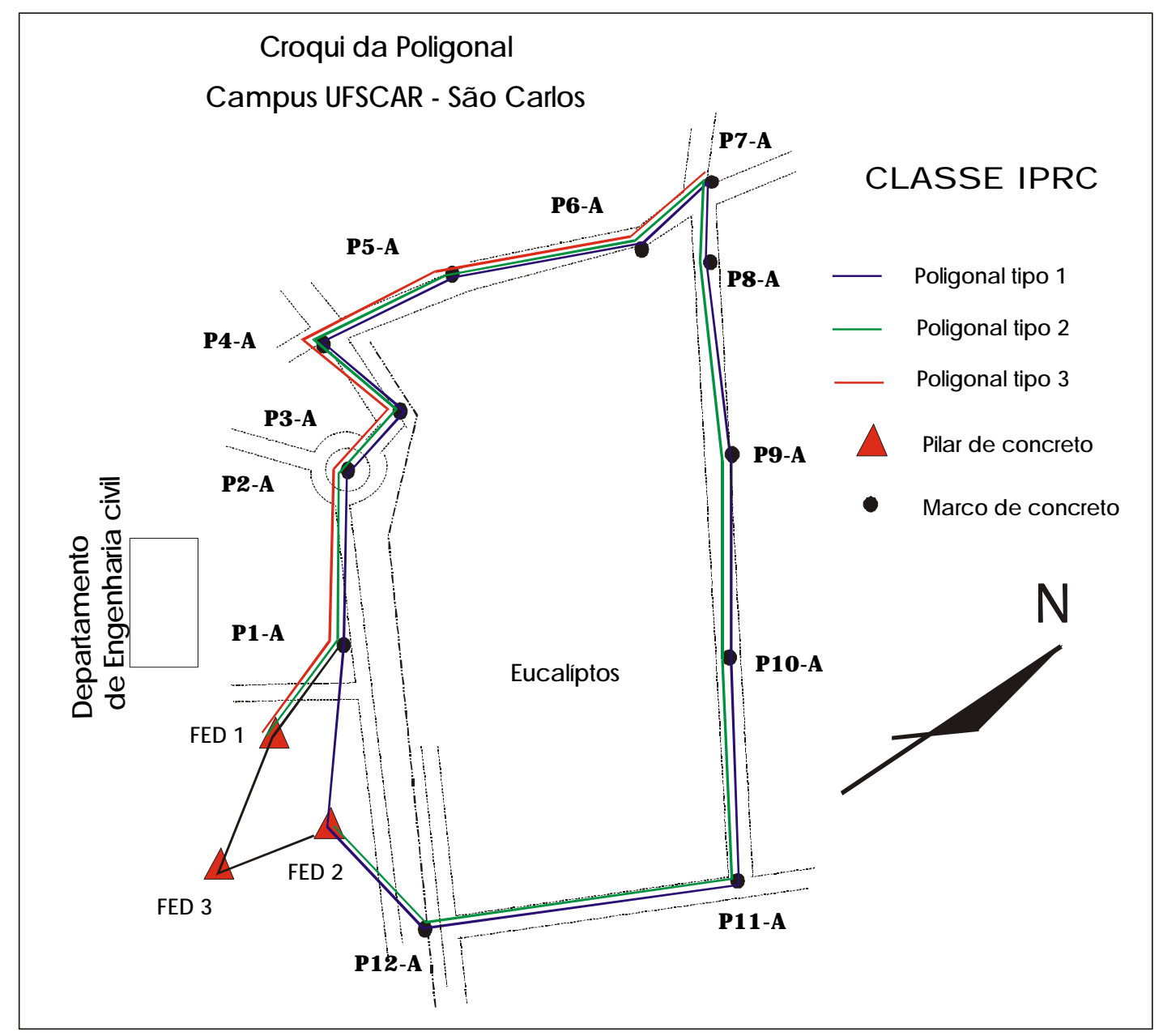

Figura 8.1: Croqui da área onde foi criada a poligonal.

A poligonal é enquadrada na classe I PRC, que segundo a norma NBR13.133 para levantamentos topográficos é descrita como:

"Apoio topográfico da rede de referência cadastral municipal, apoiada na rede geodésica densificada por poligonal classe IP ou processo equivalente". Suas características se encontram na Tabela 8.1. 
Tabela 8.1: Rede de referência cadastral municipal - Poligonais

\begin{tabular}{|c|c|c|c|c|c|c|c|c|}
\hline \multirow[b]{2}{*}{ Classe } & \multicolumn{2}{|c|}{ Metodologia } & \multicolumn{4}{|c|}{ Desenvolvimento } & \multirow[b]{2}{*}{$\begin{array}{l}\text { Nivela- } \\
\text { mento } \\
\text { geomé- } \\
\text { trico dos } \\
\text { vértices }\end{array}$} & \multirow[b]{2}{*}{$\begin{array}{c}\text { Mate- } \\
\text { rializa } \\
\text {-ção }\end{array}$} \\
\hline & Angular & Linear & $\begin{array}{c}\text { Extensão } \\
\text { máxima } \\
\text { (L) }\end{array}$ & $\begin{array}{c}\text { Lado } \\
\text { mínimo } \\
\left(\mathrm{d}_{\text {min }}\right)\end{array}$ & $\begin{array}{l}\text { Lado } \\
\text { médio } \\
\left(\mathrm{d}_{\text {med }}\right)\end{array}$ & $\begin{array}{c}\text { Número } \\
\text { máximo } \\
\text { de } \\
\text { vértices } \\
\text { (N) }\end{array}$ & & \\
\hline I PRC & $\begin{array}{c}\text { Método das } \\
\text { direções com } \\
\text { centragem } \\
\text { forçada, três } \\
\text { séries de leituras } \\
\text { conjugadas direta } \\
\text { e inversa, } \\
\text { horizontal e } \\
\text { vertical. } \\
\text { Teodolito classe } \\
3 .\end{array}$ & $\begin{array}{c}\text { Leituras } \\
\text { recíprocas } \\
\text { (vante e ré) } \\
\text { com } \\
\text { distanciômetro } \\
\text { eletrônico } \\
\text { Classe 2. }\end{array}$ & $\begin{array}{c}03 \mathrm{~km} \\
(\mathrm{P})\end{array}$ & $\begin{array}{c}100 \mathrm{~m} \\
(\mathrm{P})\end{array}$ & $\begin{array}{c}\geq 200 \\
\mathrm{~m} \\
(\mathrm{P}) \\
\geq 100 \\
\mathrm{~m} \\
(\mathrm{~S})\end{array}$ & $\begin{array}{l}16 \\
(\mathrm{P})\end{array}$ & $\begin{array}{l}12 \mathrm{~mm} \\
\sqrt{K} \\
\text { (I N para } \\
\text { principal) } \\
\\
16 \mathrm{~mm} \\
\sqrt{K} \\
\text { (I N para } \\
\text { secundária) }\end{array}$ & $\begin{array}{c}\text { Marcos } \\
\text { ou } \\
\text { pinos }\end{array}$ \\
\hline
\end{tabular}

As tolerâncias de fechamento para a classe I PRC são:

A) Tipo 1 - poligonais apoiadas e fechadas numa só direção e num só ponto.

$$
\text { Angular: } T_{\alpha} \leq a+b \sqrt{N}
$$

Linear após a compensação angular: $T_{p} \leq c+d \sqrt{L(\mathrm{~km})}$

Erro relativo linear após a compensação angular: $e_{r} \leq \frac{T_{p}}{L}$

B) Tipo 2 - poligonais apoiadas e fechadas em direções e pontos distintos com desenvolvimento curvo.

$$
\text { Angular: } T_{\alpha} \leq a+b \sqrt{N}
$$


Linear após a compensação angular: $T_{p} \leq c+d \sqrt{L(\mathrm{~km})}$

Erro relativo linear após a compensação angular: $e_{r} \leq \frac{T_{p}}{L}$

C) Tipo 3 - poligonais apoiadas e fechadas em direções e pontos distintos com desenvolvimento retilíneo.

Angular: $T_{\alpha} \leq a+b \sqrt{N}$

Transversal antes da compensação angular: $T_{t} \leq c+e L(\mathrm{~km}) \sqrt{N-1}$

Longitudinal antes da compensação angular: $T_{l} \leq c+f \sqrt{L(\mathrm{~km})}$

Erro relativo linear após a compensação angular: $e_{r} \leq \frac{T_{p}}{L}$

Onde:

$a=$ erro médio angular da rede de apoio multiplicado por $\sqrt{2}$ (duas direções)

$b=$ coeficiente de tolerância para o erro de medição angular

$c=$ erro médio de posição dos pontos de apoio de ordem superior multiplicado por $\sqrt{2}$ (duas direções)

$d=$ coeficiente de tolerância para o erro de fechamento linear em $\mathrm{m} / \mathrm{km}$

$e=$ coeficiente de tolerância para o erro transversal acarretado pelo erro angular $\mathrm{em} \mathrm{m} / \mathrm{km}$

$f=$ coeficiente de tolerância para o erro longitudinal acarretado pelo erro da medição linear.

$\mathrm{O}$ item descrito anteriormente vale para compensação e ajustamento. Para ajustamento ainda tem-se os valores máximos aceitáveis a seguir:

a) para erro médio relativo entre quaisquer duas estações poligonais 


$$
\begin{aligned}
e_{r D} & \leq \frac{T_{p}}{D_{\text {med }} \sqrt{N-1}}=\frac{T_{p}(N-1)}{L_{m} \sqrt{N-1}} \\
D_{\text {med }} & =\frac{L_{m}}{N-1}
\end{aligned}
$$

onde:

$e_{r D} \quad$ erro médio relativo máximo aceitável entre duas estações poligonais após o ajustamento

$T_{p}$ tolerância do erro de fechamento linear após a compensação angular

$L_{m}$ extensão da poligonal em $\mathrm{m}$

$N$ número de estações da poligonal

b) para erro médio em azimute

$$
e_{A Z} \leq \pm \frac{T \alpha}{\sqrt{N}}
$$

onde:

$e_{A Z} \quad$ erro médio máximo aceitável em azimute, após ajustamento

$T \alpha$ tolerância do fechamento angular

c) para erro médio em coordenadas (de posição)

$$
e_{v} \leq \pm e_{r D} \cdot D_{m e d}
$$

onde:

$e_{v} \quad$ erro médio máximo aceitável em coordenadas (de posição), após ajustamento

$e_{r D} \quad$ erro médio relativo máximo aceitável entre quaisquer duas estações poligonais 
Estes valores devem servem de controle para os seus valores correspondentes obtidos nos cálculos, após ajustamento mencionados no item 6.5.6 da NBR 13133 como preestabelecidos e máximos aceitáveis. Estes valores são calculados como a seguir:

a) erro relativo em coordenadas (de posição)

$$
e_{r D} \leq \pm \sqrt{\frac{c x^{2}+c y^{2}}{\Delta x^{2}+\Delta y^{2}}}
$$

b) erro relativo em azimute

$$
e_{A Z} \leq \pm \sqrt{\frac{\sum \Delta \alpha^{2}}{N-1}}
$$

c) erro médio de coordenadas (de posição)

$$
e_{v}= \pm \sqrt{\frac{\sum\left(c x^{2}+c y^{2}\right)}{N-2}}
$$

onde:

$\begin{array}{ll}\Delta x \text { e } \Delta y & \text { coordenadas relativas ou projeções dos lados } \\ c x \text { e cy } & \text { correções aplicadas na compensação respectivamente para } \\ & \text { coordenadas relativas } \Delta x e \Delta y \\ \Delta \alpha & \text { diferença entre o ângulo observado e o cálculo após o } \\ & \text { ajustamento } \\ & \text { número de vértices poligonais, incluindo os de chegada e } \\ & \text { partida }\end{array}$




\section{3 - Levantamento dos Pontos do Polígono}

O levantamento dos pontos foi realizado utilizando receptores GPS System 9400 e uma estação total TC 805L (Teodolito eletrônico + Distanciômetro eletrônico MED) com precisão angular de 3 segundos e distância com $2 \mathrm{~mm}+2 \mathrm{ppm}$. Ambos equipamentos são da marca Leica e os receptores GPS são de propriedade do Laboratório de Mensuração do Departamento de Transportes da EESC/USP. A estação total foi cedida gentimente pela Wild Brasil S/A para a elaboração do presente trabalho.

\subsection{1 - Levantamento Utilizando Receptores GPS}

No levantamento com receptores GPS LEICA SR9400 (L1) foi executado o método estático. Em se tratando do método de levantamento estático, uma das antenas receptoras ocupará um dos pontos, FED 2, de coordenadas conhecidas e a outra antena ocupará o ponto P1-A que juntamente com FED 2 compõe o primeiro alinhamento da poligonal e onde se deseja determinar as coordenadas. As observações foram realizadas por um tempo de 1 hora com taxa de armazenamento de 15 segundos, ângulo de corte de $15^{\circ}$. Ao término da seção de observação conclui-se a coleta de dados gravando-os na coletadora de dados; manteve-se a antena receptora do ponto P1-A da poligonal e retirando a antena do ponto-base FED 2 passando-o para o ponto subseqüente da poligonal. Com este procedimento, as antenas passaram a coletar dados nos P1-A e P2-A da poligonal. Assim sendo, a seção de observação passou a apresentar características semelhantes a descrita anteriormente e assim sucessivamente de maneira a determinar todos os vetores dos alinhamentos da poligonal, retornando no ponto de partida FED 2.

Encerrado o levantamento das observações dos alinhamentos da poligonal, os

dados foram processados utilizando softwares comerciais que acompanham os equipamentos GPS. 
Em seguida, de acordo com croqui da área levantada, desenvolveu-se a rede de ajustamento para a poligonal, criando os novos vetores a serem levantados, triângulando a área criada.

No processamento dos dados utilizou-se o modelo troposférico de Hopfield e modelo ionosférico de Klobuchar, e o resultado do processamento apresentou as coordenadas no sistema WGS-84. Posteriormente, as coordenadas foram transformadas em diferentes superfícies de referência (UTM e Geodésicas geográficas SAD69).

Um dos critérios de análise do resultado aplicado neste trabalho foi a observação dos valores do RMS ("Root Mean Square”) que corresponde ao desvio de um ajustamento pelos mínimos quadrados. Para os pontos com maior RMS e com ambigüidade não fixada, refez-se o processamento do mesmo com desabilitação dos satélites de baixa altitude e no caso dos alinhamentos compreendidos entre os pontos 7-A a 12-A os satélites baixos em relação à uma plantação de eucaliptos adjacente ao lado do polígono. Fez-se este processo até que o RMS se tornasse pequeno e a obtenção da ambigüidade inteira.

Após a solução de todos vetores partiu-se para o ajustamento da rede GPS através do software Star Net Plus 5.0, com a entrada das diferenças de coordenadas, ou seja $\Delta X, \Delta Y, \Delta Z$. O resultado é a rede GPS ajustada, com os valores finais das coordenadas e seus desvios padrão, as elipses de erros absolutas dos pontos respectivamente. Neste ajustamento se propôs primeiro o ajustamento dos vetores que compõem os alinhamentos do contorno da poligonal e depois o ajustamento da mesma com a soma de mais vetores a esta compondo a triangulação.

\subsection{2 - Levantamento Utilizando Estação Total}

No método convencional, com o uso da Estação Total 805L, executou-se o levantamento da poligonal seguindo visadas à ré e a vante dos alinhamentos da poligonal, descrito pelos pontos utilizados no levantamento por GPS, apenas no 
contorno da poligonal, com a determinação dos ângulos e distâncias de acordo com a norma NBR 13.133 (1994).

A Norma NBR 13.133 (1994) prescreve que os ângulos horizontais devem ser levantados seguindo o método das direções. Este método consiste em medições angulares horizontais determinantes nas duas posições de medição (direta e inversa), chamadas leituras conjugadas, lidas a partir de uma direção tomada como origem. Para observação de "n" séries de leituras conjugadas, o intervalo de reiteração deve ser $180 \%$. Como por exemplo, se forem três séries de leituras conjugadas, o intervalo de reiteração deve ser $180^{\circ} / 3=60^{\circ}$, e a direção-origem deve ocupar, no limbo horizontal do teodolito, posições nas proximidades de $0^{\circ}, 60^{\circ}, 120^{\circ}$. Os valores dos ângulos medidos pelo método das direções são as médias aritméticas dos seus valores, conforme a teoria dos erros, obtidos nas diversas séries.

A necessidade da obtenção dos ângulos se faz devido o cálculo das coordenadas dos pontos, no sistema de referência local, para que se possa executar posterior transformação de sistema, no caso o sistema de coordenadas UTM (Universal Transverso de Mercator) adotado no Brasil.

De acordo com o descrito no Capítulo 4: Teodolitos Eletrônicos, fez-se o levantamento segundo o método das direções com visadas na posição direta e inversa e com leitura simples com apenas uma determinação de ângulo em apenas uma posição do limbo já que as Estações Totais compensam os erros de eixo, excentricidade e graduação e os seus ângulos já é uma média de leituras. O intuito é comparar os valores finais de fechamento e desvios padrão entre as leituras seguindo o método das direções e leitura simples.

O comprimento dos lados da poligonal deve ser na medida do possível, constante, evitando a existência simultânea de lados muito longos e muitos curtos. As distâncias inclinadas, obtidas por medidores eletrônicos de distâncias, devem ser reduzidas no plano horizontal levando em conta o ângulo de inclinação ou zenital lidos. Quando a distância for suficientemente pequena não é necessário corrigir o ângulo de inclinação ou zenital da refração e esfericidade da Terra. As distâncias horizontais (pequenas) ou distâncias esféricas devem levar em conta o nível de 
referência altimétrica do sistema de projeção topográfica para a redução ao nível do mar. Esta redução é dada por:

$$
\Delta D=-\frac{h_{m}}{H+R_{m}} \cdot D
$$

Neste levantamento as distâncias foram obtidas com a Estação Total 805L, anotando temperatura e pressão para a correção em ppm que deve ser introduzida na mesma no ato da medição da distância e em paralelo foi executada a mesma medição sem a correção ppm para que se possa fazer a correção da mesma distância pela fórmula empírica de Barel \& Sears confrontando os resultados.

As altitudes dos pontos da poligonal foram obtidas por nivelamento trigonométrico, partindo-se de um marco oficial de altitude conhecida próximo a área de estudo. O método aplicado foi o das observações zenitais recíprocas descritas no MANUAL TÉCNICO CÁLCULOS GEODÉSICOS (1959) E CONTROLE DAS OBSERVAÇÕES RECÍPROCAS (1969) onde um dos teodolitos T2 foi instalado no ponto de partida e o outro no ponto a vante da poligonal. As visadas simultâneas foram executadas em duas séries de 3 medidas diretas e inversas respectivamente, coincidindo-se em primeiro lugar o fio superior estadimétrico com o centro ótico do outro instrumento instalado, e em seguida o fio médio e por fim o fio inferior também com centro ótico do instrumento a vante. A mesma operação foi realizada com o instrumento a vante, só que visando o instrumento a ré, conforme Figura 8.2. O resultado das observações a ré e a vante é a média das médias das três observações realizadas em cada um dos teodolito. 


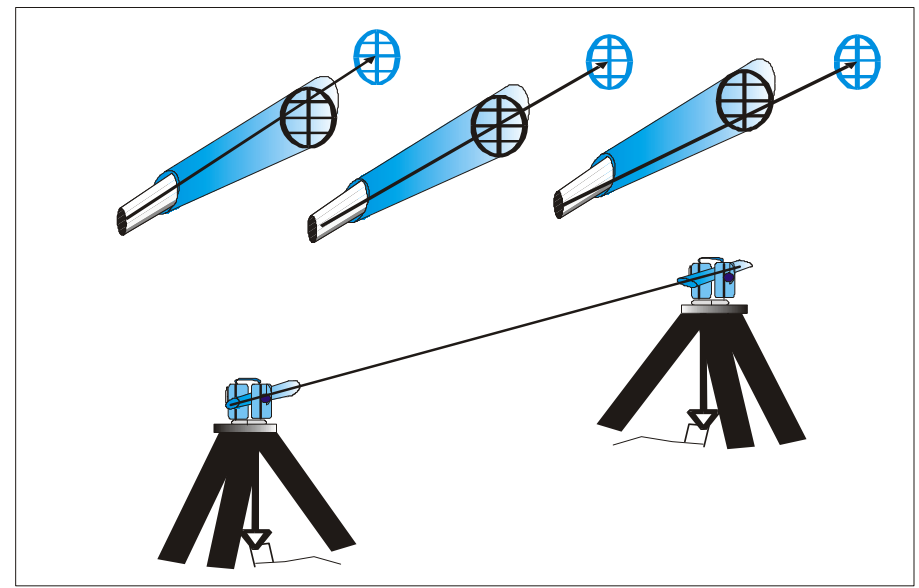

Figura 8.2: Representação das visadas recíprocas utilizando-se dois teodolitos com visadas coincidindo fio superior, médio e inferior, respectivamente, com o centro ótico do outro instrumento.

Para garantir os resultados foi executado também o nivelamento geométrico da poligonal com o nível geodésico automático NI 002 ótico-mecânico Karl Zeiss JENA.

Tem-se que um dos fatores limitantes da precisão do nivelamento trigonométrico é dada pela determinação da altura do instrumento, que na maioria dos casos é executada com o uso de uma trena.

Neste trabalho, a altura do instrumento foi realizada por nivelamento trigonométrico determinando a diferença de nível entre uma RN (Referência de Nível) e o ponto instalado, com suas cota determinada por nivelamento geométrico, determinando-se a cota do centro ótico do instrumento.

Recomenda-se que este procedimento deve ser realizado sempre no início e no encerramento de um trabalho; isto é importante para que se possa determinar a altura de saída e chegada do centro ótico do teodolito, eliminando-se o efeito da altura do instrumento no cálculo de fechamento da poligonal no plano vertical. A altura do instrumento neste caso serve apenas ao cálculo da cota do ponto instalado partindo-se da cota do centro ótico do instrumento.

O erro de fechamento da poligonal é dado pelo somatório das diferenças de nível entre os centros ótico dos instrumentos. Para a verificação e comparação da 
medida da altura do instrumento foi também realizada a leitura da mesma com o auxílio da trena medindo-se do ponto instalado até a marca lateral do equipamento e com um pino de ferro graduado que se encaixa no centro do parafuso de pressão da base do teodolito no tripé apoiando-se no fundo do teodolito servindo-se como marca de medida da trena até o piquete. A medida da altura do instrumento neste caso é realizada com trena medindo-se da ponta do parafuso até o piquete somando-se ao valor a quantidade graduada do pino de ferro que reflete a altura do centro ótico do teodolito até a ponta deste mesmo pino, no caso $350 \mathrm{~mm}$.

O esquema de leitura da altura do instrumento é mostrado na Figura (8.3). Em um teste inicial a diferença entre a trena e o pino ficou entre 1 e $2 \mathrm{~mm}$ e entre o pino e a altura do instrumento calculada por diferença de nível trigonométrica ficou menor do que $1 \mathrm{~mm}$.

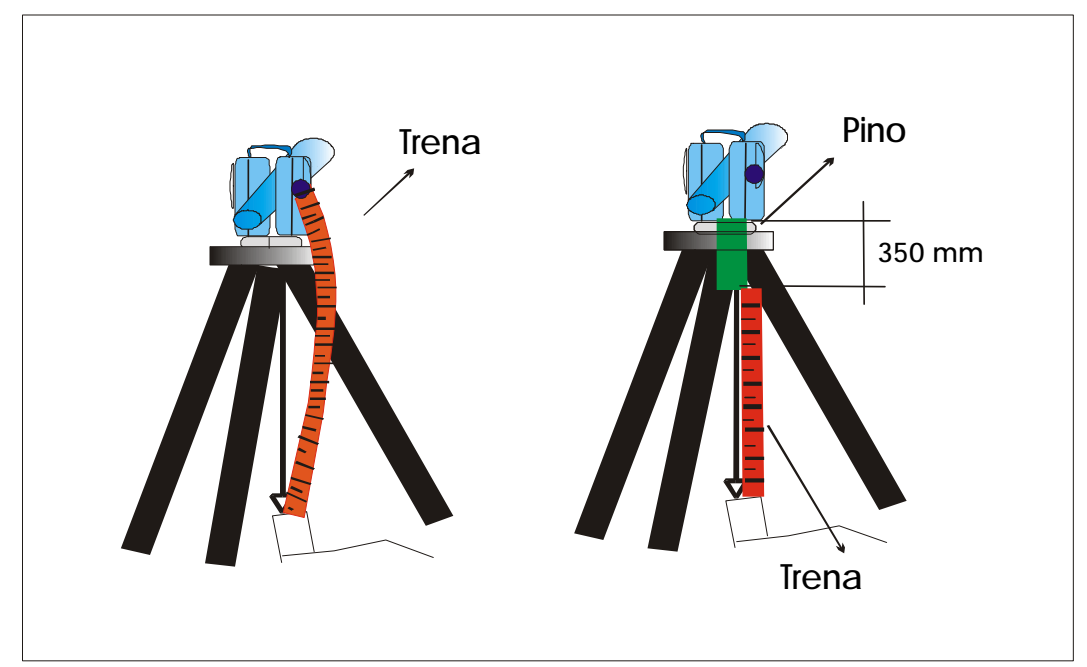

Figura 8.3: Representação da medida da altura do instrumento usando trena e pino graduado.

\section{4 - Determinação das Coordenadas}

As coordenadas foram obtidas a partir das coordenadas conhecidas dos pontos inicial e final de cada poligonal e corrigindo e ajustando as observações obtidas no campo. Após a obtenção das coordenadas ajustadas e corrigidas estas foram transformadas para o sistema cartesiano geodésico e o sistema UTM de projeção para 
comparação com as coordenadas obtidas por GPS, fazendo também análise das distâncias transformadas de um sistema para outro.

\subsection{1 - Correção das Observaç̃̃es}

A correção das observações foi realizada de acordo com a norma NBR-13133 (1994). Os erros angulares foram distribuídos proporcionalmente ao número de vértices da poligonal dado pela diferença entre os azimutes finais calculados e azimute de chegada conhecido. Os erros de cada poligonal foi comparado com as tolerâncias preconizadas pela norma para as poligonais do tipo 1, 2 e 3 já descritos anteriormente.

Os erros lineares foram distribuídos proporcionalmente ao perímetro determinados pela diferença entre a soma das projeções dos alinhamentos em cada eixo e a diferença entre as coordenadas iniciais e finais dos pontos dos respectivos eixos para o percurso. Os valores dos erros são comparados com os determinados pela norma para as poligonais do tipo 1, 2 e 3 já descritos.

\subsection{2 - Ajustamento das Observações}

Para poligonais da classe I PRC o ajustamento das observações será feito seguindo o método condicionado usando as equações de fechamento na poligonação como a seguir, conforme VERONEZ et al (1997):

$$
\begin{aligned}
& f_{1}=x_{\text {in. }}-x_{\text {fin. }}+\sum_{i=1}^{n}\left(d_{i}^{a} \cdot \operatorname{sen} A z_{\text {alinham } . i}^{a}\right)=0 \\
& f_{2}=y_{\text {in. }}-y_{\text {fin. }}+\sum_{i=1}^{n}\left(d_{i}^{a} \cdot \cos A z_{\text {alinham } . i}^{a}\right)=0 \\
& f_{3}=A z_{\text {in. }}-A z_{\text {fin. }}+\sum_{i=1}^{n}\left(\alpha{ }_{i}^{a}\right)-(n+2) \cdot 180^{\circ}=0
\end{aligned}
$$


Considerando $n$ lados e ângulos externos à poligonal, sendo:

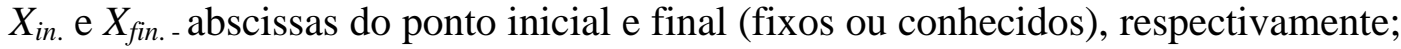

$Y_{\text {in. }}$ e $Y_{\text {fin. }}$ ordenadas do ponto inicial e final (fixos ou conhecidos), respectivamente;

$A z_{\text {in. }}$ e $A z_{\text {fin. }}$ azimutes inicial e final (fixos ou conhecidos), respectivamente.

$d_{i}^{a}, \alpha_{i}^{a}$ e $A z^{a}$ alinham.i correspondem, respectivamente, distância observada ajustada do alinhamento $i$, ângulo horizontal observado ajustado do alinhamento $i$ e azimute ajustado do alinhamento $i$.

Todos os programas desenvolvidos se encontram no Anexo I 


\section{CAPÍTULO 9 - RESULTADOS E DISCUSSÕES}

\section{1 - Coordenadas dos Pontos Obtidas por GPS}

As coordenadas dos pontos obtidas por GPS estão referenciadas no sistema Geográfico WGS-84 e SAD-69, e UTM SAD-69. Como mencionado anteriormente o ajustamento dos vetores foram realizados primeiro apenas com os vetores que descrevem o perímetro da poligonal e depois com a soma dos vetores que juntamente com estes anteriores compõem a triangulação da poligonal, conforme figuras 9.1 e 9.2. O ajustamento foi realizado em WGS-84 e depois transformadas para SAD-69 e o ponto FED 2 é a injunção mínima.

Tabela 9.1: Coordenadas da poligonal contorno no sistema WGS-84

\begin{tabular}{|c|c|c|c|c|c|}
\hline & \multicolumn{5}{|c|}{ Coordenadas WGS-84 e UTM WGS-84 } \\
\hline & \multicolumn{5}{|c|}{ Polígono Contorno } \\
\hline Ponto & Latitude (s) & Longitude $(\mathbf{w})$ & Norte $(\mathbf{m})$ & Leste $(\mathbf{m})$ & $\begin{array}{c}\text { Altura Geomé- } \\
\text { trica }(\mathbf{m})\end{array}$ \\
\hline FED2 & $21^{\circ} 58^{\prime} 53,04971^{\prime \prime}$ & 47은 $52^{\prime} 41,62760^{\prime \prime}$ & $7.566 .435,529$ & $202.777,360$ & 848,627 \\
\hline $001 \mathrm{~A}$ & $21^{\circ} 58^{\prime} 51,89298 "$ & $47^{\circ} 52^{\prime} 46,80226^{\prime \prime}$ & $7.566 .468,331$ & $202.628,164$ & 849,946 \\
\hline $002 \mathrm{~A}$ & $21^{\circ} 58^{\prime} 51,27387^{\prime \prime}$ & $47^{\circ} 52^{\prime} 54,85184^{\prime \prime}$ & $7.566 .483,031$ & $202.396,762$ & 848,919 \\
\hline $003 \mathrm{~A}$ & $21^{\circ} 58^{\prime} 46,29247^{\prime \prime}$ & $47^{\circ} 52^{\prime} 57,79656^{\prime \prime}$ & $7.566 .634,737$ & $202.309,352$ & 853,063 \\
\hline $004 \mathrm{~A}$ & $21^{\circ} 58^{\prime} 46,64214^{\prime \prime}$ & 47은 $53^{\prime} 03,01679^{\prime \prime}$ & $7.566 .621,152$ & $202.159,719$ & 847,300 \\
\hline $005 \mathrm{~A}$ & $21^{\circ} 58^{\prime} 40,78931^{\prime \prime}$ & $47^{\circ} 53^{\prime} 03,01178 "$ & $7.566 .801,271$ & $202.156,466$ & 850,101 \\
\hline $006 \mathrm{~A}$ & $21^{\circ} 58^{\prime} 33,88280^{\prime \prime}$ & $47^{\circ} 53^{\prime} 00,49258^{\prime \prime}$ & $7.567 .015,177$ & $202.224,769$ & 855,933 \\
\hline $007 \mathrm{~A}$ & $21^{\circ} 58^{\prime} 31,41111^{\prime \prime}$ & $47^{\circ} 53^{\prime} 01,40671^{\prime \prime}$ & $7.567 .090,747$ & $202.197,096$ & 854,801 \\
\hline $008 \mathrm{~A}$ & $21^{\circ} 58^{\prime} 32,68007^{\prime \prime}$ & $47^{\circ} 52^{\prime} 59,49490^{\prime \prime}$ & $7.567 .052,730$ & $202.252,708$ & 857,164 \\
\hline 009A & $21^{\circ} 58^{\prime} 36,27763^{\prime \prime}$ & 47은 52, 51,02884" & $7.566 .946,596$ & $202.497,800$ & 860,741 \\
\hline $010 \mathrm{~A}$ & $21^{\circ} 58^{\prime} 40,00927^{\prime \prime}$ & 47은 $52^{\prime} 43,22097^{\prime \prime}$ & $7.566 .835,977$ & $202.724,074$ & 856,296 \\
\hline $011 \mathrm{~A}$ & $21^{\circ} 58^{\prime} 43,71098^{\prime \prime}$ & $47^{\circ} 52^{\prime} 34,80252^{\prime \prime}$ & $7.566 .726,606$ & $202.967,852$ & 848,397 \\
\hline $012 \mathrm{~A}$ & 21ㅇ5' 51,81855" & 47은 $52^{\prime} 38,23119^{\prime \prime}$ & $7.566 .475,251$ & $202.874,132$ & 846,743 \\
\hline
\end{tabular}


Pode-se notar que as coordenadas obtidas por GPS possuem os desvios padrão altos devido a grande dificuldade do mesmo medir em regiões com obstrução. Nesta poligonal a partir do ponto $7 \mathrm{~A}$, há uma plantação de eucaliptos dificultando a recepção dos sinais transmitidos pelos satélites e causando multicaminhamento.

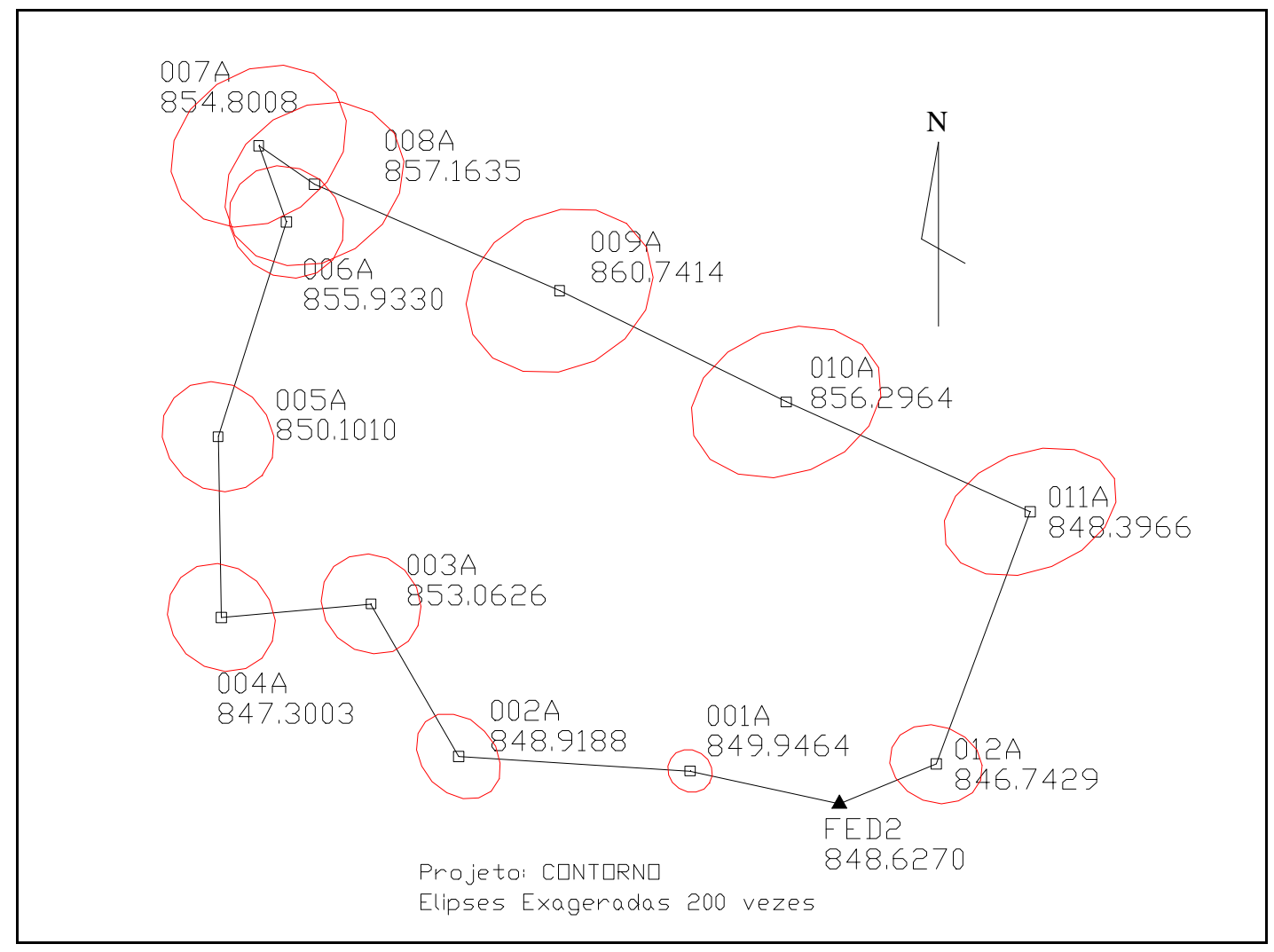

Figura 9.1: Pontos ajustados da Poligonal Contorno. 
Tabela 9.2: Coordenadas da poligonal triangulação em WGS-84

\begin{tabular}{|c|c|c|c|c|c|}
\hline & \multicolumn{5}{|c|}{ Coordenadas WGS-84 e UTM } \\
\hline & \multicolumn{5}{|c|}{ Polígono Completo } \\
\hline Ponto & Latitude (s) & Longitude (w) & Norte $(\mathbf{m})$ & Leste $(\mathbf{m})$ & $\begin{array}{l}\text { Altura Geomé- } \\
\text { trica }(\mathbf{m})\end{array}$ \\
\hline FED2 & $21^{\circ} 58^{\prime} 53,04971^{\prime \prime}$ & $47^{\circ} 52^{\prime} 41,62760^{\prime \prime}$ & $7.566 .435,529$ & $202.777,360$ & 848,627 \\
\hline $001 \mathrm{~A}$ & $21^{\circ} 58^{\prime} 51,89273^{\prime \prime}$ & 47은 $46,80212^{\prime \prime}$ & $7.566 .468,338$ & $202.628,168$ & 850,040 \\
\hline $002 \mathrm{~A}$ & $21^{\circ} 58^{\prime} 51,27369^{\prime \prime}$ & $47^{\circ} 52^{\prime} 54,85078^{\prime \prime}$ & $7.566 .483,037$ & 202.3 & ,212 \\
\hline $003 \mathrm{~A}$ & $21^{\circ} 58^{\prime} 46,29245^{\prime \prime}$ & $47^{\circ} 52^{\prime} 57,79611^{\prime \prime}$ & $7.566 .634,738$ & 202.3 & 853,404 \\
\hline $004 \mathrm{~A}$ & $21^{\circ} 58^{\prime} 46,64195^{\prime \prime}$ & 47은 53,03,01663" & $7.566 .621,158$ & 202.1 & 847,670 \\
\hline $005 \mathrm{~A}$ & $21^{\circ} 58^{\prime} 40,7$ & 47은 53,01186" & $7.566 .801,281$ & 202. & 494 \\
\hline $006 \mathrm{~A}$ & $21^{\circ} 58^{\prime} 33,8$ & $47^{\circ} 53^{\prime} 00,49280^{\prime \prime}$ & $7.567 .015,191$ & 202.2 & 350 \\
\hline $007 \mathrm{~A}$ & $21^{\circ} 58^{\prime} 31,40992^{\prime \prime}$ & $47^{\circ} 53^{\prime} 01,40500^{\prime \prime}$ & $7.567 .090,784$ & 7,144 &, 838 \\
\hline $008 \mathrm{~A}$ & $21^{\circ} 58^{\prime} 32,67880^{\prime \prime}$ & $47^{\circ} 52^{\prime} 59,49341^{\prime \prime}$ & $7.567 .052,770$ & $202.252,750$ & 858,227 \\
\hline 009A & $21^{\circ} 58,36$, & 47은 52' 51,02846" & $7.566 .946,645$ & 202.4 & 861,986 \\
\hline $010 \mathrm{~A}$ & $21^{\circ} 58^{\prime} 40,00765^{\prime \prime}$ & $47^{\circ} 52^{\prime} 43,22328^{\prime \prime}$ & $7.566 .836,026$ & $202.724,006$ & 857,152 \\
\hline $011 \mathrm{~A}$ & $21^{\circ} 58^{\prime} 43,70946^{\prime \prime}$ & $47^{\circ} 52^{\prime} 34,80333^{\prime \prime}$ & $7.566 .726,652$ & $202.967,828$ & 848,592 \\
\hline $012 \mathrm{~A}$ & $21^{\circ} 58^{\prime} 51,81902^{\prime \prime}$ & $47^{\circ} 52^{\prime} 38,23185^{\prime \prime}$ & $7.566 .475,236$ & $202.874,144$ & 846,473 \\
\hline
\end{tabular}

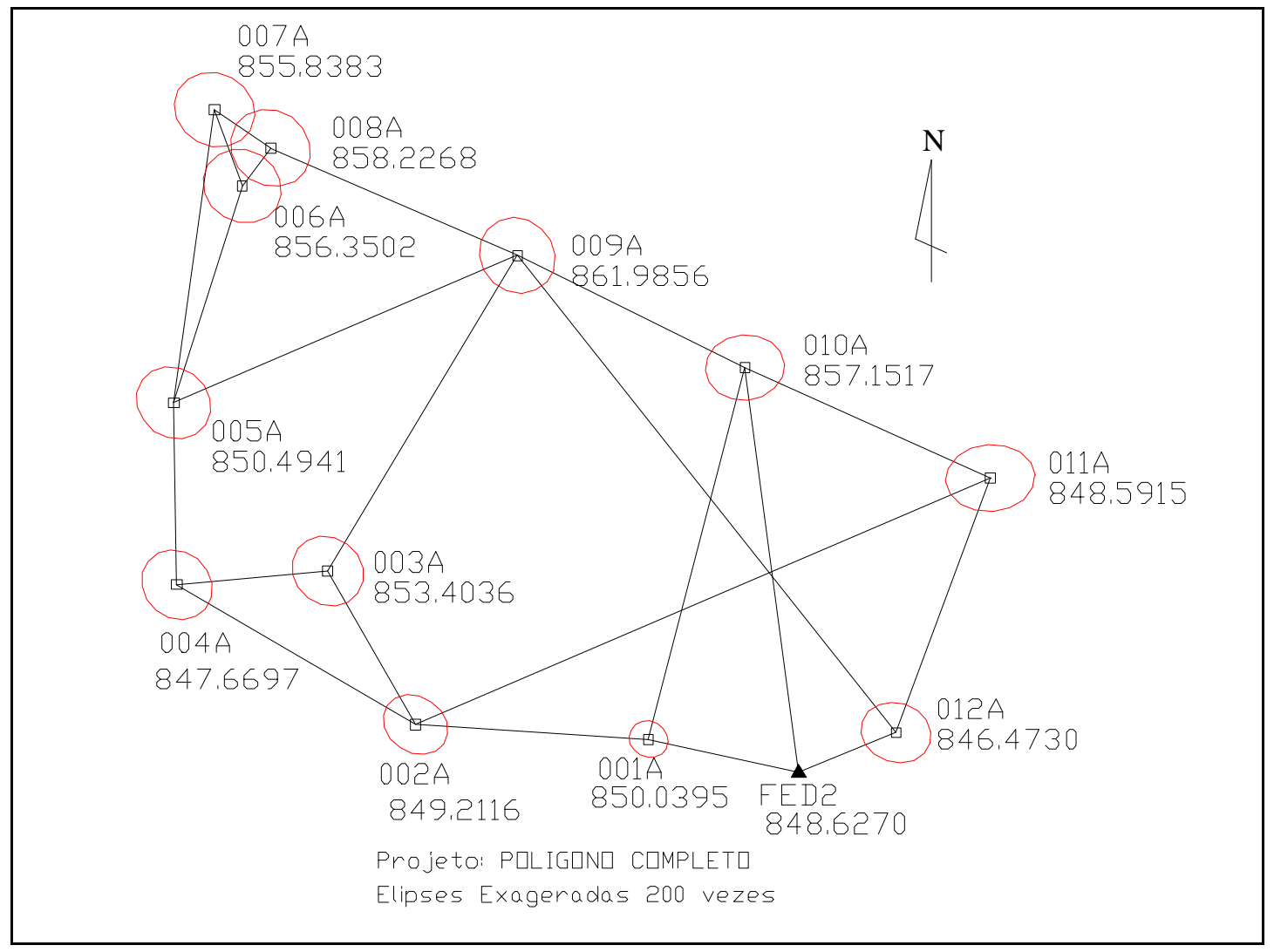

Figura 9.2: Pontos ajustados da Poligonal triangulação. 
Diferenças entre as coordenadas dos pontos em UTM WGS-84 nas duas poligonais:

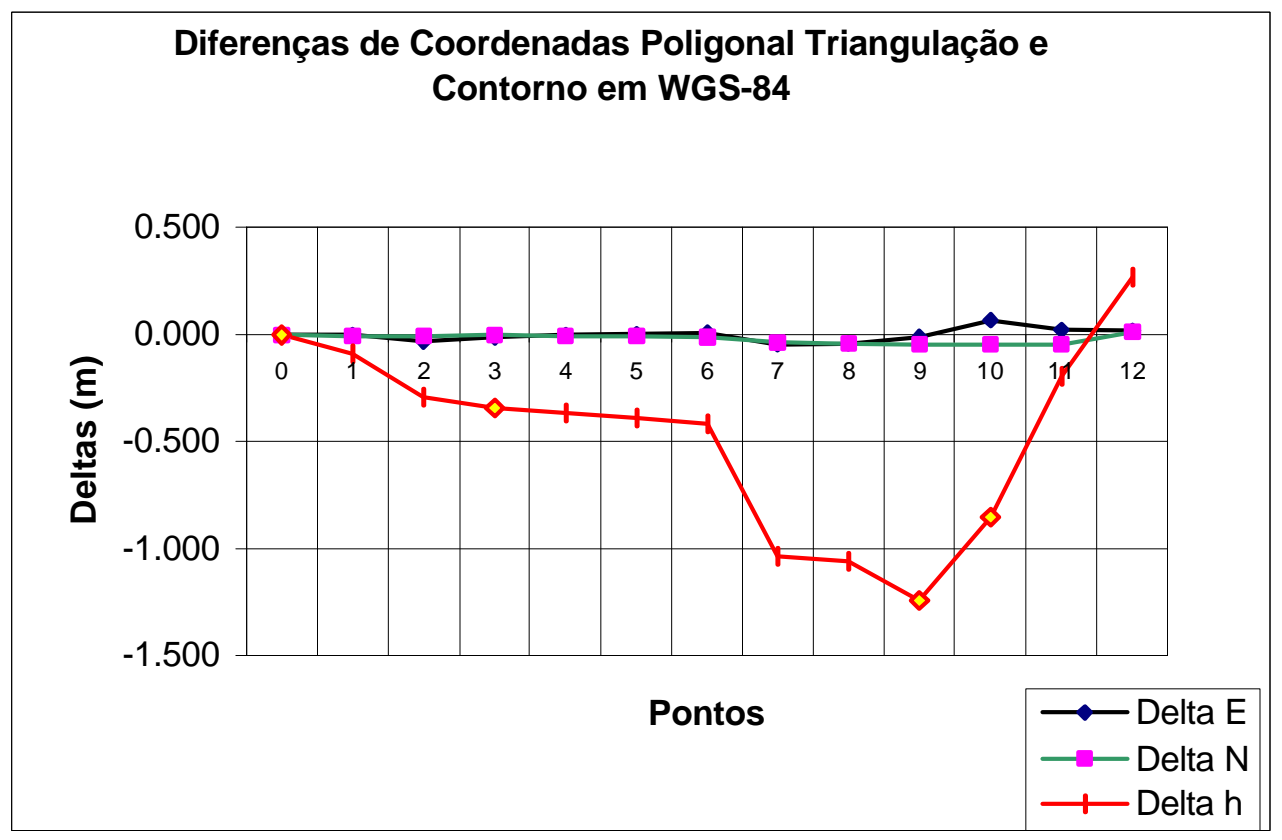

Figura 9.3: Diferenças entre as coordenadas dos pontos UTM (WGS-84) nas poligonais Contorno e Triangulação

Coordenadas dos pontos das poligonais descritas acima no sistema SAD-69:

Tabela 9.3: Coordenadas dos pontos da poligonal contorno no sistema SAD-69

\begin{tabular}{|c|c|c|c|c|c|}
\hline \multicolumn{4}{|c|}{ Coordenadas UTM em SAD-69 Polígono Contorno } & \multirow[b]{2}{*}{ Leste $(\mathbf{m})$} & \multirow[b]{2}{*}{$\begin{array}{c}\text { Altura Geomé- } \\
\text { trica }(\mathbf{m})\end{array}$} \\
\hline Ponto & Latitude (s) & Longitude (w) & Norte $(\mathbf{m})$ & & \\
\hline FED2 & $21^{\circ} 58^{\prime} 51,31683^{\prime \prime}$ & $47^{\circ} 52^{\prime} 40,00106^{\prime \prime}$ & $7.566 .481,328$ & $202.821,967$ & 855,888 \\
\hline $001 \mathrm{~A}$ & $21^{\circ} 58^{\prime} 50,16012^{\prime \prime}$ & $47^{\circ} 52^{\prime} 45,17568^{\prime \prime}$ & $7.566 .514,130$ & $202.672,772$ & 857,206 \\
\hline 002A & $21^{\circ} 58^{\prime} 49,54103 "$ & $47^{\circ} 52^{\prime} 53,22520^{\prime \prime}$ & $7.566 .528,831$ & 202. & 856,177 \\
\hline $003 \mathrm{~A}$ & $21^{\circ} 58^{\prime} 44,55966^{\prime \prime}$ & $47^{\circ} 52^{\prime} 56,16991^{\prime \prime}$ & 7.566 .68 & 202.3 & 0,322 \\
\hline $004 \mathrm{~A}$ & $21^{\circ} 58^{\prime} 44,90918^{\prime \prime}$ & $47^{\circ} 53^{\prime} 01,39058^{\prime \prime}$ & $7.566 .699,330$ & $203.926,489$ & 854,570 \\
\hline $005 \mathrm{~A}$ & $21^{\circ} 58^{\prime} 39,05654^{\prime \prime}$ & $47^{\circ} 53^{\prime} 01,38510^{\prime \prime}$ & $7.566 .847,070$ & 202.2 & 360 \\
\hline $006 \mathrm{~A}$ & $21^{\circ} 58^{\prime} 32,15006^{\prime \prime}$ & $47^{\circ} 52^{\prime} 58,86595^{\prime \prime}$ & $7.567 .060,975$ & $202.269,377$ & 195 \\
\hline 007A & $21^{\circ} 58^{\prime} 29,67838^{\prime \prime}$ & $47^{\circ} 52^{\prime} 59,78008^{\prime \prime}$ & 7.567 & 202.2 &, 063 \\
\hline $008 \mathrm{~A}$ & 21응 $30,94733^{\prime \prime}$ & $47^{\circ} 52^{\prime} 57,86828^{\prime \prime}$ & 7.567. & 202. & 426 \\
\hline 009A & $21^{\circ} 58^{\prime} 34,54485^{\prime \prime}$ & $47^{\circ} 52^{\prime} 49,40228^{\prime \prime}$ & $7.566 .992,394$ & $202.542,408$ & 868,004 \\
\hline $010 \mathrm{~A}$ & $21^{\circ} 58^{\prime} 38,27645^{\prime \prime}$ & $47^{\circ} 52^{\prime} 41,59446 "$ & $7.566 .881,775$ & $202.768,681$ & 863,560 \\
\hline $011 \mathrm{~A}$ & $21^{\circ} 58^{\prime} 41,97812^{\prime \prime}$ & $47^{\circ} 52^{\prime} 33,17606^{\prime \prime}$ & $7.566 .772,404$ & $202.012,459$ & 855,662 \\
\hline $012 \mathrm{~A}$ & 21은 58,08566" & 47은 $52^{\prime} 36,60468 "$ & $7.566 .521,050$ & $202.918,739$ & 854,005 \\
\hline
\end{tabular}


Tabela 9.4: Coordenadas dos pontos da poligonal triangulação no sistema SAD-69

\begin{tabular}{|c|c|c|c|c|c|}
\hline \multicolumn{4}{|c|}{ Coordenadas UTM em SAD-69 Polígono Completo } & \multirow[b]{2}{*}{ Leste $(\mathbf{m})$} & \multirow[b]{2}{*}{$\begin{array}{c}\text { Altura Geomé- } \\
\text { trica }(\mathbf{m})\end{array}$} \\
\hline Ponto & Latitude $(\mathbf{s})$ & Longitude $(\mathbf{w})$ & Norte $(\mathbf{m})$ & & \\
\hline FED2 & $21^{\circ} 58^{\prime} 51,31683^{\prime \prime}$ & $47^{\circ} 52^{\prime} 40,00106^{\prime \prime}$ & $7.566 .481,328$ & 202821,967 & $855,88 \varepsilon$ \\
\hline $001 \mathrm{~A}$ & $21^{\circ} 58^{\prime}$ & $7^{\circ} 52^{\prime} 45,1$ & 7.566 . & 202 & 7,300 \\
\hline $002 \mathrm{~A}$ & $21^{\circ} 58$ & $47^{\circ} 52^{\prime}$ & 7.566 & 202 & 470 \\
\hline $003 \mathrm{~A}$ & $21^{\circ} 58^{\prime} 4$ & $47^{\circ}-52^{\prime} 56,1$ & 7.566 & & 663 \\
\hline $004 \mathrm{~A}$ & $21^{\circ} 58^{\prime} 44,90916^{\prime \prime}$ & $47^{\circ} 53^{\prime} 01,3$ & 7.56 & & \\
\hline $005 \mathrm{~A}$ & $21^{\circ} 58^{\prime} 39,05622^{\prime \prime}$ & $47^{\circ} 53^{\prime}$ & 7.56 & 72 & 753 \\
\hline $006 \mathrm{~A}$ & $21^{\circ} 58^{\prime} 3$ & $47^{\circ} 52^{\prime} 58,86$ & 7.567 & 202 & 612 \\
\hline $007 \mathrm{~A}$ & $21^{\circ} 58^{\prime} 29,67719^{\prime \prime}$ & 470 52' 59,77837" & 7.567. & 202 & 863 \\
\hline $008 \mathrm{~A}$ & $21^{\circ} 58^{\prime} 30,94606^{\prime \prime}$ & $47^{\circ} 52^{\prime} 57,86679^{\prime \prime}$ & 7.567 & 202 & 489 \\
\hline $009 \mathrm{~A}$ & $21^{\circ} 58^{\prime} 34,54327^{\prime \prime}$ & $47^{\circ} 52^{\prime} 49,40190^{\prime \prime}$ & 7.566. & 418 & 249 \\
\hline $010 \mathrm{~A}$ & $21^{\circ} 58^{\prime} 3$ & $47^{\circ} 52^{\prime} 41,59677^{\prime \prime}$ & $7.566 .881,824$ & 314 & \\
\hline $011 \mathrm{~A}$ & $21^{\circ} 58^{\prime} 41,97660^{\prime \prime}$ & 47은 $32^{\prime} 3,17687^{\prime \prime}$ & 7.566 .7 & 435 & 57 \\
\hline $012 \mathrm{~A}$ & $21^{\circ} 58^{\prime} 50,08613^{\prime \prime}$ & 47ㅇ5' 36,60534" & $7.566 .521,035$ & $202.918,721$ & 853,735 \\
\hline
\end{tabular}

\subsection{Coordenadas pelo Processo Convencional}

As coordenadas finais corrigidas para a poligonal do tipo 1 estão na tabela 9.5.

Tabela 9.5: Coordenadas corrigidas para a poligonal tipo 1

\begin{tabular}{|c|c|c|c|c|c|}
\hline & \multicolumn{2}{|l|}{ Coordenadas } & & & \\
\hline Ponto & $\mathrm{X}$ & $Y$ & & & \\
\hline FED 2 & 152.295 .288 & 255.804 .182 & & & \\
\hline $1 \mathrm{~A}$ & 152.146.815 & 255.839 .784 & & & \\
\hline $2 \mathrm{~A}$ & 151.915 .848 & 255.858 .848 & & & \\
\hline $3 A$ & 151.831 .347 & 256.012 .079 & & & \\
\hline $4 \mathrm{~A}$ & 151.681 .564 & 256.001 .328 & & & \\
\hline $5 \mathrm{~A}$ & 151.681 .703 & 256.181 .374 & & & \\
\hline $6 \mathrm{~A}$ & 151.753 .973 & 256.393 .840 & & & \\
\hline $7 \mathrm{~A}$ & 151.727 .806 & 256.469 .900 & & & \\
\hline $8 \mathrm{~A}$ & 151.782 .653 & 256.430 .857 & & & \\
\hline $9 \mathrm{~A}$ & 152.025.521 & 256.320 .163 & & & \\
\hline $10 \mathrm{~A}$ & 152.249.513 & 256.205 .372 & & lerânci & \\
\hline $11 \mathrm{~A}$ & 152.490 .957 & 256.091 .507 & Angular & & $(\mathbf{m})$ \\
\hline $12 \mathrm{~A}$ & 152.392 .775 & 255.842 .047 & & $t_{p}$ & $e_{r}$ \\
\hline Erro $(\mathbf{m})$ & -0.019 & -0.013 & & 0,109 & \\
\hline Erro absol (m) & & 23 & & & 0,045 \\
\hline Erro angular & 000'09” & & $0^{\circ} 00^{\prime} 28,8$ " & & \\
\hline
\end{tabular}




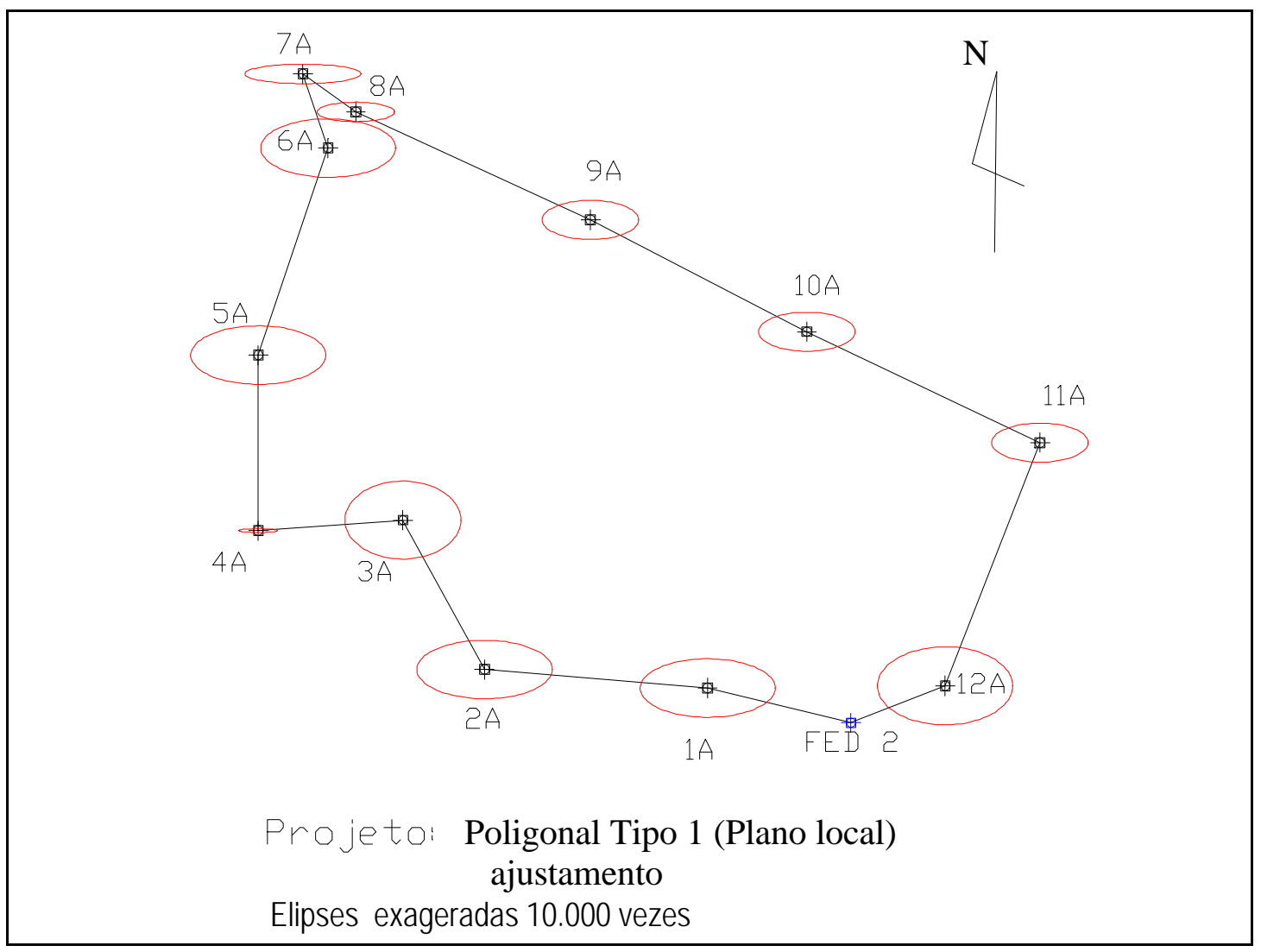

Figura9.4: Representação das coordenadas ajustadas pelo método condicional poligonal tipo 1 .

Pode-se notar que o resultado nesta poligonal tipo 1 no levantamento com a Estação Total teve um menor desvio padrão do que as ajustadas obtidas por GPS. Nestas condições onde a vegetação prejudica a recepção dos sinais transmitidos por satélite e com bases curtas a Estação Total teve um melhor desempenho. As elipses de erros da poligonal topográfica ficaram na faixa abaixo de $10 \mathrm{~mm}$ enquanto que as elipses de erro da poligonal por GPS ficaram em torno de 20 centímetros.

As coordenadas finais corrigidas para a poligonal do tipo 2 estão na Tabela 9.6. 
Tabela 9.6: Coordenadas corrigidas para a poligonal tipo 2

\begin{tabular}{|c|c|c|c|c|c|}
\hline & \multicolumn{2}{|l|}{ Coordenadas } & & & \\
\hline Ponto & $\mathrm{X}$ & $\mathrm{Y}$ & & & \\
\hline FED 2 & 152.295.288 & 255.804 .182 & & & \\
\hline $1 \mathrm{~A}$ & 152.146.817 & 255.839 .782 & & & \\
\hline $2 \mathrm{~A}$ & 151.915 .852 & 255.858 .852 & & & \\
\hline $3 \mathrm{~A}$ & 151.831 .355 & 256.012 .085 & & & \\
\hline $4 \mathrm{~A}$ & 151.681 .572 & 256.001 .339 & & & \\
\hline $5 \mathrm{~A}$ & 151.681 .718 & 256.181 .386 & & & \\
\hline $6 \mathrm{~A}$ & 151.753 .995 & 256.393.852 & & & \\
\hline $7 A$ & 151.727.831 & 256.469 .913 & & & \\
\hline $8 \mathrm{~A}$ & 151.782.677 & 256.430 .869 & & & \\
\hline $9 \mathrm{~A}$ & 152.025.543 & 256.320.167 & & & \\
\hline $10 \mathrm{~A}$ & 152.249.531 & 256.205.368 & Tolerâncias & & \\
\hline $11 \mathrm{~A}$ & 152.490.971 & 256.091 .492 & Angular & Linear & \\
\hline $12 \mathrm{~A}$ & 152.392.777 & 255.842 .040 & & $t_{p}$ & $e_{r}$ \\
\hline Erro (m) & -0.034 & -0.008 & & & \\
\hline Erro absoluto & 0.035 & & & 0,178 & 0,075 \\
\hline Erro angular & $-0 \div 00^{\prime} 02,4 "$ & & $0^{\circ} 00^{\prime} 29,2 "$ & & \\
\hline
\end{tabular}

As coordenadas finais corrigidas para a poligonal do tipo 3 estão na tabela 9.7.

Tabela 9.7: Coordenadas corrigidas para a poligonal tipo 3

\begin{tabular}{|c|c|c|c|c|c|}
\hline & \multicolumn{2}{|c|}{ Coordenadas } & & & \\
\hline Ponto & $\bar{X}$ & $\overline{\mathrm{Y}}$ & & & \\
\hline FED 1 & 152.218 .738 & 255.770 .592 & & & \\
\hline $1 \mathrm{~A}$ & 152.146.817 & 255.839 .783 & & & \\
\hline $2 \mathrm{~A}$ & 151.915 .854 & 255.858 .859 & & & \\
\hline $3 \mathrm{~A}$ & 151.831 .360 & 256.012 .096 & & & \\
\hline $4 \mathrm{~A}$ & 151.681 .577 & 256.001 .356 & Tolerâncias & & \\
\hline $5 \mathrm{~A}$ & 151.681 .730 & 256.181 .405 & Angular & Linear & \\
\hline $6 \mathrm{~A}$ & 151.754 .018 & 256.393.870 & & $t_{t}$ & $\overline{e_{r}}$ \\
\hline Erro (m) & -0.04 & -0.022 & & 0,130 & \\
\hline Erro absoluto & 0.035 & & & $t_{1}$ & 0,075 \\
\hline Erro angular & $-0^{\circ} 00^{\prime} 13,1^{\prime \prime}$ & & $0^{\circ} 00^{\prime} 23,0^{\prime \prime}$ & 0,123 & \\
\hline
\end{tabular}

Diferenças entre as coordenadas dos pontos entre as poligonais do tipo 1, 2 e 3 para os trechos comuns: 


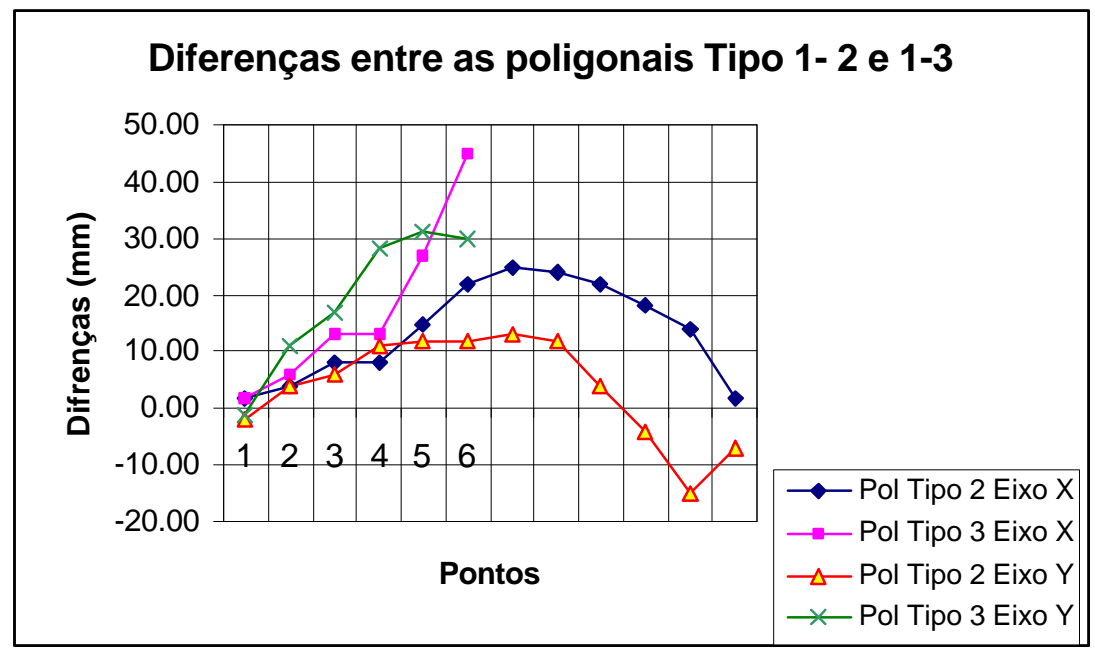

Figura 9.5: Representação das diferenças entre coordenadas das poligonais tipo 1, 2, 3.

De acordo com o gráfico pode-se observar que há uma rotação para a direita das orientações de saídas das poligonais tipo 2 e tipo 3 em relação a tipo 1. Mesmo assim todas as poligonais estão dentro do limite estabelecido pela NBR 13133.

Os erros angulares apresentadas nas tabelas anteriores vêm da série de medidas na posição direta e inversa da luneta do teodolito. Comparando este erro com o erro causado pela medição simples com apenas uma observação do ângulo horizontal pode-se dizer que o erro apresentado é menor do que o erro da medida simples pelo fato dos erros de colimação no alvo, ou seja, de falha humana. A medida simples por sua vez também ficou dentro dos limites de tolerância ditados pela NBR 13113. A repetição se faz necessária justamente para reduzir as falhas humanas e as possíveis calibrações incorretas do instrumento. A calibração deve ser realizada no início de cada trabalho de campo.

As distâncias que deram origem às coordenadas foram medidas com as correções de ppm introduzidas no ato da medição e sem as correções de ppm. Esta última foi corrigida pela fórmula empírica de Barel \& Sears e seu resultado mostrouse satisfatório em relação àquela reduzida diretamente pela Estação Total. As poucas diferenças maiores do que $1 \mathrm{~mm}$ foram devido a imprecisão da escolha no ábaco da correção ppm e as condições ambientais que variam constantemente e pelo fato de não medir a umidade que foi assumida um valor médio de $70 \%$. 


\section{3 - Coordenadas Obtidas por Ajustamento}

Tabela 9.8: Coordenadas dos pontos da poligonal do tipo 1, 2 e 3

\begin{tabular}{|c|c|c|c|c|c|c|c|c|}
\hline \multirow{3}{*}{\begin{tabular}{|c|} 
Poligonais \\
Ponto
\end{tabular}} & \multicolumn{4}{|c|}{ Tipo1 } & \multicolumn{4}{|c|}{ Tipo2 } \\
\hline & Coordenada X & $s x$ & Coordenada Y & sy & $\begin{array}{c}\text { Coordenada } \\
X\end{array}$ & sx & $\begin{array}{c}\text { Coordenada } \\
Y\end{array}$ & sy \\
\hline & $\mathrm{m}$ & $\mathrm{mm}$ & $\mathrm{m}$ & $\mathrm{mm}$ & $\mathrm{m}$ & $\mathrm{mm}$ & $\mathrm{m}$ & $\mathrm{mm}$ \\
\hline FED 1 & 152218.738 & 0.0 & 255842.038 & 0.0 & 152218.738 & 0.0 & 255842.038 & 0.0 \\
\hline $1 \mathrm{~A}$ & 152146.817 & 6.5 & 255839.784 & 2.7 & 151146.817 & 7.2 & 255839.780 & 6.9 \\
\hline $2 A$ & 151915.852 & 7.0 & 255858.850 & 3.4 & 151915.854 & 10.8 & 255858.849 & 1.0 \\
\hline $3 A$ & 151831.351 & 4.0 & 256012.079 & 6.0 & 151831.354 & 5.1 & 256012.082 & 9.2 \\
\hline $4 \mathrm{~A}$ & 151681.570 & 0.2 & 256001.329 & 2.3 & 151681.574 & 0.0 & 256001.335 & 0.8 \\
\hline $5 A$ & 151681.708 & 2.7 & 256181.374 & 6.7 & 151681.717 & 0.4 & 256181.384 & 10.3 \\
\hline $6 \mathrm{~A}$ & 151753.977 & 3.1 & 256393.840 & 6.5 & 151753.993 & 0.5 & 256393.853 & 9.8 \\
\hline $7 \mathrm{~A}$ & 151727.811 & 1.1 & 256469.898 & 5.9 & 151727.827 & 0.2 & 256469.914 & 9.2 \\
\hline $8 \mathrm{~A}$ & 151782.659 & 0.6 & 256430.853 & 3.7 & 151782.674 & 0.1 & 256430.868 & 5.7 \\
\hline $9 \mathrm{~A}$ & 152025.529 & 1.6 & 256320.158 & 4.6 & 152025.539 & 0.2 & 256320.164 & 4.7 \\
\hline $10 \mathrm{~A}$ & 152249.521 & 1.7 & 256205.364 & 4.6 & 152249.527 & 0.3 & 256205.362 & 5.7 \\
\hline $11 \mathrm{~A}$ & 152490.966 & 1.7 & 256091.497 & 4.7 & 152490.967 & 0.3 & 256091.484 & 4.7 \\
\hline $12 \mathrm{~A}$ & 152392.781 & 3.7 & 255842.038 & 6.7 & 152392.771 & 0.6 & 255842.036 & 5.1 \\
\hline FED 2 & 152295.288 & 0.0 & 255804.182 & 0.0 & 152295.288 & 0.0 & 255804.182 & 0.0 \\
\hline \multicolumn{5}{|c|}{ Tipo3 } & & & & \\
\hline \multirow[t]{2}{*}{ Ponto } & Coordenada X & $s x$ & Coordenada Y & sy & & & & \\
\hline & $\mathrm{m}$ & $\mathrm{mm}$ & $\mathrm{m}$ & $\mathrm{mm}$ & & & & \\
\hline FED 1 & 152218.738 & 0.0 & 255842.038 & 0.0 & & & & \\
\hline $1 \mathrm{~A}$ & 152146.823 & 11.7 & 255839.791 & 11.4 & & & & \\
\hline $2 A$ & 151915.844 & 14.6 & 255858.887 & 16.2 & & & & \\
\hline $3 A$ & 151831.360 & 13.7 & 256012.125 & 14.8 & & & & \\
\hline $4 \mathrm{~A}$ & 151681.561 & 0.8 & 256001.394 & 11.0 & & & & \\
\hline $5 \mathrm{~A}$ & 151681.723 & 13.4 & 256181.430 & 14.5 & & & & \\
\hline $6 \mathrm{~A}$ & 151754.018 & 0.0 & 256393.870 & 0.0 & & & & \\
\hline
\end{tabular}

Nestas coordenadas obtidas por ajustamento houve erros de ajustamento em cada eixo descritos na tabela 9.9 devido aos pesos determinados para cada observação.

Tabela 9.9: Diferença de fechamento nos eixos coordenados X e Y no ajustamento.

\begin{tabular}{|c|c|c|}
\hline $\begin{array}{c}\text { Tipo de } \\
\text { Poligonal }\end{array}$ & $\begin{array}{c}\text { Erro eixo X } \\
(\mathrm{mm})\end{array}$ & $\begin{array}{c}\text { Erro eixo Y } \\
(\mathrm{mm})\end{array}$ \\
\hline 1 & +7 & -7 \\
2 & -3 & -3 \\
3 & +2 & +4 \\
\hline
\end{tabular}


Como esperado a poligonal tipo 3 teve os maiores desvios padrões apresentados na 9.8 dados pela rotação do azimute de partida que determinou coordenadas de partida e de chegada distorcidas da realidade.

Os erros de ajustamento foram comparados com os preconizados pela norma para ajustamento como descrito no Capítulo 8, e estão na tabela abaixo:

Tabela 9.10: Comparação dos erros aceitáveis 6.5 .8 com os calculados por ajustamento item 6.5 .6

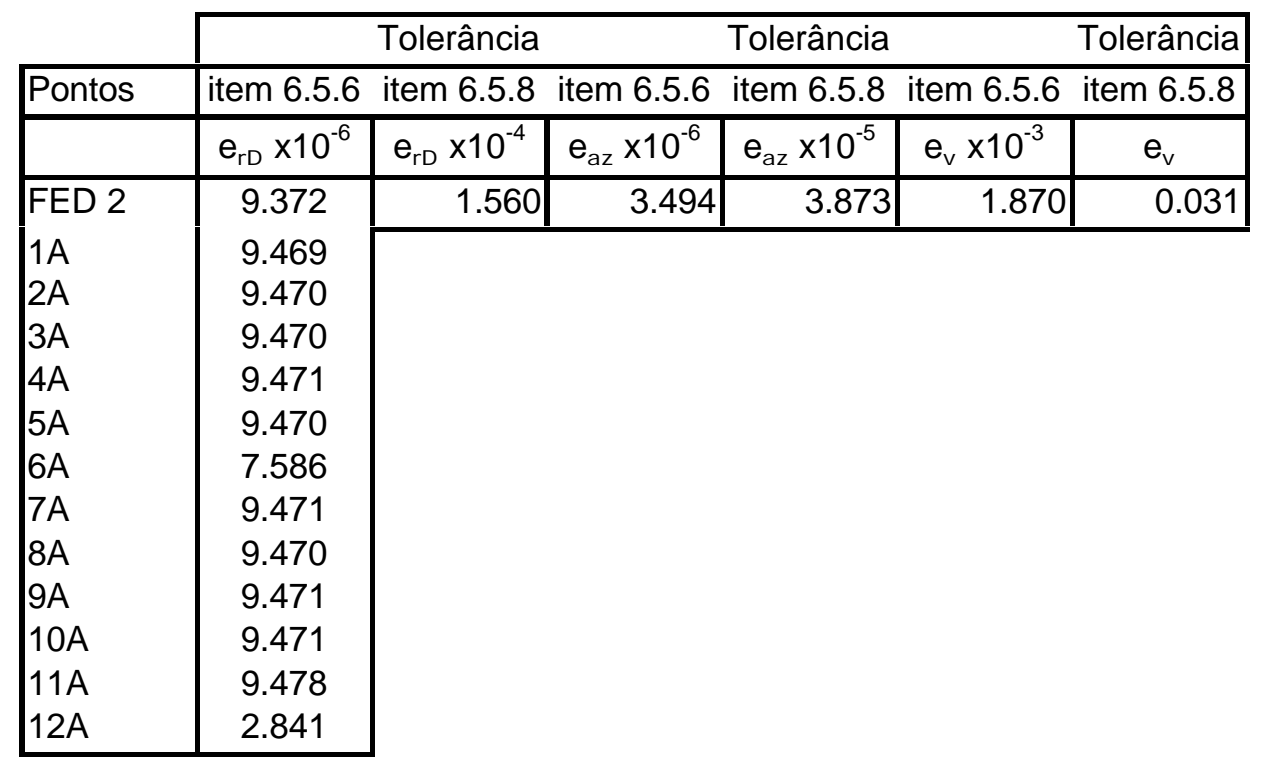

O item 6.5.6 preconiza os erros relativos aceitáveis para ajustamento dependentes dos erros calculados também por compensação que é o caso das correções das coordenadas relativas em X e Y. Outro aspecto é a obrigatoriedade das comparações com os erro linear após compensação angular, erro relativo de fechamento após a compensação angular, fechamento longitudinal, antes da compensação angular (poligonais tipo 3), e transversal antes da compensação angular (poligonais tipo 3) que no ajustamento não é obtido diretamente pelo método condicional empregado. O método condicional empregado ajusta as observações de campo, ângulo e distâncias, em conjunto e simultaneamente apresentando os resíduos das destas observações brutas. Assim no processo de ajustamento não se têm as 
correções nas coordenadas relativas da poligonal que é necessária no cálculo dos erros médios relativos entre duas estações e erro médio de coordenadas; também não se determina o erro relativo de fechamento linear após compensação angular. Desta forma é preciso fazer compensação em paralelo para que se possa avaliar os erros médios relativos de fechamento no ajustamento tanto quanto os parâmetros para a determinação dos erros toleráveis para o ajustamento.

\section{4 - Distâncias Horizontais da Poligonal Reduzidas nas Diferentes Superfícies de Referência}

A distância horizontal corrigida na poligonal tipo 1 foi reduzida nas diversas superfícies de referência, tais como esférica, geodésica e plana UTM. Estas distâncias encontradas estão na Tabela 9.11.

Tabela 9.11: distância horizontal reduzida nas diversas superfícies de referência.

\begin{tabular}{|c|c|c|c|c|c|c|c|}
\hline & & \multicolumn{6}{|c|}{ Distância } \\
\hline \multirow{4}{*}{ Código } & \multirow{4}{*}{ Alinham. } & & \multirow{2}{*}{\multicolumn{2}{|c|}{$\begin{array}{c}\text { Reduzidas ao nível } \\
\text { do mar }\end{array}$}} & \multirow{2}{*}{\multicolumn{2}{|c|}{ UTM }} & \multirow[t]{2}{*}{ Elipsoidal } \\
\hline & & \multirow{3}{*}{\begin{tabular}{l|} 
Horizontal \\
Plan, local
\end{tabular}} & & & & & \\
\hline & & & Equa & & GPS & Local & \\
\hline & & & 5.28 & 5.5 & & Equ. 5.98 & Equ 5.24 \\
\hline 0 & 12 FED 2 & 104.583 & 104.568 & 104.568 & 104.585 & 104.626 & 104.568 \\
\hline 1 & FED 2_1A & 152.682 & 152.662 & 152.654 & 152.757 & 152.767 & 152.660 \\
\hline 2 & 1A_2A & 231.752 & 231.720 & 231.718 & 231.841 & 231.882 & 231.719 \\
\hline 3 & 2A_3A & 174.986 & 174.962 & 174.912 & 175.060 & 175.084 & 174.968 \\
\hline 4 & $3 A \_4 A$ & 150.169 & 150.149 & 150.039 & 150.286 & 150.253 & 150.147 \\
\hline 5 & 4A_5A & 180.046 & 180.022 & 180.000 & 180.153 & 180.147 & 180.030 \\
\hline 6 & $5 A \_6 A$ & 224.421 & 224.391 & 224.315 & 224.548 & 224.547 & 224.399 \\
\hline 7 & 6A_7A & 80.435 & 80.424 & 80.422 & 80.480 & 80.481 & 80.428 \\
\hline 8 & $7 A \_8 A$ & 67.324 & 67.315 & 67.273 & 67.358 & 67.362 & 67.316 \\
\hline 9 & 8A_9A & 266.905 & 266.869 & 266.853 & 267.052 & 267.054 & 266.868 \\
\hline 10 & 9A_10A & 251.693 & 251.659 & 251.658 & 251.795 & 251.832 & 251.659 \\
\hline 11 & 10A_11A & 266.947 & 266.910 & 266.875 & 267.230 & 267.095 & 266.910 \\
\hline 12 & 11A_12A & 268.085 & 268.049 & 267.892 & 268.314 & 268.235 & 268.060 \\
\hline
\end{tabular}

Gráfico apresentando as diferenças das distâncias reduzidas nas demais superfícies de referência a partir da distância horizontal medida no plano local. Nesta 
análise também foi incluída a distância UTM dado pelo processamento das observações GPS.

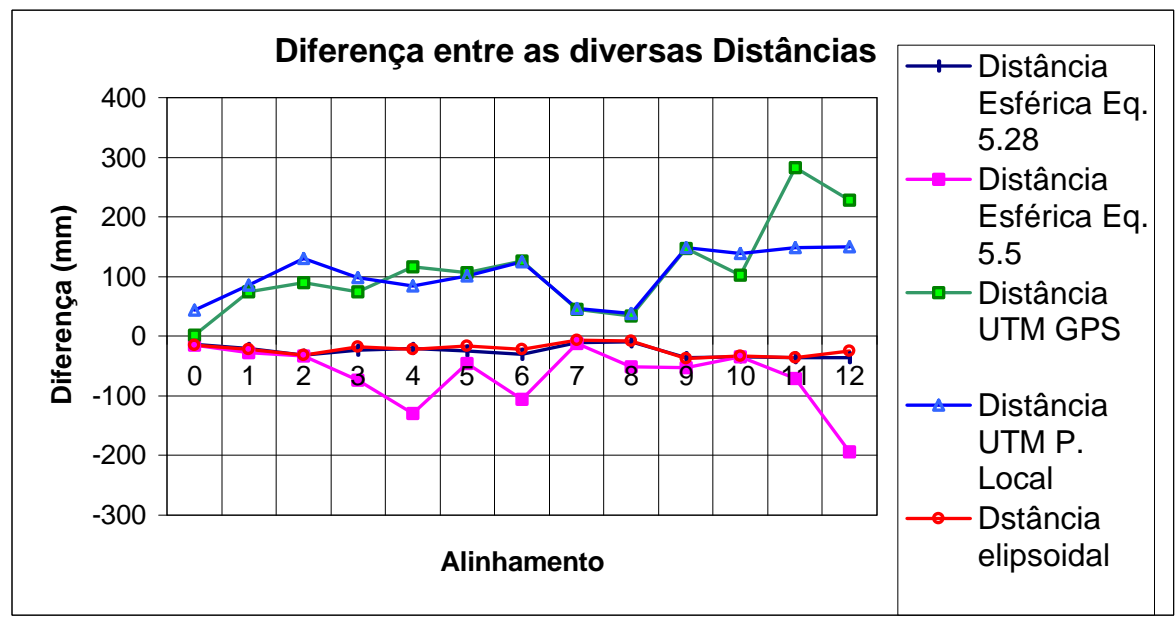

Figura 9.5: Representação da diferença das distâncias nas diversas superfícies de referência em relação a distância horizontal medida no plano local.

De acordo com o gráfico vê-se a necessidade da redução das distâncias de uma superfície para outra para alcançar melhor precisão no cálculo das coordenadas. Nota-se que a distância esférica dada pela equação 5.28, descrita por SILVA (1999), tem uma menor variação em relação a distância horizontal do que a equação 5.5 descrita por VANICECK (1986). Estas distâncias dadas pelas equações 5.5 e 5.28 foram reduzidas em planas UTM usando o fator de escala do ponto de partida. Em seguida determinou-se as projeções de cada alinhamento que somando às coordenas UTM do ponto FED 2 chegou-se a um erro de fechamento para o eixo X de $10 \mathrm{~mm}$ e $76 \mathrm{~mm}$ e no eixo Y de $19 \mathrm{~mm}$ e $66 \mathrm{~mm}$ para a equação 5.28 e 5.5 respectivamente. Portanto, a equação 5.28 teve um melhor resultado na obtenção da distância esférica de aproximação ao elipsóide analisando o erro de fechamento nos eixos X e Y. Comparando esta distância esférica também com a distância elipsoidal dada pela equação 5.24, descrita por RAPP (1989) seus desvios são menores. A distância elipsoidal por sua vez teve os erros de $19 \mathrm{~mm}$ no eixo $\mathrm{X}$ e de $18 \mathrm{~mm}$ no eixo $\mathrm{Y}$ comparável à distância esférica da equação 5.28. Estes erros são devidos aos fatores 
de escala aplicados para transformar a distância no nível do mar em plana e as aproximações dos cálculos das distâncias esféricas e elipsoidais.

Quando se transformou as distâncias horizontais em projeções no sistema cartesiano geodésico pelas equações descritas por RAPP (1989) a soma destas determinou um erro de fechamento de $-47 \mathrm{~mm}$ em X, $+23 \mathrm{~mm}$ em Y e $-18 \mathrm{~mm}$ em Z.

Analisando a distância UTM obtida por GPS e a transformada pela distância horizontal nota-se uma variação maior justamente na região onde há a plantação de eucaliptos e o GPS tem suas limitações.

\section{5 - Cotas do Nivelamento Trigonométrico Ajustadas e as Cotas do Nivelamento Geométrico}

A Tabela 9.12 apresenta as cotas obtidas por nivelamento trigonométrico e seus desvios padrões e cotas do nivelamento geométrico para os pontos da poligonal.

Tabela 9.12: Cotas dos pontos dadas por nivelamento trigonométrico e geométrico

\begin{tabular}{|c|c|c|c|}
\hline & \multirow{2}{*}{\begin{tabular}{c|} 
Cota \\
Trigonométrica
\end{tabular}} & & \multirow{2}{*}{$\begin{array}{c}\text { Cota } \\
\text { Geométrico }\end{array}$} \\
\hline Ponto & & $\bar{S}$ & \\
\hline FED 2 & 854.91630 & 0.8 & 854.9132 \\
\hline $1 \mathrm{~A}$ & 856.45400 & 0.0 & 856.4540 \\
\hline $2 \mathrm{~A}$ & 855.48310 & 1.6 & 855.4836 \\
\hline $3 A$ & 859.67910 & 1.3 & 859.6755 \\
\hline $4 \mathrm{~A}$ & 853.94190 & 1.1 & 853.9420 \\
\hline $5 A$ & 856.76530 & 1.3 & 856.7612 \\
\hline $6 \mathrm{~A}$ & 862.61510 & 1.6 & 862.6114 \\
\hline $7 \mathrm{~A}$ & 862.11120 & 0.6 & 862.1059 \\
\hline $8 \mathrm{~A}$ & 864.49010 & 0.5 & 864.4831 \\
\hline $9 A$ & 868.17370 & 0.9 & 868.1681 \\
\hline $10 \mathrm{~A}$ & 863.84160 & 1.7 & 863.8394 \\
\hline $11 \mathrm{~A}$ & 854.66320 & 1.9 & 854.6629 \\
\hline $12 \mathrm{~A}$ & 851.55130 & 1.9 & 851.5511 \\
\hline
\end{tabular}

O gráfico a seguir apresenta as diferenças entre as cotas dos nivelamentos trigonométrico e geométrico para os pontos da poligonal. 


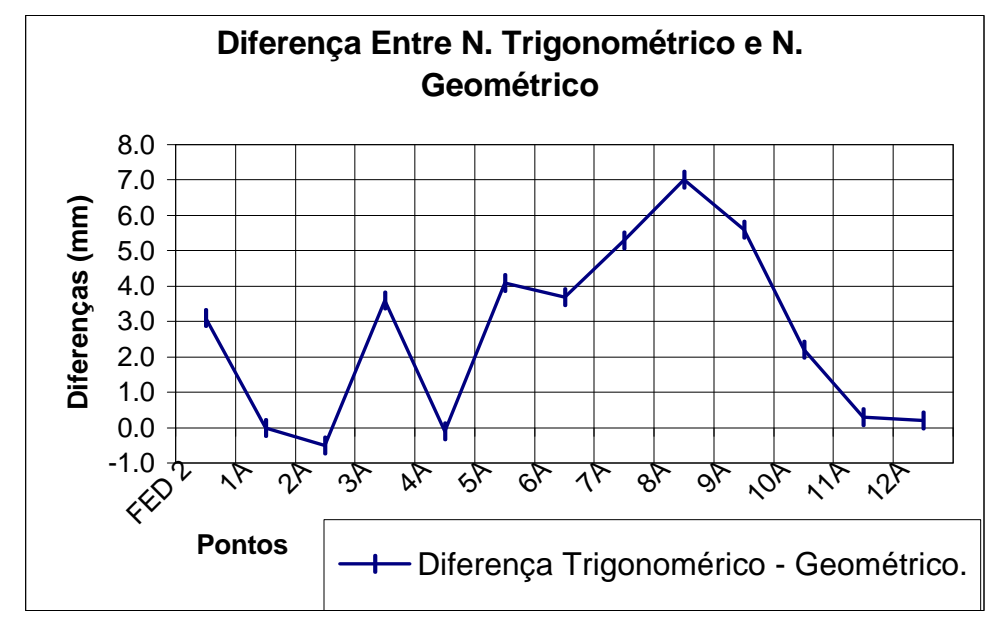

Figura 9.6: Diferenças entre cotas nivelamento trigonométrico e geométrico.

Os erros de fechamento para os dois nivelamento foram iguais no valor -4.7 $\mathrm{mm}$ inferior ao valor da norma de $\operatorname{Erro}=12 \cdot \sqrt{2.42}=18,7 \mathrm{~mm}$. Dos valores apresentados pode-se concluir que o nivelamento trigonométrico com todo o rigor no levantamento pode ser executado sem prejuízos na precisão das cotas e é comparável ao nivelamento geométrico quando se executa visadas zenitais recíprocas para as devidas correções da refração.

Em um teste realizado fazendo as leituras do ângulo zenital na posição direta e inversa na observação do prisma instalado também em um tripé (centragem forçada), com altura do instrumento e prisma sendo medida à trena, e em períodos da manhã onde a variação da refração é maior teve-se um erro de fechamento de $35 \mathrm{~mm}$, acima do permitido por norma. Podemos destacar como problemas as medidas de altura de instrumento e prisma realizadas com a trena e, a visada do alinhamento 8A - 9A foi realizada muito próxima a superfície da terra. A variação da medida da trena para os outro dispositivos ficou em torno de $2 \mathrm{~mm}$ e a diferença de nível entre a medida direta de $8 \mathrm{~A}$ - 9A e a medida em que o alinhamento foi divido em duas partes ficou em torno de $6 \mathrm{~mm}$. Nota-se também que o erro de fechamento vertical na posição direta e inversa $\left(360^{\circ}\right)$ da luneta para a região da poligonal no período da manhã e no período d tarde variou até 20 segundos. 


\section{0 - CONCLUSÕES E RECOMENDAÇÕES}

Pelos resultados obtidos na poligonal de base curta desenvolvida na região de São Carlos no campus da Universidade Federal de São Carlos pode-se dizer que a combinação de levantamentos com Estação Total e GPS são possíveis e atendem as tolerâncias da NBR 13133. Tem-se que estar atento ao fato das limitações de cada instrumentos ligadas às condições da área a ser levantada.

Nesta poligonal percebe-se a dificuldade de medição utilizando GPS na região coberta por árvores e da Estação Total em alinhamentos próximos ao solo. Todos estes fatores são determinantes na obtenção da precisão do levantamento dos pontos e, salientando, para se limitar o uso de cada um dos instrumentos nos diversos levantamentos.

Os fatores climáticos devem ser levados em conta nas medições de ângulos e distâncias tanto na determinação da refração e eliminação de seus efeitos na determinação das coordenadas.

As reduções de uma superfície para outra se mostrou importante devido as diferenças entre as distâncias serem significantes para trabalhos de precisão e se não aplicadas pode acarretar em erros provenientes da geometria do sistema de referência que somados aos erros acidentais geram coordenadas com desvios acima do desejado e preconizado pela norma.

O nivelamento trigonométrico pode ser uma alternativa para levantamentos altimétricos de precisão comparável ao nivelamento geométrico. Em regiões de difícil execução do nivelamento geométrico (encostas) pode-se aplicar o nivelamento trigonométrico com os rigores devidos descritos anteriormente. Uma das falhas da 
NBR 13133 é não mencionar o nivelamento trigonométrico para levantamentos altimétricos de precisão, cita apenas o nivelamento geométrico.

De acordo com o trabalho desenvolvido e resultados conseguidos pode-se sugerir a mudança da norma inserindo o nivelamento trigonométrico como uma alternativa para levantamentos altimétricos, fazendo a descrição do método e controles do mesmo.

O presente estudo verificou-se apenas em bases curtas os efeitos atmosféricos e geométricos cabendo um estudo para bases longas. A limitação do plano local descrito pela norma de $80 \mathrm{~km}$ não foi testado no trabalho devido a extensão do levantamento executado não atingir o limite preconizado.

A repetição das observações se mostra necessária para garantir o resultado da medição no intuito de eliminar os erros humanos e atmosféricos mais do que os erros instrumentais já que os instrumentos eletrônicos possuem componentes de controle e se mostraram eficazes. 


\section{REFERÊNCIAS BIBLIOGRÁFICAS}

ABNT, Associação Brasileira de Normas Técnicas: NBR13133 - Execução de levantamento topográfico. Rio de Janeiro, 1994.

BRINKER, R.C.; WOLF, P.R. (1994).Elementary Surveying, $9^{\mathfrak{a}}$ edição, New York: HaperCollins.

BURNSIDE,C.D. (1991). Electromagnetic Distance Measurement, $3^{a}$ edição, BSP Profissional Books.

CAMARGO, P.O., MONICO, J.FG., ISHIKAWA, M.I., ITAME, O.Y. (1998). Posicionamento GPS para apoio de Poligonais Topográficas: Análise do erro de Fechamento, COBRAC 1998 - Congresso Brasileiro de Cadastro Técnico Multifinalitário, UFSC Florianópolis.

CINTRA, J.P. (1989). Sistema UTM - Noções de Geodésia e Cartografia. São Paulo, EPUSP -PTR.

CINTRA, J.P. (1995). Teodolitos Eletrônicos, Congresso Brasileiro de Cartografia, 17. EPUSP - Escola Politécnica da Universidade de São Paulo. 
CINTRA, J.P. (1989). Sistema U.T.M. (Noções de Geodesia e Cartografia), PTR-266 - Técnicas Topográficas e Cartográficas, EPUSP - Escola Politécnica da Universidade de São Paulo, Departamento de Transportes.

CHAVES, E.E.D. (1998). Análise da Qualidade de Dados Georreferenciados Utilizando a Tecnologia GPS. Dissertação (Mestrado) - Escola de Engenharia de São Carlos, Universidade de São Paulo.

COOPER, M.A.R. (1987). Modern Theodolites and levels, $2^{a}$ edição, The City University, London - BSP Professional Books.

COOPER, M.A.R. (1986). Fundamentals of survey measurement and analysis, $1^{\mathrm{a}}$ edição, Departament of Civil Engineering The City University, London - Collins Professional and Techinical Books.

CUNHA, M.J.P., SANTOS, M.C.S., ANDRADE, J.B. (1997). Aplicação do Sistema de Posicionamento Global para Unificação de Bases Cadastrais, GisBrasil 1997.

DOMINGUES, F.A.A. (1979). Topografia e Astronomia de Precisão para engenheiros e arquitetos, MacGraw-Hill do Brasil ltda.

ELFICK, M., FRYER, J., BRINKER, R.,WOLF, P. (1994). Elementary surveying, $8^{\mathrm{a}}$ edição - HarperCollins Publishers ltd, Uk.

FREITAS, L.E. (1997). Sistema de Navegação por Satélite GPS - Funcionamento do Sistema e suas Aplicações, FATEC - SP. http://www.geocities.com/CapeCanaveral/Lab/9947/index.htm . 
FUNDAÇÃO INSTITUTO BRASILEIRO DE GEOGRAFIA E ESTATÍSTICA IBGE, (1986). Tabelas para Cálculos no Sistema de Projeção Universal Transverso de Mercator (UTM) (Elipsoide Internacional de 1967), Rio de Janeiro.

GEMAEL, C. (1994).Introdução ao Ajustamento de Observações: aplicações geodésicas, editora da Universidade Federal do Paraná - UFPR, Curitiba - PR.

GRIPP Jr., J., SILVA, A. S. (1997). O Sistema U.T.M. Operações Principais (Notas de aulas), Engenharia de Agrimensura, Departamento de Engenharia Civil, Universidade Federal de Viçosa (UFV) - MG.

GRIPP Jr., J., SILVA, A. S. (1997). Geodésia Geométrica (Notas de aulas), Engenharia de Agrimensura, Departamento de Engenharia Civil, Universidade Federal de Viçosa (UFV) - MG.

HAZAY, I. (1970). Adjusting Calculations in Surveying, Akadémiai Kiadó, Budapest.

HOFFMANN-WELLENHOF, B., LICHETENEGGER, H.,COLLINS, J. (1997). Global Positioning System, $4^{a}$ edição, Springer-Verlag/Wien.

JORDAN, D.W. (1944). Tratado General de Topografia V. I. Barcelona, Editorial Gustavo Gili, S.A.

KAHMEN, H., FAIG, W. (1988). Surveying, Walter de Gruyter - Berlin- New York.

KENNIE, T.J.M, PETRIE, G. (1993). Engineering Surveying Techonology, $1^{\mathrm{a}}$ edição, Blackie Academic \& Professional - USA, Halsted Press. 
LEICK, A. (1995). GPS Satellite Surveying. 2.ed. New York,John Wiley \& Sons.

LISBÔA, C.E.M. (1969). O contrôle das observações zenitais recíprocas, Serviço Geográfico do Exército, IV congresso de cartografia - Belo Horizonte.

LUNARDI, O.A., FERREIRA, A.A. (1997). Emprego de Rastreadores GPS no Mapeamento Sistemático da Região Sul do Brasil, GisBrasil 1997.

MANSO, F.A. (1975) Manual técnico T 34-410- Nivelamento trigonométrico, $1^{\mathrm{a}}$ edição, Ministério do exército - Estado Maior do Exército.

MIKAIL, E.M.; GRACIE, G. (1981). Analysis and adjustament of survey measurements; Van Nostrand Reinold, New York.

MIKAIL, E.M.; ACKERMANN, F. (1976). Observation and least squares; IEP_A Dun-Donnelley Publisher, New York.

MOFFIT, F.H., BOUCHARD, H. (1987). Surveying, $8^{a}$ edição, Harper \& Row, New York.

MONICO, J.F.G., CAMARGO, P.O., SILVA, E.F., (1997). Integração GPS de Navegação e RBMC no Posicionamento e Cálculo de Áreas: Análise dos Resultados, GisBrasil.

MORAES, R.V., FITZGIBBON, K.T.,WALTER, F. (1998). O Sistema GPS, Divisão de Engenharia Aeronáutica e eletrônica, ITA, GPS Brasil.

MOREIRA, A.P. (1998). Métodos de cálculos de coordenadas tridimensionais para controle de obras de engenharia, Escola de engenharia de São Carlos - São Carlos - SP, tese de doutorado. 
MUELLER, I.I., RAMSAYER, K.H. (1979). Introduction to surveying - Fredrick Ungar Publishing Co/New York.

PRICE, W.F., UREN, J. (1989). Laser Surveying, $1^{\text {a }}$ edição, Van Nostrand Reinold (International) Co. Ltd, Londres.

RIBAS, E.B, SARAIVA, C.C.S. (1997). Parâmetros para Utilização do GPS na Reambulação de Mapas Municipais: Viabilidade e Restrições, GisBrasil.

SCHOFIELD, W. (1993). Engineering Surveying, $4^{\mathrm{a}}$ edição, Butterworth-Heinemann ltd.

SEGANTINE, P.C.L. (1995). Estabelecimento e Ajuste de uma Rede Geodésica no Estado de São Paulo, com o Sistema de Posicionamento NAVISTAR/GPS; tese (doutorado) - Departamento de Engenharia de Transportes, Escola Politécnica da Universidade de São Paulo - SP.

SEGANTINE, P.C.L. (1999). GPS Sistema de Posicionamento Global. Apostila editada pela Escola de Engenharia de São Carlos, Universidade de São Paulo.

SERVICE MANUAL DI1600/TC1600 (1990), General Description Doc Code SML 556.904.

SILVA, I., ERWES, H. (1999). Apostila do IV Curso de Atualização em Topografia e GPS (segundo a NBR 13.133). Apostila não publicada, Escola de Engenharia de São Carlos, Universidade de São Paulo.

SILVA, I. (1993). Instrumentos topográficos modernos - topografia moderna, Congresso brasileiro de cartografia, 16; Rio de Janeiro. 
TORGE, W. (1980). Geodesy. Berlin, Walter de Gruyter.

VANICEK, P., KRAKIWSKY, E.J. (1986). Geodesy: The Concepts, $2^{\circledR}$ edição. North Holland.

VERONEZ, M. R., SÁ, L. A. C. M., SILVA I.(1997). O Ajustamento de Poligonais Topográficas Pelo Método dos Mínimos Quadrados - resumo; XVIII Congresso de Cartografia, Rio de Janeiro.

ZEISK, K. (1999). A new generation of Total Station from Leica Geosystem Tps1100 Professional Series, Leica Geosystems AG, Heerbrugg, Switzerland. 
ANEXO I

$\bar{A}$ 


\section{Programa para Transformação de Coordenadas Geodésicas Geográficas para UTM SAD-69}

Transformação de coordenadas Geodésicas em UTM SAD-69

Latitude de comparação para o cálculo do comprimento do arco no caso do equador até o meridiano

$$
\begin{array}{ll}
\phi \mathrm{I}:=0 & \text { Ponto } 1 \mathrm{~A} \\
\text { latitude } & \text { longitude } \\
\text { grau }:=-21 & \text { graul }:=-47 \\
\min :=58 & \operatorname{minl}:=52 \\
\sec :=50.15936 & \operatorname{secl}:=45.17583 \\
\phi:=\text { grau }-\frac{\min }{60}-\frac{\sec }{3600} & \phi=-21.9805998222 \\
\lambda:=\text { graul }-\frac{\operatorname{minl}}{60}-\frac{\operatorname{secl}}{3600} & \lambda=-47.8792155083
\end{array}
$$

deve-se abaixar o mc da alternativa escolhida para MC para dar prioridade ao valor correto

Cálculo do Meridiano Central quando negativo

$$
\begin{aligned}
& \mathrm{MC}:=\left(\text { floor }\left(\frac{\text { graul }}{6}\right) \cdot 6\right)+3 \\
& \mathrm{MC}=-45
\end{aligned}
$$

Cálculo de P

$$
P:=0.0001 \cdot(\lambda-\mathrm{MC}) \cdot 3600 \quad \mathrm{P}=-1.036517583
$$

$$
\begin{aligned}
& \text { Cálculo de I } \\
& \text { ko }:=0.9996 \text { fator de escala do meridiano central } \\
& \mathrm{S}:=0 \quad \text { comprimento do arco do meridiano até o equador } \\
& \mathrm{a}:=6378160 \\
& \mathrm{~b}:=6356774.719 \quad \text { as }:=1 \cdot \frac{\pi}{3600180} \quad \phi:=\frac{\pi}{180} \cdot \phi \quad \phi \mathrm{I}:=\frac{\pi}{180} \cdot \phi \mathrm{I} \\
& \mathrm{e}:=\frac{\sqrt{\mathrm{a}^{2}-\mathrm{b}^{2}}}{\mathrm{a}} \quad \mathrm{e}=0.081820180369054 \quad \phi=-0.3836338385 \phi \mathrm{I}=0 \\
& \mathrm{~N}:=\frac{\mathrm{a}^{2}}{\left(\mathrm{a}^{2} \cdot \cos (\phi)^{2}+\mathrm{b}^{2} \cdot \sin (\phi)^{2}\right)^{\frac{1}{2}}} \quad \mathrm{~N}=6.381153053310^{6}
\end{aligned}
$$




$$
\begin{aligned}
& \mathrm{K}:=(\phi \mathrm{I}-\phi) \cdot \frac{180}{\pi} \cdot 3600 \cdot \sin (\text { as }) \quad \mathrm{K}=0.383633838459555 \\
& \mathrm{~L}:=\sin (2 \cdot \phi \mathrm{I})-\sin (2 \cdot \phi) \quad \mathrm{L}=0.694171078649311 \\
& \mathrm{M}:=\sin (4 \cdot \phi \mathrm{I})-\sin (4 \cdot \phi) \quad \mathrm{M}=0.999342642952678 \\
& \mathrm{~N} 1:=\sin (6 \cdot \phi \mathrm{I})-\sin (6 \cdot \phi) \quad \mathrm{N} 1=0.744502684548724 \\
& \mathrm{Pp}:=\sin (8 \cdot \phi \mathrm{I})-\sin (8 \cdot \phi) \quad \mathrm{Pp}=0.072458391901665 \\
& Q:=\sin (10 \cdot \phi \mathrm{I})-\sin (10 \cdot \phi) \quad \mathrm{Q}=-0.640190126601188 \\
& A:=1+\frac{3}{4} \cdot e^{2}+\frac{45}{64} \cdot e^{4}+\frac{175}{256} \cdot e^{6}+\frac{11025}{16384} \cdot e^{8}+\frac{43659}{65536} \cdot e^{10} \quad A=1.005052624771712 \\
& \text { B }:=\frac{3}{4} \cdot e^{2}+\frac{15}{16} \cdot e^{4}+\frac{525}{512} \cdot e^{6}+\frac{2205}{2048} \cdot e^{8}+\frac{72765}{65536} \cdot e^{10} \quad B=5.063232096392586 \cdot 10^{-3} \\
& C:=\frac{15}{64} \cdot e^{4}+\frac{105}{256} \cdot e^{6}+\frac{2205}{4096} \cdot e^{8}+\frac{10395}{16384} \cdot e^{10} \quad C=1.062810732043754 \cdot 10^{-5} \\
& \mathrm{D}:=\frac{35}{512} \cdot \mathrm{e}^{6}+\frac{315}{2048} \cdot \mathrm{e}^{8}+\frac{31185}{131072} \cdot \mathrm{e}^{10} \quad \mathrm{D}=2.082189675503393 \cdot 10^{-8} \\
& E:=\frac{315}{16384} \cdot e^{8}+\frac{3465}{65536} \cdot e^{10} \quad E=3.932753496249586 \cdot 10^{-11} \\
& \mathrm{~F}:=\frac{639}{131072} \cdot \mathrm{e}^{10} \quad \mathrm{~F}=6.555340536788744 \cdot 10^{-14} \\
& \mathrm{~S}:=\mathrm{a} \cdot\left(1-\mathrm{e}^{2}\right) \cdot\left(\mathrm{A} \cdot \mathrm{K}-\frac{1}{2} \cdot \mathrm{B} \cdot \mathrm{L}+\frac{1}{4} \cdot \mathrm{C} \cdot \mathrm{M}-\frac{1}{6} \cdot \mathrm{D} \cdot \mathrm{N} 1+\frac{1}{8} \cdot \mathrm{E} \cdot \mathrm{Pp}-\frac{1}{10} \cdot \mathrm{F} \cdot \mathrm{Q}\right) \quad \mathrm{S}=2431660.694 \\
& \mathrm{I}:=\mathrm{S} \cdot \mathrm{ko} \quad \mathrm{I}=2430688.03
\end{aligned}
$$

\section{Cálculo de II}

II $:=-1 \cdot \mathrm{N} \cdot \sin (\phi) \cdot \cos (\phi) \cdot \frac{\sin (\text { as })^{2}}{2} \cdot k o \cdot 10^{8}$

II $=2.6018464742 \cdot 10^{3}$

Cálculo de III

$$
\begin{aligned}
& \mathrm{e}:=\left(\frac{\mathrm{a}^{2}-\mathrm{b}^{2}}{\mathrm{a}^{2}}\right)^{\frac{1}{2}} \quad \mathrm{e} 1:=\mathrm{e} \cdot \frac{\mathrm{a}}{\mathrm{b}} \\
& \text { III }:=\frac{\sin (\mathrm{as})^{4} \cdot \mathrm{N} \cdot \sin (\phi) \cdot \cos (\phi)^{3}}{24} \cdot\left(5-\tan (\phi)^{2}+9 \cdot \mathrm{e} 1^{2} \cdot \cos (\phi)^{2}+4 \cdot \mathrm{e} 1^{4} \cdot \cos (\phi)^{4}\right) \cdot \mathrm{ko} \cdot 10^{16} \\
& \text { III }:=\text { III } \cdot-1 \quad \text { III }=2.142663345
\end{aligned}
$$

Cálculo de IV

$$
\begin{aligned}
& \text { IV }:=\mathrm{N} \cdot \cos (\phi) \cdot \sin (\text { as }) \cdot \mathrm{ko} \cdot 10^{4} \\
& \text { IV }=2.8676458763 \cdot 10^{5}
\end{aligned}
$$




\section{Cálculo de V}

$$
\begin{aligned}
& \mathrm{V}:=\sin (\text { as })^{3} \cdot \frac{\mathrm{N}}{6} \cdot \cos (\phi)^{3} \cdot\left(1-\tan (\phi)^{2}+\mathrm{el}^{2} \cdot \cos (\phi)^{2}\right) \cdot \mathrm{ko} \cdot 10^{12} \\
& \mathrm{~V}=81.4213607629
\end{aligned}
$$

\section{Cálculo de A6}

A6 : $=\sin (\text { as })^{6} \cdot \mathrm{N} \cdot \sin (\phi) \cdot \frac{\cos (\phi)^{5}}{720} \cdot\left(61-58 \cdot \tan (\phi)^{2}+\tan (\phi)^{4}+270 \cdot \mathrm{e}^{2} \cdot \cos (\phi)^{2}-330 \cdot \mathrm{e} 1^{2} \cdot \sin (\phi)^{2}\right) \cdot \mathrm{ko} \cdot 10^{24}$ A6 $=-1.559781354 \$ 10^{-3}$

\section{Cálculo de B5}

$$
\begin{aligned}
& \mathrm{B} 5:=\sin (\text { as })^{5} \cdot \mathrm{N} \cdot \frac{\cos (\phi)^{5}}{120} \cdot\left(5-18 \cdot \tan (\phi)^{2}+\tan (\phi)^{4}+14 \cdot \mathrm{e} 1^{2} \cdot \cos (\phi)^{2}-58 \cdot \mathrm{e}^{2} \cdot \sin (\phi)^{2}\right) \cdot \mathrm{ko} \cdot 10^{20} \\
& \mathrm{~B} 5=0.0206993514
\end{aligned}
$$

\section{Fórmulas}

$$
\begin{aligned}
& \mathrm{N} 1:=\mathrm{I}+\mathrm{II} \cdot \mathrm{P}^{2}+\mathrm{III} \cdot \mathrm{P}^{4}+\mathrm{A} 6 \cdot \mathrm{P}^{6} \\
& \mathrm{EL}:=500000+\mathrm{IV} \cdot \mathrm{P}+\mathrm{V} \cdot \mathrm{P}^{3}+\mathrm{B} 5 \cdot \mathrm{P}^{5}
\end{aligned}
$$

\section{Para o Hemisfério Sul}

$$
\mathrm{NL}:=10000000-\mathrm{N} 1 \quad \mathrm{NL}=7566514.157
$$

$\mathrm{EL}=202672.767$

$\mathrm{MC}=-45$

Equação XVIII

$\mathrm{XVIII}:=\frac{1+\mathrm{e}^{2} \cdot \cos (\phi)^{2}}{2 \cdot \mathrm{N}^{2} \cdot \mathrm{ko}^{2}} \cdot 10^{12}$

\section{Cálculo de q:}

$q:=0.000001 \cdot($ EL- 500000)

$q=-0.2973272$

Cálculo de k:

$$
\mathrm{k}:=\mathrm{ko} \cdot\left(1+\mathrm{XVIII} \cdot \mathrm{q}^{2}+0.00003 \mathrm{q}^{4}\right) \quad \mathrm{k}=1.0006924905
$$


Cálculo da convergência Meridiana:

\section{Cálculo dos parâmetros}

\section{XII}

$\mathrm{XII}:=\sin (\phi) \cdot 10^{4}$

$$
\mathrm{XII}=-3.74310^{3}
$$

XIII

$\mathrm{XIII}:=\sin \left(1 \cdot \frac{\pi}{180 \cdot 3600}\right)^{2} \cdot \sin (\phi) \cdot \frac{\cos (\phi)^{2}}{3} \cdot\left(1+3 \cdot e 1^{2} \cdot \cos (\phi)^{2}+2 \cdot e 1^{4} \cdot \cos (\phi)^{4}\right) \cdot 10^{12}$ $\mathrm{XIII}=-2.56569$

C'5

$$
\mathrm{C} 5:=\sin \left(1 \cdot \frac{\pi}{180 \cdot 3600}\right)^{4} \cdot \sin (\phi) \cdot \frac{\cos (\phi)^{4}}{15} \cdot\left(2-\tan (\phi)^{2}\right) \cdot 10^{20} \quad \text { C5 }=-0.00187
$$

Convergência Meridina

$$
\begin{array}{rlr}
\mathrm{C}:=\mathrm{XII} \cdot \mathrm{P}+\mathrm{XIII} \cdot \mathrm{P}^{3}+\mathrm{C} 5 \cdot \mathrm{P}^{5} & \mathrm{C}=3882.468 & \text { resultado em segundos } \\
\mathrm{Cg}:=\text { floor }\left(\frac{\mathrm{C}}{3600}\right) & \mathrm{Cg}=1 \\
\mathrm{Cm}:=\text { floor }\left(\frac{\mathrm{C}-\mathrm{Cg} \cdot 3600}{60}\right) & \mathrm{Cm}=4 \\
\mathrm{Cs}:=(\mathrm{C}-\mathrm{Cg} \cdot 3600-\mathrm{Cm} \cdot 60) & \mathrm{Cs}=42.46833
\end{array}
$$




\section{Programa para Transformar UTM SAD-69 para Geodésicas Geográficas}

Para transformar de UTM para GEODÉSICAS

$$
\begin{aligned}
& \mathrm{E}:=202672.767 \quad \mathrm{~N}:=7566514.153 \quad \text { Ponto } 1 \mathrm{~A} \\
& \mathrm{EL}:=(500000-\mathrm{E}) \quad \text { módulo } \quad \mathrm{NL}:=10000000-\mathrm{N} \\
& \text { ko }:=0.9996 \text { fator de escala do meridiano central } \\
& \mathrm{S}:=0 \quad \text { comprimento do arco do meridiano até o equador } \\
& \text { So }:=\frac{\text { NL }}{k 0} \quad a:=6378160 \\
& \begin{array}{lll}
\mathrm{e}:=\frac{\sqrt{\mathrm{a}^{2}-\mathrm{b}^{2}}}{\mathrm{a}} & \mathrm{b}:=6356774.719 & \text { as }:=1 \cdot \\
& \mathrm{e}=0.081820180369054 & \text { e1 }:=\mathrm{e} \cdot \frac{\mathrm{a}}{\mathrm{b}}
\end{array} \\
& \mathrm{A}:=1+\frac{3}{4} \cdot \mathrm{e}^{2}+\frac{45}{64} \cdot \mathrm{e}^{4}+\frac{175}{256} \cdot e^{6}+\frac{11025}{16384} \cdot e^{8}+\frac{43659}{65536} \cdot e^{10} \quad \mathrm{~A}=1.005052624771712 \\
& \text { B }:=\frac{3}{4} \cdot e^{2}+\frac{15}{16} \cdot e^{4}+\frac{525}{512} \cdot e^{6}+\frac{2205}{2048} \cdot e^{8}+\frac{72765}{65536} \cdot e^{10} \quad B=5.063232096392586 \cdot 10^{-3} \\
& C:=\frac{15}{64} \cdot e^{4}+\frac{105}{256} \cdot e^{6}+\frac{2205}{4096} \cdot e^{8}+\frac{10395}{16384} \cdot e^{10} \quad C=1.062810732043754 \cdot 10^{-5} \\
& \mathrm{D}:=\frac{35}{512} \cdot \mathrm{e}^{6}+\frac{315}{2048} \cdot \mathrm{e}^{8}+\frac{31185}{131072} \cdot \mathrm{e}^{10} \quad \mathrm{D}=2.082189675503393 \cdot 10^{-8} \\
& E:=\frac{315}{16384} \cdot e^{8}+\frac{3465}{65536} \cdot e^{10} \quad E=3.932753496249586 \cdot 10^{-11} \\
& F:=\frac{639}{131072} \cdot e^{10} \quad F=6.555340536788744 \cdot 10^{-14}
\end{aligned}
$$

$\phi \mathrm{I}:=0 \quad \phi:=0 \quad \mathrm{n}:=0 . .100$

$$
\mathrm{Z}(\phi \mathrm{I}):=\mid \begin{aligned}
& \mathrm{S} 1 \leftarrow 0 \\
& \mathrm{n} \leftarrow 0 \\
& \text { while } \mathrm{n}<100 \\
& \mid\left[\begin{array}{l}
\left.\mathrm{K} \leftarrow(\phi \mathrm{I}-\phi) \cdot \frac{180}{\pi} \cdot 3600 \cdot \sin (\text { as })\right] \\
(\mathrm{L} \leftarrow(\sin (2 \cdot \phi \mathrm{I})-\sin (2 \cdot \phi))) \\
(\mathrm{M} \leftarrow(\sin (4 \cdot \phi \mathrm{I})-\sin (4 \cdot \phi))) \\
(\mathrm{N} 1 \leftarrow(\sin (6 \cdot \phi \mathrm{I})-\sin (6 \cdot \phi))) \\
(\mathrm{Pp} \leftarrow(\sin (8 \cdot \phi \mathrm{I})-\sin (8 \cdot \phi))) \\
\mathrm{Q} \leftarrow \sin (10 \cdot \phi \mathrm{I})-\sin (10 \cdot \phi) \\
{\left[\begin{array}{l}
\mathrm{S} 1 \leftarrow \mathrm{a} \cdot\left(1-\mathrm{e}^{2}\right) \cdot\left(\mathrm{A} \cdot \mathrm{K}-\frac{1}{2} \cdot \mathrm{B} \cdot \mathrm{L}+\frac{1}{4} \cdot \mathrm{C} \cdot \mathrm{M}-\frac{1}{6} \cdot \mathrm{D} \cdot \mathrm{N} 1+\frac{1}{8} \cdot \mathrm{E} \cdot \mathrm{Pp}-\frac{1}{10} \cdot \mathrm{F} \cdot \mathrm{Q}\right) \\
\mathrm{A}
\end{array}\right)} \\
\phi \mathrm{I}
\end{array}\right. \\
& \begin{array}{l}
\mathrm{I} \leftarrow \phi \mathrm{I}+\frac{\mathrm{So}-\mathrm{S} 1}{\mathrm{~A} \cdot \mathrm{a} \cdot\left(1-\mathrm{e}^{2}\right)} \\
\mathrm{n} \leftarrow 1
\end{array}
\end{aligned}
$$




$$
\begin{aligned}
& \mathrm{Z}(\phi \mathrm{I})=0.384075005417697 \\
& \phi 1:=\mathrm{Z}(\phi \mathrm{I})
\end{aligned}
$$

$$
\mathrm{N}:=\frac{\mathrm{a}^{2}}{\left(\mathrm{a}^{2} \cdot \cos (\phi 1)^{2}+\mathrm{b}^{2} \cdot \sin (\phi 1)^{2}\right)^{\frac{1}{2}}}
$$$$
\mathrm{N}=6381159.604
$$

Cálculo de VII

$$
\begin{aligned}
& \mathrm{VII}:=\frac{\tan (\phi 1)}{2 \cdot \mathrm{N}^{2} \cdot \sin (\mathrm{as})} \cdot\left(1+\mathrm{e}^{2} \cdot \cos (\phi 1)^{2}\right) \cdot \frac{1}{\mathrm{ko}^{2}} \cdot 10^{12} \quad \mathrm{VII}=1.03 \cdot 10^{3} \\
& \text { Cálculo de VIII }
\end{aligned}
$$

$\mathrm{W}:=\left(5+3 \cdot \tan (\phi 1)^{2}+6 \cdot \mathrm{e} 1^{2} \cdot \cos (\phi 1)^{2}-6 \cdot e 1^{2} \cdot \sin (\phi 1)^{2}-3 \cdot e 1^{4} \cdot \cos (\phi 1)^{4}-9 \cdot e 1^{4} \cdot \cos (\phi 1)^{2} \cdot \sin (\phi 1)^{2}\right)$

$$
\mathrm{VIII}:=\frac{\tan (\phi 1)}{24 \cdot \mathrm{N}^{4} \cdot \sin (\text { as })} \cdot(\mathrm{W}) \cdot \frac{1}{\mathrm{ko}^{4}} \cdot 10^{24} \quad \quad \mathrm{VIII}=11.5798636319
$$

\section{Cálculo de IX}

IX $:=\frac{\sec (\phi 1)}{\mathrm{N} \cdot \sin (\text { as })} \cdot \frac{1}{\mathrm{ko}} \cdot 10^{6}$

$$
\mathrm{IX}=3.488 \cdot 10^{4}
$$

\section{Cálculo de X}

$$
\mathrm{X}:=\left[\frac{\sec (\phi 1)}{6 \cdot \mathrm{N}^{3} \cdot \sin (\text { as })} \cdot\left(1+2 \cdot \tan (\phi 1)^{2}+\mathrm{e}^{2} \cdot \cos (\phi 1)^{2}\right) \cdot \frac{1}{\mathrm{ko}^{3}} \cdot 10^{18}\right]
$$

\section{Cálculo de D6}

$\mathrm{T}:=\left[61+90 \cdot \tan (\phi 1)^{2}+45 \cdot \tan (\phi 1)^{4}+107 \cdot \mathrm{e} 1^{2} \cdot \cos (\phi 1)^{2}-162 \cdot \mathrm{e} 1^{2} \cdot(\sin (\phi 1))^{2}-45 \cdot \mathrm{e} 1^{2} \cdot \tan (\phi 1)^{2} \cdot \sin (\phi 1)^{2}\right]$

$$
\mathrm{D} 6:=\frac{\tan (\phi 1)}{720 \cdot \mathrm{N}^{6} \cdot \sin (\text { as })} \cdot \mathrm{T} \cdot\left(\frac{1}{\mathrm{ko}^{6}} \cdot 10^{36}\right) \quad \mathrm{D} 6=0.1329819662
$$

\section{Cálculo de E5}

$\mathrm{E} 5:=\frac{\sec (\phi 1)}{120 \cdot \mathrm{N}^{5} \cdot \sin (\text { as })} \cdot\left(5+28 \cdot \tan (\phi 1)^{2}+24 \cdot \tan (\phi 1)^{4}+6 \cdot \mathrm{e}^{2} \cdot \cos (\phi 1)^{2}+8 \cdot \mathrm{e} 1^{2} \cdot \sin (\phi 1)^{2}\right) \cdot \frac{1}{\mathrm{ko}^{5}} \cdot 10^{30}$ 
Cálculo da Latitude

$$
\begin{aligned}
& \mathrm{q}:=\mathrm{EL} \cdot 10^{-6} \quad \mathrm{q}=0.297327233 \\
& \phi:=\phi 1 \cdot 3600 \cdot \frac{180}{\pi}-\mathrm{VIII} \cdot \mathrm{q}^{2}+\mathrm{VIII} \cdot \mathrm{q}^{4}-\mathrm{D} 6 \cdot \mathrm{q}^{6} \quad \phi:=\frac{\phi}{3600} \\
& \phi=21.98059982150534 \quad \phi \mathrm{g}:=\text { floor }(\phi) \quad \phi \mathrm{m}:=\text { floor }((\phi-\phi \mathrm{g}) \cdot 60) \\
& \phi \mathrm{s}:=\left[\left(\phi-\phi \mathrm{g}-\frac{\phi \mathrm{m}}{60}\right) \cdot 3600\right] \\
& \phi \mathrm{g}=21 \quad \phi \mathrm{m}=58 \quad \phi \mathrm{s}=50.15936
\end{aligned}
$$

\section{Cálculo da Longitude}
$\mathrm{d} \lambda:=\mathrm{IX} \cdot \mathrm{q}-\mathrm{X} \cdot \mathrm{q}^{3}+\mathrm{E} 5 \cdot \mathrm{q}^{5}$
$\mathrm{d} \lambda=1.037 \cdot 10^{4}$
$\mathrm{d} \lambda:=\mathrm{d} \lambda \cdot \frac{1}{3600}$

Se antes do Meridiano Central
$\lambda:=45+\mathrm{d} \lambda$
$\lambda=47.879216$

Se depois do Meridiano Central

$$
\begin{aligned}
& \lambda=47.87921550946389 \quad \lambda \mathrm{g}:=\text { floor }(\lambda) \quad \lambda \mathrm{m}:=\text { floor }((\lambda-\lambda \mathrm{g}) \cdot 60) \\
& \lambda \mathrm{s}:=\left[\left(\lambda-\lambda \mathrm{g}-\frac{\lambda \mathrm{m}}{60}\right) \cdot 3600\right] \\
& \lambda \mathrm{g}=47 \quad \lambda \mathrm{m}=52 \quad \lambda \mathrm{s}=45.17583
\end{aligned}
$$


Programa para Transformação de Coordenadas Locais em UTM SAD-69

Transformações de coordenadas locais em planas UTM

$$
\begin{array}{lll}
\mathrm{Na}:=7566481.332 & \mathrm{k}_{0}:=1.000691394 & \text { PONTO FED2 }-1 \mathrm{~A} \\
\mathrm{Ea}:=202821.967 & \text { Red }:=\frac{854.9163}{6362735.0+854.9163} \\
\mathrm{CMa}:=1+\frac{04}{60}+\frac{40.58111}{3600} & &
\end{array}
$$

Coordenadas locais dos pontos A e B :

$$
\begin{array}{ll}
\mathrm{Xa}:=152295.288 & \mathrm{Xb}:=152146.815 \\
\mathrm{Ya}:=255804.182 & \mathrm{Yb}:=255839.784
\end{array}
$$

Cálculo da distância ab:

$$
\operatorname{Dab}:=\left[\sqrt{(\mathrm{Xb}-\mathrm{Xa})^{2}+(\mathrm{Yb}-\mathrm{Ya})^{2}}\right] \cdot \mathrm{k}_{0} \cdot(1-\mathrm{Red}) \quad \mathrm{Dab}=152.766844
$$

Cálculo do azimute plano $\mathrm{ab}=\theta \mathrm{ab}$ :

$$
\mathrm{t}:=\frac{\mathrm{Xb}-\mathrm{Xa}}{\mathrm{Yb}-\mathrm{Ya}} \quad \mathrm{t}=-4.170355598 \quad \theta \mathrm{ab}:=\operatorname{atan}(\mathrm{t}) \cdot \frac{180}{\pi} \quad \theta \mathrm{ab}=-76.51576839
$$

Cálculo do azimute verdadeiroab $=\alpha a b$ :

$$
\alpha \mathrm{ab}:=\theta \mathrm{ab}-\mathrm{CMa} \quad \alpha \mathrm{ab}=-77.59370758
$$

Cálculo das projeções ( coordenadas parciais ):

$$
\begin{array}{ll}
\Delta \mathrm{Eab}:=\mathrm{Dab} \cdot \sin \left(\alpha \mathrm{ab} \cdot \frac{\pi}{180}\right) & \Delta \mathrm{Eab}=-149.199538 \\
\Delta \mathrm{Nab}:=\mathrm{Dab} \cdot \cos \left(\alpha \mathrm{ab} \cdot \frac{\pi}{180}\right) & \Delta \mathrm{Nab}=32.820824
\end{array}
$$

Cálculo das coordenadas planas - sistema UTM:
$\mathrm{Nb}:=\mathrm{Na}+\Delta \mathrm{Nab}$
$\mathrm{Nb}=7566514.153$
$\mathrm{Eb}:=\mathrm{Ea}+\Delta \mathrm{Eab}$
$\mathrm{Eb}=202672.767$ 


\section{Programa para Cálculo de Distância Elipsóidica a partir das Distâncias Horizontais}

Para o alinhamento FED 2 - 1A:

$$
\begin{aligned}
& \lambda_{0}:=-\left(21+\frac{58}{60}+\frac{51.31683}{3600}\right) \quad \phi_{0}:=-\left(47+\frac{52}{60}+\frac{40.00107}{3600}\right) \quad \lambda_{0}:=\lambda_{0} \cdot \frac{\pi}{180} \\
& \Delta \mathrm{xL}:=\mathrm{x}_{1}-\mathrm{x}_{0} \quad \Delta \mathrm{yL}:=\mathrm{y}_{1}-\mathrm{y}_{0} \quad \Delta \mathrm{zL}:=\operatorname{Cota}_{1}-\operatorname{Cota}_{0} \quad 180 \\
& \mathrm{R}:=\left[\begin{array}{ccc}
-\sin \left(\phi_{0}\right) \cdot \cos \left(\lambda_{0}\right) & -\sin \left(\lambda_{0}\right) & \cos \left(\phi_{0}\right) \cdot \cos \left(\lambda_{0}\right) \\
-\sin \left(\phi_{0}\right) \cdot \sin \left(\lambda_{0}\right) & \cos \left(\lambda_{0}\right) & \cos \left(\phi_{0}\right) \cdot \sin \left(\lambda_{0}\right) \\
\cos \left(\phi_{0}\right) & 0 & \sin \left(\phi_{0}\right)
\end{array}\right] \quad \Delta \mathrm{L}:=\left[\begin{array}{c}
\Delta \mathrm{xL} \\
\Delta \mathrm{yL} \\
\Delta \mathrm{zL}
\end{array}\right] \\
& \Delta \operatorname{Geod}_{1}:=\mathrm{R} \cdot \Delta \mathrm{L} \\
& \Delta \operatorname{Geod}_{1}=\left[\begin{array}{c}
-87.83613 \\
73.84691 \\
-100.72514
\end{array}\right]
\end{aligned}
$$

Para o alinhamento 1A - 2A:

$$
\begin{aligned}
& \lambda_{1}:=-\left(21+\frac{58}{60}+\frac{50.15936}{3600}\right) \\
& \phi_{1}:=-\left(47+\frac{52}{60}+\frac{45.17583}{3600}\right) \quad \lambda_{1}:=\lambda_{1} \cdot \frac{\pi}{180} \\
& \Delta \mathrm{xL}:=\mathrm{x}_{2}-\mathrm{x}_{1} \quad \Delta \mathrm{yL}:=\mathrm{y}_{2}-\mathrm{y}_{1} \quad \Delta \mathrm{zL}:=\operatorname{Cota}_{2}-\operatorname{Cota}_{1} \quad \phi_{1}:=\phi_{1} \cdot \frac{\pi}{180} \\
& \mathrm{R}:=\left[\begin{array}{ccc}
-\sin \left(\phi_{1}\right) \cdot \cos \left(\lambda_{1}\right) & -\sin \left(\lambda_{1}\right) & \cos \left(\phi_{1}\right) \cdot \cos \left(\lambda_{1}\right) \\
-\sin \left(\phi_{1}\right) \cdot \sin \left(\lambda_{1}\right) & \cos \left(\lambda_{1}\right) & \cos \left(\phi_{1}\right) \cdot \sin \left(\lambda_{1}\right) \\
\cos \left(\phi_{1}\right) & 0 & \sin \left(\phi_{1}\right)
\end{array}\right] \quad \Delta \mathrm{L}:=\left[\begin{array}{c}
\Delta \mathrm{xL} \\
\Delta \mathrm{yL} \\
\Delta \mathrm{zL}
\end{array}\right] \\
& \Delta \operatorname{Geod}_{2}:=\mathrm{R} \cdot \Delta \mathrm{L} \\
& \Delta \operatorname{Geod}_{2}=\left[\begin{array}{c}
-152.33262 \\
82.04476 \\
-154.18680
\end{array}\right]
\end{aligned}
$$


Coordenadas Cartesianas a partir das projeções em X Y e Z:

$$
\begin{aligned}
& a:=6378160 \\
& \mathrm{~b}:=6356774.719 \\
& \mathrm{e}:=\frac{\sqrt{\mathrm{a}^{2}-\mathrm{b}^{2}}}{\mathrm{a}} \\
& \mathrm{e} 1:=\frac{\sqrt{\mathrm{a}^{2}-\mathrm{b}^{2}}}{\mathrm{~b}} \\
& \mathrm{~h}:=\text { Ogeod }+ \text { Cota }_{0} \\
& \mathrm{~N}:=\frac{\mathrm{a}}{\sqrt{1-\mathrm{e}^{2} \cdot \sin \left(\phi_{0}\right)^{2}}} \\
& \mathrm{e}=0.08182018 \\
& \mathrm{e} 1=0.08209544 \\
& \text { Coordenada }_{0}:=\left[\begin{array}{l}
(\mathrm{N}+\mathrm{h}) \cdot \cos \left(\phi_{0}\right) \cdot \cos \left(\lambda_{0}\right) \\
(\mathrm{N}+\mathrm{h}) \cdot \cos \left(\phi_{0}\right) \cdot \sin \left(\lambda_{0}\right) \\
{\left[\mathrm{N} \cdot\left(1-\mathrm{e}^{2}\right)+\mathrm{h}\right] \cdot \sin \left(\phi_{0}\right)}
\end{array}\right] \quad \text { Coordenada }_{0}=\left[\begin{array}{r}
3974809.5394 \\
-1604387.8969 \\
-4708419.9537
\end{array}\right]
\end{aligned}
$$

Ponto 1A

$$
\text { Coordenada }_{1}:=\text { Coordenada }_{0}+\Delta \text { Geod }_{1}
$$$$
\text { Coordenada }_{1}=\left[\begin{array}{c}
3974721.7033 \\
-1604314.05 \\
-4708520.6789
\end{array}\right]
$$

Ponto 2A

$$
\text { Coordenada } a_{2}:=\text { Coordenada }{ }_{1}+\Delta \text { Geod }_{2} \quad \text { Coordenada }{ }_{2}=\left[\begin{array}{c}
3974569.3707 \\
-1604232.0053 \\
-4708674.8657
\end{array}\right]
$$


Erro devido a transformação da distância plano local para Geodésica Cartesiana:

Calculando as coordenadas para a superfície do elipsóide:

Para o ponto FED 2:

$\mathrm{h}:=-\left[\right.$ Cota $_{(0)}+$ Ogeod $]$

PCoord $_{0}:=\left[\begin{array}{c}(\mathrm{h}) \cdot \cos \left(\phi_{0}\right) \cdot \cos \left(\lambda_{0}\right) \\ (\mathrm{h}) \cdot \cos \left(\phi_{0}\right) \cdot \sin \left(\lambda_{0}\right) \\ (\mathrm{h}) \cdot \sin \left(\phi_{0}\right)\end{array}\right] \quad$ PCoord $_{0}=\left[\begin{array}{c}-529.3596 \\ 213.6701 \\ 631.2864\end{array}\right]$

Coordenada $_{0}:=$ Coordenada $_{0}+$ PCoord $_{0} \quad$ Coordenada $_{0}=\left[\begin{array}{c}3974280.1798 \\ -1604174.2268 \\ -4707788.6674\end{array}\right]$

$\mathrm{h}:=-\left[\operatorname{Cota}_{(1)}+\right.$ Ogeod $]$

PCoord $_{1}:=\left[\begin{array}{c}(\mathrm{h}) \cdot \cos \left(\phi_{1}\right) \cdot \cos \left(\lambda_{1}\right) \\ (\mathrm{h}) \cdot \cos \left(\phi_{1}\right) \cdot \sin \left(\lambda_{1}\right) \\ (\mathrm{h}) \cdot \sin \left(\phi_{1}\right)\end{array}\right] \quad$ PCoord $_{1}=\left[\begin{array}{c}-530.3038 \\ 214.0478 \\ 632.4429\end{array}\right]$

Coordenada $_{1}:=$ Coordenada $_{1}+$ PCoord $_{1} \quad$ Coordenada $_{1}=\left[\begin{array}{c}3974191.3995 \\ -1604100.0022 \\ -4707888.2360\end{array}\right]$

Para o ponto 2A:

$\mathrm{h}:=-\left[\mathrm{Cota}_{(2)}+\right.$ Ogeod $]$

PCoord $_{2}:=\left[\begin{array}{c}(\mathrm{h}) \cdot \cos \left(\phi_{2}\right) \cdot \cos \left(\lambda_{2}\right) \\ (\mathrm{h}) \cdot \cos \left(\phi_{2}\right) \cdot \sin \left(\lambda_{2}\right) \\ (\mathrm{h}) \cdot \sin \left(\phi_{2}\right)\end{array}\right] \quad$ PCoord $_{2}=\left[\begin{array}{c}-529.6764 \\ 213.7927 \\ 631.7434\end{array}\right]$

Coordenada $_{2}:=$ Coordenada $_{2}+$ PCoord $_{2} \quad$ Coordenada $_{2}=\left[\begin{array}{c}3974039.6943 \\ -1604018.2126 \\ -4708043.1223\end{array}\right]$ 
Deltas entre cada alihamento:

Para alinhamento FED 2 - 1A:

$$
\Delta \text { Geod }_{1}:=\text { Coordenada }_{1}-\text { Coordenada }_{0}
$$$$
\Delta \operatorname{Geod}_{1}=\left[\begin{array}{c}
-88.78 \\
74.225 \\
-99.569
\end{array}\right]
$$

Para alinhamento $1 \mathrm{~A}-2 \mathrm{~A}$ :

$\Delta$ Geod $_{2}:=$ Coordenada $_{2}-$ Coordenada $_{1}$

$\Delta \operatorname{Geod}_{2}=\left[\begin{array}{l}-151.705 \\ 81.79 \\ -154.886\end{array}\right]$

Para alinhamento $2 \mathrm{~A}-3 \mathrm{~A}$ :

$$
\Delta \operatorname{Geod}_{3}:=\text { Coordenada }_{3}-\text { Coordenada }_{2}
$$

$\Delta \operatorname{Geod}_{3}=\left[\begin{array}{c}-0.767 \\ 165.537 \\ -56.664\end{array}\right]$

Para alinhamento $3 \mathrm{~A}-4 \mathrm{~A}$ :

$$
\Delta \text { Geod }_{4}:=\text { Coordenada }_{4}-\text { Coordenada }_{3}
$$

$\Delta \operatorname{Geod}_{4}=\left[\begin{array}{c}-107.038 \\ 31.608 \\ -100.438\end{array}\right]$

Para alinhamento 4A - 5A:

$$
\Delta \operatorname{Geod}_{5}:=\text { Coordenada }_{5}-\text { Coordenada }_{4} \quad \Delta \text { Geod }_{5}=\left[\begin{array}{l}
67.475 \\
166.907 \\
0.093
\end{array}\right]
$$


Cálculo da distância na superfície elipsóidica a partir das projeções Cartesianas obitidas acima:

Para o alinhamento FED 2 1A:

$$
\begin{aligned}
& \mathrm{c}_{1}:=\sqrt{\left[\left(\Delta \operatorname{Geod}_{1}\right)_{0,0}\right]^{2}+\left[\left(\Delta \operatorname{Geod}_{1}\right)_{1,0}\right]^{2}+\left[\left(\Delta \operatorname{Geod}_{1}\right)_{2,0}\right]^{2}} \\
& \eta_{0}:=\mathrm{e}^{2} \cdot \cos \left(\phi_{0}\right)^{2} \\
& \mu_{0}:=\frac{\mathrm{e} 1^{2} \cdot \sin \left(2 \cdot \phi_{0}\right) \cdot \cos \left(\alpha_{1}\right)}{1+\left(\eta_{0}\right)^{2} \cdot \cos \left(\alpha_{1}\right)^{2}} \quad \mu_{1}:=\frac{\mathrm{e}{ }^{2} \cdot\left(\sin \left(\phi_{0}\right)^{2}-\cos \left(\phi_{0}\right)^{2} \cdot \cos \left(\alpha_{1}\right)\right)}{1+\left(\eta_{0}\right)^{2} \cdot \cos \left(\alpha_{1}\right)^{2}} \\
& \mathrm{R}:=\sqrt{\left.\left[(\operatorname{Coordenada})_{0,0}\right]^{2}+\left[(\operatorname{Coordenada})_{0}\right)_{1,0}\right]^{2}+\left[(\operatorname{Coordenada})_{2,0}\right]^{2}} \\
& \mathrm{~s}_{1}:=\mathrm{c}_{1} \cdot\left[1+\frac{1}{6} \cdot\left(\frac{\mathrm{c}_{1}}{2 \cdot \mathrm{R}}\right)^{2}+\frac{3}{40} \cdot\left(\frac{\mathrm{c}_{1}}{2 \cdot \mathrm{R}}\right)^{4}+\frac{5}{112} \cdot\left(\frac{\mathrm{c}_{1}}{2 \cdot \mathrm{R}}\right)^{6}+\frac{\mu_{0}}{2} \cdot\left(\frac{\mathrm{c}_{1}}{2 \cdot \mathrm{R}}\right)^{3}+\frac{3}{5} \cdot \mu_{1} \cdot\left(\frac{\mathrm{c}_{1}}{2 \cdot \mathrm{R}}\right)^{4}\right] \\
& \mathrm{s}_{1}=152.6603 \quad \mathrm{c}_{1}=152.6603
\end{aligned}
$$

Para o alinhamento 1A 2A:

$$
\begin{aligned}
& c_{2}:=\sqrt{\left[\left(\Delta \operatorname{Geod}_{2}\right)_{0,0}\right]^{2}+\left[\left(\Delta \operatorname{Geod}_{2}\right)_{1,0}\right]^{2}+\left[\left(\Delta \operatorname{Geod}_{2}\right)_{2,0}\right]^{2}} \\
& \eta_{1}:=e 1^{2} \cdot \cos \left(\phi_{1}\right)^{2} \\
& \mu_{0}:=\frac{\mathrm{e} 1^{2} \cdot \sin \left(2 \cdot \phi_{1}\right) \cdot \cos \left(\alpha_{2}\right)}{1+\left(\eta_{1}\right)^{2} \cdot \cos \left(\alpha_{2}\right)^{2}} \quad \mu_{1}:=\frac{\mathrm{e}^{2} \cdot\left(\sin \left(\phi_{1}\right)^{2}-\cos \left(\phi_{1}\right)^{2} \cdot \cos \left(\alpha_{2}\right)\right)}{1+\left(\eta_{1}\right)^{2} \cdot \cos \left(\alpha_{2}\right)^{2}} \\
& R:=\sqrt{\left[\left(\text { Coordenada }_{1}\right)_{0,0}\right]^{2}+\left[\left(\text { Coordenada }_{1}\right)_{1,0}\right]^{2}+\left[\left(\text { Coordenada }_{1}\right)_{2,0}\right]^{2}} \\
& \mathrm{~s}_{2}:=\mathrm{c}_{2} \cdot\left[1+\frac{1}{6} \cdot\left(\frac{\mathrm{c}_{2}}{2 \cdot \mathrm{R}}\right)^{2}+\frac{3}{40} \cdot\left(\frac{\mathrm{c}_{2}}{2 \cdot \mathrm{R}}\right)^{4}+\frac{5}{112} \cdot\left(\frac{\mathrm{c}_{2}}{2 \cdot \mathrm{R}}\right)^{6}+\frac{\mu_{0}}{2} \cdot\left(\frac{\mathrm{c}_{2}}{2 \cdot \mathrm{R}}\right)^{3}+\frac{3}{5} \cdot \mu_{1} \cdot\left(\frac{\mathrm{c}_{2}}{2 \cdot \mathrm{R}}\right)^{4}\right] \\
& \mathrm{s}_{2}=231.7192 \quad \mathrm{c}_{2}=231.7192
\end{aligned}
$$


Ficha Técnica dos Instrumentos

http://www.leica.com/ ESTAÇÕES TOTAIS TC605/TC805/TC905

\begin{tabular}{|c|c|c|c|}
\hline ESPEOACAÇÕES & TC605/L & TC805/L & TC905/L \\
\hline $\begin{array}{l}\text { Predisão angular } \\
\text { Leitura angular } \\
\text { Aunerto da dgjetiva } \\
\text { Acancel/3 Prismas } \\
\text { Predsão linear }\end{array}$ & $\begin{array}{l}5 " \text { segundbs } \\
1 " \text { segundb } \\
28 X \\
1300 \text { mx2000m } \\
3 \mathrm{~mm}+3 \text { ppom }\end{array}$ & $\begin{array}{l}3 \text { " segundbs } \\
1 " \text { segindo } \\
30 X \\
3500 \mathrm{~m} \times 5000 \mathrm{~m} \\
2 \mathrm{~mm}+2 \mathrm{ppm}\end{array}$ & $\begin{array}{l}2 " \text { segundos } \\
1 " \text { segundo } \\
30 x \\
3500 m \times 5000 m \\
2 m m+2 p p m\end{array}$ \\
\hline Merớria & \multicolumn{3}{|c|}{$\begin{array}{l}\text { Interma: } 3000 \text { gravando medições au coordenadas } \\
\text { Extema: RS232 }\end{array}$} \\
\hline Progranas intemos & \multicolumn{3}{|c|}{$\begin{array}{l}\text { Coordenada da estação eorientação, Locação, Estação Live, } \\
\text { Distânda entre pantos, linha de referênda, Área, Medida rápica }\end{array}$} \\
\hline Bateria & \multicolumn{3}{|c|}{ Comduração de 10 horas inintemytos } \\
\hline Peso & $4.3 \mathrm{~kg}$ & $5.6 \mathrm{~kg}$ & $5.6 \mathrm{~kg}$ \\
\hline
\end{tabular}

GPS TOPOGRÁFICO SYSTEM SR9400

AUNDADEDE RECPÇÃOÉCAPAZDERASTREAR CONINUAMENIE, CÓDCOEFASEDOSINALLIEM PEONENOS12 CANASINDEPEDENIES. PREOSÃODEUMALNHABASEAPÓSPROCESSAMENIO

\begin{tabular}{|c|c|c|}
\hline - FASEDITENCAL & $\begin{array}{l}\text { MODOESTÁATCO } \\
\text { MOOSTTOP \&CO } \\
\text { MODOANBMÁTCO }\end{array}$ & $\begin{array}{l}05 \text { a } 10 m m+2 p p m \\
10 a 20 m+2 p p m \\
10 a 20 m+2 p p m\end{array}$ \\
\hline - CÓCODRERENAL & $\begin{array}{l}\text { MOOOESTÁTCO } \\
\text { MOSOANBMÁICO }\end{array}$ & $\begin{array}{l}30 \mathrm{~cm} \\
50 \mathrm{~cm}\end{array}$ \\
\hline PROCESSAMENIC & $\begin{array}{l}\text { PONIOISOADO, APÓS } \\
\text { EIOREPPACAL } \\
\text { IRÁPIDOESTÁICOEANEMÁICO }\end{array}$ & $\begin{array}{l}\text { ENIRE } 1 \mathrm{e} 5 \mathrm{~m} \\
\text { DE } 30 \mathrm{a} 50 \mathrm{~cm}\end{array}$ \\
\hline
\end{tabular}


TEODLITO ÓTICO - T2 WILD

\begin{tabular}{|c|c|c|}
\hline \multicolumn{2}{|c|}{ Aumento da luneta } & $30 X$ \\
\hline \multicolumn{2}{|c|}{ Diâmetro do campo visual a $1000 \mathrm{~m}$} & $29 \mathrm{~m}$ \\
\hline \multicolumn{2}{|c|}{ Distância de enfoque mínima } & $2,2 \mathrm{~m}$ \\
\hline \multicolumn{2}{|c|}{ Precisão ângulo horizontal } & $1 "$ \\
\hline \multicolumn{2}{|l|}{ Leitura direta } & - \\
\hline \multicolumn{2}{|l|}{ Estimada } & - \\
\hline \multirow[t]{2}{*}{$\begin{array}{l}\text { Índice vertical } \\
\text { automático }\end{array}$} & $\begin{array}{l}\text { Amplitude de } \\
\text { oscilação livre }\end{array}$ & \pm 5 \\
\hline & $\begin{array}{l}\text { Precisão de } \\
\text { estabilização }\end{array}$ & $\pm 0,3$ \\
\hline \multicolumn{2}{|c|}{ Sensibilidade do nível de alidade } & $20 "$ \\
\hline \multirow[t]{2}{*}{ Peso } & instrumento & $6,0 \mathrm{~kg}$ \\
\hline & estojo & $3,1 \mathrm{~kg}$ \\
\hline
\end{tabular}

NÍVEL ÓTICO - NI 002 Carl Zeiss JENA

\begin{tabular}{|l|l|}
\hline Aumento da luneta & $40 \mathrm{X}$ \\
\hline Diâmetro do campo visual & $55 \mathrm{~mm}$ \\
\hline Distância de enfoque mínima & $2,2 \mathrm{~m}$ \\
\hline Campo de ângulo de visão vertical & $1^{\circ} 17^{\prime}$ \\
\hline Distância mínima de enfoque & $1,5 \mathrm{~m}$ \\
\hline Constante de multiplicação & 100 \\
\hline Constante de adição & 0,37 \\
\hline Acurácia & $\pm 0,2 \mathrm{~mm} / \mathrm{km}$ \\
\hline Compensador & $\pm 10 ’$ \\
\hline Nivelamento & $0,05{ }^{\prime \prime}$ \\
\hline Acurácia de nivelamento & $5,1 \mathrm{~kg}$ \\
\hline tempo & \\
\hline Peso & \\
\hline
\end{tabular}

